UNIVERSIDADE DE SÃO PAULO

INSTITUTO DE GEOCIÊNCIAS

\title{
CARACTERIZAÇÃO DOS DEPÓSITOS FLUVIAIS DA FORMAÇÃO SÃO SEBASTIÃO (BACIA DO TUCANO - BA) COMO ANÁLOGO DE RESERVATÓRIO
}

\author{
VERSÃO CORRIGIDA
}

Heitor Gardenal Figueiredo

Orientadora: Profa. Dra. Liliane Janikian Paes de Almeida

\section{DISSERTAÇÃO DE MESTRADO}

Programa de Pós-graduação em Geoquímica e Geotectônica

São Paulo

2017 
Autorizo a reprodução e divulgação total ou parcial deste trabalho, por qualquer meio convencional ou eletrônico, para fins de estudo e pesquisa, desde que citada a fonte.

Ficha catalográfica preparada pelo Serviço de Biblioteca e Documentação do Instituto de Geociências da Universidade de São Paulo

Figueiredo, Heitor Gardenal

Caracterização da Formação São Sebastião (Bacia do Tucano - BA) como análogo de reservatório / Heitor Gardenal Figueiredo. - São Paulo, 2017. 245 p. + apêndices

Dissertação (Mestrado) : IGc/USP

Orient.: Almeida, Liliane Janikian Paes de

1. Análogos de reservatório 2. Heterogeneidades 3. Permeabilidade 4. Porosidade 5. Formação São Sebastião I. Título 


\section{Agradecimentos}

Primeiramente à Deus pela saúde, comprometimento e foco para realização deste trabalho. Aos meus pais, Ibner Figueiredo e Silvana Gardenal Figueiredo, pela confiança e convívio ao longo desses dois anos. À Aline Ansara pelo convívio e revisões no texto.

À minha orientadora Liliane Janikian pela confiança, paciência, discussões técnicas e ensinamentos, e ao meu coorientador, Carlos Guedes (UFPR), pelo auxilio técnico, discussões, ensinamentos e pela estadia em sua casa durante período essencial para o desenvolvimento da pesquisa. Ao Renato Paes pelas discussões, respaldo técnico e ensinamentos.

À todos demais professores do Instituto de Geociências da Universidade de São Paulo que me formaram geólogo, em especial ao Miguel Basei. Nesses dois anos em especial ao Paulo Gianinni, pelas discussões, e Paulo Bogianni e André Negrão, pelo acompanhamento nos trabalhos de monitoria para a graduação. À todos os funcionários do IGC-USP, em especial à Jordana e Elaine, do laboratório de sedimentologia, e ao Ubiratã.

À professora Liliana Diogo do Instituto de Astronomia e Geofísica por liberar minha entrada todos os horários durante a reta final desse estudo e utilização do software RMS. À todos os funcionários do IAG-USP, em especial ao Marco Claro, pelo suporte técnico.

Aos integrantes do grupo de pesquisa MOcó pelo convívio e auxílio, em especial ao: Paulo Koji, Maria Paula Ramos, Cristiano, Natália Naches, André Marconato, Felipe Figueiredo, Daniela Goulios, Júlio Cesar e Larissa Natsumi.

Aos amigos de pós-graduação pelo convívio, em especial aos companheiros de sala e vizinhos de sala: Daniel do Valle, Rudney Almeida, Luana Morais, Gisele Utida, Gustavo Prado, Guilherme Raffaeli, Rafael Cassati, Gustavo Ramos e Gabriel Oseas. Ao amigo Binho Lambert, o qual representou nesses dois anos todos os amigos do período de graduação. 
À GDRONES e à amizade do Diretor da empresa, George, que permitiu a parceria e realização de grande parte desse estudo.

À Weatherford e Schlumberger por permitirem as análises de grande parte das amostras da pesquisa. Em especial ao Thiago Abreu, funcionário da Weatherford, e ao André Souza, funcionário da Schlumberger.

Ao Programa de Recursos Humanos da PETROBRAS (PRH-241) pela bolsa de estudos e reserva técnica utilizada em análises, e em especial ao Adriano Sousa, funcionário do PRH no IGC-USP, o qual auxiliou na emissão e preparo de documentos.

À FAPESP pelo respaldo financeiro para a realização da pesquisa, pelos projetos 2013/01825-3, 2014/16739-8, e 2016/03091-5.

Por fim, à todos meus amigos, colegas e familiares pelo convívio. 


\section{Resumo}

Reconhece-se, por estudos prévios, as complexas heterogeneidades de fácies nos depósitos sedimentares siliciclásticos fluviais, presentes na exploração de hidrocarbonetos. Devido à amostragem, custosa e insuficiente, na indústria, os modelos geológicos construídos possuem alta incerteza associada. Visando auxiliar tanto a exploração quanto a recuperação, foram executados estudos de análogos de reservatório na Formação São Sebastião, na Bacia do Tucano Central. Para isso, com base na dinâmica de processos fluviais, integraram-se análises de micro (petrografia e diagênese) e mesoheterogeneidades (fácies e elementos arquiteturais) tridimensionalmente, junto à permoporosidade, culminando em modelos geológicos de elementos arquiteturais, fácies e permeabilidade. As características permoporosas da Formação São Sebastião estão sujeitas tanto a controles deposicionais (elementos arquiteturais) como a controles diagenéticos (petrofácies), os quais se correlacionam. Os elementos arquiteturais, portadores de características mais efetivas como reservatório são as barras unitárias, seguidas pelas compostas. Em mesoescala, ambas são representadas majoritariamente por cruzadas tabulares e acanaladas de diferentes dimensões. A mediana para permeabilidade das barras unitárias e compostas é de $6000 \mathrm{mD}$ e $4500 \mathrm{mD}$, enquanto para porosidade é de $21,0 \%$ e $16,9 \%$, respectivamente. Em contrapartida, as barreiras de permeabilidademais importantes são representadas pelos topos de barra contínuos que majoritariamente apresentam estruturas de marca ondulada e estruturas plano paralelas, em mesoescala, e petrofácies com alta concentração de micas. A mediana de permeabilidade dos topos de barra é $200 \mathrm{mD}$, já a de porosidade é $13,5 \%$. Como barreiras de permeabilidades subordinadas, encontram-se os canais abandondados (pouco freqüentes nos afloramentos), em mesoescala, representados por estruturas de marcas onduladas e convolutas; e, em microescala, relacionadas a altas concentrações de micas e pseudomatriz. A mediana da permeabilidade nos canais abandonados é $50 \mathrm{mD}$ e a da porosidade é $16,1 \%$. Os modelos geológicos gerados com os dados de permeabilidade e fácies apontaram para anisotropias de baixa permeabilidade nos topos de barra e canais abandonados. Os topos 
de barra possuem continuidade lateral maior que $200 \mathrm{~m}$ em alguns locais, resultando em grande impacto no fluxo dentro do reservatório. As anisotropias de alta permeabilidade podem ser observadas principalmente na base dos depósitos de barras. Essas anomalias estão relacionadas com arenitos médios a grossos, portadores de cruzadas tabulares. Deste modo, nos depósitos analisados, a permeabilidade é controlada principalmente pela granulometria e concentração de pseudomatriz e micas, com influência subordinada das estruturas sedimentares. Já a porosidade, também controlada pela concentração de pseudomatriz e micas, possui forte influência das estruturas sedimentares e seleção granulométrica, mas não tem correlação com a granulometria.

Palavras-chave: Permeabilidade, porosidade, análogo de reservatório, heterogeneidades e Formação São Sebastião 


\section{Abstract}

The complex facies heterogeneities in fluvial deposits are present in the oil and gas industry. Due to expensive and insufficient sampling, in this industry, geological models which are created to assist the hydrocarbon exploration contain many uncertainties. Aiming to assist in this situation, studies on outcrops reservoirs analogues were performed in Sao Sebastião Formation, in Central Tucano Basin. Based on fluvial sedimentology, micro (petrography and diagenesis) and mesoheterogeneities (facies and architectural elements) analyses were conducted. Porosity and permeability were likewise analyzed. The data obtained were used to create architectural, facies and permeability models. Porosity and permeability are mainly controlled by two correlated variables: depositional controls (architectural elements) and diagenetic controls (petrofacies). The architectural elements with the most effective characteristics as reservoir are the unit bars, followed by the compound bars. Both architectural elements are represented by small to large $(0.2 \mathrm{~m}$ up to $1.5 \mathrm{~m})$ planar and through cross strata. The median permeability of unit bars is $6000 \mathrm{mD}$, and the median of compound bars is $5000 \mathrm{mD}$. The median porosity of unit bars is $21.0 \%$, and the median of compound bar is $16.9 \%$. On the other hand, the most important permeability barriers are the continuous bar tops, they are represented in mesoscale by climbing ripples structures and horizontal bedding. Bartops have shown a high mica assembly in microscale analyses. The median permeability of this element is $200 \mathrm{mD}$, and the median porosity is $13.5 \%$. The abandoned channels are subordinated permeability barriers in São Sebastiao Formation. In mesoscale they are mainly represented by climbing ripples structures and convolute bedding. In microscale they are related to high mica and pseudomatrix content. The permeability median of abandoned channels is $50 \mathrm{mD}$, and the median porosity is $16.1 \%$. The geological models created also pointed out to bar tops and abandoned channels as permeability barriers. The bar tops can reach $200 \mathrm{~m}$ or more of lateral continuity, representing the highest flux barrier inside the reservoir. The positives anisotropies of permeability are linked to medium to coarse sandstones with planar cross strata. Therefore, in Sao Sebastiao Formation the permeability is 
controlled primarily by grain size, pseudomatrix and mica content. Sedimentary structures also impact the permeability subordinately. The porosity is handed likewise by the pseudomatrix and mica content, but also by the sedimentary structures and grain sorting. Nevertheless, porosity is not correlated with grain size.

Key words: Permeability, porosity, reservoir analogue, heterogeneities and São Sebastião Formation 


\section{Sumário}

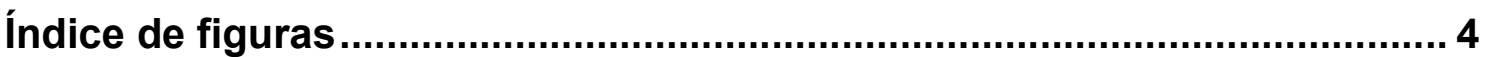

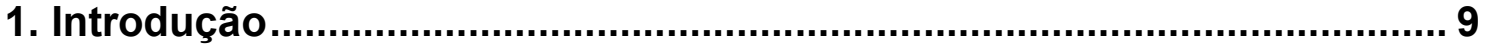

2. Objetivos 10

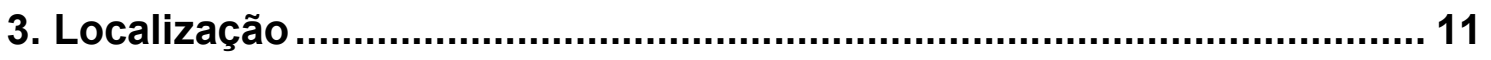

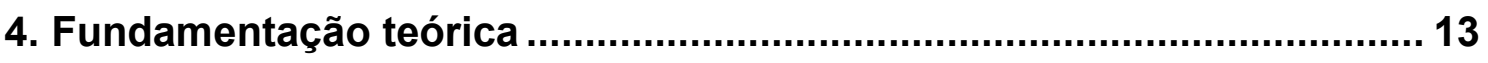

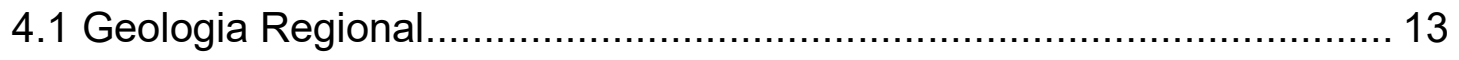

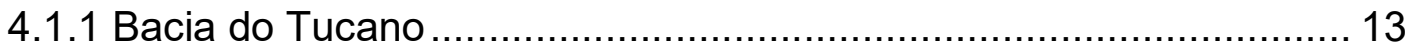

4.1.2 Estratigrafia e evolução da bacia do Tucano ................................. 15

4.1.3 Formação São Sebastião ...................................................... 18

4.2 Fácies, processos sedimentares e elementos arquiteturais fluviais....... 22

4.2.1 Fácies e processos sedimentares.............................................. 22

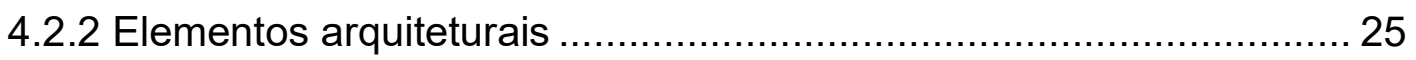

4.2.3 Estilos de reservatórios fluviais de hidrocarbonetos ........................ 29

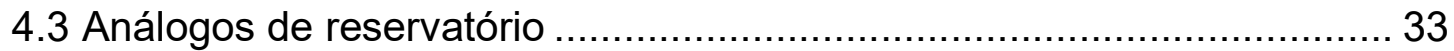

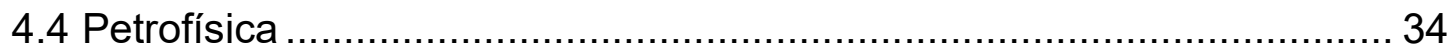

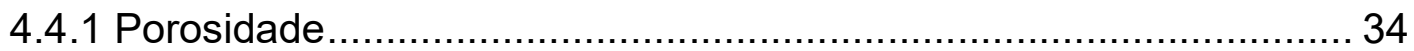

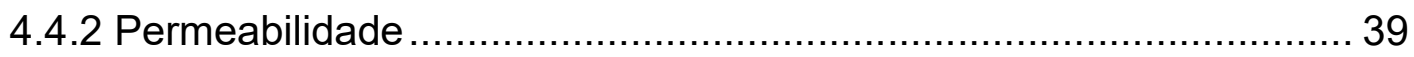

4.5 Controles da diagênese clástica, autigênese diagenética e implicações na

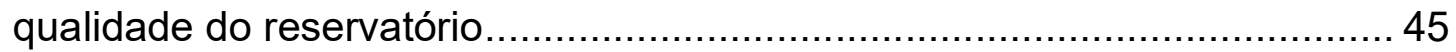

4.5.1 Controladores da diagênese clástica ........................................... 45

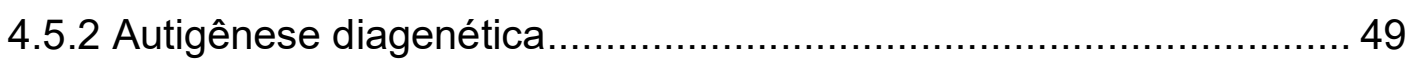

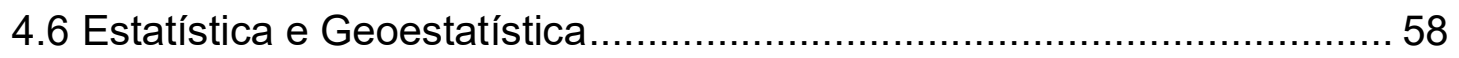

4.6.1 Conceitos matemáticos, estatísticos e geoestatísticos ..................... 58

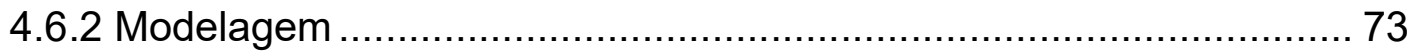

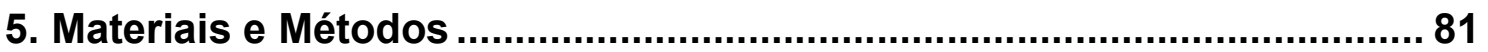

5.1 Trabalhos de Campo - análise de fácies, elementos arquiteturais,

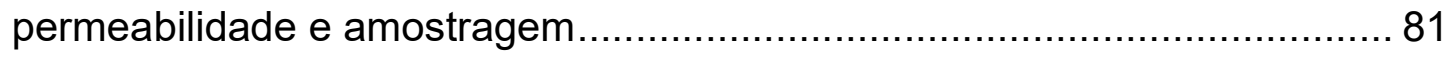

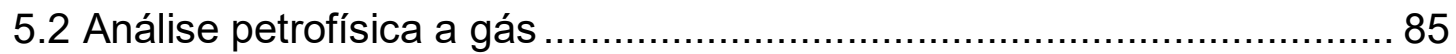

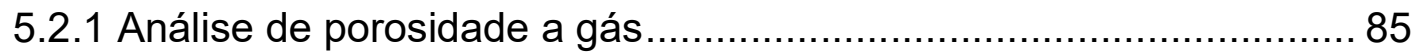

5.2.2 Análise de permeabilidade a gás em regime permanente ................ 86

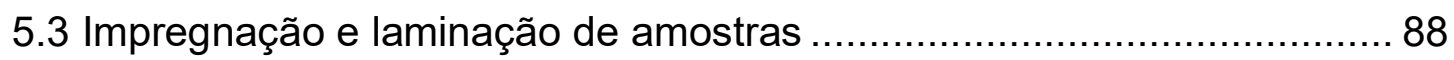


5.4 Descrição petrográfica e porosidade em lâmina

5.5 Processamento de imagens obtidas por drone e geração de modelos 3D

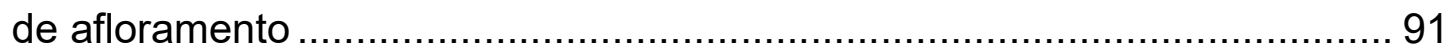

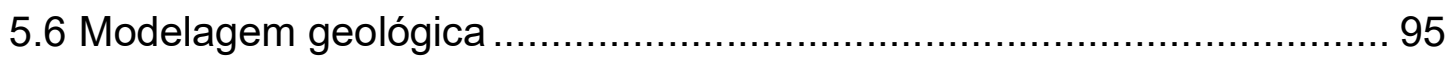

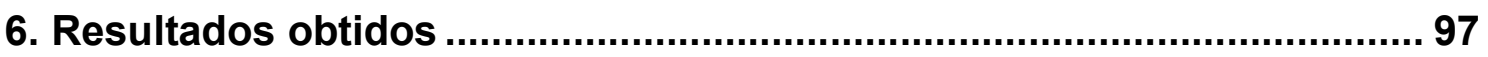

6.1 Análise de fácies, associação de fácies e elemento arquitetural ............ 97

6.1.1 Fácies Sedimentares ........................................................... 97

6.1.2 Associações de fácies e elementos arquiteturais .......................... 110

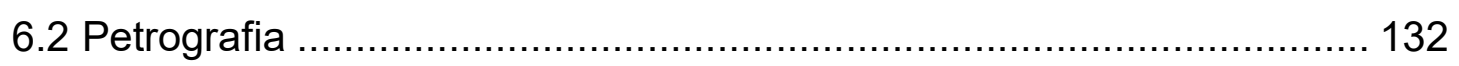

6.2.1 Composição mineralógica....................................................... 132

6.2.2 Análise granulométrica e seleção granulométrica.......................... 142

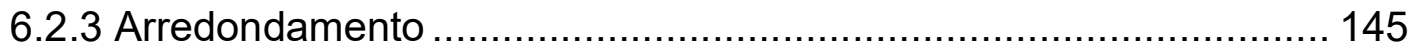

6.2.4 Empacotamento e contatos de grãos ......................................... 150

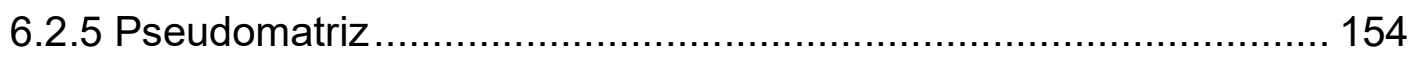

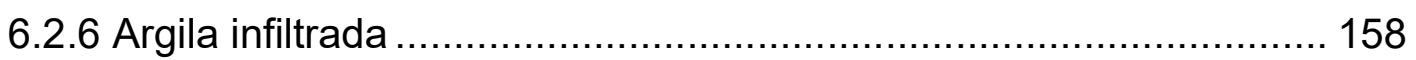

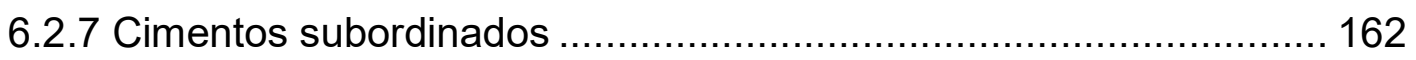

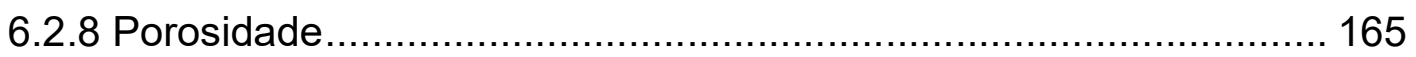

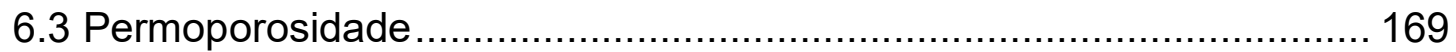

6.3.1 Análises de porosidade........................................................ 170

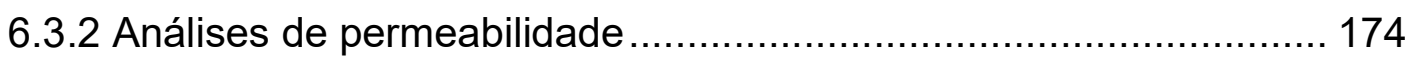

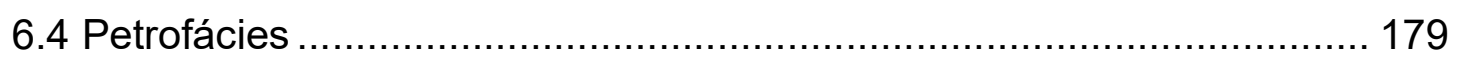

6.5 Modelo de afloramento 3D e modelagem geológica .............................. 181

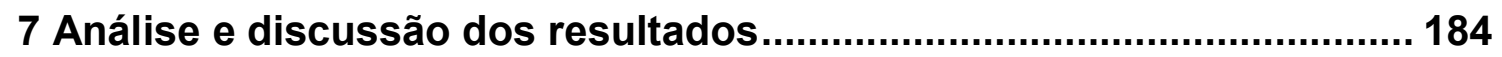

7.1 Resultados das metodologias de porosidade ..................................... 184

7.2 Controles deposicionais na qualidade de reservatórios ....................... 189

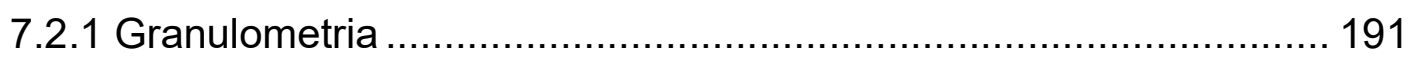

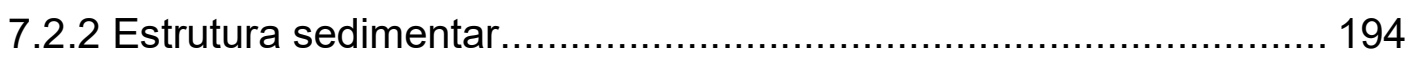

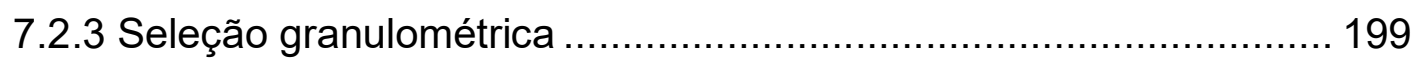

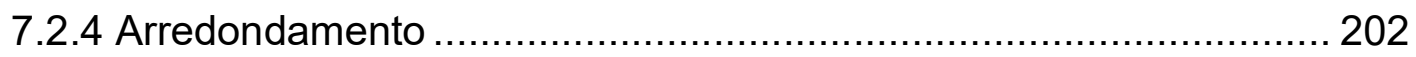

7.3 Controles diagenéticos na qualidade de reservatórios.......................... 205

7.3.1 Composição mineralógica e compactação .................................... 205

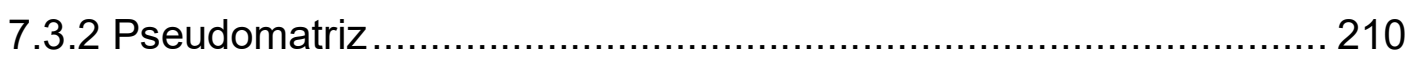

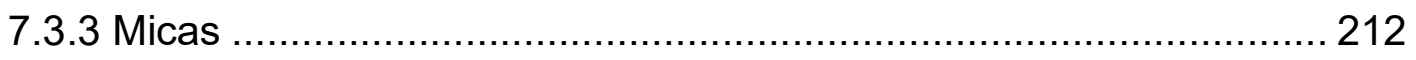

7.3.4 Argilas infiltradas e diagenéticas ............................................. 213 


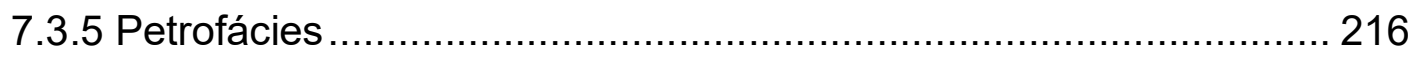

7.4 A Formação São Sebastião como análogo de reservatório ................... 218

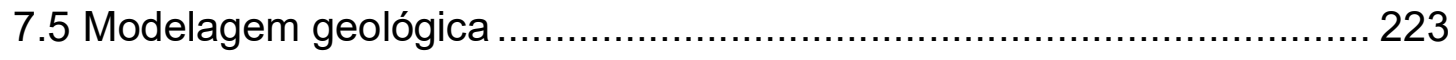

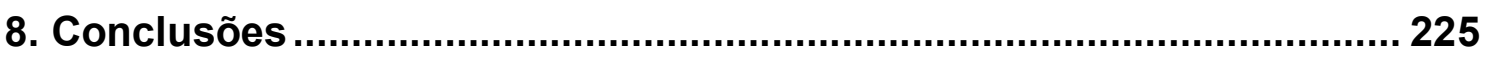

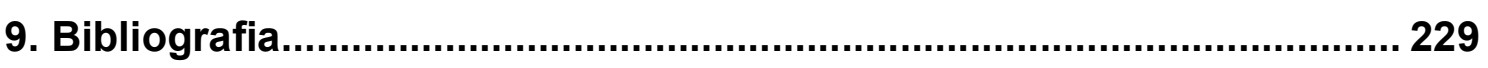

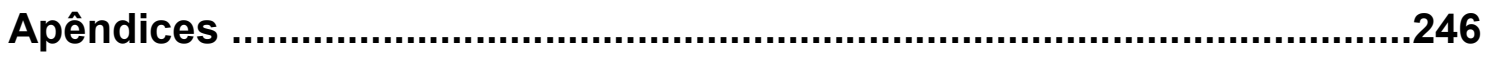




\section{Índice de figuras}

Figura 1- Localização dos afloramentos estudados .................................... 12

Figura 2 - Compartimentação tectônica e profundidade do embasamento nas

Bacias do Tucano e Jatobá

Figura 3 - Rift do Recôncavo-Tucano-Jatobá e distribuição litológica

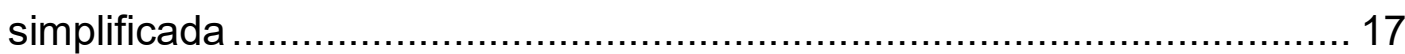

Figura 4 - Coluna e carta estratigráfica da Bacia do Tucano Central e Sul...... 21

Figura 5 - Influência da granulometria e velocidade de fluxo na formação das

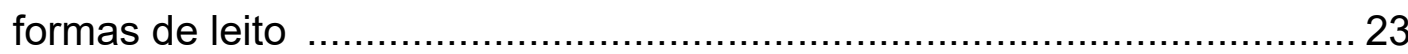

Figura 6 - Descrição de fácies em ambientes fluviais .................................... 24

Figura 7 - Elementos arquiteturais utilizados por Li et al., 2015................... 27

Figura 8 - Geometria deposicional e do reservatório..................................... 30

Figura 9- Tipos de reservatório descritos por Galloway \& Hobday, 1996......... 32

Figura 10 - Diferentes empacotamentos resultando em diferentes porosidades

Figura 11- Grãos com diferentes granulometrias preenchendo espaço poroso36

Figura 12 - Grãos com diferenças de esfericidades preenchendo o mesmo

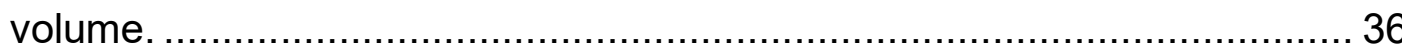

Figura 13 - Aumento da compactação resultando na diminuição do volume

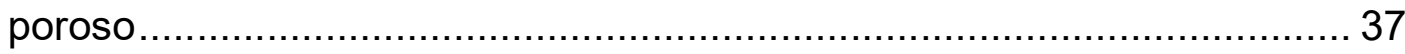

Figura 14 - Anisotropia de permeabilidade ................................................. 43

Figura 15 - Diminuição da permeabilidade e porosidade em relação ao

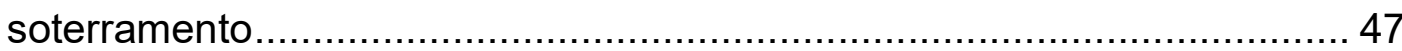

Figura 16 - Precipitação de quartzo relacionado ao aumento de profundidade 50

Figura 17- Medianas de temperaturas de homogeneização de inclusões flúidas

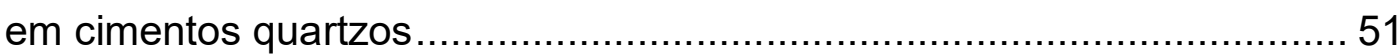

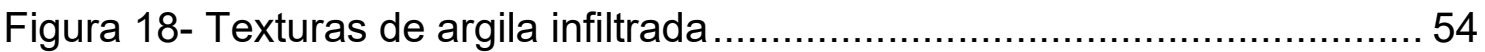

Figura 19 - Impurezas no cutan e textura shrinkage ...................................5

Figura 20 - Elementos analisados em sistema deltaico com porosidades

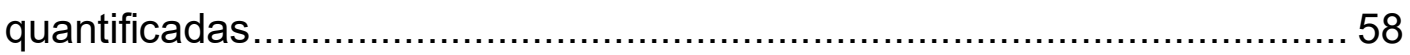

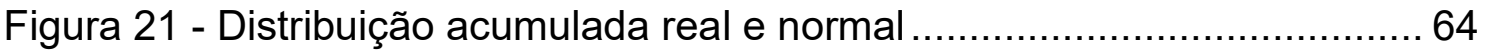

Figura 22 - Raio de busca dos pontos para o variograma.................................66

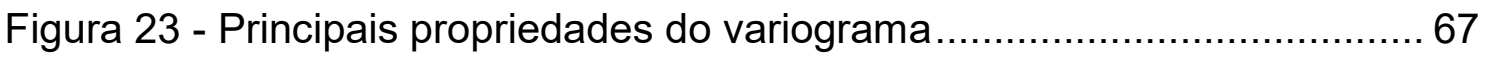

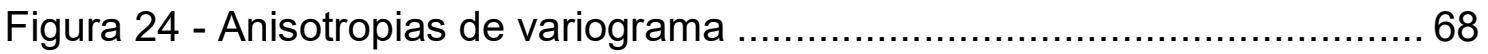

Figura 25 - Caminhos aleatórios obtidos na simulação sequencial.................. 71

Figura 26 - Diferentes escalas de heterogeneidades encontradas na exploração

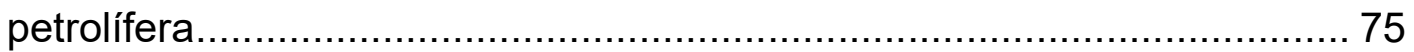

Figura 27 - Acamamento proporcinal e paralelo........................................... 77

Figura 28 - Modelo baseado em objetos e em pixels .................................. 78

Figura 29 - Sete principais heterogeneidades de reservatório ........................ 80

Figura 30 -(a)Vant sobrevoando o afloramento (b) permeâmetro(c) GPS Hiper

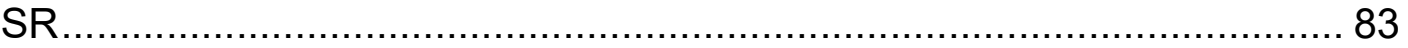


Figura 31- Crossplot da permeabilidade obtida por meio a injeção de gás nitrogênio em função de valores admensionais de permeabilidade obtidos pelo permeâmetro de campo ................................................... 83

Figura 32 - (a) Furadeira utilizada (b) furadeira e serra copo (c) serra copo (d) amostragem realizada ............................................................... 84

Figura 33 - Fluxograma para o tratamento das imagens dos drones ............... 92

Figura 34 - Alinhamento da câmera e malha e nuvem de pontos esparsos..... 92

Figura 35 - Localização estimada da câmera e criação dos pontos de controle

Figura 36 - Demarcação no modelo 3D das principais superfícies sedimentares

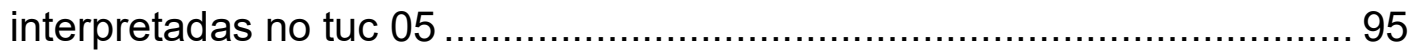

Figura 37 - Fluxograma da modelagem geológica .................................... 96

Figura 38 - Croqui total e posicionamento dos croquis detalhados com descrição das superfícies do tuc05............................................. 101

Figura 39 - Croqui total do afloramento tuc41 .................................... 101

Figura 40 - Mosaico tuc05.1 ........................................................... 108

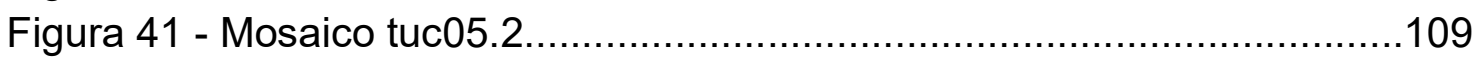

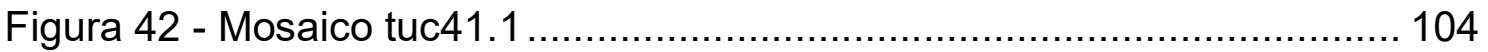

Figura 43 - Mosaico tuc41.2 ....................................................... 105

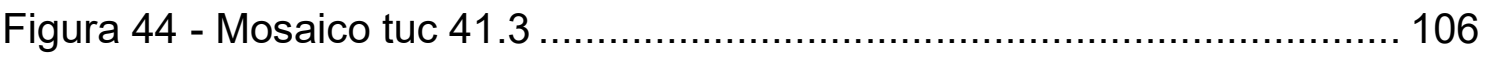

Figura 45 - Mosaico tuc41.4.............................................................113

Figura 46 - Geometria e superfícies de barra unitária do afloramento tuc05 . 113

Figura 47 - Geometria e principais superfícies limitantes de barra unitária, no afloramento tuc41 f................................................................. 114

Figura 48 - a) Fotografia retirada por vant e (b) croqui da fácies Amcu, no afloramento tuc41 .................................................................. 114

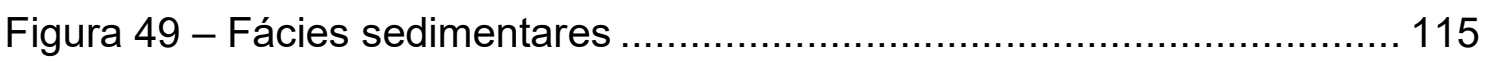

Figura 50 - Estrutura cruzada composta em cosets (Amcc) variando lateralmente para fácies convoluta (Acon) .................................... 117

Figura 51 - Geometria e principais superfícies limitantes de barra composta do afloramento tuc41................................................................... 119

Figura 52 - Continuidade lateral maior que $150 \mathrm{~m}$, observada nos dois topos de barra destacados no afloramento tuc 41 , próximos às superfícies c (basal)

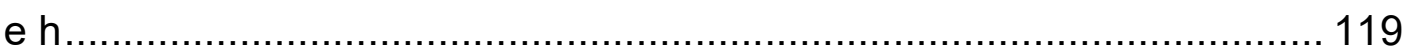

Figura 53 - Topo de barra em detalhe no afloramento tuc41 ...................... 122

Figura 54 - Estruturas climbbing ripples (marcas onduladas) em arenitos finos (fácies Afr), tipicamente encontrados em topos de barra, ou mesmo canais abandonados ........................................................................... 123

Figura 55 - Imagem aérea, por vant, com interpretação dos preenchimentos de canais, do afloramento tuc05 ..................................................... 126

Figura 56 - Geometria de canais abandonados preenchendo superfícies 5, côncavas (destacadas na cor roxo). Contato lateral com a superfície 6, limitadora (na cor azul marinho) do canal abandonado de maior porte. Superfície 3 (ou c), basal de barra composta (na cor salmão) .............. 131 
Figura 57 - Diagrama ternário evidenciando alta maturidade na composição mineralógica dos arenitos da Formação São Sebastião.......................... 133

Figura 58 - Diagramas ternários de composição mineralógica........................ 134

Figura 59 - Micrografias de detalhe da composição mineralógica................... 136

Figura 60 - Histograma da presença de micas e intraclastos......................... 138

Figura 61 - Box plots dos elementos arquiteturais pela concentração de micas e

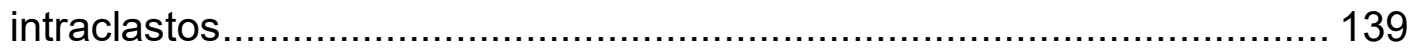

Figura 62 - Box plots dos elementos arquiteturais dos afloramentos tuc05 e tuc41 pela porcentagem de fragmentos argilosos e concentração de micas 141

Figura 63 - Scatter plot de granulometria por desvio padrão de granulometria distinguindo os elementos arquiteturais

Figura 64 - Box plots dos elementos arquiteturais em função da granulometria e

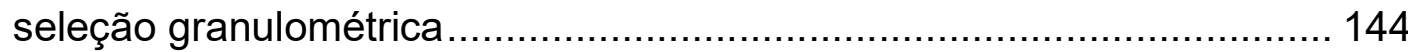

Figura 65 - Histograma de arredondamento ........................................... 145

Figura 66 - Box plots dos elementos arquiteturais do afloramento tuc05 em função do arredondamento.............................................................. 146

Figura 67 - Box plots dos elementos arquiteturais do afloramento tuc $41 \mathrm{em}$

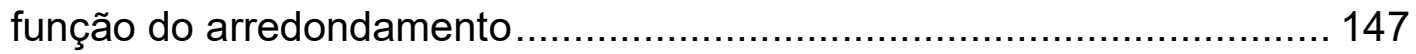

Figura 68 - Box plots da granulometria em função do arredondamento......... 149

Figura 69 - Box plots do grau de seleção em função do arredondamento ..... 150

Figura 70 - Histograma do índice de empacotamento (Kahn, 1956) e de contato de grãos nos afloramentos tuc05 e tuc41 ......................................... 151

Figura 71 - Box plots dos elementos arquiteturais em função dos índices de empacotamento (Kahn, 1956) e dos contatos de grão .......................... 152

Figura 72 - Box plots dos elementos arquiteturais de cada afloramento em função dos índices de empacotamento (Kahn, 1956) e dos contatos de

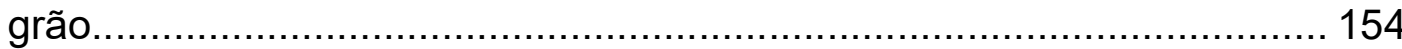

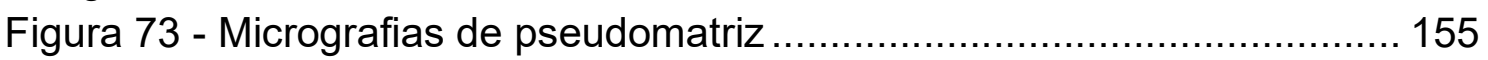

Figura 74 - Histograma do índice da presença de pseudomatriz .................. 156

Figura 75 - Box plots dos elementos arquiteturais em função da presença de

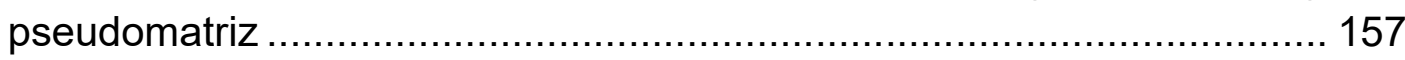

Figura 76 - Box plots dos elementos arquiteturais de cada afloramento em função da presença de pseudomatriz.................................................. 158

Figura 77 - Micrografias de texturas de argila infiltrada................................ 159

Figura 78 - Histograma do índice da presença de argila infiltrada ................. 160

Figura 79 - Box plots dos elementos arquiteturais em função da presença de

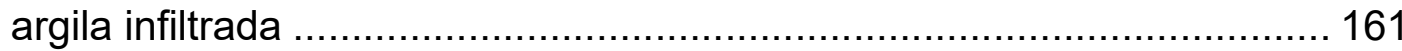

Figura 80 - Box plots dos elementos arquiteturais em cada afloramento em função da presença de argila infiltrada .............................................. 162

Figura 81 - Micrografias de argila diagenética.............................................. 164

Figura 82 - Micrografias de sobrecrescimento de feldspato alcalino.............. 165

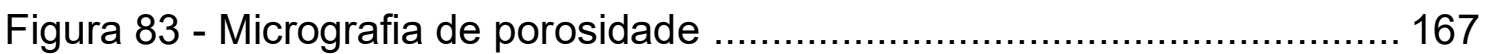

Figura 84 - Histograma discriminado tipos de porosidades.......................... 168 
Figura 85 - Scatter plots da porosidade intragranular pela porosidade intergranular nos afloramentos tuc05 e tuc41 .................................... 169

Figura 86 - Histograma da porosidade obtida por meio a injeção de gás

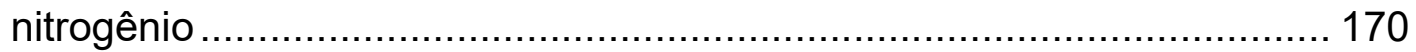

Figura 87 - Box plots dos elementos arquiteturais em função da porosidade obtida pelo método de gás nitrogênio .......................................... 171

Figura 88 - Box plots dos elementos arquiteturais dos dois afloramentos em função da porosidade obtida pelo método de injeção de gás nitrogênio nas amostras da Formação São Sebastião.............................................. 172

Figura 89 - Histogramas da porosidade obtida por imagem pelo software LAS 173

Figura 90 - Box plots dos elementos arquiteturais em função da mediana da porosidade obtida por imagem pelo software LAS 174

Figura 91 - Histograma da permeabilidade obtida por meio a injeção de gás 175

Figura 92 - Box plots dos elementos arquiteturais em função da permeabilidade obtida pelo método de injeção de gás 176

Figura 93 - Histograma da permeabilidade obtida in situ pelo permeâmetro de

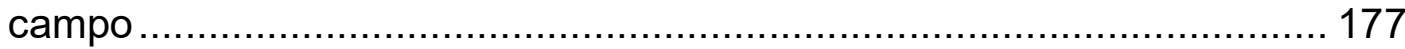

Figura 94 - Box plots dos elementos arquiteturais em função da permeabilidade, obtida in situ, pelo permeâmetro de campo................. 178

Figura 95 - Crossplots da porosidade por imagem e por gás em função da permeabilidade a gás.............................................................. 185

Figura 96 - a) Box plots da quantidade de pseudomatriz e intervalos de porosidade por imagem em função do desvio padrão da porosidade por imagem .

Figura 97 - Box plots das diferentes granulometrias, nos depósitos de barras, pela permeabilidade.

Figura 98 - Box plots das diferentes granulometrias, nos depósitos de topo de barra, preenchimento de canal e canais abandonados, pela permeabilidade

Figura 99 - Box plots de mediana da porosidade por imagem em função da granulometria.

Figura 100 - Box plots das estruturas sedimentares nos depósitos de barra unitária, em função da permeabilidade.

Figura 101 - Box plots das estruturas sedimentares, nos depósitos de barra composta, em função da permeabilidade.

Figura 102 - Box plots das estruturas sedimentares, nos depósitos de topo de barra, em função da permeabilidade.

Figura 103 - Box plots das estruturas sedimentares, nos canais abandonados, em função da permeabilidade......................................................... 198

Figura 104 - Box plots das estruturas sedimentares, dos preenchimentos de canais, em função da permeabilidade. 198 
Figura 105 - Box plots de mediana da porosidade obtida por imagem, em função da estrutura sedimentar nas amostras da Formação São Sebastião. 198

Figura 106 - Box plots das diferentes seleções granulométricas em função da permeabilidade e porosidade, nos arenitos da Formação São Sebastião201 Figura 107 - Box plots de mediana da porosidade obtida por imagem (para diferentes estruturas sedimentares) em função do arredondamento....... 204

Figura 108 - Box plots da compactação em função da presença de

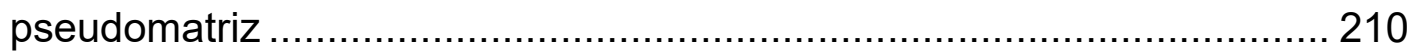

Figura 109 - Box plots da presença de pseudomatriz em função da permeabilidade e porosidade........................................................ 212

Figura 110 - Box plots da presença de micas em função da permeabilidade e porosidade 213

Figura 111 - Box plots da presença de argila infiltrada em função da permeabilidade e porosidade e relação entre a manifestação de pseudomatriz e argila infiltrada..................................................... 215

Figura 112 - Box plots das diferentes petrofácies pela permeabilidade e porosidade 217

Figura 113 - Histogramas representativos das frequências das petrofácies dentro de cada elemento arquitetural 219

Figura 114 - Boxs plots da anisotropia de permeabilidade horizontal-vertical. 


\section{Introdução}

Reservatórios siliciclásticos de hidrocarbonetos dificilmente possuem corpos arenosos de mesmas características, como geometria, conectividade, porosidade, permeabilidade, diagênese e trama estrutural. Essas variáveis são resultado das heterogeneidades presentes no reservatório.

A predição de heterogeneidade de reservatório é de suma importância para o planejamento e execução de eficientes estratégias de produção de hidrocarbonetos, desde a exploração até a produção. O reservatório é analisado em diversas escalas, desde micrômetros até centenas de metros, englobando variações de: arquitetura deposicional, fácies, processos diagenéticos e trama estrutural (Miall, 1977, 1985, 1996, 2000; Hornung, \& Aigner, 1999; Scherer, \& De Ros, 2009; Morad et al., 2010; Pranter et al 2014; Howell et al., 2014; entre outros).

$\mathrm{Na}$ fase inicial, a quantidade de dados para geração de modelos geológicos que guiam a exploração é escassa. Em contrapartida, os análogos de afloramento oferecem informações com baixíssimo custo e são ferramentas muito úteis para criação de modelos geológicos. Essa ferramenta é utilizada em larga escala para criação de modelos geológicos (Vipond, 2005; Brandsæter et al., 2005; Aune, 2006; Enge et al., 2007; Howell et al., 2014 ).

A coleta de dados significativos para um modelo na escala do reservatório é muito difícil e custosa pelas circunstâncias em que o mesmo se encontra, enquanto que nos afloramentos essa coleta é mais viável. Assim, buscam-se analogias observadas em afloramento correlacionando-as ao reservatório como, por exemplo: a geometria dos depósitos, distribuição e associação de fácies dentro da arquitetura deposicional e correlação com características petrofísicas.

Além disso, os reservatórios são modelados com base em células na ordem de centenas de metros no eixo x e y e unidades de metro no eixo $z$. Essa escala de análise é muito questionável devido à anisotropia dos depósitos sedimentares, principalmente em reservatórios fluviais, os quais variam em 
dimensões menores que o tamanho das células. Isso proporciona dificuldades na escala de trabalho. Atividades de upscaling são feitas pelo programa computacional, as quais não refletem geologicamente as características das menores anisotropias, muitas vezes debilitando a recuperação dos hidrocarbonetos.

Como mencionado, a anisotropia dos reservatórios fluviais é muito alta, nos quais os arenitos podem variar mineralogicamente entre todos os campos de imaturo a super maturo, bem arredondados a mal arredondados, bem selecionados a mal selecionados, finos a grossos e até com matriz lamosa a conglomerático. Essas características são resultado da variação da energia nos sistemas fluviais, os quais proporcionam grande diversidade nos tipos de transporte e deposição (Boggs, 2012). Como resultado, gera-se diferentes características texturais, as quais exercem controle sobre aos atributos permoporsos (Sowek, 2013).

A escassez da análise minuciosa nos depósitos sedimentares pode refletir os baixos valores de recuperação nos reservatórios atuais. Contudo, sabe-se atualmente que a geração de modelos em escala de microdetalhe em todo o reservatório possui baixa viabilidade devido ao alto custo da aquisição de dados. Como solução, os análogos de afloramento podem fornecer essas informações, com baixo custo de aquisição de dados.

\section{Objetivos}

O presente estudo teve como principal objetivo analisar dois extensos afloramentos da Formação São Sebastião como análogos de reservatório, visando auxiliar o melhor entendimento das heterogeneidades sedimentológicas que influenciam as anisotropias dos reservatórios fluviais.

Com esse intuito buscou-se caracterizar a permeabilidade e porosidade das rochas da Formação São Sebastião e as principais variáveis que controlam essas características mesoscopicamente (fatores deposicionais) e 
microscopicamente (fatores diagenéticos). Visou-se a compartimentação dos elementos arquiteturais e associá-los a melhores e piores reservatórios conforme as heterogeneidades, geometria e, principalmente, características permoporosas.

Além disso, o trabalho teve como objetivo a utilização de métodos alternativos aos utilizados pela indústria para análise de porosidade (estimativa de porosidade por lâmina) e permeabilidade (permeâmetro de campo) em análogos de afloramento.

\section{Localização}

Os dois afloramentos estudados encontram-se na região nordeste do território brasileiro, na Bacia do Tucano, localizada na zona UTM 24S (figura 1). O afloramento TUC-05 situa-se na estrada BR-110, na porção leste da Bacia do Tucano Central, ao sul da cidade de Jeremoabo-BA.

O afloramento TUC-41 localiza-se na estrada BR-235, na parte oeste da Bacia do Tucano, região do vale do Vaza Barris, na cidade de Canudos-BA. 


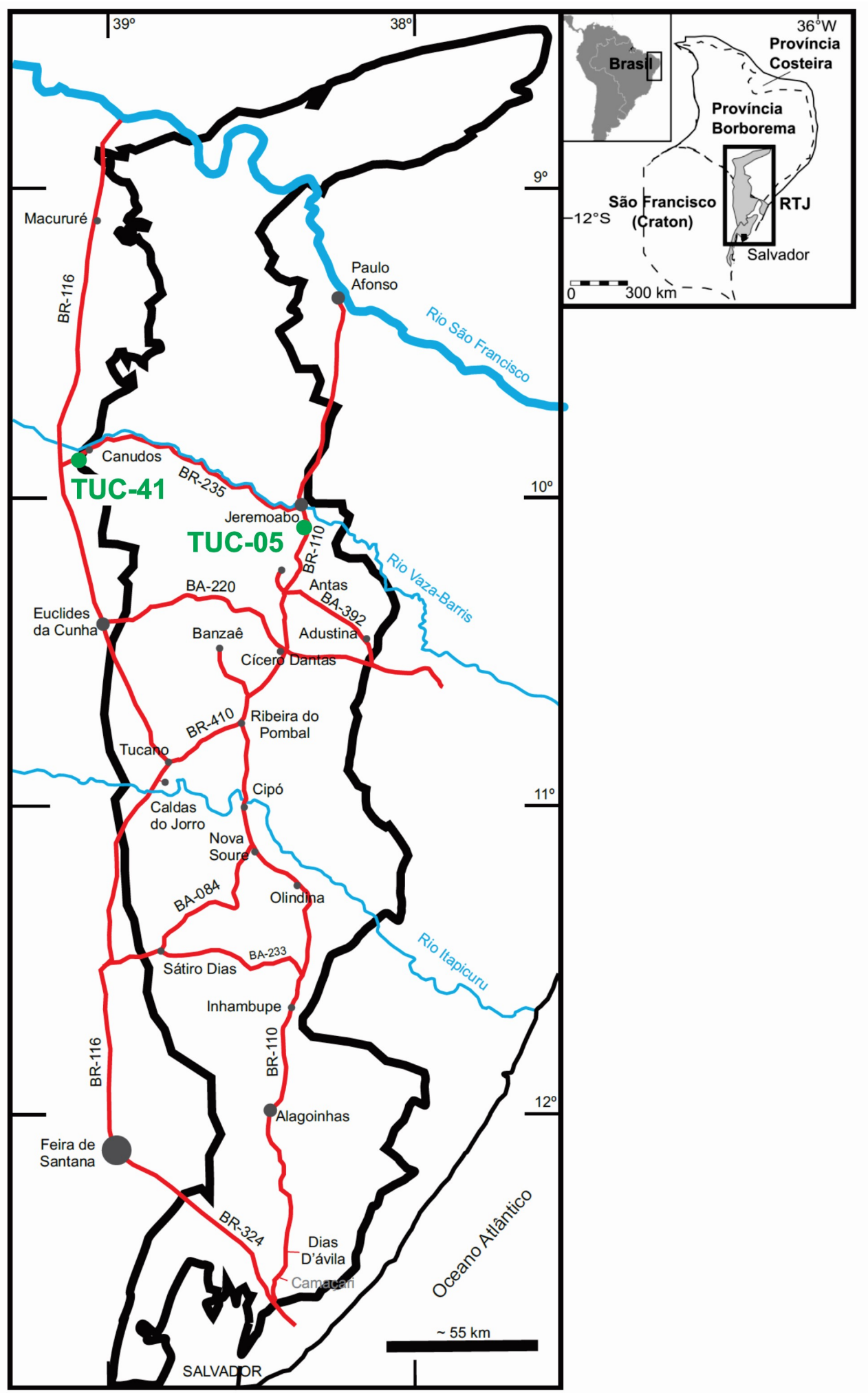

Figura 1- Localização dos afloramentos estudados (TUC-05 e TUC-41) (Modificado de Freitas, 2014) 


\section{Fundamentação teórica}

Neste capítulo foi executada revisão bibliográfica dos itens relevantes para o trabalho. Primeiramente, contempla os trabalhos realizados na Bacia do Tucano, com base na relação entre a estratigrafia e evolução da Bacia. O foco foi dado principalmente na Formação São Sebastião, onde se desenvolveu a pesquisa. Posteriormente, englobou a descrição de fácies e elementos arquiteturais, trabalhos de análogos de reservatório, petrofísica básica e seus controles sedimentológicos, e, diagênese clástica e sua implicação em reservatórios. Por fim, discorreu-se sobre estudos geoestatísticos e de modelagem utilizados na indústria do petróleo, principalmente.

\subsection{Geologia Regional}

\subsubsection{Bacia do Tucano}

A Bacia do Tucano, assim como as Bacias do Recôncavo e Jatobá, é resultado do braço abortado, intracontinental, do rift que deu origem à margem leste brasileira. O não desenvolvimento desse segmento ocorreu devido à perda de calor, gerada no rifteamento inicial. O processo foi muito prolongado (20 Ma, datado por ostracodes), perdendo calor e culminando, possivelmente, na ausência de subsidência termal. A abertura ocorreu do Jurássico superior até o Cretáceo inferior (Milani \& Davison, 1988).

O Rift possui área de $47.000 \mathrm{~km}^{2}$ subdivididos entre as Bacias do Recôncavo (11.500 km²), Tucano $\left(30.500 \mathrm{~km}^{2}\right)$ e Jatobá $\left(5.000 \mathrm{~km}^{2}\right)$ (Santos \& Reis, 2011). A abertura ocorreu preferencialmente na direção N-S, com possível rotação da placa brasiliana, geradora da assimetria observada na Bacia do Jatobá. A Bacia do Tucano é limitada estruturalmente: a sul pelo Alto de Aporá, separando-a da Bacia do Recôncavo; e, a norte pelo Arco de São Francisco, limitando-a da bacia do Jatobá (figura 2) (Milani \& Davison, 1988). 
Os estudos sobre a Bacia do Tucano compartimentam-na em: Bacia do Tucano Sul, Bacia do Tucano Central e Bacia do Tucano Norte. A Bacia do Tucano Central é limitada: a sul pela falha de transferência Itapicuru e a norte pelo Arco de Vaza Barris. A falha de transferência Itapicuru é classificada como uma falha transpressional, gerando estruturas em flor positivas. Essas foram normeadas por Milani \& Davison (1988) como "cactus structure", devido à geometria das falhas dos "ramos". O Arco Vaza Barris é interpretado pelos mesmos autores como uma zona de transferência, apesar dos mesmos comentarem a não existência de evidências portadoras de estruturas rúpteis orientadas NW-SE.

A geologia estrutural da Bacia do Tucano é muito complexa. Acredita-se que as fraquezas do embasamento (Cráton São Francisco e Província Borborema) controlaram a geometria assimétrica, observada pelo registro dos half grabens (Almeida et al., 1977). Os estilos tectônicos do Tucano Sul e Central são similares, devido: aos depocentros na borda leste do rift (figura 2); e, às principais falhas extensionais orientadas N025, mergulhando para NW. Já as feições estruturais apresentadas no Tucano Norte são particulares em relação ao restante da bacia. Três diferentes famílias de falhas destacam-se nessa zona $\left(15^{\circ} \mathrm{Az}, 85^{\circ} \mathrm{Az}\right.$ e $\left.235^{\circ} \mathrm{Az}\right)$. No restante da bacia falhas com direção NE-SW são predominantes. Além disso, o depocentro muda de leste para oeste, ao norte do Arco de Vaza Barris (figura 2) (Milani \& Davison, 1988). 


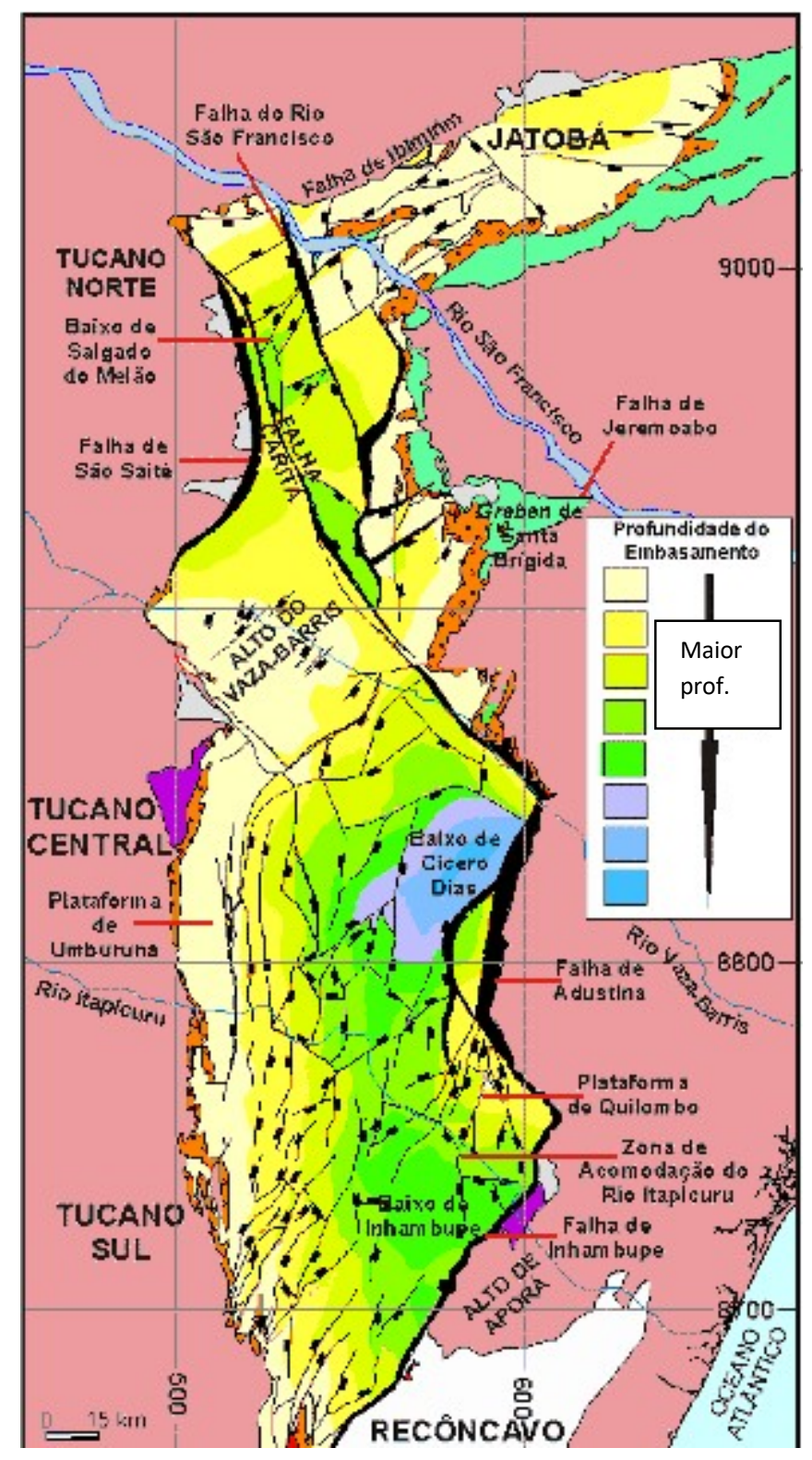

Figura 2 - Compartimentação tectônica e profundidade do embasamento nas bacias do Tucano e Jatobá (Magnavita et al., 2003)

\subsubsection{Estratigrafia e evolução da bacia do Tucano}

A estratigrafia da Bacia do Tucano é dividida conforme a atividade do rift. Costa et al., (2007) definiram os estágios: pré-rift, do Neojurássico ao Eoberriasiano; sin-rift, do Eoberriasiano ao Eoaptiano; e, pós-rift no Neoaptiano (figura 3 e 4). 
A sequência pré-rift consiste no momento anterior à subsidência mecânica. A bacia possuía características similares a uma bacia intracratônica: pouco profunda, extensa e com tectonismo incipiente. Os ambientes instalados no momento eram: flúvio-eólicos, com maior concentração na parte sul da bacia, pertencentes à Formação Sergi e Água Grande; transgressivos lacustes, representados pelo Membro Capianga e pela Formação Itaparica; e, depósitos aluviais, da Formação Aliança e Sergi (Santos et al., 1990).

A fase rift instalou-se com o início da subsidência mecânica e transgressão sobre os ambientes subaéreos. Essa transgressão proporcionou a deposição de pelitos, no contexto de bacia "faminta", posicionando os folhelhos lacustres do Membro Tauá (Formação Candeias) sobre arenitos eólicos da Formação Água Grande (Caixeta et al., 1994). Outra evidência da implantação da fase sin-rift, após o levantamento das ombreiras, é a erosão das mesmas, resultando na deposição de conglomerados de borda da Formação Salvador (Ghignone, 1972).

A diminuição das taxas de subsidência, no Neovalanginiano, acarretou o assoreamento das bacias por progradações deltaicas, representadas na estratigrafia pelo Grupo llhas. Além disso, iniciou-se a implantação de sistemas flúvio-eólicos do Grupo Massacará. O preenchimento da bacia ocorreu preferencialmente do norte para o sul do rift.

No Eohauteriviano-Neohauteriviano, ocorreu um segundo evento distencional, ampliando depocentros, resultando no aumento da espessura da sucessão sedimentar e reativando falhas. Neste contexto, sobre a área estudada neste trabalho, depositaram-se principalmente sedimentos fluviais, com retrabalhamento subordinado eólico da Formação São Sebastião. Periodicamente, os sistemas progradantes da bacia eram afogados por sistemas deltaicos, da Formação Pojuca (Costa et al., 2007).

No Neobarremiano-Eoaptiano ocorreu uma terceira distensão do sistema, o qual gerou as maiores taxas de distensão do rift nas Bacias do Tucano-Jatobá. Essa distensão reativou e criou novas falhas. Além disso, o volume de depósitos dos conglomerados da Formação Salvador, ao longo das falhas de borda, aumentou (Santos et al., 1990). 
Com o fim da subsidência mecânica da bacia, segundo Magnavita et al. (1994; 2003), contestado por outros autores (Figueiredo, 2013; Freitas, 2014), instala-se a fase de subsidência termal, com menor profundidade e maior extensão que a subsidência mecânica, assemelhando-se às bacias do tipo sag. Os depósitos da fase sin-rift são recobertos por depósitos aluviais da Formação Marizal. Para outros autores, como Freitas (2014), a Formação Marizal ainda estaria inserida no contexto sin-rift. A principal evidência para essa classificação trata-se de depósitos conglomeráticos de borda, encontrados nessa formação. Outro fator que suportaria essa frente é a constatação de falhas sin-sedimentares, em escala de afloramento, assim como a presença de estruturas convolutas, as quais teriam gênese atribuída a sismos tectônicos.

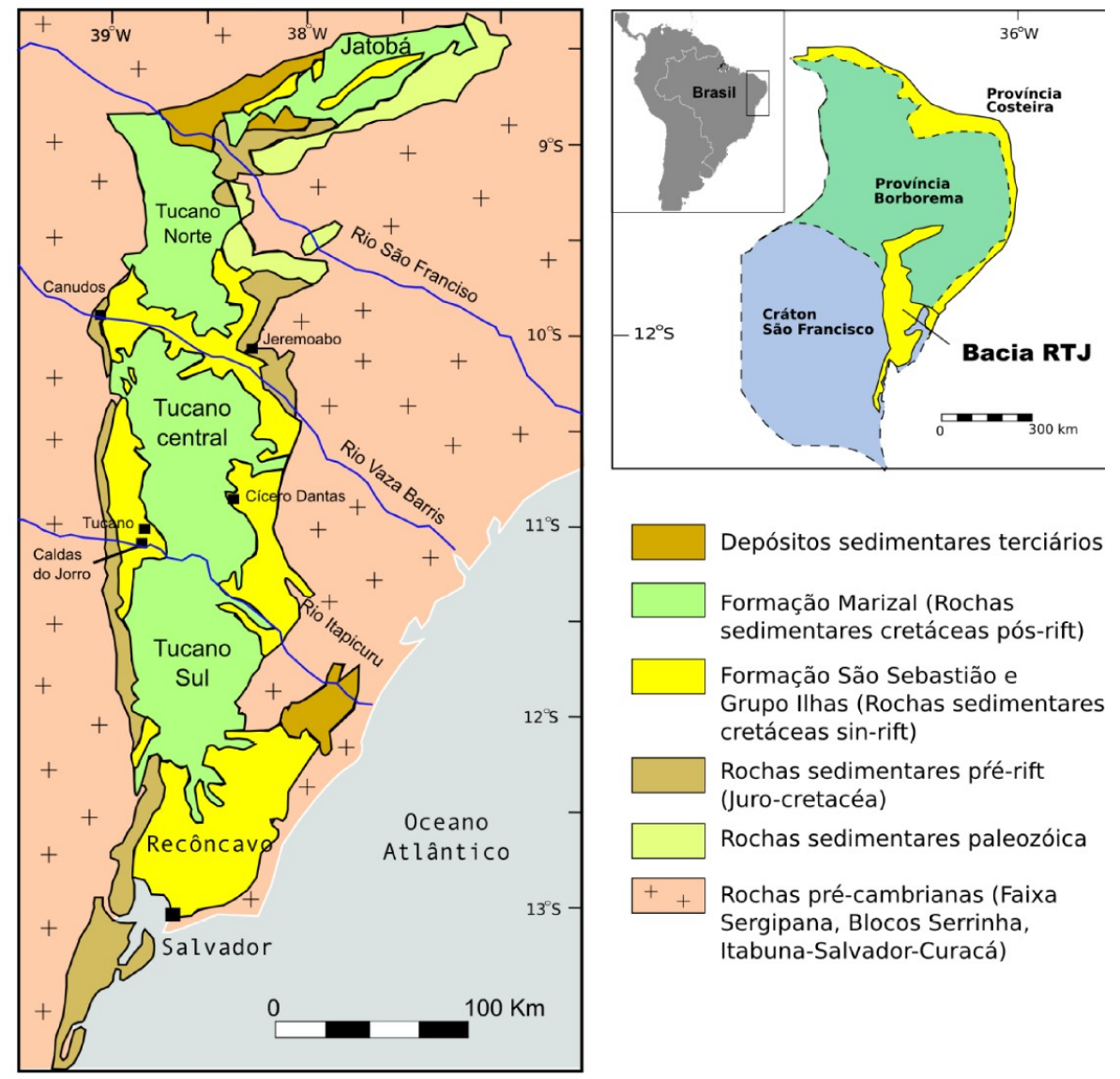

Figura 3 - Rift do Recôncavo-Tucano-Jatobá e distribuição litológica simplificada. Extraído de Magnavita (1994) 


\subsubsection{Formação São Sebastião}

A Formação São Sebastião ocorre sobreposta aos depósitos deltaicos progradacionais, do Grupo Ilhas, por contato gradacional, e sotoposta, por discordância angular, à Formação Marizal. A distinção entre depósitos associados a ambientes fluviais do Grupo Ilhas e da Formação São Sebastião é difícil no Tucano Central segundo Santos \& Reis (2011).

Litologicamente, a Formação São Sebastião é composta por arenitos de coloração avermelhada que gradam de muito finos a muito grossos com alta concentração de grânulos e seixos. A mineralogia é composta por quartzo, feldspatos, argilas e micas. A estruturação desses corpos é variada, guiada por seixos e grânulos ou lâminas argilosas, apresentando estratificações cruzadas e convolutas (Santos \& Reis, 2011). Subordinados aos arenitos encontram-se rochas siliciclásticas mais finas, definidas pelo mesmo autor como folhelhos micáceos e feldspáticos. Os mesmos folhelhos foram descritos por Viana et al. (1971) como material de argilas sílticas variegadas.

Figueiredo (2013) executou o trabalho mais detalhado sobre descrição faciológica, elementos arquiteturias e implicações tectônicas da Formação São Sebastião. A Formação foi descrita em afloramentos por toda a Bacia do Tucano.

Os principais elementos arquiteturais descritos por Figueiredo (2013) foram distinguidos em: barras unitárias ou dunas grandes compostas; barras de acréscimo a jusante, preenchimento de canais pequenos, canais abandonados, leques de rompimento marginal, planícies de inundação, dunas eólicas e depósitos de topo de barra.

Figueiredo (2013) classificou o padrão fluvial principal da Formação São Sebastião como um sistema axial ao rift, portador de paleocorrentes preferenciais para sul. Adicionalmente, subdividiu o padrão fluvial em: regiões onde as taxas de subsidências eram maiores, localizadas próximas ao Baixo de Cícero Dantas; e, regiões onde as taxas eram menores. Regiões associadas às maiores taxas de subsidência foram interpretadas como rios 
transportadores de carga mista, enquanto os rios das menores eram transportadores de carga de fundo. O autor ressalta como principal registro dos diferentes padrões de drenagem a preservação de planícies de inundação, localizadas nas regiões de maiores taxas de subsidência.

Ainda segundo Figueiredo (2013), a proveniência da Formação São Sebastião está associada a sedimentos policíclicos de sucessoões Paleozóicas e Mesozóicas. Esses sedimentos caracterizam-se por alta maturidade. Essa maturidade não é encontrada na Formação Marizal, sobreposta. O tal fato é interpretado, segundo o autor, como resultado da reativação das falhas de borda e mudança da área fonte principal.

Além da mudança da proveniência, feições tectônicas foram brevemente descritas tanto por Figueiredo (2013), como Freitas (2014), mas principalmente por Destro et al. (2003), na Formação São Sebastião. Este último descreveu e interpretou bandas de deformação e juntas encontradas nas proximidades da falha de Jeremoabo. Comprovando, portanto, a deposição da Formação concomitante a eventos tectônicos. 


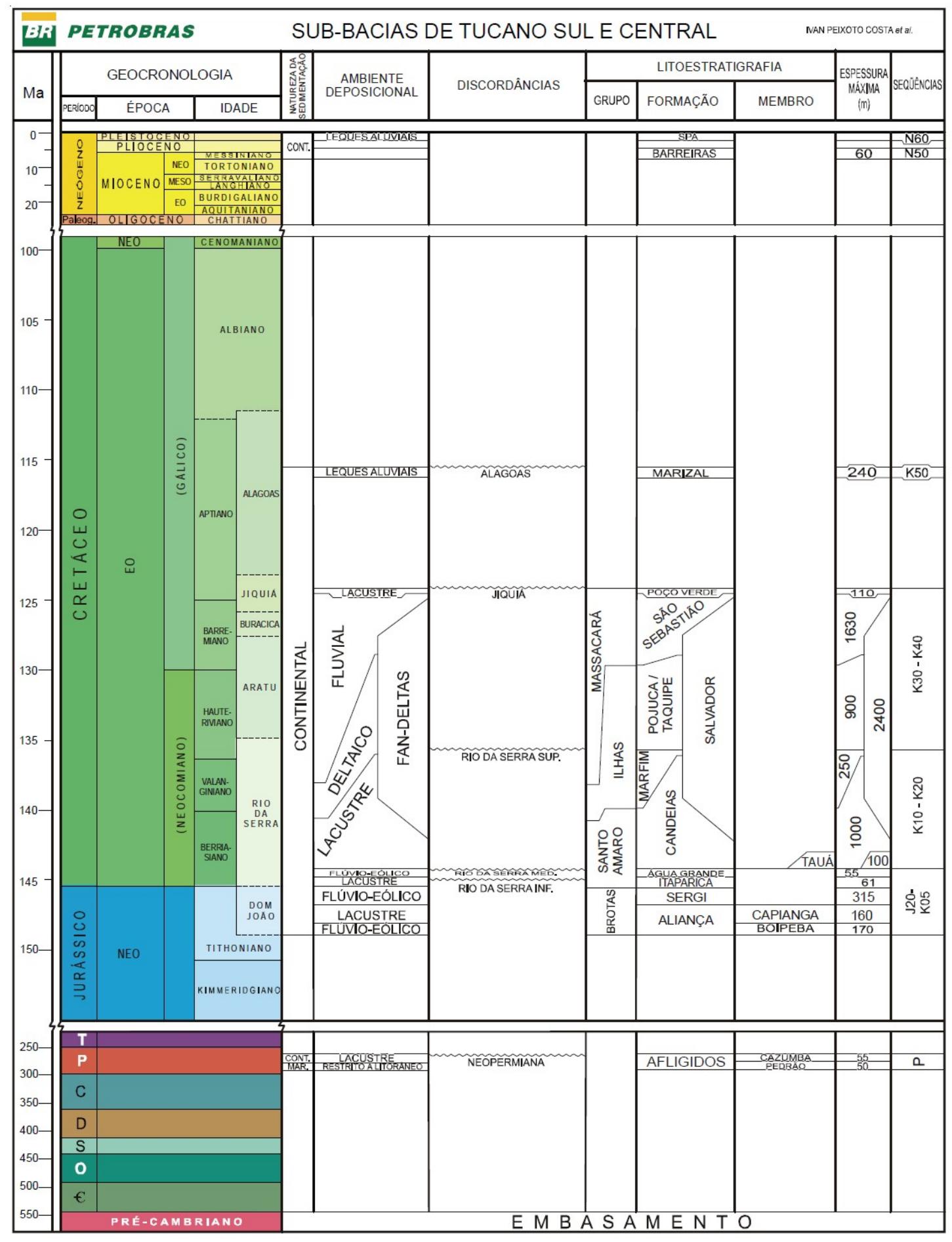




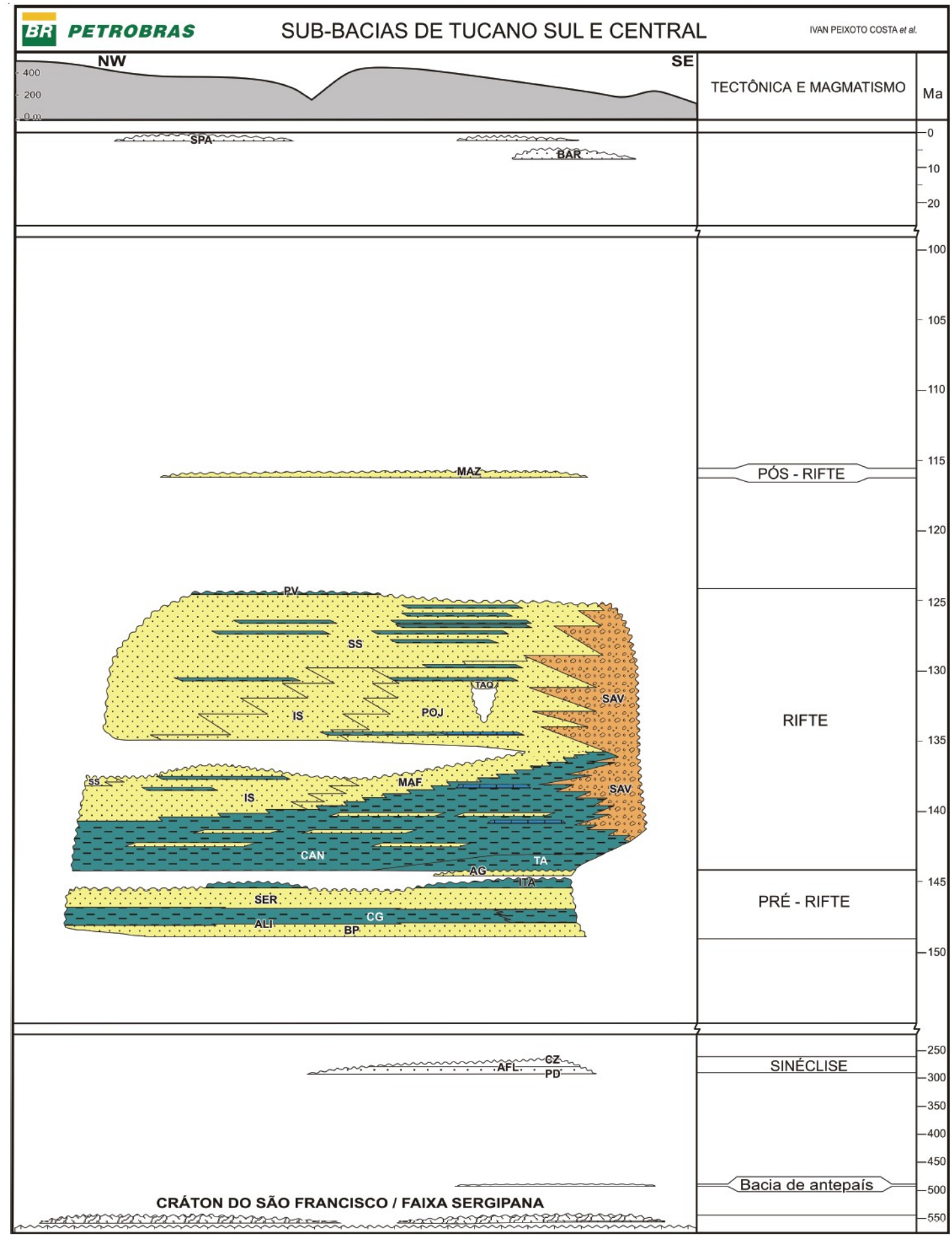

Figura 4 - Coluna e carta estratigráfica da bacia do Tucano Central e Tucano Sul (Costa et al., 2007) 


\subsection{Fácies, processos sedimentares e elementos arquiteturais}

\section{fluviais}

A nomenclatura de fácies descrita por Miall $(1977 ; 1985 ; 1996)$ foi consagrada e muito utilizada como guia na descrição de depósitos fluviais. Contudo, as associações de fácies para identificação de elementos arquiteturais do autor é muito contestada e modificada por diversos autores (Hjellback, 1997; Bridge \& Lunt, 2006; e Li et al., 2015). Essa divergência ocorre devido a simplicidade da nomenclatura de Miall (1977;1985;1996), frente a complexidade da dinâmica fluvial. Nos resultados serão utilizadas as fácies similares, mas alternativas as de Miall (1977;1985;1996). Já para os elementos arquiteturais foram utilizados principalmente os elementos de Miall (1977;1985;1996) e de Li et al., 2015.

\subsubsection{Fácies e processos sedimentares}

A descrição de fácies é técnica recorrente nos estudos sobre depósitos sedimentares. Essa, por sua vez, remete-se aos principais processos sedimentares formadores das rochas.

A interpretação dos processos sedimentares, associados à gênese das fácies sedimentares possibilitam melhor compreensão sobre os mecanismos atuantes na formação das mesmas.

Nos ambientes fluviais, Miall (1996) considera que os processos geradores das fácies de cascalho são compartimentados conforme dois mecanismos principais de transporte. O primeiro trata-se de fluxos turbulentos com baixa concentração de sedimentos. Isso resulta em texturas complexas, devido ao fato dos fluxos interagirem e mudarem rapidamente de direção. A mudança é resultado da: quantidade de sedimento transportada, variações na turbulência, variações climáticas, erosão e deposição. 
O segundo processo descrito pelo autor caracteriza-se pelo fluxo lâminar, conhecido como fluxo gravitacional de sedimentos, resultando, geralmente, em estruturas erosivas. O mesmo destaca ainda que a gradação inversa é característica nesse sistema, resultado das colisões intergranulares. Nas colisões, os grãos mais grossos migram para regiões de menor stress, localizadas nas extremidades do conjunto de sedimentos transportados. Esse tipo de fluxo é freado em regiões próximas ao final do curso do rio, devido à diminuição do gradiente e menor lubrificação.

Segundo Miall (1996), as fácies arenosas, nos ambientes fluviais, são depositadas e transportadas principalmente por carga de fundo e suspensão intermitente (saltação), podendo culminar em diversas formas de leito. Segundo Ashley (1990), os três principais fatores controladores das diferentes formas de leito arenosas fluviais são: granulometria, profundidade e velocidade do fluxo. As principais formas de leito segundo esse autor são antidunas, dunas e marcas onduladas (figura 5).

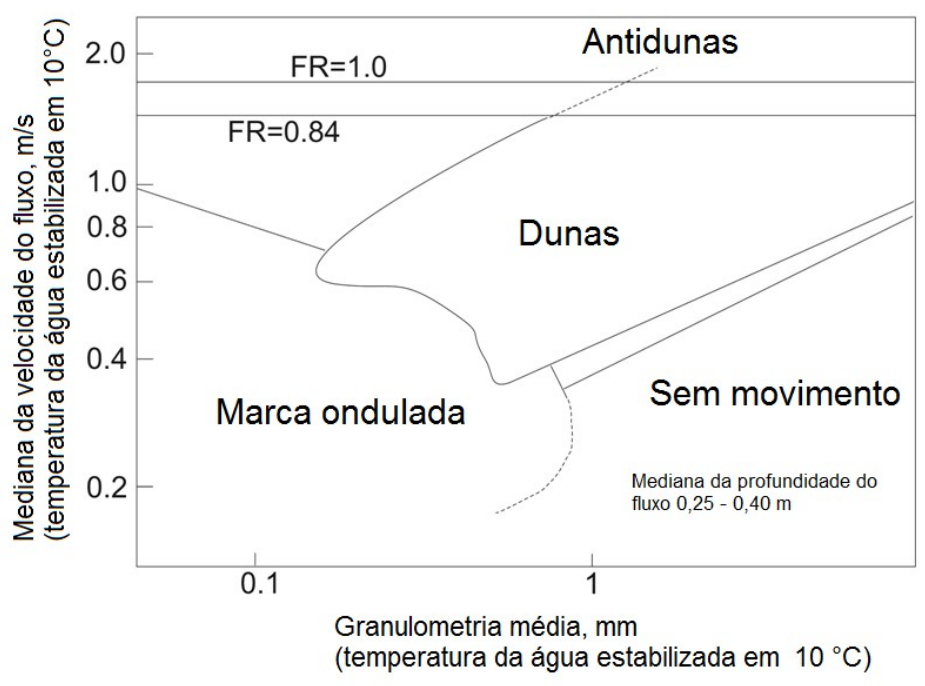

Figura 5 - Influência da granulometria e velocidade de fluxo na formação das formas de leito (modificado de Ashley, 1990)

As fácies portadoras de sedimentos mais finos são depositadas, em grande maioria, através da decantação. Esse processo, em canais ativos, é dificultado devido ao fluxo da água nos rios, ocorrendo apenas em períodos de 
menor ou ausência de fluxo. Esse tipo de depósito ocorre em locais de baixa ou ausente turbulência, como planícies de inundação, canais abandonados, ou então em locais distais ao extravasamento de canais (Miall, 1996).

Com base nos processos sedimentares formadores de estruturas, granulometria, seleção granulométrica, componentes acessórios entre outras características texturais, Miall (1977) criou a divisão de fácies para sistemas fluviais (figura 6). A simbologia utilizada possui a primeira letra maiúscula relacionada à granulometria, e a segunda e terceira letras minúsculas, relacionadas à textura e estrutura, respectivamente. Outros critérios também utilizados por outros autores (Walker, 1992 e Reading, 1996) para classificação de fácies são: conteúdo fossilífero, composição e geometria.

\begin{tabular}{|c|c|c|c|}
\hline Código & Fácies & struturas sedimentares & Interpretacão \\
\hline Gmm & Suportado pela matriz, cascalho maciçc & Gradação fraca & Debris flow plástico (viscoso) \\
\hline Gmg & Suportado pela matriz, maciço & Gradação inversa a normal & Pseudoplástico Debris flow plástico (viscoso) \\
\hline Gci & Suportado pelo arcabouço, maciço $C$ & Gradação inversa & $\begin{array}{l}\text { Debris flow rico em clastos, ou } \\
\text { pseudoplastico debris flow }\end{array}$ \\
\hline Gcm & Clasto suportado, cascalho maciço - & - & $\begin{array}{l}\text { Pseudoplastico debris flow rico (carga de } \\
\text { fundo inerte, fluxo turbulento) }\end{array}$ \\
\hline Gh & $\begin{array}{l}\text { Clasto suportado,acamamento } \\
\text { cascalhoso }\end{array}$ & $\begin{array}{l}\text { Acamamento horizontal, } \\
\text { imbricação }\end{array}$ & $\begin{array}{l}\text { Formas de leito longitudinais, } \\
\text { depósitos de lag e sieve }\end{array}$ \\
\hline Gt & Cascalho, estratificado & Cruzada acanalada & Preenchimento de canais pequenos \\
\hline $\mathrm{Gp}$ & Cascalho, estratificado & Cruzada tabular & $\begin{array}{l}\text { Formas de leito transversas, crescimentos } \\
\text { deltaicos de barras remanescentes }\end{array}$ \\
\hline St & $\begin{array}{l}\text { Areia fina a muito grossa, } \\
\text { pode ser seixosa }\end{array}$ & $\begin{array}{l}\text { Cruzada acanalada } \\
\text { solitária ou agrupada }\end{array}$ & Dunas linguoides sinuosas \\
\hline$S p$ & $\begin{array}{l}\text { Areia fina a muito grossa, } \\
\text { pode ser seixosa }\end{array}$ & $\begin{array}{l}\text { Cruzada tabular } \\
\text { solitária ou agrupada }\end{array}$ & Formas de leito transversas e sinuosas \\
\hline $\mathrm{Sr}$ & Areia muito fina a grossa & Marca ondulada & Regime de fluxo baixo \\
\hline Sh & $\begin{array}{l}\text { Areia fina a muito grossa, } \\
\text { pode ser seixosa }\end{array}$ & Laminação plano paralela & Fluxo em leito plano (fluxo crítico) \\
\hline SI & $\begin{array}{l}\text { Areia fina a muito grossa, } \\
\text { pode ser seixosa }\end{array}$ & $\begin{array}{l}\text { Cruzada de baixo ângulo } \\
\left(<15^{\circ}\right)\end{array}$ & $\begin{array}{l}\text { Preenchimentos de escavações ou } \\
\text { antidunas }\end{array}$ \\
\hline Ss & $\begin{array}{l}\text { Areia fina a muito grossa, } \\
\text { pode ser seixosa }\end{array}$ & Escavações rasas & Preenchimentos de escavações \\
\hline Sm & Areia fina a grossa & $\begin{array}{l}\text { Maciça ou laminação } \\
\text { insipiente }\end{array}$ & Depósitos de fluxo gravitacional \\
\hline $\mathrm{FI}$ & Areia, silte, argila & $\begin{array}{l}\text { Laminação fina ou marcas } \\
\text { onduladas muito pequenas }\end{array}$ & $\begin{array}{l}\text { Planícies de inundação, canais abandonados } \\
\text { ou depósitos de cheias }\end{array}$ \\
\hline Fsm & Silte, argila & Maciço & Back swamps, ou canais abandonados \\
\hline Fm & Silte, argila & $\begin{array}{l}\text { Maciço, cracks de } \\
\text { dessecação }\end{array}$ & $\begin{array}{l}\text { Drapes, canais abandonados ou planícies de } \\
\text { inundação }\end{array}$ \\
\hline $\mathrm{Fr}$ & Silte, argila & Maciço, raízes, bioturbação & Solo incipiente \\
\hline
\end{tabular}

Figura 6 - Descrição de fácies em ambientes fluviais (modificado de Miall, 1996) 


\subsubsection{Elementos arquiteturais}

Um conjunto de fácies diferentes pode ser agrupado quando preenchem alguma geometria ou possuem a gênese compartilhada (Allen, 1983). A essa associação de fácies, produto da sobreposição dos processos sedimentares, nomeia-se elemento arquitetural. A base para a classificação dos elementos arquiteturais fluviais pode ser guiada segundo Mial (1985). Porém, contestações de alguns autores e diferentes classificações, também são muito reconhecidas na literatura sobre sedimentologia fluvial (Bridge \& Lunt, 2006; Hjellbackk, 1997; Hornung \& Aigner, 1999; e Li et al., 2015).

Os elementos arquiteturais (EA) segundo Miall (1985) são divididos conforme a área de ocorrência em relação ao canal principal. Os EA de canais são: canais $(\mathrm{CH})$; barras de cascalho $(\mathrm{GB})$; depósitos de fluxos gravitacionais (SG); formas de leito arenosas (sandy bedforms) (SB); barras de acréscimo frontal (DA); barras de acréscimo lateral (LA); e, lençóis de areia laminados (LS). Já os elementos arquiteturais formados nas periferias dos canais são: levees (LV); canais de crevasse (CR); leques de crevasse (CS); finos de planície de inundação (FF); e, canais abandonados ( $\mathrm{CH}(\mathrm{FF}))$ Adicionalmente, outros autores, como Hornung \& Aigner (1999) detalham a descrição dos $\mathrm{CH}$ com base na carga de transporte.

Canais são compostos em sua grande maioria por areia e cascalho. A denominação dos elementos arquiteturais como canais utiliza-se, segundo Miall (1985), apenas quando não é possível a distinção entre DA e LA. O reconhecimento desse elemento arquitetural em afloramento é facilitado pela geometria côncava para cima de sua base. Quando encontrados, os canais podem fornecer informações importantíssimas, como profundidade e largura, refletidas pela espessura da camada de areia presente e mergulho das margens da estrutura, respectivamente. As fácies encontradas nos canais podem variar muito, por isso não se tem um conjunto de fácies esperado para um canal definido pelo autor.

As barras de cascalho são encontradas em rios com alta vazão, resultantes de pulsos com diferentes origens: de erosão, avulsão de canal, 
variação do nível de base e outros mecanismos geradores de sedimentos grossos. Os sedimentos cascalhosos aglomeram-se em barras, centrais ou laterais. Diferentes autores como Ashmore (1991), Leddy et al. (1993) e Germanosky \& Schumm (1993), modelaram barras cascalhosas e propuseram diferentes mecanismos formadores e consequências desse elemento arquitetural. As fácies mais comuns nos GB segundo Miall (1985) são Gp, Gh e Gt.

Segundo Miall (1985), os depósitos de fluxos gravitacionais muitas vezes ocorrem correlacionados às barras de cascalho. Esse tipo de depósito é formado por fluxo de detritos, resultando em geometria lobada alongada. Diferente dos canais, os SG não possuem bases erosivas, e geralmente preenchem áreas portadoras de topografias irregulares. A textura peculiar desse depósito é a gradação inversa, assim como texturas desorganizadas. As fácies $\mathrm{Gmm}$, Gmg, Gci e Gcm são predominantes nos SG.

As formas de leito arenosas (sandy bedforms) englobam diferentes formas de leito. Esse elemento arquitetural é caracterizado por Miall (1985) como um processo agradacional. As formas de leito englobadas nesse elemento arquitetural são compostas por: campo de dunas de fundo de canal, assembléia de preenchimento de canal raso, leques de crevasse, canais de crevasse e topos de barra (Miall 1996). Os topos de barra foram descritos com mais detalhe por Bristow (1993). Caracterizam-se por estratificações cruzadas de pequena escala, com granulometria de areia fina a média e lama associada. Essa forma de leito é gerada em locais onde a lâmina d'água encontra-se fina, sobre as barras.

Além das barras, lençóis de areia laminados são interpretados por Sneh (1983) e outros como resultados de cheias nos rios, gerando condições de regime superior, depositando areia. Esse processo ocorreria sobre superfícies planas e bases erosionais. O resultado apresenta principalmente fácies Sh e SI. Subordinadas a essas fácies são encontradas estratificações cruzadas tabulares gradando para estratificações cruzadas acanaladas com ripples no topo. Essa mudança de estruturas refletiria a diminuição gradual do regime de fluxo desde a descarga inicial. 
Em uma categoria a parte dos demaif elementos, devido à alta complexidade na geometria interna, separa-se as barras de acréscimo tanto frontal (DA) como lateral (LA) (Miall, 1985). Esses dois elementos arquiteturais são os principais produtos do acréscimo em canais arenosos, muitas vezes com argila e cascalho subordinado. A diferença entre os DA e os LA é a orientação do acréscimo em relação ao estrato cruzado. O "cuttof" utilizado por Miall (1996) é de $60^{\circ}$, ou seja, trata-se de uma DA quando o ângulo é menor que $60^{\circ}$. Já uma acreção lateral é reconhecida por ângulo maior que $60^{\circ}$. Apesar da separação comentada, em um mesmo rio é muito comum a presença de DA gradando lateralmente para LA (Miall, 1996). As litofácies encontradas nesses elementos arquiteturais, segundo Miall (1996) são: St, Sp, Sh, Sl e Sr.

Classificações alternativas para os mesmos complexos corpos arenosos acrescionários também foram descritas: por Hjellback (1997), dividindo-os em barras simples, estágio transicional entre barras simples e dunas complexas, dunas complexas e complexos acrecionários; por Bridge \& Lunt (2006) utilizando os termos dunas, barras unitárias e barras compostas; e, mais recentemente, Li et al., 2015 classificou seus elementos arquiteturais mais detalhadamente (figura 7).

\begin{tabular}{|c|c|c|c|c|c|}
\hline \multicolumn{2}{|c|}{ Elementos } & \multirow{2}{*}{$\begin{array}{l}\begin{array}{l}\text { Associação } \\
\text { de fácies }\end{array} \\
\mathrm{Sp}, \mathrm{St}, \mathrm{Sm} \\
\mathrm{Sh}, \mathrm{SI}, \mathrm{Sr}\end{array}$} & \multirow[t]{2}{*}{ Croqui } & \multirow{2}{*}{$\begin{array}{l}\text { Descrição } \\
\text { Alta sinuosidade, superficie basal côncava } \\
\text { para cima, corpos de arenitos assimétricos } \\
\text { granodecrescentes }\end{array}$} & \multirow{2}{*}{$\begin{array}{l}\text { Interpretação } \\
\text { Migração lateral do canal, pode localizar-se } \\
\text { próximo á barras longitudinais }\end{array}$} \\
\hline $\begin{array}{l}\text { Tipos de } \\
\text { canais }\end{array}$ & $\mathrm{CHm}$ & & & & \\
\hline & $\mathrm{CHs}$ & $\begin{array}{l}\text { Sp, St, Sm, } \\
\text { Sh, Sl, Sr }\end{array}$ & & $\begin{array}{l}\text { Baixa sinuosidade, superficie basal côncava } \\
\text { para cima, possui ciclos com diminuição da } \\
\text { espessura de sets e granulometria para o topo }\end{array}$ & $\begin{array}{l}\text { Formada entre duas barras com baixa } \\
\text { sinuosidade }\end{array}$ \\
\hline & $\mathrm{CHf}$ & $\begin{array}{l}\text { Sm, St, SI, } \\
\text { Sr. Fl }\end{array}$ & & $\begin{array}{l}\text { Consiste predominantemente por pelitos, } \\
\text { raramente com intraclastos de lama }\end{array}$ & $\begin{array}{l}\text { Depósitos de canais abandonatos preenchidos } \\
\text { com baixa energia }\end{array}$ \\
\hline & $\mathrm{HO}$ & St, Sp & & $\begin{array}{l}\text { Froma côncava para cima, com superficie basal } \\
\text { erosiva escavada, com tendência granodecrescente, } \\
\text { pode apresentar intraclastos argilosos }\end{array}$ & $\begin{array}{l}\text { Preenchimento de escavações em canais } \\
\text { abandonados }\end{array}$ \\
\hline \multirow[t]{4}{*}{$\begin{array}{l}\text { Tipos de } \\
\text { barras }\end{array}$} & DA & Sp, St, Sh & & $\begin{array}{l}\text { Forma externa tabular, definida por } \\
\text { superficies acrescionárias de Quarta } \\
\text { ordem mergulhando na mesma direção que } \\
\text { as cruzadas }\end{array}$ & $\begin{array}{l}\text { Deposição de macroformas que crescem para } \\
\text { a jusante por progradação }\end{array}$ \\
\hline & LA & $\mathrm{Sp}, \mathrm{St}, \mathrm{Sr}$ & & $\begin{array}{l}\text { Forma externa tabular, definida por } \\
\text { superfícies acrescionárias de Quarta ordem } \\
\text { com séries únicas tangenciais na base }\end{array}$ & $\begin{array}{l}\text { Acresção lateral de barras simples e } \\
\text { compostas }\end{array}$ \\
\hline & UB & $\mathrm{Sp}, \mathrm{St}, \mathrm{Sr}$ & & $\begin{array}{l}\text { Sets de estratificação cruzada de grande porte, } \\
1 \text { a } 5 \text { m de espessura, maior que } 10 \mathrm{~m} \text { de } \\
\text { continuidade lateral }\end{array}$ & $\begin{array}{l}\text { Formada em altos regimes de fluxo em } \\
\text { cinturão de vanais com acresção lateral }\end{array}$ \\
\hline & CB & $\begin{array}{l}\text { Sp, St, Sh, } \\
\text { Sr }\end{array}$ & & $\begin{array}{l}\text { Corpos de arenitos com cruzadas e ripples, } \\
\text { dezenas a centenas de metros de cont. } \\
\text { lateral e mais que dez metros de espessura }\end{array}$ & Agradação vertical de dunas ou barras simples \\
\hline $\begin{array}{l}\text { Planície } \\
\text { de inun. }\end{array}$ & OF & $\mathrm{Fm}, \mathrm{FI}$ & 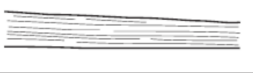 & $\begin{array}{l}\text { Unidades do tipo sheet de coloração roxa, } \\
\text { pouco espessas e muito continuas } \\
\text { lateralmente }\end{array}$ & $\begin{array}{l}\text { Depósitos de baixa energia em condições } \\
\text { oxidantes na planície de inundação nas cheias }\end{array}$ \\
\hline
\end{tabular}

Figura 7 - Elementos arquiteturais utilizados por $\mathrm{Li}$ et al. 2015 em depósitos fluviais (modificado). Os EA são divididos em quatro tipos de canais, quatro tipos de barras e depósitos de planícies de inundação. 
Os elementos arquiteturais provenientes de processos que ocorrem nas periferias dos canais são caracterizados, em sua maioria, por sedimentos mais finos que os encontrados nos canais. Esses elementos, segundo Miall (1996), podem ser classificados em três diferentes classes: sedimentos relativamente grossos, provenientes do extravasamento do fluxo dos canais (LV, CR e CS); sedimentos finos de ambientes de baixa energia (FF e $\mathrm{CH}(\mathrm{FF})$ ); e, sedimentos bioquímicos, formados devido a atividades orgânicas, pedogênese e outros processos.

Os levees são laminados e possuem ritmicidade entre camadas de silte e marcas onduladas de areia fina. Nesse elemento arquitetural, fósseis de vertebrados, bioturbações e marcas de raízes podem ser encontrados. Os leques e canais de crevasse são classificados no mesmo grupo que os levees. Os canais consistem em fluxos canalizados (CR), compostos por granulometria areia-média (próximo ao canal principal do rio) a areia-fina (porções distais) e litofácies St, Sr e Ss. Já os leques (CS) ocorrem onde o fluxo proveniente do $\mathrm{CR}$ é desconfinado, resultando em lentes de granulometria decrescente à medida que a deposição se distancia do CR. As fácies comumente encontradas nas CS são St e Sr, com estruturas sedimentares hidrodinâmicas, raízes de plantas e bioturbações. As CS muitas vezes são cortadas por CR e lateralmente variam para depósitos de planície de inundação (Miall, 1996).

Os sedimentos de planícies de inundação e de canais abandonados são finos, depositados em ambientes calmos, por decantação, resultando em rochas laminadas. A textura encontrada também pode ser maciça, pois a laminação muitas vezes é destruída pelos organismos (bioturbação). A litologia nesses depósitos é monótona, com variações de cor e textura. As planícies de inundação possuem uma continuidade lateral muito maior que os canais abandonados, que por sua vez tem geometria característica. Outro fator para a distinção dos dois depósitos é a maior continuidade lateral das fácies nas planícies de inundação, devido ao menor declive encontrado nesse elemento arquitetural (Miall, 1996). Segundo Toonen et al. (2012), a monotonia de fácies de canais abandonados pode não ocorrer, principalmente devido aos 
processos graduais de abandonos e reativações esporádicas de canais abandonados.

\subsubsection{Estilos de reservatórios fluviais de hidrocarbonetos}

Os reservatórios fluviais compõem grande parte das reservas de hidrocarbonetos mundiais. Nos Estados Unidos encontram-se os depósitos fluviais da Bacia do Leste do Texas, na unidade Woodbine; da Bacia do Anadarko, na Formação Morrow e entre outros. No Equador, na Bacia do Oriente, nas Formações Hollin e Napo (Sowek, 2013). No Brasil, podem ser tomados como exemplos de reservatórios fluviais produtores as Formações Sergi e Açu, das Bacias do Recôncavo e Potiguar, respectivamente (Castro et al., 1981; De Ros \& Scherer 2012).

Os reservatórios de hidrocarbonetos e suas heterogeneidades são estudados para criação de modelos geológicos, facilitando a predição de anisotropias. Segundo Miall (1996), dois estudos são essenciais neste trabalho: a geometria do sistema deposicional e a geometria do reservatório.

A geometria dos sistemas fluviais, segundo Miall (1996), é dividida entre cunhas clásticas (clastic wedges) e preenchimentos de paleocanais (paleovalley fill) (figura 8). As cunhas clásticas são camadas espessas de arenitos formados em áreas muito íngremes devido ao soerguimento de uma área fonte como consequência da tectônica de falhas, o que geralmente ocorre em bacias rift ou foreland. As cunhas são formadas no momento em que o aporte sedimentar é maior que a taxa de geração de espaço de acomodação. Esse tipo de depósito pode variar as fácies tanto para um sistema de delta marinho, como para um sistema dominado por sedimentos finos, como ambientes lacustres. Diferentemente das cunhas clásticas, os preenchimentos de paleocanais ocorrem em áreas de baixa declividade e muito extensas, comuns em bacias intracratônicas, porém também são documentadas em margens continentais extensionais e em bacias de foreland, em regiões distais aos orógenos. O preenchimento desses canais é associado a grandes 
descontinuidades, resultando em diminuição no nível de base e grande aporte sedimentar.

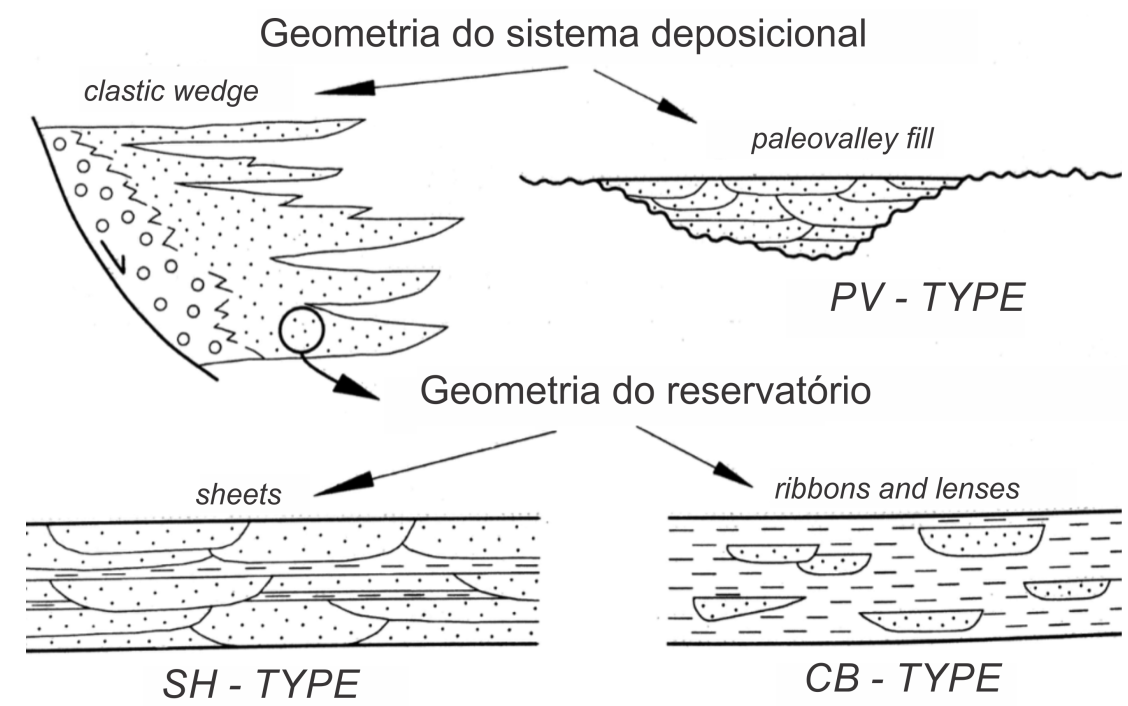

Figura 8 - Geometria deposicional, dividida em cunha clástica e preenchimento de paleocanal, e do reservatório, em sheets e ribbons and lenses, de sistemas fluviais (Miall 1996)

Apesar de englobar grande parte dos depósitos fluviais, essa divisão restringe muito todos os tipos de depósitos encontrados e possuem um caráter muito simplista para a complexidade dos reservatórios fluviais.

Outra classificação simplista, antigamente muito utilizada, é a classificação fluvial entre sistemas entrelaçados e meandrantes, a qual perdeu força em meio aos especialistas em sistemas fluviais (Reineck \& Singh 1980). Porém, para a indústria essa classificação ainda é muito importante, utilizada atualmente conforme o tipo de transporte realizado pelos sistemas. Devido ao transporte, carga de fundo ou suspensão, dois principais tipos de geometria de reservatório foram designados por Friend (2009): (i) sheet sandstones (SH types) (predomínio de transporte por carga de fundo) e (ii) sandstones ribbons and lenses (CB types) (predomínio de transporte por suspensão). O autor diferenciou os dois estilos entre lateralmente contínuos e lateralmente restritos, respectivamente. Alguns autores ainda adicionam a essas duas geometrias uma intermediária, composta por rios que misturam os dois tipos de transporte. A simples classificação dos depósitos pelo transporte vigente no rio, a princípio não auxiliaria a indústria petrolífera, mas implícitos nessa classificação, 
residem variáveis muito importantes, como a conectividade dos corpos arenosos.

(i) sheet sandstones ( $\mathrm{SH}$ types): A grande maioria dos reservatórios do tipo "sheet sandstones" são formados em rios com alto gradiente hidráulico. Esses seriam portadores de sedimentos mais grossos, com raras acumulações de sedimentos finos (fácies não reservatório), culminando em alto índice de conectividade entre os corpos arenosos, altas porosidades e permeabilidades. Porém, o sistema petrolífero com reservatório proveniente dessa geometria pode não ser efetivo, devido à ausência de barreiras de permeabilidade. Outros sistemas também geram reservatórios com a geometria "sheet sandstones", como os rios de baixa declividade e energia, mas sob a influência de baixos potenciais de preservação de sedimentos finos, da planície de inundação, resultando assim em uma amalgamação de canais preenchidos, como é o caso de reservatórios na Bacia de Cooper, na Austrália (Stuart et al., 1988).

(ii) sandstones ribbons and lenses: A geometria sandstones ribbons and lenses é formada em canais arenosos isolados por sedimentos finos. O exemplo mais utilizado para essa geometria é o de barras laterais com variação lateral para planícies de inundação. Apesar da definição desse tipo de geometria para rios onde predomina o transporte por suspensão, trabalhos como os de Dranfield et al (1987) mostram que rios classificados como entrelaçados (transporte por carga de fundo) também podem apresentar essa geometria de reservatório. Comparados aos sheet sandstones, essa geometria de reservatório possui volumes menos contínuos de "reservatório limpo". São gerados vários reservatórios de pequena extensão intercalados com sedimentos finos, ao invés de um grande reservatório, como ocorrem nos sheet sandstones.

Finalmente, baseados pela geometria do sistema deposicional e do reservatório, três estilos de reservatório fluviais foram definidos por Galloway \& Hobday (1996) (figura 9). O primeiro deles, conhecido como "camada de bolo", é caracterizado por extensa continuidade lateral dos litotipos, típico de sistemas fluviais entrelaçados, com geometia de reservatório semelhante ao tipo "sheet". O segundo possui menor continuidade lateral e conectividade entre os corpos 
arenosos que o primeiro. É conhecido como quebra-cabeça, no qual se encontram antigos canais arenosos separados ocasionalmente por barreiras de permeabilidade. Esse tipo de reservatório é relacionado a rios meandrantes transportadores de sedimentos grossos ou mesmo rios entrelaçados, mas com preservação de depósitos de planície de inundação. O terceiro e último tipo de reservatório possui uma conectividade muito baixa entre canais permeáveis, com uma geometria muito complicada e difícil de ser mapeada. Devido à essa complexidade, o nome atribuído a esse tipo de reservatório é labirinto.

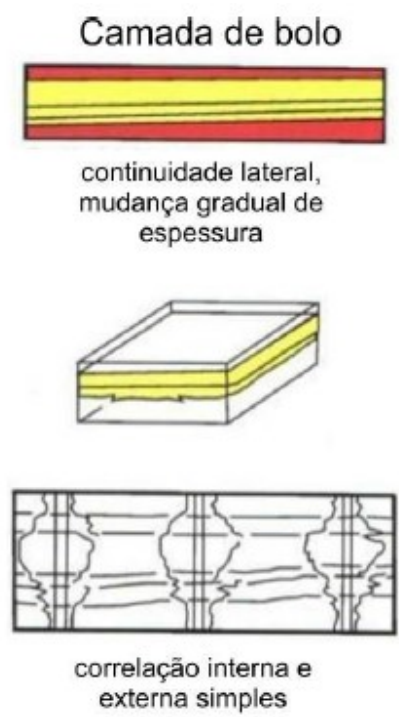

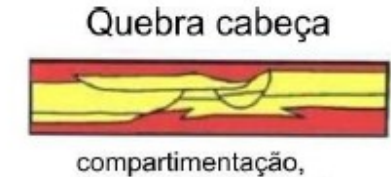

compartimentação, contraste textural abrupto
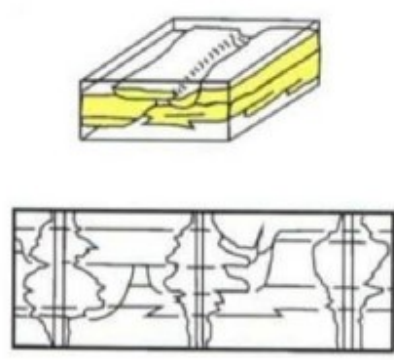

correlação externa simples; correlação interna difícil
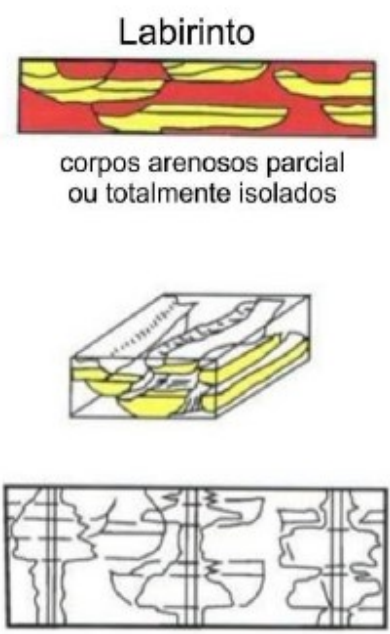

correlaçäo externa dificil

Figura 9- Tipos de reservatório descritos por Galloway \& Hobday, 1996. Retirado de Sowek (2013).

Apesar dos modelos de reservatórios fluviais apresentados, reconhecese que os reservatórios fluviais são muito mais complexos que os modelos apresentados anteriormente. Porém, entre os modelos apresentados, o mais adequado é o proposto por Galloway \& Hobday (1996).

O estudo e detalhamento da complexidade do reservatório in loco é de difícil acesso e alto custo, logo, foram desenvolvidos os estudos de análogos de reservatório. 


\subsection{Análogos de reservatório}

Os análogos de reservatório são utilizados em larga escala pela indústria petrolífera nos dias atuais (Howell et al 2014). Esse estudo pode ser discriminado em três categorias: sistemas deposicionais modernos; simulações experimentais e afloramentos (trabalho em questão) (Alexander, 1993).

As heterogeneidades de um reservatório caracterizam-se resumidamente por variações texturais e mineralógicas presentes nas rochas e podem ser analisadas em diferentes escalas, através de diversas ferramentas. Dentre as escalas estão as: microscópicas, macroscroscópicas, mesoscópicas, megoscópicas e gigascópicas, sendo que as três primeiras são analisadas com mais freqüência em estudos de afloramento. As heterogeneidades são analisadas microscopicamente por lâminas petrográficas, MEV e ressonância magnética nuclear, consistindo principalmente em: tipo e tamanho de grão e de poro; tamanho de garganta de poro; quantificação de porosidade; empacotamento; cimentação; compactação, entre outros. As macroscópicas são reconhecidas em forma de plug, com análises de porosidade e permeabilidade. Já as mesoscópicas são analisadas por meio de perfilagem, e associações de fácies nos análogos de afloramento. As heterogeneidades na escala megoscópica e gicoscópica dificilmente são analisadas em estudos de análogos, mas compreendem as distâncias entre poços perfurados, e escala de uma bacia inteira, respectivamente (Tiab \& Donaldson, 2004).

Muitos trabalhos de análogos de reservatório já foram e continuam sendo executados (Alsop et al., 2013, Martinius \& Naess, 2005, Luthic \& Flint 2013, Dalrymple, 2001, Pranter et al 2014, Howell et al 2014; Hurst et al 2015; Racey et al 2016; Bowman, 2016). Grande parte dos trabalhos segue o mesmo workflow, na qual a primeira etapa é a classificação do afloramento em fácies, posteriormente agrupadas em elementos arquiteturais. Para esse feito utilizamse observações e descrições de afloramento, mas também lâminas petrográficas para distinção de microheterogeneidades entre fácies. Feito isso são adquiridos dados de maior interesse para a indústria, como modelo de fácies, geometrias, anisotropias entre outros. Para aquisição desses dados, uma infinidade de métodos pode ser empregada, como: permeâmetro de 
campo (Fossen et al 2009), análises petrofísicas de porosidade e permeabilidade a gás (Yangquan et al 2005), perfilagem, análises de porosidade em lâmina, diversos tipos de GPS (Enge et al 2007), fotomosaicos (Taylor \& Ritts 2004) , LIDAR (Ekeland et al 2008) e entre outras tecnologias

Os estudos dos análogos, de fato, auxiliam a melhora dos modelos de reservatório. Porém, existem alguns fatores críticos mencionados por Alexander (1993) que devem ser levados em consideração, como: a escolha dos afloramentos e representatividade do mesmo para o reservatório; problemas de escala; e, a diferença de idades e processos sofridos pelo afloramento e pelo reservatório.

\subsection{Petrofísica}

A petrofísica é a ciência que busca caracterizar os fenômenos físicos presentes nas rochas (Tiab \& Donaldson 2004). Essa análise é de suma importância para indústria do petróleo, já que reduz a incerteza: tanto na estimativa de reservas como da produção; dimensionamento da produção; e, a viabilidade econômica do reservatório. Além disso, a petrofísica é uma ferramenta muito importante para a calibração dos dados de perfilagem.

A petrofisica divide-se em três frentes: petrofísica básica, petrofísica especial e petrofísica digital. Neste trabalho, duas análises da petrofísica básica foram utilizadas: porosidade e permeabilidade absoluta.

\subsubsection{Porosidade}

Quando depositadas, as rochas sedimentares não formam camadas perfeitas, totalmente encaixadas, devido à irregularidade dos grãos, diferentes empacotamentos, diferentes taxas de aporte, compactação, entre outros fatores. Os "vazios" entre as camadas e grãos são nomeados como 
porosidade. Essa medida estatística é definida matematicamente pela relação (Tiab \& Donaldson, 2004):

$$
\begin{aligned}
& \Phi=\left(V_{b}-V_{g r}\right) / V_{b}=V_{p} / V_{b} \text { (equação 1) } \\
& \Phi=\text { porosidade } \\
& \bigvee_{\mathrm{b}}=\text { volume sólido } \\
& V_{g r}=\text { volume de grão } \\
& V_{p}=\text { volume poroso }
\end{aligned}
$$

As características texturais e estruturais das rochas sedimentares, influenciadas por diversos processos geológicos, exercem grande interferência na porosidade. As variáveis controladoras da porosidade, quando analisadas separadamente são: empacotamento, seleção granulométrica, esfericidade, arredondamento, compactação, cimentação, dissolução e fraturamento.

Segundo o experimento realizado por Graton \& Fraser (1935), com esferas uniformes, ou seja, com a mesma granulação, provou-se que diferentes arranjos de empacotamento geram diferentes porosidades (figura10).

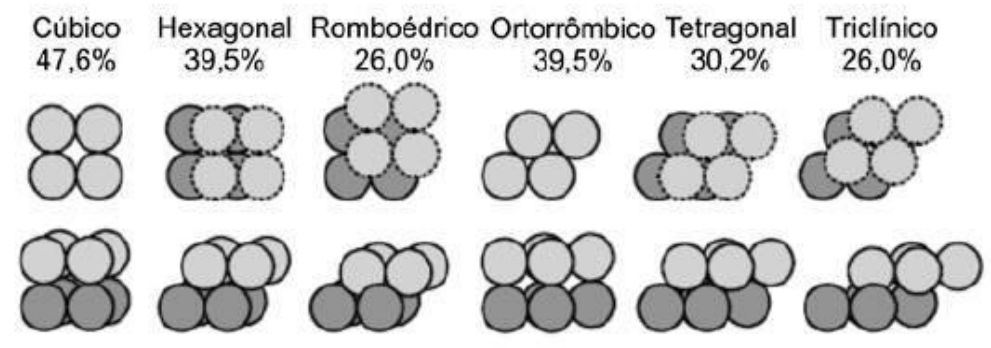

Figura 10 - Diferentes empacotamentos de rocha resultando em diferentes valores de porosidades. (de Glover, 2000, retirado de Geisick et al., 2009) (Fraser \& Graton, 1935).

Segundo Boggs (2012) a seleção granulométrica é o desvio padrão das medidas de diâmetros dos grãos depositados. A porosidade é afetada negativamente caso exista alto desvio padrão entre as granulometrias 
presentes na amostra. Partículas de argila e silte, em uma rocha composta em sua maioria por areia, por exemplo, colocariam-se entre os grãos de areia, ocupando poros que não seriam obstruídos caso a rocha fosse composta apenas por grãos de areia (figura 11).

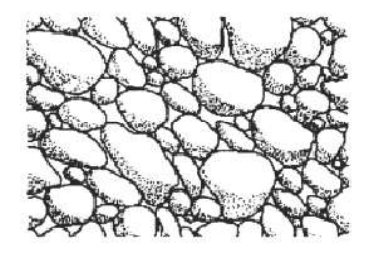

Figura 11- Grãos com diferentes granulometrias preenchendo espaço que seria poroso caso os mesmos possuíssem mesma granulometria (Tiab\& Donaldson 2004)

A esfericidade é uma propriedade dependente exclusivamente da mineralogia, remetente à área fonte dos sedimentos depositados, e interferem no arranjo dos grãos (Boggs, 2012). Quanto mais esféricos os grãos, maior é o volume poroso resultante (figura 12).

A

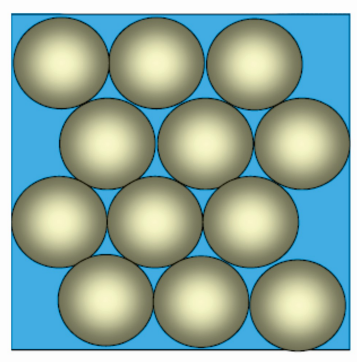

B

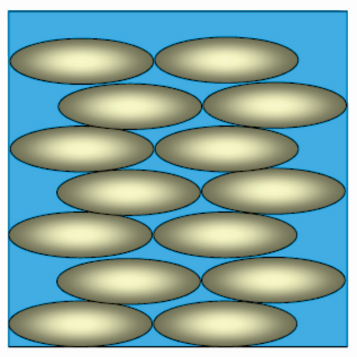

Figura 12 - Grãos com diferenças de esfericidades preenchendo o mesmo volume. Figura A com grãos portadores de alta esfericidade (12 esferas) e figura B com grãos pouco esféricos (14 elipses), resultado em diferentes porosidades. Modificado de Cruz (2014)

O arredondamento é definido pela quantidade de irregularidades na superfície dos grãos, relacionados com a duração do transporte e granulometria (Boggs, 2012). As irregularidades atuam de forma a preencher os espaços porosos da rocha, diminuindo a porosidade. 
A porosidade no instante da deposição em rochas siliciclásticas, em média, encontra-se por volta de $40 \%$. A compactação pode diminuí-la até próximo de zero (Gluyas \& Cade, 1997) (figura 13). Alguns trabalhos como: (Sombra \& Chang 1997), Lundergard (1992), propõem diferentes maneiras para quantificar a compactação e sua influência no decréscimo de porosidade. Esse processo pode culminar: na expulsão de fluidos, "pressure solution" entre outros processos que facilitariam a posterior cimentação. Outros fatores não ligados à compactação também podem ocasionar a cimentação como, por exemplo, a percolação de fluidos. Assim como a compactação, a cimentação diminui a porosidade, precipitando minerais neoformados, os quais ocupam poros pré-cimentação. Porém, em alguns casos, a formação de cimento envolvente ("coatings") pode contribuir para a manutenção de altas porosidades, evitando outros tipos de cimentações mais prejudiciais a porosidade.

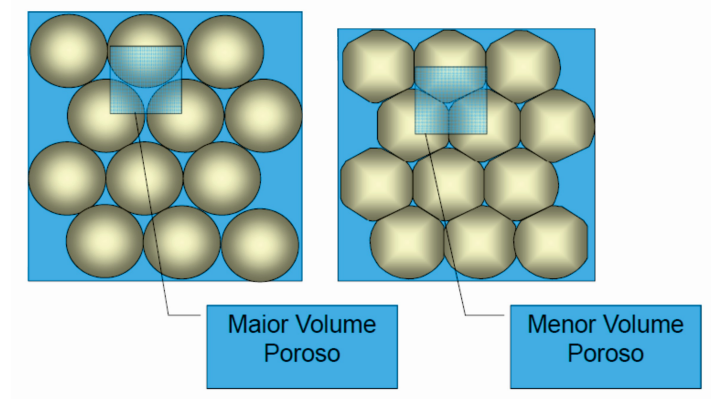

Figura 13 - Aumento da compactação resultando na diminuição do volume poroso. Modificado de Cruz (2014)

Diferente da compactação e cimentação, a dissolução e o fraturamento são diretamente proporcionais ao aumento de porosidade. A dissolução ocorre devido às mudanças nas condições em que as rochas são submetidas, resultado da alteração da solubilidade dos minerais, ou devido à percolação de fluidos pobres ou ricos em determinado elemento. Já o fraturamento é função da tectônica local e culmina na abertura de volumes porosos. 


\subsubsection{Classificações de porosidade}

Devido à grande gama de profissionais relacionadas à indústria do petróleo, principalmente geólogos, geofísicos e engenheiros, existem diferentes classificações de porosidades. As classificações de porosidade também variam em relação ao tipo de rocha analisada. Neste trabalho foram estudadas rochas siliciclásticas, logo a classificação de porosidade em carbonatos não será mencionada.

Segundo a comunidade geológica, as porosidades são divididas entre porosidades de origem primária ou secundária. A porosidade primária é aquela formada junto à deposição dos sedimentos. Já a porosidade secundária é obtida devido a algum fator pós-deposicional. Outra forma de caracterização da porosidade é conforme o local onde estão encontrados os poros (Tiab \& Donaldson, 2004):

Porosidade intergranular: é a porosidade remetente ao espaço entre os grãos detríticos, na maioria dos casos, em rochas siliciclásticas, a mais volumosa. Possui poros em média com 0,5 milímetros de diâmetro.

Porosidade intercristalina: porosidade entre os planos de clivagem dos minerais, também conhecida como microporosidades (Pitman, 1971), muito comum em argilas. Esse tipo possui poros menores que 0,5 $\mu \mathrm{m}$.

Porosidade intragranular: porosidade interna ao grão, geralmente causada por dissolução. As dissoluções também podem estar relacionadas a eventos maiores, dissolvendo vários grãos por inteiro, chamada de porosidade por dissolução.

Porosidade entre os planos de acamamento: porosidade concentrada paralelamente a estratificação da rocha.

Porosidade por fraturamento: porosidade gerada devido a um esforço tectônico local;

A porosidade é caracterizada, segundo Tiab \& Donaldson (2004) pelos engenheiros em porosidade absoluta e efetiva. Desde a deposição do 
sedimento até a Telodiagênese, a rocha é submetida a diversas condições, as quais podem manter os poros conectados ou isolá-los. Devido a essas condições os engenheiros classificam os poros rentáveis para indústria de petróleo (porosidade efetiva) e a porosidade total (porosidade absoluta). A porosidade efetiva é definida pela relação do volume de poros interconectados sobre o volume total da amostra. Já porosidade absoluta é resultado da relação do volume de poros totais sobre o volume total da amostra.

\subsubsection{Permeabilidade}

Além da porosidade, a permeabilidade é uma variável indispensável para o estudo de hidrocarbonetos. Essa variável, diferente da porosidade, é uma medida vetorial e não escalar.

A permeabilidade define-se como a capacidade de um meio em transmitir um ou mais fluidos. Essa propriedade foi definida por Darcy e é calculada com base na equação do mesmo, levemente modificada. Essa se caracteriza igualando a vazão $(\mathrm{Q})$, em centímetros por segundo; a capacidade de um corpo em transmitir um fluido (K); multiplicada pela área onde o fluido irá percorrer (A), em centímetros quadrados; multiplicada pela diferença de pressão do fluido na entrada e na saída do corpo em questão (P1-P2), em atm; dividido pelo resultado da multiplicação entre a viscosidade do fluido $(\mu)$, em centipoise, e o comprimento da amostra (L), em centímetros. Logo, tem-se:

$$
\mathrm{Q}=\mathrm{K} \cdot \mathrm{A} \cdot(\mathrm{P} 1-\mathrm{P} 2) / \mu \cdot \mathrm{L}
$$

(equação 2)

Deve-se levar em consideração que a lei de Darcy, segundo o mesmo, é válida apenas quando: o meio encontra-se 100\% saturado em um único fluído, com ausência da interação rocha-fluido e em condições de um escoamento linear de um fluido newtoniano. 
Assim como a porosidade, a permeabilidade também é fortemente influenciada por variáveis geológicas. Todas as variáveis que influenciam na porosidade, também influenciam, mesmo que em diferente magnitude, na permeabilidade: empacotamento, seleção granulométrica, esfericidade, arredondamento, compactação, cimentação, dissolução e grau de fraturamento. Além disso, variáveis adicionais como granulometria, presença de argilas e pressão efetiva também são controladoras da permeabilidade (Tiab \& Donaldson, 2004).

O empacotamento exerce controle sobre a permeabilidade devido a diferentes empacotamentos gerarem maiores ou menores gargantas de poro. O empacotamento cúbico, por exemplo, gera maiores gargantas de poro que o triclínico (figura 13). Trabalhos como o de Slichter (1899), baseado na relação de Kozeny, mostram equações que relacionam o empacotamento com a permeabilidade e porosidade.

A alta seleção granulométrica impede que as gargantas de poro sejam preenchidas por grãos menores, aumentando a permeabilidade. $O$ alto arredondamento e esfericidade também aumentam os volumes das gargantas de poro. Já a compactação tem uma relação inversamente proporcional à permeabilidade: com o seu aumento, os grãos se aproximam e as gargantas de poro diminuem (Tiab \& Donaldson, 2004).

A cimentação e a dissolução atuam de formas contrárias na manutenção da permeabilidade. A cimentação sempre diminui a permeabilidade do reservatório, agindo conforme a morfologia apresentada. Cimentações pervasivas fecham grande parte do volume poroso, diminuindo a permeabilidade do reservatório. A cimentação na morfologia de coatings ou rims, também causa déficit na permeabilidade, mas ao invés de obliterar totalmente as gargantas de poro, ela diminui o raio das mesmas. Apesar de menos prejudicial que a cimentação pervasiva, os coatings e rims também são prejudiciais à permeabilidade, pois diminuirão as gargantas de poro. Já a dissolução, seja ela de grãos ou de cimento, sempre gerará vias pororosas na rocha, culminando no aumento de permeabilidade local (Kupecz et al., 1997). 
Assim como a dissolução, o fraturamento é diretamente proporcional ao aumento da permeabilidade. Ambos os processos geram vias muito permeáveis nos reservatórios, aumentando a mesma em até quatro escalas de grandeza (Tiab \& Donaldson, 2004). Em contrapartida, próximo a zonas de falha a permeabilidade diminui devido à formação de "gouge", ou até mesmo bandas de deformação (Destro et al., 2003). Outro fator que deve ser levado em conta e pode também diminuir a permeabilidade é a facilidade para percolação de fluidos no local, resultando na cimentação da área.

A granulometria é um fator muito influente na permeabilidade. Nos estudos de reservatório, é a propriedade textural da rocha que possui maior coeficiente de relação com a permeabilidade. A maior granulometria é correlácionavel ao tamanho das gargantas de poro (Shepherd, 1989)

A presença de argilas em rochas reservatório geralmente é prejudicial à permeabilidade. As argilas como coatings, cutans, pore lining, por cimentação pervasiva e entre outros hábitos, fecham ou diminuem o volume das gargantas de poro, diminuindo em escalas de grandeza a permeabilidade (Moraes \& De Ros, 1992; Worden \& Morad, 2003; Scherer \& De Ros, 2009; Morad et al 2010).

Devido ao fato de quase todas as variáveis que influenciam a porosidade também influenciarem na permeabilidade, foi desenvolvida por Kozeny et al (1927) uma relação entre as variáveis. Para essa correlação foi determinado um corpo poroso com sessão de área $(A)$ e comprimento $(L)$ determinado, composto por certa quantidade de tubos paralelos $(n)$ com raio determinado $(r)$ e mesma distância do corpo poroso (L), com um cimento impermeável intertubos. Logo, tem-se:

$$
q=\left(n \cdot \pi \cdot r^{4} \cdot \Delta p\right) /(8 \cdot \mu \cdot L)
$$

Outras relações entre permeabilidade $(K)$ e porosidade $(\Phi)$ utilizando a equação de Kozeny, equação de Darcy (equação 2) e a equação de 
porosidade (equação 1) em um sistema de equações para, tem-se (Tiab\& Donaldson, 2004):

$$
\mathrm{K}=\Phi^{2} \mathrm{r} / 8
$$

(equação 4)

Com a manipulação matemática, que não é o foco desse trabalho, outras equações foram derivadas das equações 1, 2 e 3 envolvendo porosidade e permeabilidade e podem ser obsevadas com maior detalhe em Tiab \& Donaldson (2004).

As equações mostradas anteriormente tratam o meio como "tubos". Esse cenário é muito diferente da complexa heterogeneidade encontrada em reservatórios. Outra variável levada em conta por Tiab \& Donaldson (2004) buscando minimizar essa interpretação simplista é a tortuosidade. Ela é definida pela relação elevada ao quadrado entre caminho realmente realizado pelo fluido (La) e o comprimento do tubo (L).

$$
T=(L a / L)^{2}
$$

\subsubsection{Anisotropia de permeabilidade}

Como citado anteriormente, a permeabilidade trata-se de uma variável vetorial. Somada à heterogeneidade dos substratos geológicos, variando a direção analisada, tem-se diferentes valores de permeabilidade. Devido a essa diferença, a indústria do petróleo geralmente analisa duas direções de permeabilidade, vertical e horizontal em relação aos estratos.

A anisotropia da permeabilidade é governada majoritariamente pelos fatores condicionantes do sistema deposicional e diagenético. Quatro fatores são colocados por Tiab \& Donaldson (2004) como principais governadores da 
anisotropia da permeabilidade: forma dos grãos, laminação, cimentação, fraturamento e dissolução.

A forma alongada dos grãos favorece a anisotropia, aumentando a permeabilidade paralela ao alongamento (horizontal) e diminuindo em grande escala a permeabilidade ortogonal (vertical) (figura 14). No caso de grãos com alto grau de arredondamento e esfericidade, a isotropia dos reservatórios é favorecida.

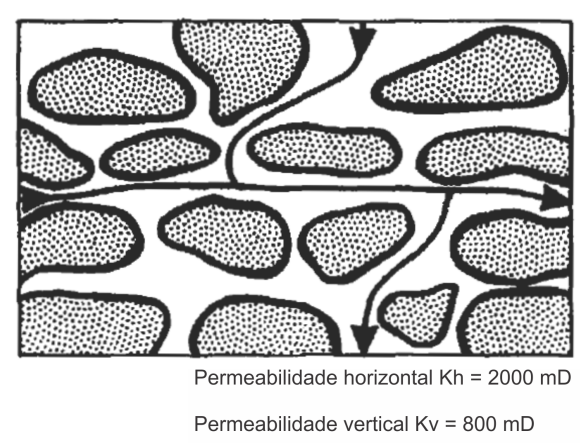

Figura 14 - Anisotropia de permeabilidade nas direções horizontal e vertical no trabalho de Clark 1969 (extraído de Tiab \& Donaldson 2004)

Assim como a forma alongada dos grãos, a laminação ocasionada por minerais placóides como muscovita, biotita, que conferem laminações em rochas pelíticas, possuem grande interferência na anisotropia do reservatório. A permeabilidade vertical é muito prejudicada por esses minerais, enquanto que a permeabilidade horizontal praticamente não é afetada.

A cimentação é outro fator que pode alterar em grande escala a anisotropia da permeabilidade do reservatório. O processo pode ser local, ou em uma direção preferencial, diminuindo a permeabilidade exclusivamente no local da cimentação. Já o fraturamento e a dissolução agem de forma contrária à cimentação, aumentam a permeabilidade em uma direção preferencial, ou em uma região específica, não alterando as demais.

A anisotropia é um parâmetro para quantificação da heterogeneidade do reservatório, pela relação entre permeabilidade horizontal $\left(\mathrm{K}_{H}\right)$ e permeabilidade vertical $\left(\mathrm{K}_{\mathrm{v}}\right)$ (Tiab \& Donaldson, 2004) : 


\subsubsection{Classificações de permeabilidade}

A permeabilidade pode ser classificada em dois diferentes cenários, sendo eles: saturação em um único fluido sem interação com o meio; saturação em diferentes fluidos com interação com o meio (Tiab \& Donaldson, 2004).

A permeabilidade absoluta é medida quando apenas um fluido satura o meio poroso. Nessa medida o fluido, desde que não interaja com a rocha, não interfere na medida, ou seja, independente do fluido a permeabilidade será a mesma.

A permeabilidade efetiva é utilizada quando a rocha é saturada por diferentes fluidos. Nesse caso deve-se calcular a permeabilidade para cada fluido. Essa variável depende do fluido e das interações dele com o meio poroso, diferentemente da permeabilidade absoluta. A soma de todas as permeabilidades efetivas nunca será maior que a permeabilidade absoluta. Débitos na permeabilidade efetiva sempre serão inseridos, provenientes da interação rocha-fluido.

Por fim, quando são medidas diferentes permeabilidades efetivas, costuma-se utilizar a permeabilidade relativa, a qual se trata da simples relação entre diferentes permeabilidades medidas.

As permeabilidades também são classificadas, assim como as porosidades, em permeabilidades primárias e secundárias (Tiab \& Donaldson, 2004). As primeiras são as adquiridas junto à deposição dos sedimentos. Já a secundária é adquirida posteriormente a formação da rocha. 


\subsection{Controles da diagênese clástica, autigênese diagenética e implicações na qualidade do reservatório}

As heterogeneidades em escala microscópica possuem como principal ferramenta de estudo a petrografia. Essa engloba tanto estudos de composição mineralógica, relações entre grãos e, principalmente processos diagenéticos.

\subsubsection{Controladores da diagênese clástica}

A diagênese, nos estudos mais recentes, é dividida em três principais estágios: Eodiagênese, Mesodiagênese e Telodiagênese (Kupecz et al., 1997). A Eodiagênese ocorre logo após a deposição, estágio inicial da diagênese. Essa etapa diagenética sofre grande influência dos sistemas deposicionais nos quais as rochas são geradas, ocorrendo majoritariamente a temperaturas e pressões baixas. Os processos diagenéticos ocorridos durante esta fase, na maioria dos casos, são dissolvidos ou recristalizados. A Mesodiagênese é um estágio posterior a eodiagênese. Neste campo a temperatura e a pressão aumentam, assim como as reações entre fluidos diagenéticos e a rocha. Os fluidos diagenéticos são constantemente modificados quimicamente devido às reações com os minerais presentes no sistema. Nesta fase ocorre o ápice de temperatura e pressão. A Telodiagênese é o ultimo estágio da diagênese. A rocha é realocada em temperaturas e pressões baixas, exposta, tornando-se mais susceptível a eventos climáticos de superfície (De Ros, 1996).

Levando em consideração os principais parâmetros controladores da diagênese clástica, possuem grande fator de impacto: a temperatura, a pressão, a composição inicial e os fluidos atuantes no local.

A temperatura exerce grande controle sobre a diagênese. Esta é função da história de soterramento da sequência sedimentar, da profundidade, do fluxo de calor na bacia e da condutividade termal das rochas adjacentes, e da 
tectônica local (De Ros, 1996). A constante elevação de temperatura geralmente leva à cimentação que, de modo instantâneo, diminui a porosidade e permeabilidade. Por isso, muitos projetos de estudo de porosidade e permeabilidade foram desenvolvidos através de relações com geotermômetros (Sombra et al., 1990).

A pressão é outro fator de grande interferência na diagênese e, consecutivamente, na qualidade de reservatórios. Essa variável é função do stress tectônico local, e aumenta linearmente com a profundidade. A pressão influi diretamente na compactação em que a rocha será submetida. A compactação, por sua vez, influenciará diretamente no volume de poros e contatos entre os grãos presentes no arcabouço (figura 15) (Primmer et al., 1997). Esse efeito pode ocorrer mecanicamente ou quimicamente. $\mathrm{Na}$ compactação mecânica, que ocorre durante o final da Eodiagênese ao começo da Mesodiagênese, os grãos são: rotacionados; fraturados; e, fragmentos líticos e feldspatos são dobrados. Os dobramentos de grãos líticos e feldspatos possivelmente culminam na formação de pseudomatriz, interferindo na porosidade e fechando as gargantas de poros, acarretando em grande decréscimo da permeabilidade (Kupecz et al., 1997). Já a compactação química gera o fenômeno conhecido como "pressure solution". Esse processo gera microfraturas entre as paredes dos grãos do arcabouço, liberando soluções com alta concentração de determinada substância, geralmente quartzo, acarretando possíveis cimentações. 


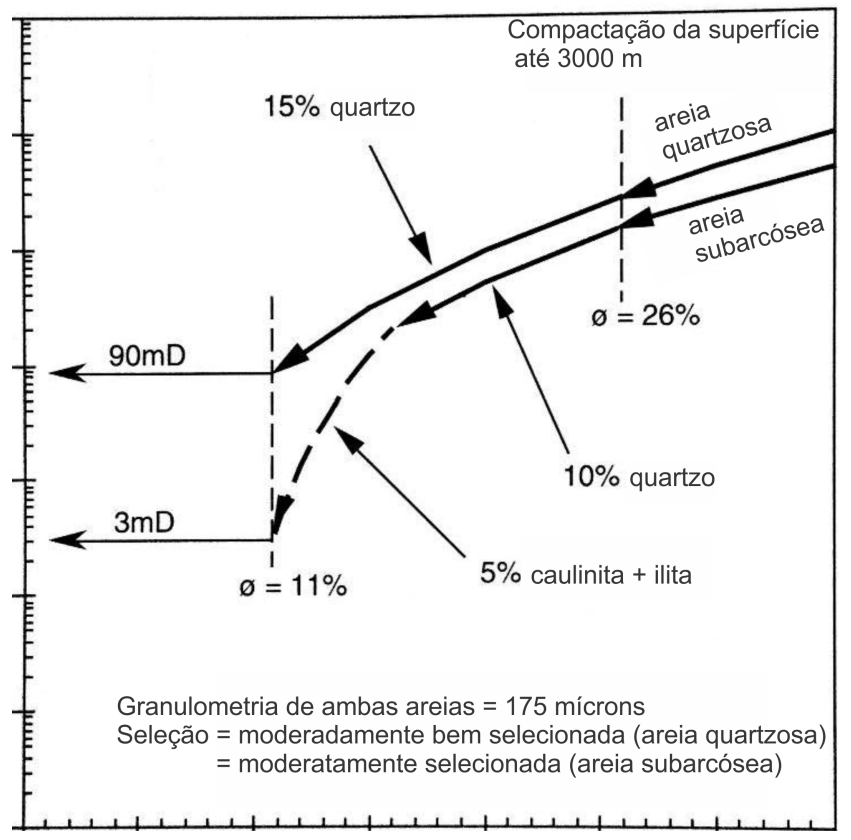

Figura 15 - Diminuição da permeabilidade e porosidade em relação ao soterramento da superfície até 3000 metros. Também nota-se diferentes valores absolutos de permeabilidade e porosidade entre areias arcóseas e quartzosas (modificado de Primmer et al., 1997).

Diversos trabalhos, como Krynine (1948), De Ros (1997), entre outros, destacam que a composição inicial das rochas clásticas em questão é de suma importância para seu desenvolvimento diagenético. A distribuição de minerais é função dos tipos de rochas expostas à erosão nas redondezas da bacia, geografia local e clima presente na área. O tipo de rocha erodida influencia na mineralogia que será transportada até a bacia. A geografia do local, por meio do relevo e distância, seleciona os minerais que são mais estáveis e menos estáveis em condições normais de pressão e temperatura. Um relevo plano e com distância considerável da área fonte até a área de deposição tende a depositar minerais mais estáveis em condições normais de pressão e temperatura, como o quartzo. Nessas condições, o transporte terá um longo tempo de duração e o quartzo é o mineral mais estável. Porém, a geografia não age sozinha na seleção mineralógica dos minerais, no caso da deposição de quartzo arenitos longínquos à área fonte e com relevo plano, um clima úmido deve estar presente, com alta taxa de intemperismo, para seleção de uma mineralogia relativamente matura. Caso o clima esteja atrelado a uma baixa taxa de intemperismo, como um clima seco, por exemplo, o mesmo relevo 
plano e distante da área fonte pode gerar rochas de mineralogia imatura.

Primmer et al. (1997) criaram um modelo de prováveis autigêneses para arenitos baseados na composição mineralógica dos mesmos. As autigêneses foram simplificadas em sete campos diferentes: dominada por: quartzo; argila; argila e quartzo; calcita precoce; evaporito; carbonato tardio; e, zeólita.

Segundo Primmer et al. (1997) quartzo arenitos tenderiam a desenvolver altas concentrações de cimentos de quartzo, enquanto argilas e carbonatos seriam tardios e ocorreriam em menor concentração. Arenitos líticos penderiam a autigênese de quartzo subordinado, argilas e carbonatos precoces, mas com uma grande concentração de cimentos de zeólita. Já um arcóseo, tenderia a taxas equilibradas de carbonato tardio e zeólitas, e, subordinadamente, apresentaria quartzo, argilas e carbonato precoce. Nesse caso o autor considera fragmentos líticos de uma determinada bacia e área fonte restrita, mas caso os fragmentos sejam ricos em argila, por exemplo, a história diagenética tende a modificar-se.

De Ros (1996) destaca que, apesar da relação da diagênese com a composição inicial, a previsão e dinâmica desse processo complicam-se quando os fluidos que percolam o sistema são levados em consideração. Segundo o autor, os principais mecanismos de migração dos fluidos são: expulsão de água por compactação, recargas meteóricas e fluidos quentes oriundos de rochas ígneas e metamórficas. O fluido mais abundante, na grande maioria dos casos, é a água meteórica. Ela ocorre com salinidade média próxima dos $100 \mathrm{mg} / \mathrm{L}$, com ácido carbônico, sulfúrico e cálcio como elementos principais. Quando este fluido entra em contato com os minerais presentes na rocha gera-se um desequilíbrio, acarretando possíveis dissoluções e precipitações. Assim como os outros parâmetros citados até então, os fluidos também possuem a relação de interdependência entre os parâmentros controladores da diagênese. A pressão, temperatura, composição inicial, geografia e clima também influenciam no comportamento dos fluidos. Tomando como exemplo o clima, fluidos em climas úmidos geralmente dissolvem carbonatos, feldspatos e minerais de argila, precipitando caulinita. Já em climas secos, ocorre a precipitação de esmectitas, feldspato alcalino e carbonatos 
(Kupecz et al 1997).

A grande maioria dos fluidos que se aproximam das rochas é determinada pelo ambiente deposicional (marinho, evaporítico ou água meteórica), assim como a composição mineralógica. Já nas etapas posteriores, os fluidos estão sujeitos a mudanças composicionais devido a diferentes interações, como transformações de matéria orgânica, interação com minerais argilosos, grãos detríticos e ácidos orgânicos (Pettijohn et al., 2012).

Além dos fatores citados até o momento, outros fatores como: a compactação de folhelhos e expulsão de fluidos (Kupecz et al., 1997); a descaboxilação da matéria orgânica liberando gás carbônico, diminuindo o pH e dissolvendo carbonatos e feldspatos (Foster, 1984); o $\mathrm{pH}$ dos fluidos; ascensão de fluidos frios pelas falhas dissolvendo carbonatos (Giles \& De Boer, 1989); e outros, também estão presentes na história diagenética dos arenitos, dificultando a interpretação dos processos sofridos pela rocha. Quanto maior a heterogeneidade dos fluidos e processos em que estes são submetidos, maior é a complexidade do reservatório em questão (Morad, 2010).

\subsubsection{Autigênese diagenética}

Nesse item serão discutidas as variedades de histórias diagenéticas em rochas siliciclásticas. Entre elas a cimentação de quartzo, carbonatos, manifestações de argilas, cimentações e pseudomatrizes de feldspatos.

\subsubsection{Cimentação de quartzo}

A cimentação de quartzo é a mais comum em arenitos com a composição mineralógica matura. Segundo Burley et al. (1989), o ponto chave da compreensão da diagênese de um reservatório de composição quartzo 
arenítica é o "timing" do sobrecrescimento de quartzo. A cimentação quartzosa tem como principal fonte o fenômeno conhecido como "pressure dissolution". Este fenômeno ocorre com a compactação química, fazendo com que os grãos de quartzo pressionem-se entre si, gerando estilólitos e dissolvendo parte dos grãos. Como resultado, tem-se o contato suturado entre os grãos e a precipitação de quartzo, já que soluções ricas em sílica não percolam longos caminhos. Outras fontes de sílica para a possível cimentação de quartzo são: dissolução ou substituição de grãos de feldspatos, reações dos argilomonerais em lutitos, esqueletos ou carapaças de organismos silicosos, alteração de materiais vulcânicos, compactação e liberação de fluidos provenientes de folhelhos, entre outros (Pettijohn et al., 1972).

A precipitação do quartzo aumenta com a elevação da temperatura e da profundidade (pressão) (Fuchtbauer, 1974) (figura 16). As temperaturas de cristalização do quartzo, segundo Gluyas et al (1993), variam entre $60^{\circ} \mathrm{C}$ e $150^{\circ} \mathrm{C}$ (figura 17). Depois de precipitado, o quartzo dificilmente é dissolvido, pois sua solubilidade é afetada apenas por pHs maiores que 9, encontrados somente em: terrenos com grande quantidade de rochas vulcânicas; e, lagos alcalinos, em regiões áridas (Pettijohn et al., 1972).

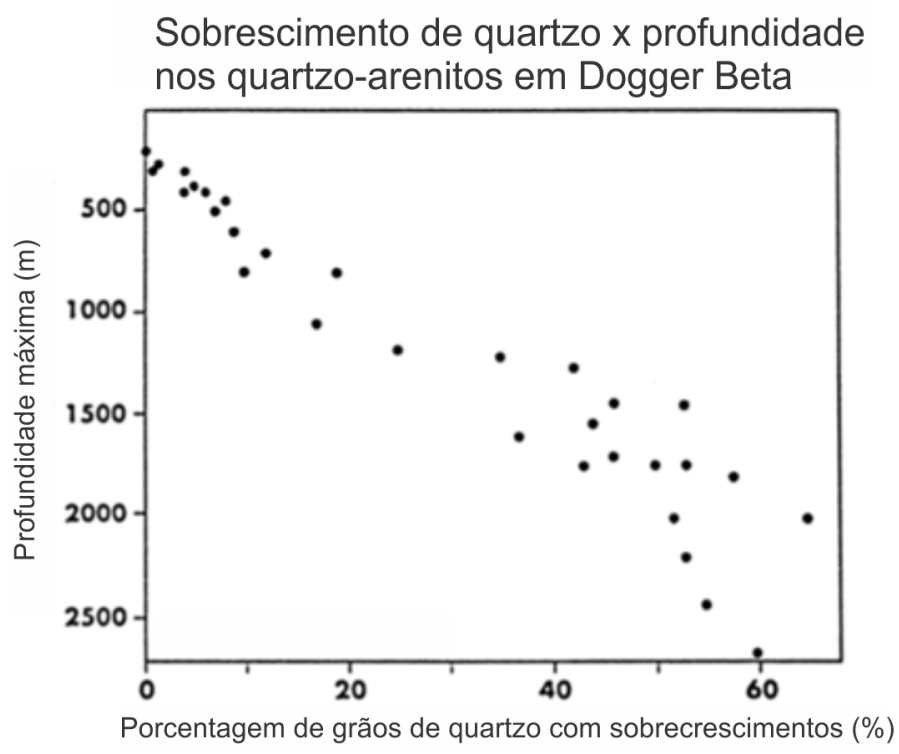

Figura 16 - Precipitação de quartzo relacionado ao aumento de profundidade (modificado de Fuchtbauer, 1974) 


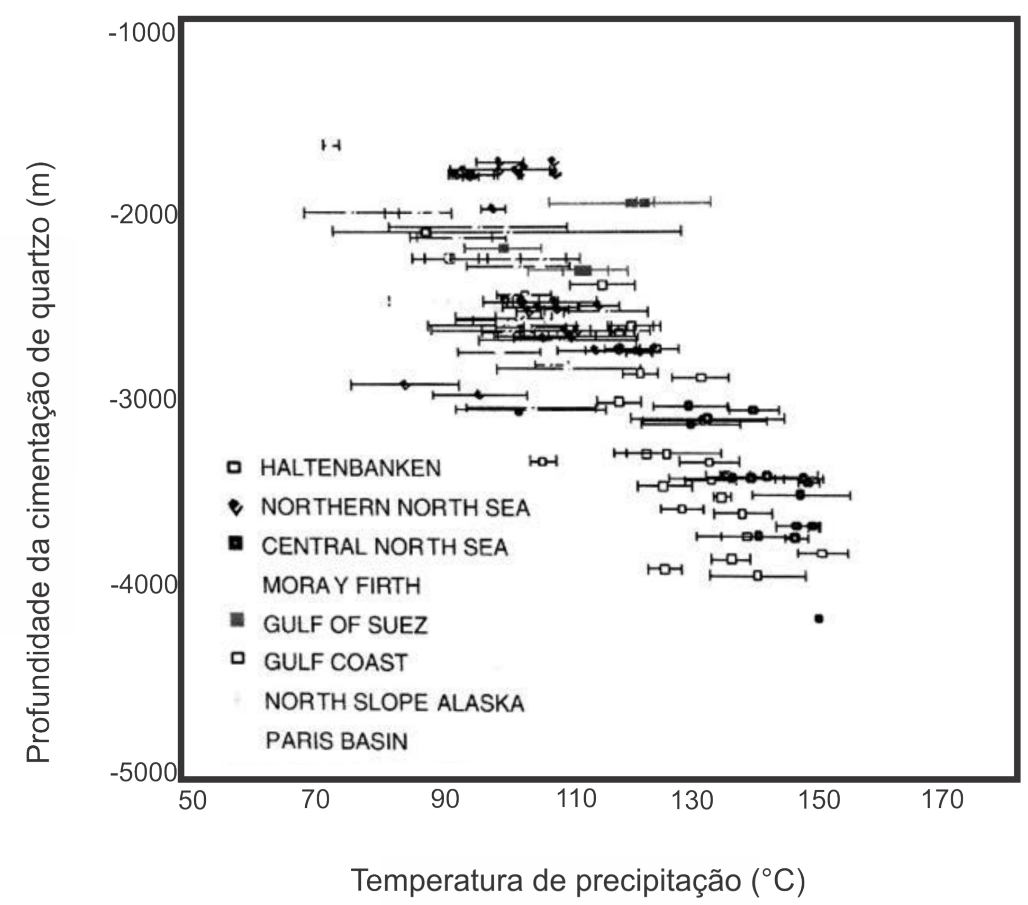

Figura 17- Medianas de temperaturas de homogeneização de inclusões flúidas trapeadas em cimentos quartzos nos arenitos, pela profundidade. O gráfico indica que os sobrecrescimentos de quartzo podem ocorrer entre $75^{\circ} \mathrm{C}$ e $160^{\circ} \mathrm{C}$ (modificado de Gluyas et al., 1993).

O principal hábito de cimentação do quartzo é o de sobrecrescimento, mas o microquartzo também manifesta-se em reservatórios. Esse cresce como "rims", proveniente de espículas de esponjas, impedindo tanto 0 sobrecrescimento e cimentação pervasiva de quartzo, como compactações muito desenvolvidas, mantendo altas porosidades no reservatório (Kupecz et al., 1997).

\subsubsection{Cimentação carbonática}

A cimentação carbonática está entre os tipos predominantes de cimento em arenitos e seu estudo é de suma importância para caracterização de reservatórios. As variedades de cimentos carbonáticos são: calcita, dolomita, ankerita, siderita e, por vezes, magnesita e rodocrosita (Morad, 1998).

Como resultado do balanço de massa, cimentos carbonátios são 
formados por dissolução e reprecipitação de cimentos carbonáticos eodiagenéticos. Os cimentos carbonáticos eodiagenéticos são formados onde estão disponíveis fragmentos detríticos de esqueletos e carapaças. Esses elementos geralmente possuem maior concentração em ambientes de trato transgressivo. Somados à baixa taxa de sedimentação, $\mathrm{pH}$ alcalino e alto conteúdo de matéria orgânica, culminam na precipitação de cimentos carbonáticos (Morad, 2010).

Outra fonte possível da cimentação carbonática é a alta concentração de cálcio, precipitando calcita. Em ambientes diagenéticos siliciclásticos isso pode ocorrer com a caulinitização da anortita ou com a albitização da anortita. Outras possíveis fontes geradoras de cimentos carbonáticos são: a presença de sedimentos vulcanoclásticos, rochas carbonáticas próximas, evaporitos e pelitos (Pettijohn et al., 2012).

Para a cimentação de dolomita é necessária diminuição na concentração de cálcio e aumento da concentração de magnésio, favorecida em ambientes evaporíticos. Ferrodolomita e ankerita podem precipitar em ambientes siliciclásticos através das reações de trocas iônicas, como ocorre na substituição da esmectita por substituída por ilita autigênica, liberando ferro e magnésio para o sistema (Pettijohn et al., 1972).

Apesar da pequena espessura dos cimentos carbonáticos, a cimentação dos mesmos pode aumentar expressivamente a qualidade de um reservatório futuramente, como também pode fechar todos os poros localmente e desviar a migração de hidrocarbonetos (Kupecz et al., 1997).

A dissolução de cimento carbonático geralmente ocorre em grandes áreas, consequentemente, aumenta a qualidade do reservatório, gerando porosidade secundária. Este aumento possui magnitude ainda mais expressiva caso a cimentação seja precoce. Como resultado, tem-se a inibição parcialda compactação. Essa dissolução é favorecida: pela alta concentração de gás carbônico (gerada pela decomposição de matéria orgânica), por fluidos empobrecidos em cálcio; entre outros (Carvalho et al., 1995).

Além da contribuição para o aumento ou diminuição da porosidade, os 
cimentos carbonáticos devem ser analisados com cuidado na recuperação do óleo. Carbonatos de ferro, como a ankerita, reagem com os ácidos injetados para a recuperação e precipitam óxidos nas gargantas de poro de arenitos, causando uma violenta diminuição no fator de recuperação dos hidrocarbonetos do campo (Morad, 1998).

\subsubsection{Argilominerais}

A cimentação de argilo-minerais em arenitos é muito comum, mas as mesmas podem manifestar-se também como "argilas infiltradas". Os argilominerais são silicatos hidratados de alumínio, os quais ocorrem frequentemente com tamanho menor que 2 micras, porém com alta relação de área superficial e volume (Klein \& Philpotts, 2012)

As argilas infiltradas são detríticas, interpretadas pela infiltração mecânica, na zona vadosa, em climas áridos e semi-áridos. Tratam-se de eventos episódicos de água e lama, como a mudança do nível freático, por exemplo, que adentram os poros. (Moraes \& De Ros, 1990).

As argilas infiltradas possuem texturas diagnósticas para diferenciá-las das argilas autigênicas são elas: "ridges and bridges", "geopetal fabrics", "loose agregates", "cutans" e "shrinkage". A "ridges and bridges" possui orientação normal ao grão (ridges) e recebe o nome de "bridges" quando a crista liga dois grãos diferentes (figura 18a). Já a textura "geopetal fabrics" consiste na acumulação desorganizada de argila em grandes poros e indicação de topo e base (figura 18b). A "loose agregates" não possui nenhuma orientação, com argilas livres entre si (figura 18c). Essa última difere dos clastos de argila devido à orientação caótica e ausência de lâminação. O "cutan" é em parte semelhante ao "coating", porém não possui a orientação normal à superfície do grão e sua espessura varia em torno do grão (figura 18d);além disso, são orientadas paralelamente a superfície do grão, tornando aparente o aspecto de partículas detríticas decantadas. O "massive agragates" é uma textura que consiste em grossos "coatings" próximos à superfície do grão e uma densa e 
caótica massa de argila no centro dos poros (Moraes \& De Ros 1990) (figura $18 \mathrm{e})$.
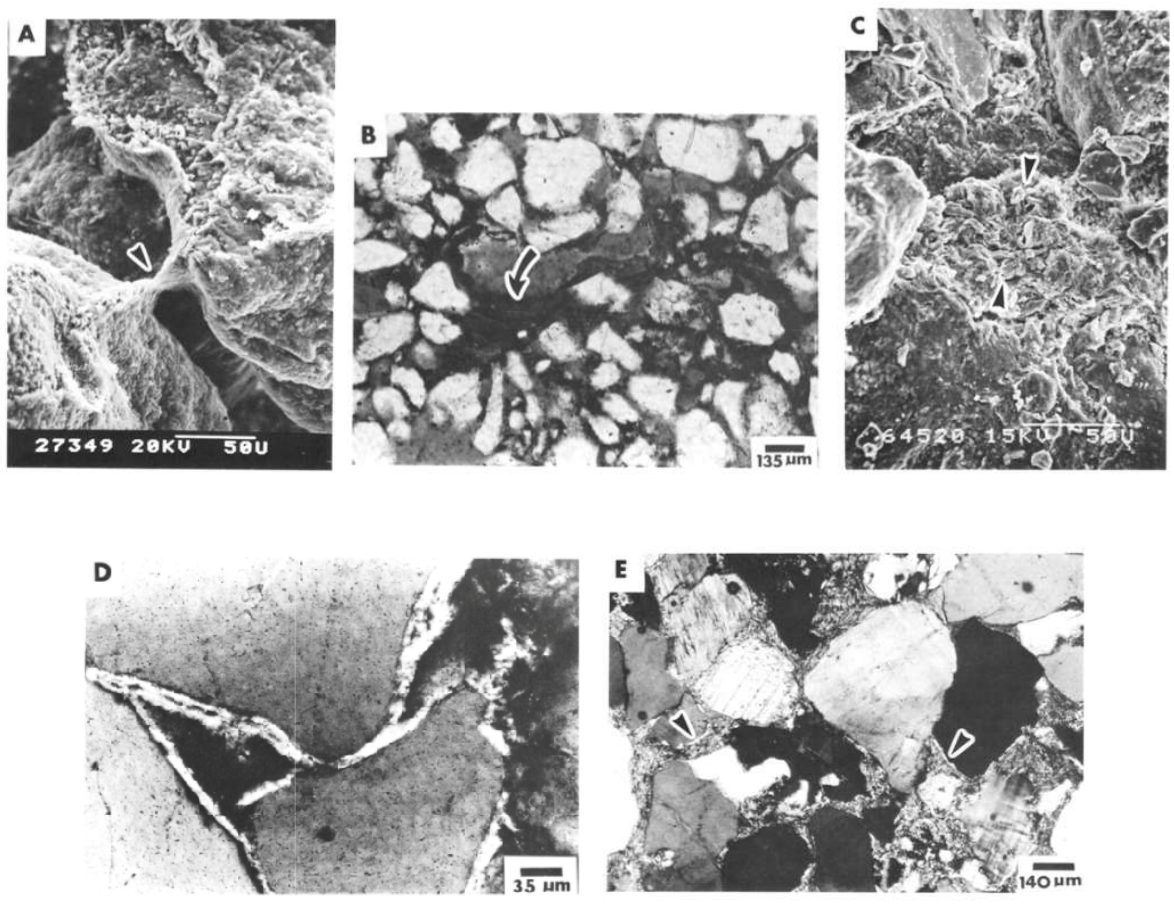

Figura 18(A) Textura ridges and bridge. (B) Textura geopetal fabrics. (C) Textura loose agregates. (D)Textura cutan. (E)Textura massive agregates. (Moraes \& De Ros 1990).
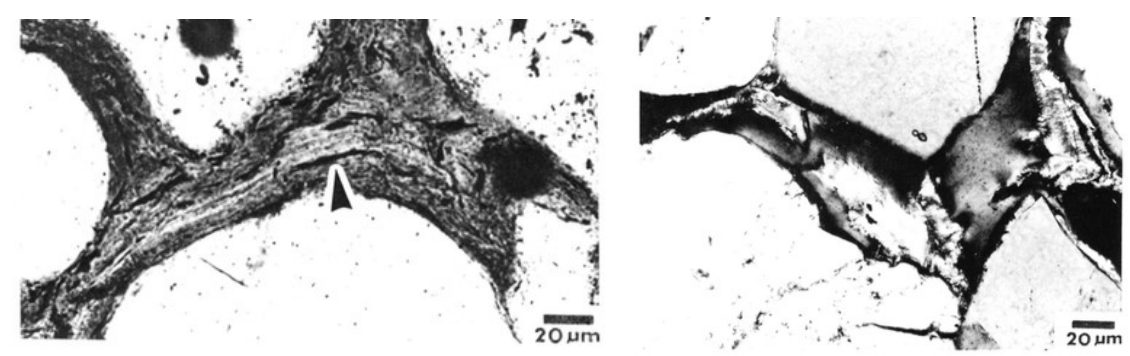

Figura 19 - Impurezas no cutan (esquerda).e Textura shrinkage (direita) (Moraes \& De Ros 1990)

Além das texturas comentadas, as argilas de origem detrítica, sempre possuem impurezas facilitando a observação da geometria do "cutan" ou dos agregados maciços (figura 19). Essas estruturas são preservadas mesmo depois de altas temperaturas diagenéticas (Moraes \& De Ros, 1990).

Segundo Kupecz et al. (1997) a maioria das argilas infiltradas trata-se de esmectita, porém após a diagênese a composição pode ser modificada para 
ilita ou clorita, causando o shrinkage (encolhimento). O shrinkage é observado devido à perda de água e ganho de alguns cátions, como alumínio, potássio ou magnésio, diminuindo o volume total da argila. A diminuição provoca o descolamento dos "cutans" da parede dos grãos e a fragmentação dos agregados maciços (figura 19).

As argilas infiltradas ("cutans") possuem grande responsabilidade na inibição do sobrecrescimento de quartzo, preservando a porosidade e qualidade dos reservatórios (Molenaar, 1986). Além disso, locais onde argilas infiltradas apresentam-se espessas inibe-se a precipitação de calcita. Após a Mesodiagênese, devido ao shrinkage, podem desenvolver porosidades secundárias consideráveis (Moraes e de Ros, 1990).

De um modo geral, apesar da manutenção da porosidade, inibição da cimentação de calcita e geração de porosidade secundária pelo shrinkage, as argilas são prejudiciais ao reservatório. A permeabilidade sofre um altíssimo decréscimo com a instalação das argilas infiltradas, resultando na diminuição das gargantas de poro, ecriando barreiras de permeabilidade nos reservatórios. Essa textura é observada e descrita no topo da formação Sergi, na Bacia do Recôncavo (Moraes e de Ros, 1992).

As argilas diagenéticas mais comuns em arenitos são: caulinita, esmectita, ilita e clorita. A caulinita e esmectita são argilas que predominam na Eodiagênese, enquanto cloritas e ilitas dominam na Mesodiagênese (Worden \& Morad, 2003).

A cimentação das argilas eodiagenéticas é relacionada com a composição inicial da rocha. Já as argilas mesodiagenéticas possuem gênese variada, mas geralmente crescem às custas das argilas eodiagenéticas, feldspatos detríticos e fragmentos líticos (Pettijohn et al., 1972). As argilas diagenéticas podem apresentar-se em diferentes texturas como:coatings, rims, booklets, pore-linning e entre outros.

O desenvolvimento de argilas autigênicas, assim como argilas infiltradas, pode inibir o sobrecrescimento de quartzo, altas taxas de compactação (quando eodiagenética), e até prevenir o cimento carbonático. Contudo, sua 
concentração excessiva pode diminuir a porosidade. Já a permeabilidade é sempre muito afetada negativamente (Kupecz et al., 1997 ).

A entrada de hidrocarbonetos no sistema pode ou não frear 0 crescimento da argila diagenética. Caso o reservatório em questão seja molhável a óleo, a diagênese é estagnada, mas se o arenito é molhável à água, o crescimento da argila sofre diminuição, mas não cessa (Kupecz et al., 1997).

\subsubsection{Feldspatos}

A cimentação de feldspatos não tem considerável importância nas análises de reservatório como os sobrecrescimentos de quartzo, argilas ou carbonatos. Porém, apesar de em menor magnitude, também interferem na porosidade e permeabilidade (Kupecz et al., 1997).

A cimentação por feldspatos potássicos ocorre geralmente devido à dissolução de feldspatos detríticos e alteração de micas (liberando sílica e potássio). Um indicador para o reconhecimento de feldspatos potássicos diagenéticos é sua estrutura cristalina mais limpa que a dos feldspatos de alta temperatura. As texturas desses cimentos podem ocorrer de três diferentes maneiras: crescimentos epitaxiais (Formação Açu, na Bacia Potiguar, Waugh, 1978), substituição pseudomórfica de grãos detríticos por agregados microcristalinos (Morad \& Peña, 1989), ou agregados microcristalinos substituindo materiais piroclásticos (Formação Areado, Bacia do São Francisco, De Ros et al., 1994).

A albitização ocorre em soluções com alta atividade de íons de sódio, em maior frequência na Mesodiagênese. A albitização é comum na diagênese de esmectitas nos lutitos, substituição de feldspatos alcalinos e também na dissolução de evaporitos. A textura mais comum desse tipo de cimento é o preenchimento de poros intragranulares em feldspatos dissolvidos ou em agregados paralelos nos poros intergranulares (Pettijohn et al., 2012). 
Apesar da cimentação de feldspatos não interferir em grande magnitude na porosidade do reservatório, a diminuição desta pode ocorrer quando os feldspatos são compactados mecanicamente, tornando-se pseudomatriz e reduzindo a porosidade primária. Por outro lado, os feldspatos são pouco estáveis na diagênese e são dissolvidos sob influência de fluidos diagenéticos, gerando ganhos de porosidade (secundária) (Pettijohn et al., 1972).

No trabalho de Smosna \& Bruner (1997) o paradigma da diminuição da porosidade primaria ou aumento da porosidade secundária comentada anteriormente para feldspatos é discutida baseada em fragmentos líticos. $O$ trabalho foi realizado em um sistema deltaico, no qual se buscou determinar a um ponto ótimo de líticos, visando a maior porosidade secundária possível. Os depósitos analisados no trabalho foram: fluvial, barra de desembocadura, ilhabarreira e crista arenosa (sand ridge). Segundo os autores a quantidade de fragmentos de rocha variava em cada tipo de depósito (figura 20), aumentando com a proximidade do sistema em relação ao continente. Contudo, a porosidade secundária não aumentava com a proximidade do continente, para tanto concluíram que, quando a quantidade de fragmentos de rocha atinge um valor muito grande, a compactação mecânica é intensa, perdendo uma quantidade irrecuperável de porosidade (primária). Logo, foi encontrado um teor ótimo para quantidade de fragmentos líticos nesse sistema, visando não perder quantidade significativa de porosidade primária, mas obter grande quantidade de porosidade secundária, pela dissolução dos fragmentos líticos. O teor sugerido pelos autores foi entre $10 \%$ e $21 \%$ (figura 20 ). 

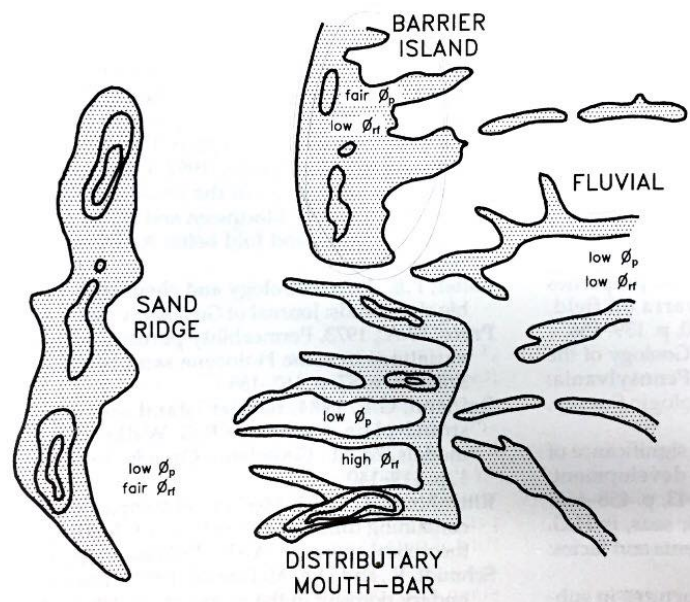

LOCK HAVEN SYSTEMS TRACT

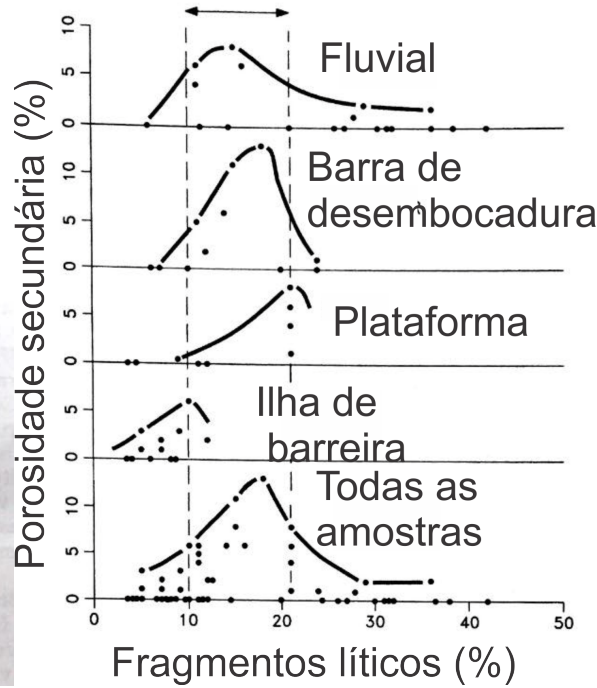

Fragmentos líticos (\%)

Figura 20- Elementos analisados em sistema deltaico com porosidades quantificadas qualitativamente (esquerda), e gráfico da relação de fragmentos líticos por porosidade secundária obtida (direita) (modificado de Smosna \& Bruner 1997)

\subsection{Estatística e Geoestatística}

A geoestatística é definida como o conjunto de estudos matemáticos e estatísticos que contemplam fenômenos temporais ou espaciais, capitalizados em relações espaciais com objetivo de modelar possíveis variáveis em pontos não amostrados (Caers, 2005). A revisão desses métodos foi importante primeiramente para entender o funcionamento dos softwares de modelagem (4.6.1) e, posteriormente, para a criação do modelo geológico nos moldes da indústria petrolífera (4.6.2).

\subsubsection{Conceitos matemáticos, estatísticos e geoestatísticos}

Os principais conceitos matemáticos, estatísticos e geoestatísticos a serem discutidos neste item correspondem ao: fenômeno espacial ou população, amostragem e erros de amostragem, estatística descritiva, tipos de variáveis, distribuição de freqüências, variogramas, krigagens e simulações estocásticas. 


\subsubsection{Fenômeno espacial ou população}

A população ou fenômeno espacial caracteriza-se como todos os valores possíveis da variável de interesse (Yamamoto \& Landim, 2013). Outras definições também são conhecidas na literatura, como a de Bussab \& Morettin (1987): "população é todo conjunto de indivíduos (ou objetos), tendo pelo menos uma variável comum observável". Devido à grande quantidade de possíveis pontos no espaço, é inviável a obtenção de todos os valores existentes possíveis da variável de interesse, tornando-se necessário uma amostragem.

\subsubsection{Amostragem e erros de amostragem}

As amostras caracterizam-se como um subconjunto restrito e conhecido da população. A amostragem é o processo inicial da avaliação estatística (Yamamoto, 2001), no qual se define o conjunto de dados (amostras) que serão utilizados para definição dos valores não amostrados. Para uma análise estatística confiável esse processo deve honrar a distribuição espacial e a variabilidade do domínio a ser estudado (Yamamoto; Lamdim, 2013).

Segundo os autores a amostragem pode ser realizada de três maneiras: aleatória simples, aleatória estratificada e aleatória sistemática. A amostragem aleatória é constituída pela retirada de "n" amostras da população, escolhida em coordenadas geográficas aleatórias sem reposição, ou seja, sem repetição de amostras. A aleatória estratificada subdivide a região em locais com dimensões fixas na direção norte sul e leste oeste, criando células. Dentro de cada célula uma amostra aleatória é retirada, logo, o número de células será igual ao número de amostras. A amostragem sistemática utiliza uma subdivisão da região parecida com a aleatória estratificada, porém os pontos são amostrados em nós ao invés de células, excluindo a aleatoriedade para 
escolha das coordenadas geográficas dos pontos dentro das células (Yamamoto \& Landim, 2013).

A amostragem sistemática possui melhor resultado, entre as comentadas acima, devido a sua melhor distribuição das amostras. Pela mesma razão, a aleatória simples tem o pior resultado entre as três mencionadas. Na grande maioria dos trabalhos a amostragem não é feita como foi predeterminada, pois alguns locais são impróprios para a ocorrência da mesma. No caso de uma amostragem feita por sondagem em uma obra de mineração, por exemplo, um ponto da amostragem planejada pode encontrarse em um rio, ou em uma mata de difícil acesso. Logo, o ponto não será amostrado. Independente do método de amostragem, quanto maior o número de dados da região onde se pretende analisar, melhor será a estimativa geoestatística (Yamamoto \& Landim, 2013).

Segundo Gy (1967), no trabalho de Yamamoto (2001), todos os métodos de amostragem possuem erros associados, sejam eles decorrentes das técnicas de amostragem, do modo em que elas são aplicadas, dos instrumentos utilizados para o fim e entre outros.

Os erros de amostragem são divididos, segundo Koch \& Link (1971) comentado no trabalho de Yamamoto (2001), conforme a etapa em que o mesmo foi gerado separando-os em: erros de preparação, erros analíticos e erros totais de amostragem. Os erros de preparação são aqueles gerados durante a preparação da amostra, anteriormente à análise da mesma, como ocorre na plugagem de testemunhos de bacias petrolíferas para posterior análise petrofísica. Os erros analíticos são aqueles observados entre os resultados das análises e o real valor da análise. Eles são sistemáticos ou aleatórios, segundo Waeny (1979) apud Yamamoto (2001). Os sistemáticos são aqueles adquiridos para todas as amostras em uma mesma proporção, como, por exemplo, uma diferença entre a porosidade real e a porosidade medida pelo perfil sônico em um reservatório de hidrocarbonetos. Os aleatórios tratam-se dos erros desconhecidos. Por fim, os erros totais de amostragem resumem-se a todos os erros adquiridos, tanto das etapas de amostragem, como preparação das amostras e analíticos. 


\subsubsection{Estatística descritiva}

Adquirido um conjunto de dados pela amostragem, necessita-se de uma estatística básica para a análise da totalidade dos dados. Para esse feito utiliza-se a estatística descritiva, que analisa a distribuição adquirida na amostragem comparada ao seu valor médio e às variações da população em torno deste valor.

O parâmetro mais simples da estatística descritiva é a média, também conhecida como esperança. Essa medida calcula a tendência central dos dados presentes na amostra. A média é resumida matematicamente como (Yamamoto 2001):

$$
\mathrm{M}=\mathrm{E}[\mathrm{Z}(\mathrm{x})]=(1 / \mathrm{n}) \cdot \sum_{i=1}^{n} X i \cdot P(x i)
$$

(equação 7)

Calculada a média, permite-se calcular a variação dos valores presentes em relação à média, variável conhecida como variância. A raiz quadrada da variância também é um parâmetro da estatística descritiva, conhecida como desvio padrão. A variância é matematicamente definida como (Yamamoto 2001):

$$
\operatorname{Var}[\mathrm{X}]=\mathrm{S}^{2}=\sum_{i=1}^{n}(X i-X m)^{2} \cdot P(x)
$$

A totalidade das amostras adquiridas na amostragem pode ser analisada como gráficos de distribuição de frequências. Esses gráficos são classificados segundo a estatística descritiva em relação ao coeficiente de assimetria e à curtose. A assimetria de uma distribuição de frequências pode ser negativa ou positiva, caso a cauda da distribuição esteja à direita da média ou à esquerda, 
respectivamente. $O$ coeficiente de assimetria é definido matematicamente como (Yamamoto 2001):

$$
\mathrm{CA}=\sum_{i=1}^{n}(X i-X m)^{4} / S^{4}
$$

(equação 9)

\subsubsection{Tipos de variáveis}

As distribuições de frequências são utilizadas para geração de modelos geoestatísticos que devem possuir variáveis regionalizadas. Variáveis regionalizadas segundo Blais \& Carlier (1968), comentado por Yamamoto (2001), correspondem a: qualquer função numérica que varia espacialmente continuamente, mas as variações não podem ser representadas por uma função determinística.

Nos campos de estudos geológicos, todas as observações quantitativas feitas em duas ou mais dimensões podem ser classificadas como variáveis regionalizadas, as quais não envolvem nenhuma interpretação probabilística (Yamamoto, 2001).

Baseado nas relações espaciais e distribuições de frequência permite-se calcular uma função que se aproxime da variação analisada (função determinística). Esse ajuste, como já mencionado, não é exato, pois a variável possui, além da componente regional (obtida pela função gerada), uma componente aleatória (Yamamoto \& Landim, 2013).

As variáveis aleatórias e regionalizadas podem ser classificadas conforme o conteúdo analisado em cada variável. Segundo Stevens (1946) comentado em Yamamoto (2001), as variáveis podem ser subdividas em contínuas e discretas. As variáveis contínuas são representadas por escalares, subdivididas em escalas relacionais e escalas intervalares. Já as discretas não envolvem escalares, são qualitativas e subdivididas em escalas nominais e ordinais. 
Quando se trabalha com variáveis regionalizadas e modelagem geoestatística o conceito da hipótese intrínseca deve ser levado em conta. Nesse conceito é aceito que a função intrínseca (semivariograma) que descreve as diferenças entre dois pontos amostrais é a mesma para todo o campo geométrico, dependendo apenas da distância e orientação entre os pontos.

\subsubsection{Distribuição de freqüências}

A distribuição de freqüências é a maneira que as unidades de uma determinada variável estão dispostas em um intervalo e em uma determinada região. A distribuição de frequências pode ser simples ou acumulada. A simples é obtida traçando-se uma curva sobre o histograma gerado pela frequência, no eixo das ordenadas, com intervalos constantes no eixo nas abcissas. A distribuição acumulada é adquirida da mesma forma que a simples, mas os valores das frequências nas ordenadas são somados às frequências dos intervalos anteriores (Yamamoto, 2001).

As variáveis geológicas são muito complexas. Quando a curva de frequência é adquirida, a equação matemática que descreve a curva é muito complexa, o que dificulta muito a manipulação dos dados. Para solucionar esse problema, os geoestatísticos sugerem que as distribuições de frequências adquiridas nas variáveis analisadas sejam aproximadas para distribuições com propriedades matemáticas conhecidas, como, por exemplo, a normal e a lognormal (Yamamoto, 2001).

A distribuição normal, ou gaussiana, é muito utilizada na modelagem de diversas variáveis naturais. Em alguns casos, mesmo que o comportamento da variável não seja o mesmo de uma distribuição normal, utiliza-se a transformada gaussiana (o inverso da função gaussiana) (equação 10) para facilitar o tratamento de dados. Os valores reais das variáveis são transformados em escores, mantendo suas frequências acumuladas. Em outras palavras, o equivalente ao quartil superior $(75 \%)$ na distribuição real 
será também o quartil superior na distribuição normal. Porém, o escore é diferente do valor real (figura 21). Nessa transformação, a média dos valores das variáveis transformadas aproxima-se de zero e a variância de um. Como conseqüência, o histograma resultante é praticamente simétrico (Yamamoto \& Landim, 2013).

$y\left(X_{i}\right)=G^{-1}\left(r\left(x_{i}\right) / n+1\right)$

(equação 10)

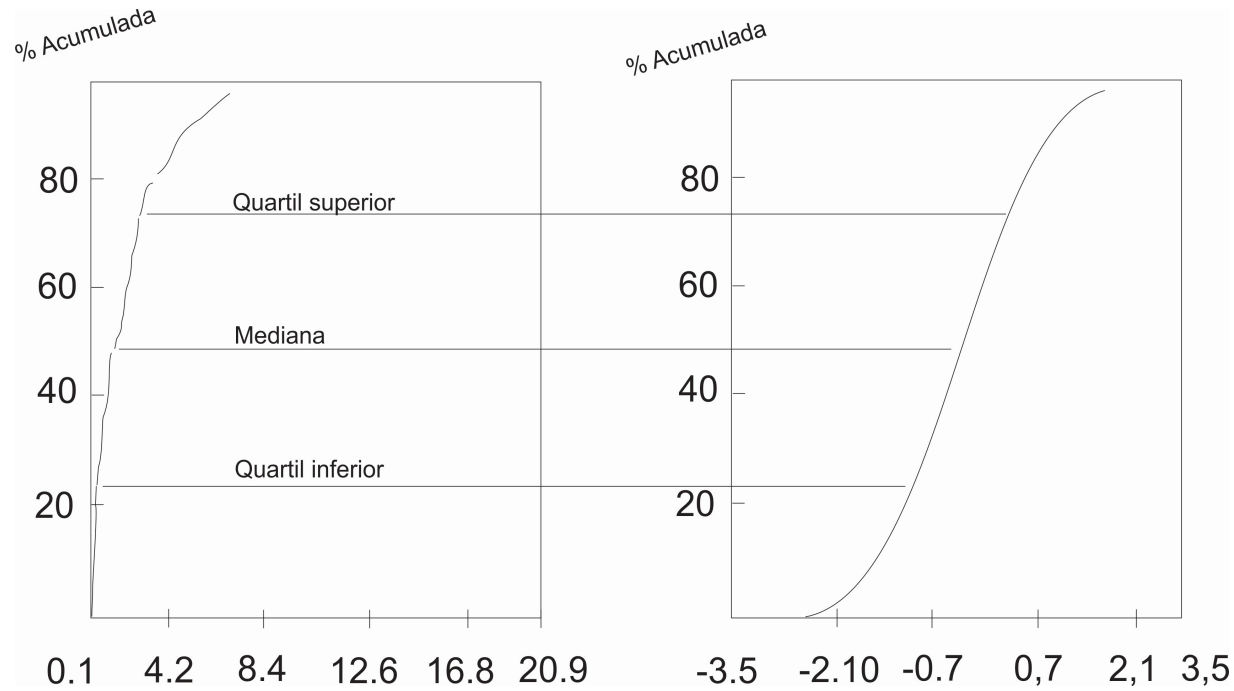

Figura 21 Distribuição acumulada real (esquerda) e distribuição acumulada normal (direita) (Modificado de Yamamoto \& Landim, 2013)

A distribuição lognormal é observada em alguns tipos de variáveis naturais. Esse tipo de distribuição é observado quando é obtida na amostragem grande quantidade de valores baixos e pequena quantidade de valores altos. Caracterizando-se uma assimetria positiva. Quando a distribuição de frequências se aproxima de uma distribuição lognormal, utiliza-se a transformada logarítmica a fim de obter uma distribuição normal. A transformada logarítimica resume-se ao logaritmo natural da variável original:

$\mathrm{Y}=\ln (\mathrm{x})$

(equação 11) 
Essa transformação, apesar da estatística compatível com uma distribuição normal (média próxima a zero e variância próxima a um), muitas vezes apresenta leve assimetria. Esse fato ocorre devido à ausência de valores intermediários (Yamamoto, 2001).

Além das transformações gaussiana e logarítmica, outra transformada muito utilizada é a indicadora. É utilizada pela indústria petrolífera para modelagem de litologias (variáveis discretas), ou pela mineração relacionada à teores de corte. A indicadora atribui o valor zero caso a variável não esteja dentro do intervalo desejado, ou não possua característica coerente com o desejado, e valor um (1) caso cumpra as exigências. A equação matemática é apresentada abaixo (Yamamoto \& Landim 2013):

$I(x, z c)=0$, se $Z(x)>$ zc ou $I(x, z c)=1$, se $Z(x) \leq z c$

(equação 12)

\subsubsection{Variogramas}

Os variogramas são utilizados para guiar a estimativa de pontos não amostrados independente da técnica geoestatística a ser utilizada posteriormente. O variograma resume-se a uma função definida pela diferença entre pares de valores atribuídos a uma mesma variável em uma distância $\mathrm{x} e$ uma distância $x+h$, em determinada direção. Matematicamente representada como (Yamamoto \& Landim, 2013):

$Y(h)=0.5 . E\left\{[Z(x+h)-Z(x)]^{2}\right\}$

(equação 13)

Para o cálculo do variograma é necessário admitir a hipótese de estacionaridade de segunda ordem: apenas a distância espacial h influencia na 
correlação entre duas variáveis aleatórias, independente da sua localização; e, que a esperança matemática existe (Yamamoto \& Landim, 2013). Esse fato leva a crer que a variável localizada possui uma distribuição isotrópica.

Sabe-se que a grande maioria dos fenômenos geológicos são anisotrópicos. Logo, faz-se necessário o cálculo de variogramas experimentais em diferentes direções, para a análise da anisotropia. Em dados 2D calculamse variogramas em quatro direções $\left(0^{\circ} ; 45^{\circ} ; 90^{\circ}\right.$; e, $\left.135^{\circ}\right)$. Já para os $3 \mathrm{D}$, além dessas direções, calcula-se a direção vertical $\left(\right.$ dip $\left.=90^{\circ}\right)$. Analisadas as principais anisotropias, são utilizados dois variogramas ortogonais entre si e, no caso das variáveis em $3 \mathrm{D}$, soma-se o vertical. Para o cálculo dos variogramas experimentais em diferentes direções, em uma amostragem irregular, como ocorre na maioria dos eventos, deve-se delimitar o raio de busca dos pontos (figura 22). Depois de calculados os variogramas experimentais, os mesmos devem ser modelados para variogramas que possuem as propriedades conhecidas. Os mais utilizados são os: esféricos, gaussianos e exponenciais (Yamamoto, 2001).

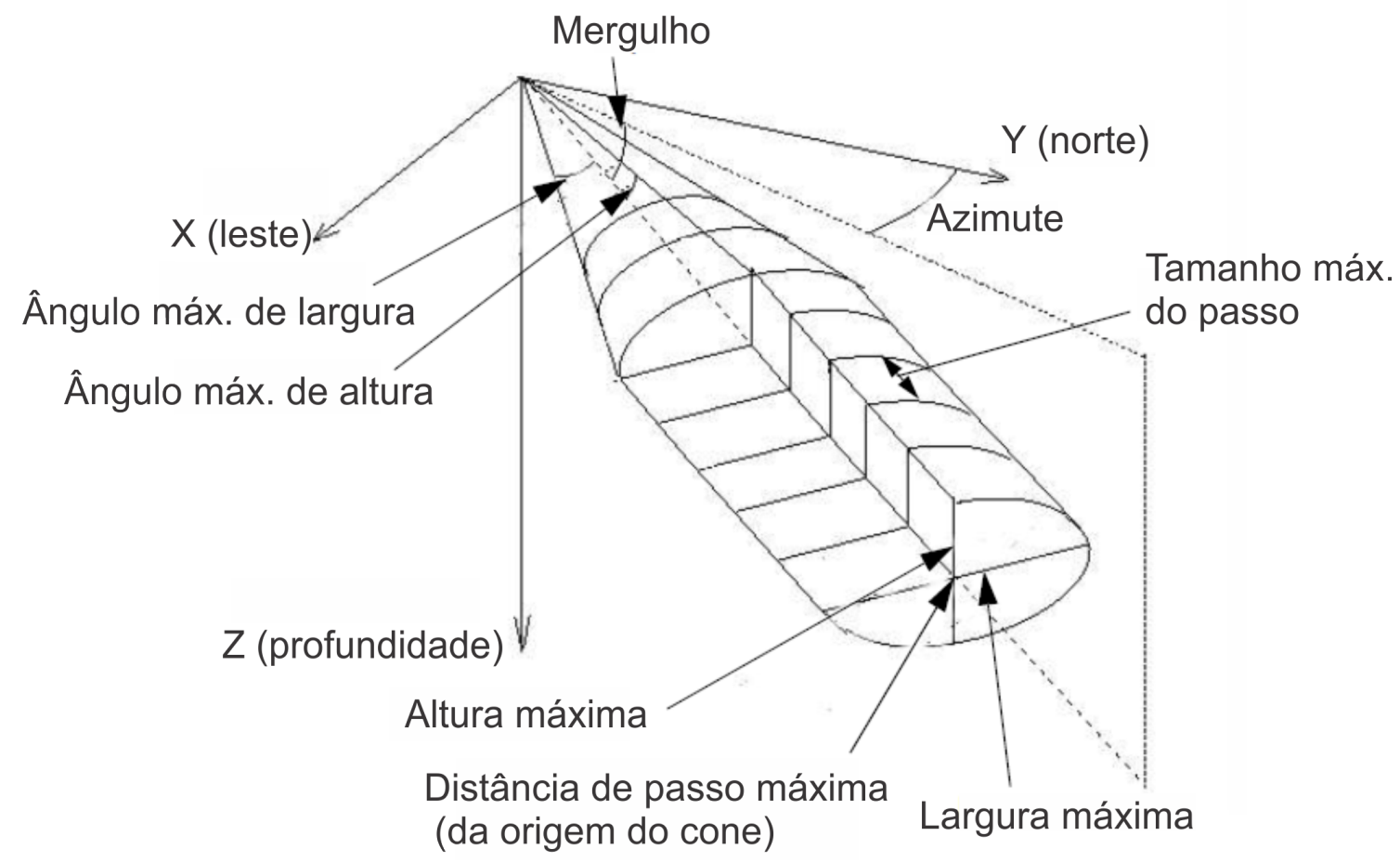

Figura 22 - Parâmetros para definição do raio de busca dos pontos a serem utilizados no cálculo do variograma (modificado do software RMS). 
Os variogramas são divididos segundo Yamamoto \& Landim (2013) em variogramas com e sem patamar. O patamar é a distância mínima em que a variância entre um par de pontos para de crescer juntamente com a distância. O início do patamar também é conhecido como o início do campo aleatório (Yamamoto, 2001). No caso dos variogramas sem patamar, o aumento da distância h leva a um aumento contínuo variância, com ausência de uma variância máxima.

Entre os variogramas com patamar, as principais propriedades são: 0 próprio patamar, amplitude, efeito pepita e a variância espacial (figura 23). A amplitude caracteriza-se pelo ponto que separa o campo estruturado do campo aleatório. É o ponto máximo que as variáveis possuem correlação. O efeito pepita, também conhecido como variância aleatória, é o valor da função variograma que a distância entre as duas amostras é muito pequena, quase igual à zero. A princípio, neste caso, a variância deveria ser zero ou próxima de zero. Em contrapartida, essa variação atribui-se a erros de amostragem, variabilidade natural da variável analisada e possíveis erros analíticos. A variância espacial é o local do campo estruturado após o efeito pepita. É a parte da função onde as amostras possuem correlação entre si e definem o comportamento da variável regionalizada que deverá ser modelado.

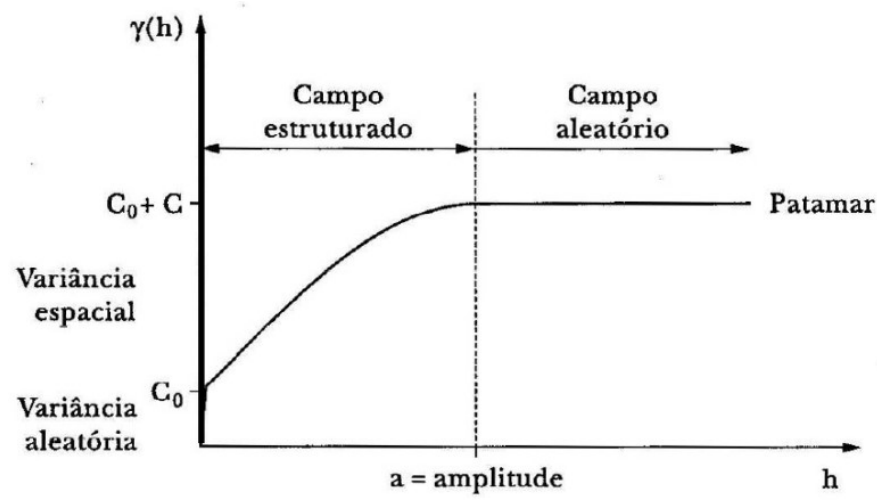

Figura 23- Principais propriedades do variograma, campo de variância espacial e aleatória, e campo estruturado e aleatório. Eixo $\mathrm{x}$ representa a distância $\mathrm{h}$ e eixo y representa a função semi-variograma (Yamamoto, 2001)

Os variogramas sem patamar podem ocorrer, segundo Yamamoto \& Landim (2013), em três principais condições: amostragem insuficiente, 
amostragem incompleta ou na presença de tendência nos dados amostrados. Nesse caso, o modelo teórico para os variogramas é o variogama de potência. Devido a não utilização desse variograma no trabalho não serão discutidas suas propriedades principais.

Outra divisão apresentada por Yamamoto \& Landim (2013) são os variogramas contínuos e descontínuos na origem. Os variogramas descontínuos são os que apresentam o efeito pepita, ou efeito pepita puro. Os contínuos são divididos entre os que possuem alta continuidade na origem e os que possuem média.

Uma vez modelados, deve-se analisar a anisotropia dos variogramas adquiridos. Caso os variogramas calculados não apresentem diferenças, o fenômeno caracteriza-se como isotrópico. No caso de anisotropias (variogramas diferentes), a mesma deve ser corrigida e modelada para o uso de um variograma comum, visando a realização de futuras estimativas ou simulações. Entre as anisotropias possíveis, Yamamoto \& Landim (2013) apresentam três: zonal, geometrica e mista (figura 24).
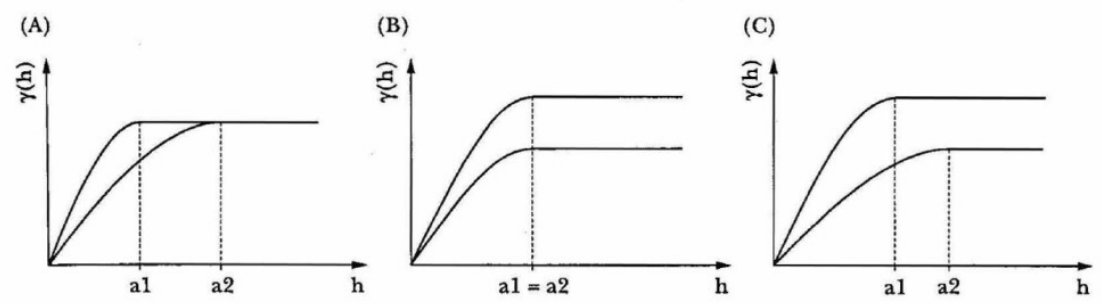

Figura 24 - Anisotropias de variograma: geometrica(A), zonal (B) e mista (C). Eixo x representa a distância h e eixo y representa a função semi-variograma (Yamamoto, 2001)

Existem diversos métodos para estimativa de pontos não amostrados. $A$ diferença entre os métodos reside na maneira em que os pontos conhecidos serão escolhidos e de que maneira os pesos serão calculados e utilizados. Os diversos métodos podem ser divididos em determinísticos, como as krigagens, e estocásticos, por exemplo, as simulações. 


\subsubsection{Krigagens}

A krigagem é um processo geoestatístico de estimativa que busca a mínima variância do erro, desenvolvido pela Escola Francesa de Geoestatística. Assim como os demais métodos geoestatísticos, a krigagem faz uso do variograma, o qual leva em conta a amplitude, o efeito pepita e a presença de anisotropia, diferente das técnicas de interpolação numérica simples.

Anteriormente à realização de uma krigagem, deve-se examinar a distribuição de frequências e o tipo de variável em questão. São apresentadas por Yamamoto \& Landim (2013) quatro principais tipos de krigagem: simples, ordinária, multigaussiana, lognormal e indicadora.

A krigagem tem como objetivo estimar um valor não amostrado por meio da vizinhança do ponto, baseado em uma análise variográfica. Para esse feito são atribuídos pesos aos valores da vizinhança conforme a proximidade do ponto a ser estimado. A equação geral da krigagem resume-se a:

$$
Z_{\mathrm{KO}}^{*}\left(\mathrm{x}_{\mathrm{o}}\right)=\sum_{i=1}^{n} \lambda i \mathrm{Z}\left(\mathrm{x}_{\mathrm{i}}\right)
$$

(equação 14)

A krigagem simples utiliza a média e variância de todos os locais constantes, dependendo apenas das distâncias que separam os pontos, diferentemente da krigagem ordinária, por exemplo, na qual a média é calculada localmente pela krigagem da média.

A krigagem indicadora, diferente das demais, faz uso de uma transformação da variável aleatória contínua em uma variável binária. Para a caracterização de uma variável binária é analisado se cada variável está ou não dentro do intervalo de interesse. As binárias são muito ligadas ao termo de teor de corte, no qual dois intervalos são definidos, acima ou abaixo do teor de corte estabelecido para determinada região. Outra forma de utilização dessa krigagem é a estimativa de variáveis discretas. O único problema para essa determinação é a construção de um variograma para cada variável, logo, o 
número de variogramas será o mesmo que o número de variáveis discretas. $\mathrm{O}$ estimador da krigagem indicadora resume-se matematicamente a (Yamamoto \& Landim, 2013):

$$
\mathrm{Z}_{\mathrm{KO}}^{*}\left(\mathrm{x}_{\mathrm{o}} ; \mathrm{zc}\right)=\sum_{i=1}^{n} \lambda i \mathrm{I}\left(\mathrm{x}_{\mathrm{i}} ; \mathrm{ZC}\right)
$$

\subsubsection{Simulações estocásticas (SGS e SIS)}

Como visto anteriormente, a krigagem busca estimar pontos não amostrados através da minimização da variância do erro. Como resultado disso, uma suavização das disperções reais é adquirida. Para a resolução desse problema outro método geoestatístico, conhecido como simulação estocástica, foi criado. Apesar de uma menor suavização e maior precisão global, a simulação estocástica possui pior precisão local, mas apresenta diferentes possíveis cenários mais próximos da realidade (Olea, 1999).

A simulação trabalha com diferentes cenários (realizações) matematicamente equiprováveis, com base nos dados amostrados e na geoestatística modelada. No caso de um reservatório de petróleo, por exemplo, a simulação pode gerar permeabilidades mais otimistas em um cenário e mais pessimistas em outro. As realizações geradas pela simulação devem ser analisadas com muito cuidado, pois podem não refletir o cenário atual. Segundo Goevarts (1997) o objetivo da simulação é a geração de diferentes realizações conjuntas das $\mathrm{N}$ variáveis aleatórias.

Dois tipos de simulação serão utilizadas nesse trabalho. A simulação gaussiana e a simulação indicadora. Ambas as simulações são sequenciais, ou seja, um método de simulação no qual os dados são simulados de maneira seqüencial, seguindo um caminho definido e os dados previamente simulados são considerados na simulação de novos dados. Além disso, essas simulações também são chamadas de condicionais, pelo fato de que se existirem dados amostrais no local a ser simulado, o valor simulado será o mesmo do dado amostral. As maiores diferenças entre as duas simulações residem: no tipo de 
krigagem utilizado para estimar os pontos não amostrados; e, nas funções transformadoras para início da simulação (Goevarts, 1997).

A simulação seqüencial primeiramente define um caminho de simulação, ou seja, um caminho aleatório, fornecedor da equiprobabilidade desta estatística (figura 25). Definida a ordem, o ponto é estimado por krigagem simples (equação 14), no caso da simulação gaussiana, utilizando os pontos pré-simulados da vizinhança e os pontos amostrados. Após a estimativa, para correção do erro de suavização das dispersões reais da krigagem, é adicionado ao valor adquirido um resíduo. $O$ resíduo é retirado aleatoriamente por Monte Carlo da função de distribuição acumulada condicional (FDAC) (equação 16). Essa função é definida pelo valor estimado por krigagem $\left(\mathrm{Y}_{\mathrm{KS}}^{*}\right)$, média condicional (equação 17), e pela variância condicional, variância de krigagem simples (equação 18), a qual segue uma distribuição normal. É importante frisar que o resíduo honra o histograma e a variância espacial da variável aleatória. Feita a simulação deste ponto, ele também servirá para a simulação dos próximos, caso esteja na vizinhança. Ou seja, será como um novo ponto amostrado (Goevarts, 1997).
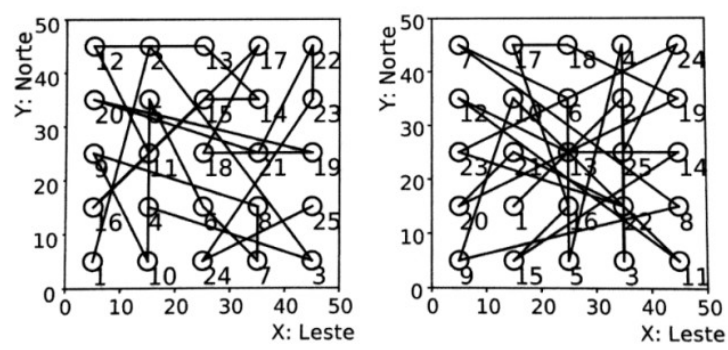

Figura 25 Exemplos de caminhos aleatórios obtidos na simulação sequencial (Yamamoto \& Landim, 2013)

$$
\begin{array}{ll}
Y_{\mathrm{s}}(\mathrm{u})=\mathrm{Y}^{*}(\mathrm{u})+\mathrm{R}(\mathrm{u}) & \text { (equação 16) } \\
\mathrm{Y}^{*}(\mathrm{u})=\sum_{b=1}^{n} \lambda_{\mathrm{b}} \mathrm{C}\left(\mathrm{u}_{\mathrm{b}}\right) & \text { (equação 17) } \\
\mathrm{\sigma}^{2} \mathrm{KS}(\mathrm{u})=\mathrm{C}(0)-\sum_{a=1}^{n} \lambda_{\mathrm{a}} \mathrm{C}\left(\mathrm{u}, \mathrm{u}_{\mathrm{a}}\right) & \text { (equação 18) }
\end{array}
$$


A função de Monte Carlo, utilizada na obtenção do resíduo da simulação, trabalha adquirindo pontos aleatórios para inferência de alguma propriedade. O exemplo mais utilizado na literatura para explicar a função é a determinação de uma área. No caso da área de um círculo, por exemplo, são determinados $\mathrm{n}$ pontos aleatórios, dos quais alguns pertencem e outros não pertencem ao círculo, os pontos pertencentes são utilizados para estimar a área em questão.

A simulação gaussiana sequencial inicialmente transforma os dados em uma distribuição normal (equação 10) com média nula e variância unitária. Transformado os dados, calcula-se o variograma da variável transformada e testa-se a hipótese de bigaussianiadade. A bigaussianidade consiste em provar com variogamas se a distribuição de dois pontos é gaussiana. A técnica desenvolvida por Goovaerts (1997) para esse teste resume-se a: transformar o conjunto de dados para o domínio gaussiano e modelar o variograma experimental dos dados; derivar a função covariância do variograma modelado; dividir a amostra em decis e através deles determinar as variáveis indicadoras; e, para cada percentil, calcular novos variogramas experimentais e modelá-los. Os variogramas experimentais e teóricos dos percentis são comparados entre eles e, caso exista uma boa correlação entre os pares, a hipótese é aceita. Confirmada a hipótese anterior, é rodada a simulação sequencial para a determinada variável, com a estimação dos valores por krigagem e adição do resíduo. Após a simulação de todos os pontos, deve-se aplicar a função inversa da transformação gaussiana, obtendo os valores reais dos dados estimados.

A simulação indicadora sequencial, por também tratar-se de um método de simulação sequencial, possui o algoritmo parecido ao da simulação sequencial gaussiana, mas é utilizada para variáveis discretas. Inicialmente, o banco de dados deve ser transformado em variáveis binárias ou teores de corte, utilizando a transformada indicadora (equação 12). Feito isso é gerado e modelado um variograma experimental para cada variável ou teor de corte. A estimativa dos pontos é executada por krigagem indicadora e pela adição de um resíduo, definido como na simulação gaussiana Deutsch (2002). 
Deve-se lembrar de que em ambas as simulações, os pontos previamente simulados são utilizados nas próximas simulações.

\subsubsection{Modelagem}

A Modelagem geoestatística é uma técnica muito utilizada em todos os ramos da geociências. Na geologia ambiental, por exemplo, é utilizada principalmente para estimar concentrações de contaminantes e a velocidade em que estes se deslocam. Na mineração, é utilizada para: o cálculo de possíveis teores, estimar o volume de minério e entre outros. A indústria petrolífera também faz uso destas técnicas, gerando modelos de porosidade, permeabilidade, litológicos, estratigráficos, de fluxo e estruturais, buscando calcular reservas e volumes recuperáveis.

Os métodos geoestatísticos possuem muitas vantagens quando comparados aos métodos convencionais de interpolação. Nos métodos convencionais, os pesos são determinados meramente em função da distância. Já com a geoestatística, os pesos são determinados a partir do variograma, gerado através de uma análise de correlação espacial. A área de influência utilizada pelos métodos convencionais não possui nenhum critério, enquanto que nos métodos geoestatísticos a área da interpolação é determinada pelo alcance do variograma. A anisotropia, sempre presente nas variáveis geológicas, é ignorada com os métodos convencionais, mas a geoestatística identifica as anisotropias presentes pelo cálculo dos variogramas e modela a mesma, detectando duas direções ortogonais de maior e menor continuidade espacial, além da direção vertical. Outro problema dos métodos convencionais são os "clusters", ou seja, os pesos não são atribuídos corretamente quando existe uma grande concentração de amostras em um local e uma menor concentração em outro, acarretando em superestimações ou subestimações. A superioridade da geoestatística na estimação de valores não conhecidos é indiscutível. 
A modelagem realizada neste trabalho assemelha-se com as provenientes da indústria petrolífera. Devido ao trabalho modelar parâmetros modelados pelas petrolíferas e tratar-se de um análogo de reservatório, foi efetuada uma breve revisão bibliográfica de como é realizado o estudo geoestatístico em reservatórios pela indústria.

\subsubsection{Modelagem na indústria petrolífera}

A modelagem geoestatística é uma técnica muito utilizada na predição de modelos petrolíferos. Essa técnica inclui diferentes métodos comentados anteriormente como a krigagem, simulação e outros não citados, como a cokrigagem e diversos tipos de regressões lineares (Cosentino, 2001).

A indústria trabalha com diferentes escalas de grandeza. São utilizada(o)s: lâminas petrográficas, da ordem de grandeza de mícrons, para a análise dos poros e da petrografia; amostras de rochas (plugs), de 1.0 polegada e meia de diâmetro e cerca de $3.0 \mathrm{~cm}$ de comprimento, para análises petrofísicas; perfilagem geofísica, de escala centimétrica a métrica, para o reconhecimento de propriedades físicas da rocha; e, em escala decamétrica, a sísmica de reflexão (figura 26). 


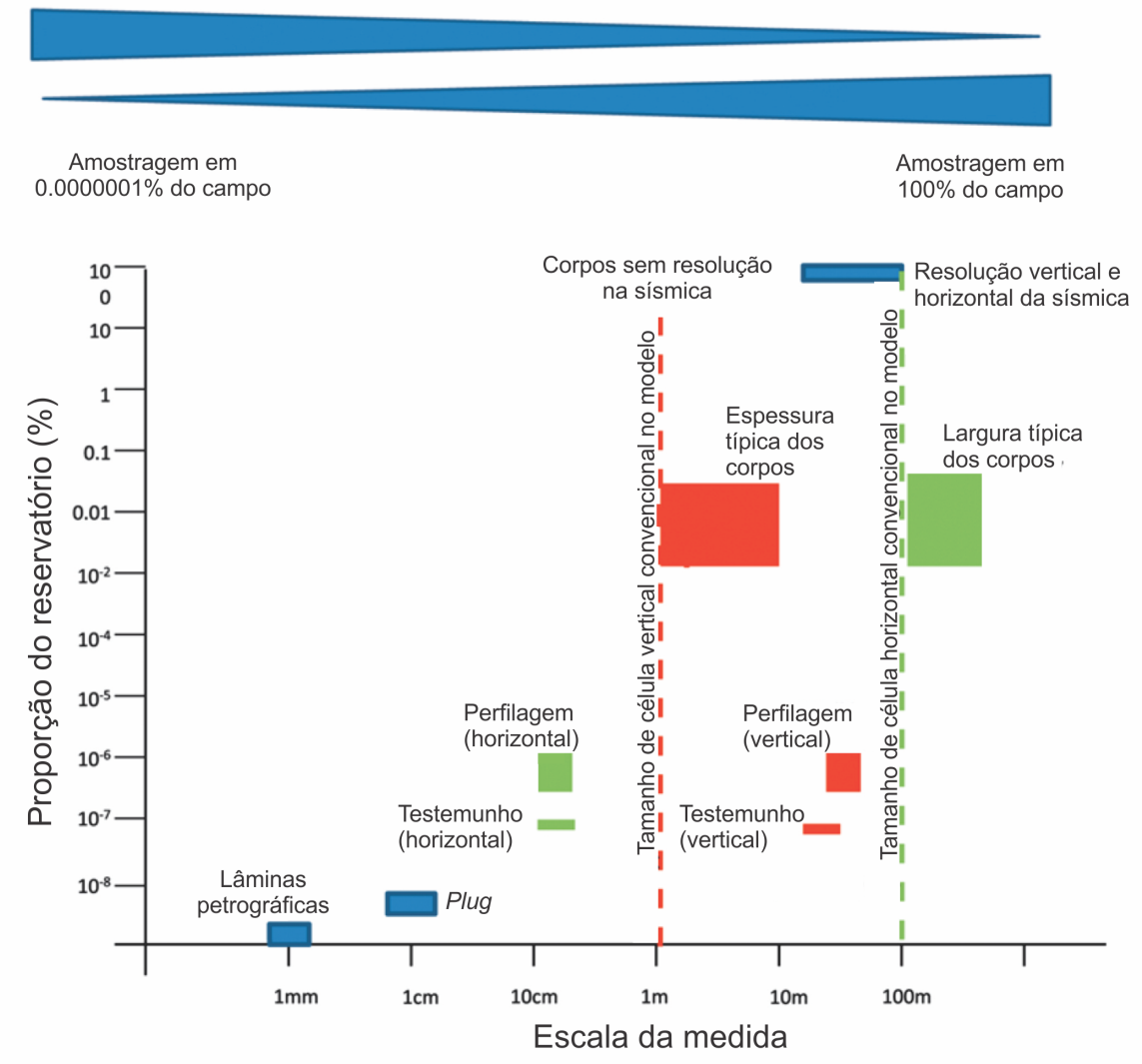

Figura 26 - Diferentes escalas de heterogeneidades encontradas na exploração petrolífera (modificado de Howell et al., 2014)

Segundo Howell et al. (2014) a ferramenta mais utilizada no início dos trabalhos, pela sua maior cobertura em área, é a sísmica de reflexão. Ela é utilizada em fase de exploração para o conhecimento da estratigrafia e geologia estrutural da bacia. Passada esta etapa, em um reservatório convencional, a geologia é refinada nos locais onde os hidrocarbonetos supostamente estariam acumulados, nos reservatórios próximos aos diferentes tipos de trapas. A partir desse nível de pesquisa, entram em vigor todos os outros procedimentos: a perfilagem, petrofísica e petrografia.

Assim que as informações do reservatório são adquiridas, deve-se analisar o sistema por inteiro, que de fato é um trabalho muito complexo. Para facilitar essa análise, são criados modelos geoestatísticos (Deutsch, 2002). 
Segundo Cosentino (2001), o estudo de reservatórios engloba quatro principais modelos: estrutural, estratigráfico, litológico e heterogeneidade de reservatório.

O modelo estrutural é o primeiro modelo a ser gerado. As falhas geológicas são geralmente identificadas pelas descontinuidades observadas na sísmica ou pela descontinuidade das litologias, observadas entre os poços. Além disso, deve-se atentar para o potencial selante das falhas, que influenciará muito no modelo de fluxo. Apenas as falhas que influenciarão no fluxo de hidrocarbonetos devem ser reportadas no modelo estrutural. Caso contrário, elas não devem ser reportadas, pois uma falha interpretada pelo geólogo como muito pequena, pode ser aumentada equivocadamente pelo engenheiro para ser inserida no modelo, acarretando em mudanças no modelo de fluxo real.

Uma vez identificadas todas as falhas, a construção do modelo pode ser iniciado. O primeiro passo é a definição de quais são as falhas responsáveis pela maior parte do fluxo no reservatório. O segundo passo é traçar as principais superfícies geológicas com auxílio de técnicas geoestatísticas. O terceiro e último passo para a criação do modelo estrutural é a inserção das falhas menores que influenciam no fluxo. O modelo estrutural é sempre o que possui mais incertezas segundo Cosentino (2001), devido aos erros dos intérpretes (error picking), erros de conversão de profundidade, variação lateral de litologia, efeito gás na sísmica e entre outros fatores.

O modelo estratigráfico é o modelo a ser gerado após o modelo estrutural. Esse tem como principal objetivo revelar a continuidade dos principais reservatórios presentes no local. A amostragem dos prospectos de petróleo é vertical, com grandes distâncias horizontais, fato que dificulta a criação do modelo estratigráfico, pois a continuidade lateral dos depósitos deve ser interpretada (Deutsch 2002). Para este modelo, segundo Cosentino (2001), geralmente se opta pelo acamamento proporcional ou paralelo. No acamamento proporcional, as sequências verticais são sempre as mesmas, enquanto que no paralelo existem superfícies truncadas por inconformidades (figura 27). Esse tipo de modelagem não é nem próximo do real, levando em 
conta a complexidade geológica existente, principalmente em modelos fluviais e deltaicos, onde se encontram muitas variações laterais de fácies em pequenas distâncias. Visando aperfeiçoar as correlações laterais do modelo estratigráfico, uma série de análises pode ser utilizada na correlação dos poços, como: a bioestratigrafia, a palinologia, as falhas, as características dos fluidos presentes, mas a análise mais importante é a dos elementos arquiteturais. Devido à dificuldade encontrada para essa análise nos reservatórios, em subsuperfície, ganharam prestígio os estudos de análogos de afloramento. As relações entre os elementos arquiteturais encontrados na superfície são muito úteis para interpretações no reservatório, porém devem ser utilizadas com cuidado (Alexander 1993).

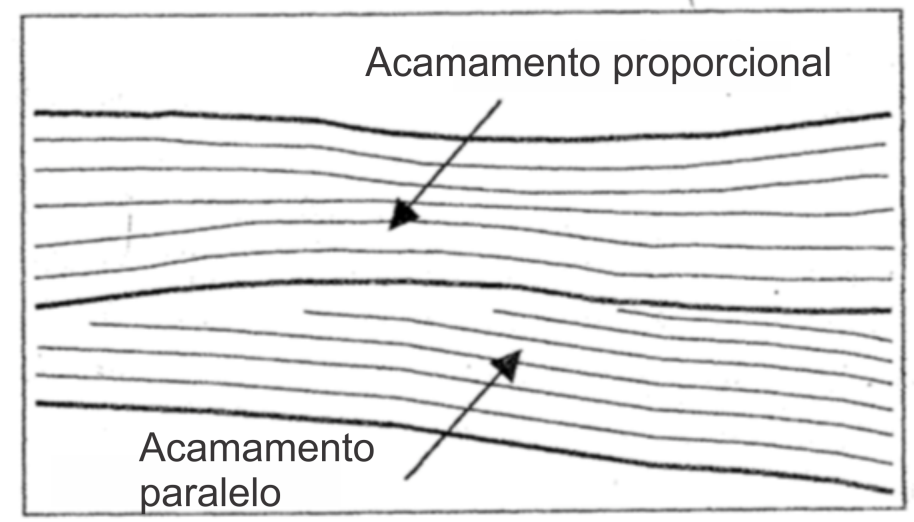

Figura 27 Acamamento proporcinal e paralelo, opções para construção de modelos geológicos (modificado de Consentino, 2001)

O reservatório, além de modelos estruturais e estratigráficos, necessita de modelos litológicos (de fácies), os quais são a união de estudos sedimentológicos dos testemunhos, interpretação da perfilagem e aplicações de técnicas geoestatísticas. Além disso, a sísmica também é utilizada em larga escala para definição de litologias, já que na maioria dos casos as duas variáveis possuem correlação. A primeira possui amostragem mais abrangente que as demais técnicas citadas. Para a correlação da sísmica com a distribuição de fácies, geralmente utiliza-se a cokrigagem. A sísmica fornece o variograma horizontal e os poços o variograma vertical. Assim a simulação indicadora sequencial é utilizada para geração do modelo de fácies. A litologia 
é muito importante no reservatório, pois as características petrofísicas têm alta correlação com as fácies. Analisando os testemunhos com muito detalhe, diferentes tipos de litologia podem ser encontrados, mas, como na modelagem das falhas, com base nas características deposicionais e petrofísicas, apenas as distinções necessárias devem ser levadas ao modelo. Em um reservatório, difícilmente o número de fácies passa de três tipos para os "non-nef" fácies e três para os "net" (Deutsch, 2002). Os modelos litológicos são divididos em modelos formados por pixels e formados por objetos (figura 28). Os primeiros citados apresentam-se de forma mais computadorizada, enquanto que os formados por objetos utilizam formas geométricas para a criação das fácies. Essas formas são muito utilizadas em ambientes fluviais, turbidíticos e deltaicos, para modelar canais abandonados, lobos, levees e entre outros (Cosentino 2001).
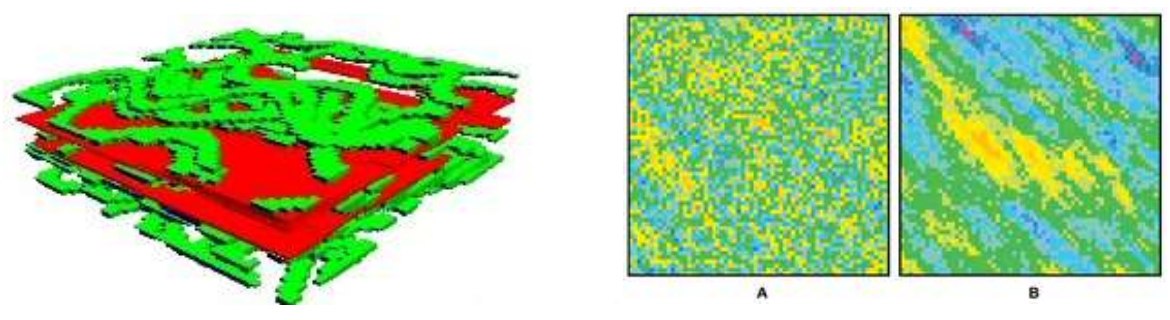

Figura 28 - Modelo baseado em objetos (esquerda) e modelo baseado em pixels (direita) Consentino (2001)

A heterogeneidade de um reservatório pode ser muito complexa. Webber (1986) dividiu as heterogeneidades em sete diferentes tipos (figura 29). Os tipos mostrados na figura ocorrem em larga escala no reservatório. Devido à alta frequência de heterogeneidades, nem todas podem ser colocadas no modelo. São anexadas apenas as heterogeneidades maiores em tamanho, conhecidas como as heterogeneidades determinadoras da "compartimentalização do reservatório". Segundo Cosentino (2001), as compartimentalizadoras são: potencial selante de falha, "genetic unit boundaries", "shales baffles and permeability streaks" e fraturas naturais. Para diminuição da permeabilidade ligada a falhas, pode ocorrer: a entrada de argila 
nos planos; a formação de zonas com "gouge" devido à fricção do movimento gerador da falha; e, a cimentação preferencial (gerada por fluidos que tem sua passagem facilitada pela abertura da falha), alterando as características petrofísicas do local. "Genetic unit boundaries" são heterogeneidades geradas pela descontinuidade das litologias, ocasionando uma grande disparidade da permeabilidade no local. Em ambientes fluviais, pode-se exemplificar esses como canais abandonados sobre extensas planícies de inundação, lentes conglomeráticas, entre outros. "Shale baffles" são barreiras verticais de permeabilidade, causadas por folhelhos, também conhecidos na literatura como "sthocastic shales". Esses possuem continuidade lateral variável, dependente do sistema deposicional. Segundo Weber (1986) a continuidade dos folhelhos é maior em ambientes marinhos, média nos deltas e menor em canais distributários e barras de pontal. "Permeability streaks" são continuidades que modificam a permeabilidade vertical dos reservatórios, por exemplo, a cimentação carbonática proveniente de processos diagenéticos em reservatórios siliciclásticos. O último tipo de heterogeneidade compartimentalizadora de reservatório são as fraturas naturais do reservatório. Essas podem variar de estilólitos até famílias regionais de fraturas. Apesar da possibilidade de serem seladas, altas concentrações de fraturas pode gerar famílias interconectadas, aumentando em escalas de grandeza a permeabilidade no reservatório, fato muito comum em reservatórios carbonáticos. As fraturas ocorrem em reservatórios siliciclásticos, mas, geralmente, em menor escala. 


\begin{tabular}{|c|c|}
\hline $\begin{array}{c}\text { Reservoir } \\
\text { heterogeneity type }\end{array}$ & \\
\hline \multicolumn{2}{|l|}{$\begin{array}{l}\text { Sealing fault } \\
\text { Semi-sealing fault } \\
\text { Non-sealing fault }\end{array}$} \\
\hline $\begin{array}{l}\text { Boundaries } \\
\text { genetic units }\end{array}$ & 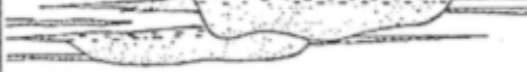 \\
\hline \multicolumn{2}{|l|}{$\begin{array}{l}\text { Permeability zonation } \\
\text { within genetic units }\end{array}$} \\
\hline \multicolumn{2}{|l|}{$\begin{array}{l}\text { Baffles within } \\
\text { genetic units }\end{array}$} \\
\hline \multicolumn{2}{|l|}{$\begin{array}{l}\text { Lamination, } \\
\text { cross-bedding }\end{array}$} \\
\hline \multicolumn{2}{|l|}{$\begin{array}{c}\text { Microscopic } \\
\text { heterogeneity, } \\
\text { textural type, } \\
\text { mineralogy }\end{array}$} \\
\hline $\begin{array}{l}\text { Fracturing tight, } \\
\text { fracturing open }\end{array}$ & \\
\hline
\end{tabular}

Figura 29 - Sete principais heterogeneidades de reservatório definidas por Webber (1986), retirado de Consentino (2001)

As heterogeneidades de menor escala também são muito importantes no fluxo de hidrocarbonetos. Este fato é evidenciado na larga quantidade de trabalhos sobre análogos de reservatório, comentados anteriormente no item 4.3.

Por fim, os modelos petrofísicos são de fundamental importância para locação dos poços produtores e injetores. O problema da amostragem horizontal reduzida na indústria petrolífera também se prolifera nesses modelos. Os modelos de porosidade obtidos pela indústria baseiam-se principalmente nos dados de perfilagem e nas análises petrofísicas realizadas em laboratório. Para a "obtenção" de uma maior quantidade de amostras de porosidade, utilizam-se atributos sísmicos como variáveis secundárias. Diversos tipos de regressões lineares ou até mesmo cokrigagens podem ser 
utilizados para a transformação de dados de atributos sísmicos para dados de porosidade. Com uma densidade maior de "dados" de porosidade, através da simulação gaussiana, são gerados modelos de porosidade para cada fácies ou camadas de reservatório. Adquirido um modelo de porosidade, o modelo de permeabilidade é gerado utilizando os dados da simulação efetuada para porosidade como variável secundária, visto que as duas variáveis possuem correlação positiva. Deve-se atentar que os dados petrofísicos adquiridos no laboratório devem ser corrigidos para pressões e condições atuantes no reservatório antes de serem inseridos no modelo (Deutsch, 2002).

\section{Materiais e Métodos}

O presente trabalho utilizou diversas técnicas geológicas, compreendendo: (i) descrição de fácies e elementos arquiteturais em trabalhos de campo, considerando propostas principalmente de Allen (1983), Miall (1996) e Li et al (2015); (ii) ensaios de permeabilidade em campo; (iii) coleta e orientação de amostras; (iv) plugagem dos blocos coletados no campo; (v) análises de petrofísica básica pelo método de injeção de gás inerte; (vi) impregnação e laminação das amostras; (vii) descrição petrográfica; e, por fim, (viii) processamento de imagens; e (xi) modelagem geoestatística.

\subsection{Trabalhos de Campo - análise de fácies, elementos} arquiteturais, permeabilidade e amostragem

A primeira etapa do trabalho consistiu na descrição de fácies e elementos arquiteturais em afloramento com base em propostas de Allen (1983), Miall $(1977,1985,1996,2000)$ e Li et al (2015). As fácies foram descritas com ênfase principal na estrutura sedimentar e granulometria, criando-se uma descrição de fácies alternativa a de Miall (1996), enquanto as superfícies sedimentares limitantes foram classificadas segundo Allen (1983), mas 
descritas detalhadamente, e os elementos arquiteturais baseados em Li et al (2015), mas também modificados (item 6.1).

Foram levantadas 91 seções estratigráficas ao todo (apêndice A e B), buscando: descrever fácies e associações de fácies; identificar as superfícies mais importantes e correlacioná-las entre as seções; observar a geometria dos depósitos; e, posteriormente, agrupar as respectivas fácies delimitando os elementos arquiteturais. Os dois afloramentos estudados (TUC05 e TUC41) foram fotografados, em terra e por VANT (drone) (figura 30A). Modelos 3D e fotomosaicos foram gerados para melhor compreensão e análise, das geometrias e continuidades laterais, dos elementos arquiteturais.

Nos mesmos locais em que foram descritas as fácies, medidas de permeabilidade, nas direções horizontais e verticais, foram obtidas através do Tinny Perm (permeâmetro de campo)(figura 30B). Esse equipamento, quando pressionado à parede do afloramento, subtrai o ar da formação, fornecendo uma medida adimensional de permeabilidade, a qual foi convertida em unidade de milidarcy (figura 31).

Durante os trabalhos de campo, antes de se realizar a coleta dos blocos para os ensaios de petrofísica, os pontos onde o mesmo seria efetuado foram raspados (cerca de dois a três centímetros da superfície do afloramento), para retirada da camada de rocha intemperizada. Nestes locais obtiveram-se os dados de permeabilidade in situ, os quais seriam posteriormente comparados aos dados de permeabilidade obtidos em ensaios de laboratório. Além disso, buscando maior precisão espacial das medidas, foram obtidas coordenadas UTM dos pontos ensaiados e das principais superfícies sedimentares, por meio do GPS Hiper SR (figura 30C). Essa localização foi posteriormente utilizada para a plotagem dos pontos e superfícies no software RMS.

Os ensaios de permeabilidade, obtidos in situ (utilizando o permeâmetro de campo) forneceram, primeiramente, resultados adimensionais para a permeabilidade, em escala de 8 a 13. Buscando a adequação dos mesmos para milidarcies, diversas amostras foram submetidas tanto a análises em campo como em laboratrório (análise de permeabilidade com injeção de gás). Como resultado, obteve-se uma equação, por regressão linear, muito confiável 
$\left(r^{2}=0.94\right)$ e representativa (51 amostras) para a transformação dos dados adimensionais de campo, da Formação São Sebastião, para milidarcy (figura 31).

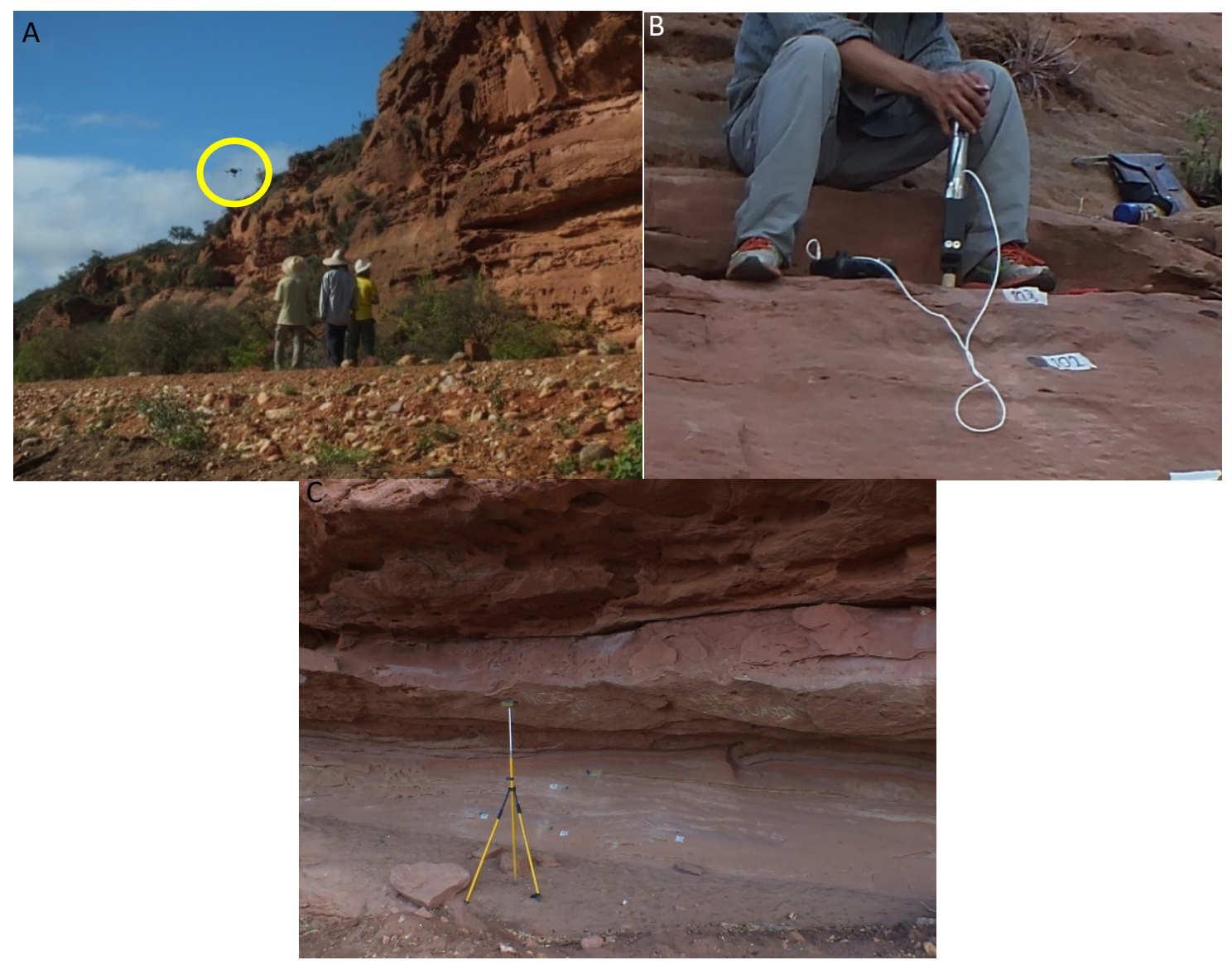

Figura 30(A)VANT sobrevoando o afloramento para confecção de modelos 3D (B) Equipamento utilizado para ensaios de permeabilidade no campo (permeâmetro)(C) GPS Hiper SR, utilizado para adiquirir a localização dos pontos no espaço.

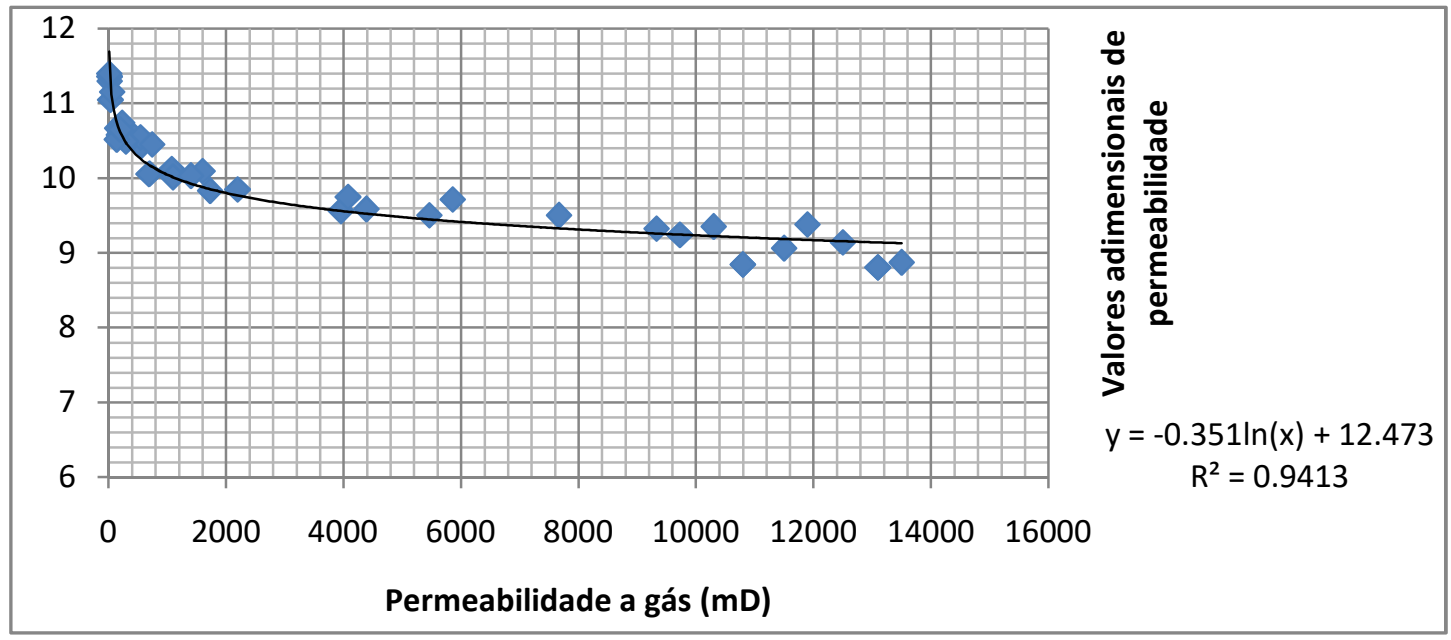

Figura 31 Crossplot da permeabilidade obtida por meio a injeção de gás nitrogênio em função de valores admensionais de permeabilidade obtidos pelo permeâmetro de campo 
Para a coleta das amostras, com o intuito de evitar a criação de microfraturas e planos preferenciais de quebra, capazes de gerar porosidades e permeabilidades não pertencentes à formação, foi utilizada uma furadeira elétrica Bosch e uma serra copo (80 milímetros de diâmetro, com corpo útil de 100 milímetros) acoplada por um adaptador SDS plus. Em cada ponto da amostragem, três testemunhos foram retirados, dois para plugagem (horizontal e vertical) e um para a confecção de duas lâminas petrográficas (horizontal e vertical). A lineação das amostras e a paleocorrente do local amostrado foram medidas em campo, possibilitando determinar as direções horizontal e vertical ao acamamento (figura 32D) (Meyer \& Krause, 2006) .
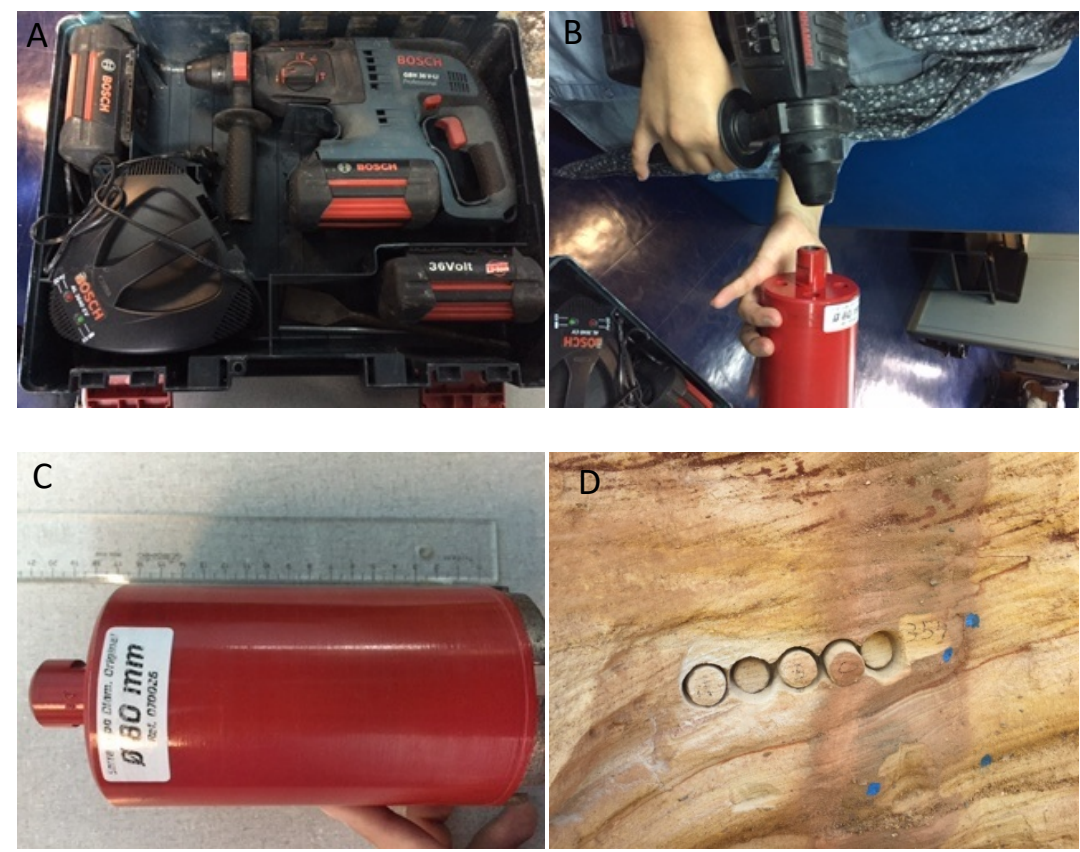

Figura 32 - (A) Furadeira utilizada na amostragem. (B) Furadeira e serra copo utilizadas na amostragem. (C) Serra copo utilizada na amostragem (D) Amostragem realizada com o conjunto furadeira e serra copo

A plugagem das amostras, em diâmetros menores, foi realizada em diferentes empresas. A primeira fase foi realizada na Schlumberger, a segunda e terceira fase na Weatherford. Os plugs foram obtidos predominantemente com 1,5 polegadas de diâmetro e 4,5 centímetros de altura em sua maioria, e, em menor quantidade, plugues com 1,0 polegada de diâmetro e cerca de 2,5 $\mathrm{cm}$ de altura. 


\subsection{Análise petrofísica a gás}

As análises petrofísicas foram realizadas nos mesmos locais onde foram plugadas as amostras. Como as amostras não possuiam óleo nos poros, não foi necessária a limpeza da mesma. As análises determinaram porosidade e permeabilidade com a utilização de um gás inerte (hélio ou nitrogênio).

\subsubsection{Análise de porosidade a gás}

Para a obtenção da porosidade, necessitou-se a pesagem e a medição (da altura e diâmetro, utilizando um paquímetro) do "plug", para obtenção do volume total. Antes do início do ensaio a amostra foi colocada dentro de um copo matriz e inserida no equipamento.

O equipamento possui duas células conectadas, uma com o volume previamente conhecido e a portadora do copo matriz; uma fonte de gás; e, um medidor de pressão digital. Quando a válvula do gás é aberta, o mesmo migra para a célula com volume (V1) conhecido, na qual é medida a pressão (P1) por um leitor digital. Após a medição, abre-se a válvula, possibilitando a conexão entre as duas células, com a migração do gás para zona de menor pressão (onde se localiza a amostra) e uma nova pressão é adquirida (P2), no volume total do sistema (V2). Para resolução deste problema utiliza-se a lei de Boyle de expansão isotérmica de um gás ideal (Young \& Freedman 2008):

$\mathrm{P} 1 \mathrm{~V} 1 / \mathrm{T} 1=\mathrm{P} 2 \mathrm{~V} 2 / \mathrm{T} 2$

(equação 19)

Admitindo que a temperatura tanto na primeira como na segunda ocasião são as mesmas, as pressões e o V1 são conhecidos, pode-se calcular o valor de V2: 
Porém, o V2 trata-se do volume de todo o sistema, somando-se o volume da tubulação que liga as duas células, o volume da célula conhecida (V1) e o volume de poros (VP). Logo, para obtenção do volume de poros é necessário subtrair do volume total do sistema (V2) o volume da tubulação e o volume da célula inicial (V1).

Por fim, para o cálculo da porosidade, é feita uma divisão simples do volume de poros (VP) calculado pela equação de Boyle sobre o volume total da amostra, calculado previamente com a ajuda do paquímetro.

\subsubsection{Análise de permeabilidade a gás em regime permanente}

Para a análise de permeabilidade, o equipamento deve conter: uma fonte de gás com vazão conhecida, um manômetro na entrada e outro na saída do corpo, para o cálculo da diferença entre pressões.

No ensaio, o plug é colocado no equipamento e o gás com viscosidade $(\mu)$ é injetado com uma vazão conhecida $(Q)$. O fluido percorre toda a área da amostra $(A)$ de comprimento $(L)$ e a diferença de pressões é medida (P1-P2). Com esses parâmetros, a permeabilidade $\mathrm{K}$ pode ser calculada através da equação de Darcy.

É importante ressaltar que a equação de Darcy é válida apenas para um fluido $100 \%$ saturado, com ausência da interação rocha-fluido e em condições de um escoamento linear de um fluido newtoniano, como já comentado. Além disso, foi executada a correção do efeito Klinkenberg. 


\subsubsection{Efeito Klinkenberg}

O efeito Klinkenberg é um fator muito importante ao analisar permeabilidades por meio da passagem de gás (método normalmente utilizado pelas indústrias de petróleo e neste trabalho). Esse fenômeno resume-se à presença do deslocamento difusional das moléculas na análise, ou seja, quando as moléculas se movimentam juntamente a massa de ar em movimento. Esse fato faz com que a estimativa da permeabilidade "meça permeabilidades já contabilizadas na primeira passagem do gás devido ao escorregamento das moléculas", resultando numa medida errônea. Através de uma relação entre a permeabilidade do mesmo meio no gás e no líquido, a equação para a correção desse efeito é definida matematicamente por (Kozeny et al 1927):

$$
\mathrm{K}_{\mathrm{L}}=\mathrm{K}_{\mathrm{g}}(1+\mathrm{b} / \mathrm{p})
$$

$$
\begin{aligned}
& \mathrm{K}_{\mathrm{L}}=\text { permeabilidade com líquido }(\mathrm{mD}) \\
& \mathrm{K}_{\mathrm{g}}=\text { permeabilidade com gás }(\mathrm{mD}) \\
& \mathrm{b}=\text { fator de correção (atm) } \\
& \mathrm{p}=\text { mediana das pressões utilizada nas medidas }(\mathrm{atm})
\end{aligned}
$$

Para melhor explicação desse fenômeno, o efeito klinkenberg mostra-se presente quando é notada a diferença entre a permeabilidade absoluta medida utilizando-se um fluido mais viscoso que o gás e o gás, em um mesmo corpo poroso e condições de escoamento.

Em laboratório, deve-se medir a permeabilidade em várias pressões médias para que seja obtida uma regressão linear do fenômeno e seja delimitado o fator de escorregamento (b), que será utilizado na correção da permeabilidade. Esse efeito é potencializado quando a análise ocorre em baixas pressões médias e quanto menor for o diâmetro das gargantas de poro analisadas (Cruz, 2014). 


\subsection{Impregnação e laminação de amostras}

Posteriormente, as análises petrofísicas as amostras restantes das extremidades dos plugues foram impregnadas com resina e corante, no laboratório de sedimentologia, do Instituto de Geociências da Universidade de São Paulo e no Instituto de Pesquisas Tecnológicas, situado dentro do campus da Universidade de São Paulo. Algumas amostras impregnadas e laminadas não foram submetidas às análises petrofísicas a gás.

Antes do início da impregnação, a amostra permaneceu na estufa por 24 horas a $50^{\circ} \mathrm{C}$ para retirar a umidade dos poros. O equipamento usado foi um impregnador Epovac. A impregnação na Universidade de São Paulo mantém a amostra vinte minutos no vácuo após a etapa da estufa, para retirada do ar nos poros. A mistura utilizada para impregnação é composta por: resina epoxy, álcool, endurecedor e corante azul. A técnica utilizada no processo é o gotejamento, onde uma gota da mistura por segundo deve ser despejada no recipiente que se encontra no vácuo. A mistura não deve ser despejada diretamente sobre a rocha, pois pode prejudicar a impregnação que ocorre por capilaridade. Terminada a impregnação, a amostra deve ser seca ao ar livre por cerca de 3 horas e, finalizado o processo, deve permanecer na estufa por mais 24 horas. Já a impregnação no Instituto de Pesquisas tecnológicas não utilizou a técnica de gotejamento. O procedimento da secagem da amostra na estufa é o mesmo, assim como a mistura, porém coloca-se uma pequena quantidade de mistura na amostra e posteriormente essa é levada ao vácuo. Esse procedimento repete-se por duas vezes, sem que a amostra seja coberta totalmente por resina antes da última colocação no vácuo. Algumas amostras repetidas foram impregnadas das duas maneiras e o resultado da porosidade foi próximo, confirmando que a segunda técnica não altera a trama da rocha.

A laminação das amostras impregnadas ocorreu no setor de laminação do Instituto de Geociências da Universidade de São Paulo. Os cortes foram realizados nas mesmas direções dos plugues. 


\subsection{Descrição petrográfica e porosidade em lâmina}

As descrições petrográficas e análises de porosidade em lâmina foram realizadas no Laboratório de petrografia sedimentar, no Instituto de Geociências da Universidade de São Paulo.

$\mathrm{Na}$ petrografia foi feita a contagem mineralógica de 300 grãos por amostra, segundo o método tradicional descrito em Ingersol (1984), com algumas modificações. A primeira modificação utilizada foi distinguir a contagem de grãos de quartzo entre policristalino e monocristalinos. Essa decisão foi feita devido a grande quantidade de fragmentos líticos silicosos na formação São Sebastião, como descrito por Figueiredo (2013). Esse fato diminuiu a quantidade de fragmentos líticos (silicosos) na porcentagem final e, usando a classificação de Folk (1968), ambos foram colocados no campo do quartzo. A outra modificação utilizada foi a contagem de poros intergranulares, intragranulares, epimatriz/pseudomatriz, argila infiltrada e argila diagenética, visto que o principal intuito do trabalho é a caracterização petrofísica. Finalmente, as lâminas descritas foram agrupadas em petrofácies de modo a facilitar o tratamento dos dados.

Além disso, foi efetuada: a contagem de 100 grãos por amostra com relação ao arredondamento, seguindo os padrões de Powers (1953); e a compactação segundo Kahn (1956). Os processos diagenéticos também foram levados em consideração. Para dinamização do processo foi criada uma forma de avaliação petrofísica, diagenética e petrográfica, levando em conta a: compactação, cimentação, empacotamento, arredondamento, presença de argilas infiltradas, pseudomatriz, micas e coeficiente de dissolução. Essas variáveis foram contabilizadas por fatores de um (1) a cinco (5) categorizadas conforme sua distribuição na seção delgada (tabela 1 e 2). 
Tabela 1 - Tabela para quantificação qualitativa de compactação na petrografia

\begin{tabular}{l}
\hline Quantificação de compactação \\
\hline 1- Grãos flutuantes em grande maioria, com contato pontual subordinado \\
2- Predomínio de contatos pontuais, com grãos flutuantes subordinados \\
3- Predomínio de compactação pontual, com planar subordinada \\
4- Predomínio de planar, com pontual subordinado \\
5- Predomínio de compactação planar, com presença de compactação química
\end{tabular}

Tabela 2 - Tabela para quantificação qualitativa de cimentos, argila infiltrada e pseudomatriz

Quantificação de cimentos, argila infiltrada e pseudomatriz

0- Inexistente
2-Presente em aproximadamente $5 \%$ dos poros da lâmina
3- Presente em aproximadamente $25 \%$ dos poros da lâmina
4- Presente em aproximadamente $50 \%$ dos poros da lâmina
5- Presente em aproximadamente $75 \%$ dos poros da lâmina

A medida de porosidade em lâmina utilizou o software LAS, o qual se baseia nas cores dos pixels para a contagem de porosidade. Como todas as lâminas foram previamente impregnadas (com corante, os poros possuíam a cor azul, facilitando a distinção).

No método descrito por Ehrlich et al (1991) e Geisick et al (2009), para adquirir-se a porosidade em seções delgadas, deve-se primeiramente definir a lente de aumento a ser utilizada, assim como o número de fotos. A escolha da lente depende da granulometria analisada. Quando a rocha possui granulometria bimodal, sugere-se o aumento de 50X, porém quando é fina e bem selecionada, o aumento de 100X é mais indicado. Devido à bimodalidade dos arenitos fluviais da Formação São Sebastião, todas as análises foram realizadas com aumento de 50X. 
Posteriormente à escolha da lente, 25 a 30 diferentes fotos da sessão delgada foram adquiridas, seguido do processamento com detecção dos pixels de coloração azul, e cálculo da área porosa. Finalmente, a mediana entre as áreas de cada foto e seu desvio padrão são fornecidos pelo software. Porém, neste trabalho o desvio padrão não foi utilizado, fato que será discutido ao longo do trabalho.

Através do LAS também foram realizadas as análises de granulometria. Foram medidos 500 pontos para cada amostra, número confiável segundo Carver (1971), tornando possível a classificação granulométrica e do grau de seleção de cada fácies.

\subsection{Processamento de imagens obtidas por drone e geração de modelos 3D de afloramento}

A digitalização 3D do afloramento foi a base, assim como a sísmica na exploração de petróleo, para a construção do modelo geológico de elementos arquiteturais, fácies e permeabilidade. $\mathrm{O}$ modelo baseou-se no tratamento das fotografias retiradas por imagens aéreas no Photoscan, utilizado na Gdrones, por parceria. As etapas de processamento são resumidas pelo fluxograma da figura 33.

Primeiramente, as fotos foram alinhadas pelo software (figura 34). A base para o alinhamento inicial utilizou o GPS da própria câmera fotográfica. Este procedimento, gerado por aerotriangulação, busca pontos correspondentes nas fotos sobrepostas, estimando a localização da câmera em cada foto (figura 35), resultando no modelo de nuvem de pontos esparsos (figura 34). 


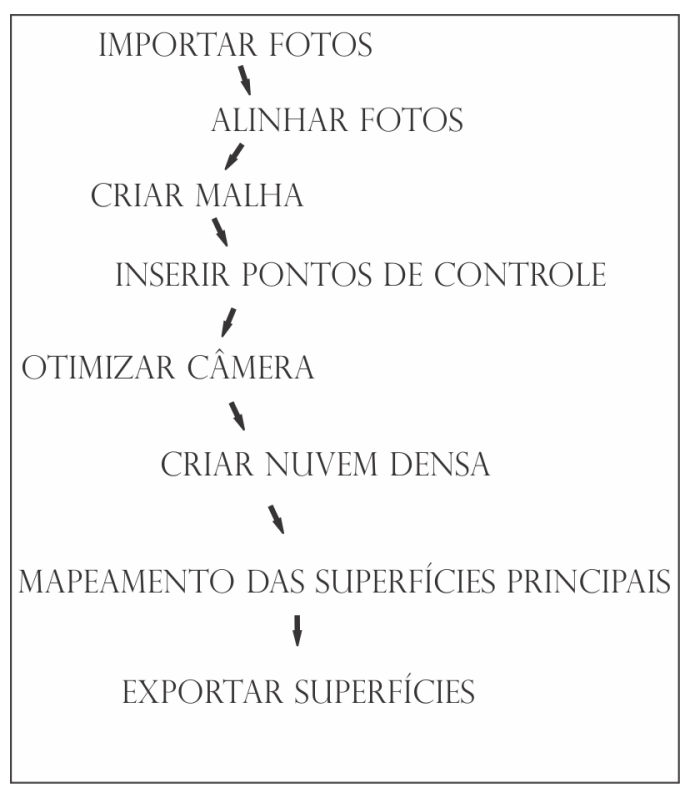

Figura 33 - Fluxograma para o tratamento das imagens dos drones

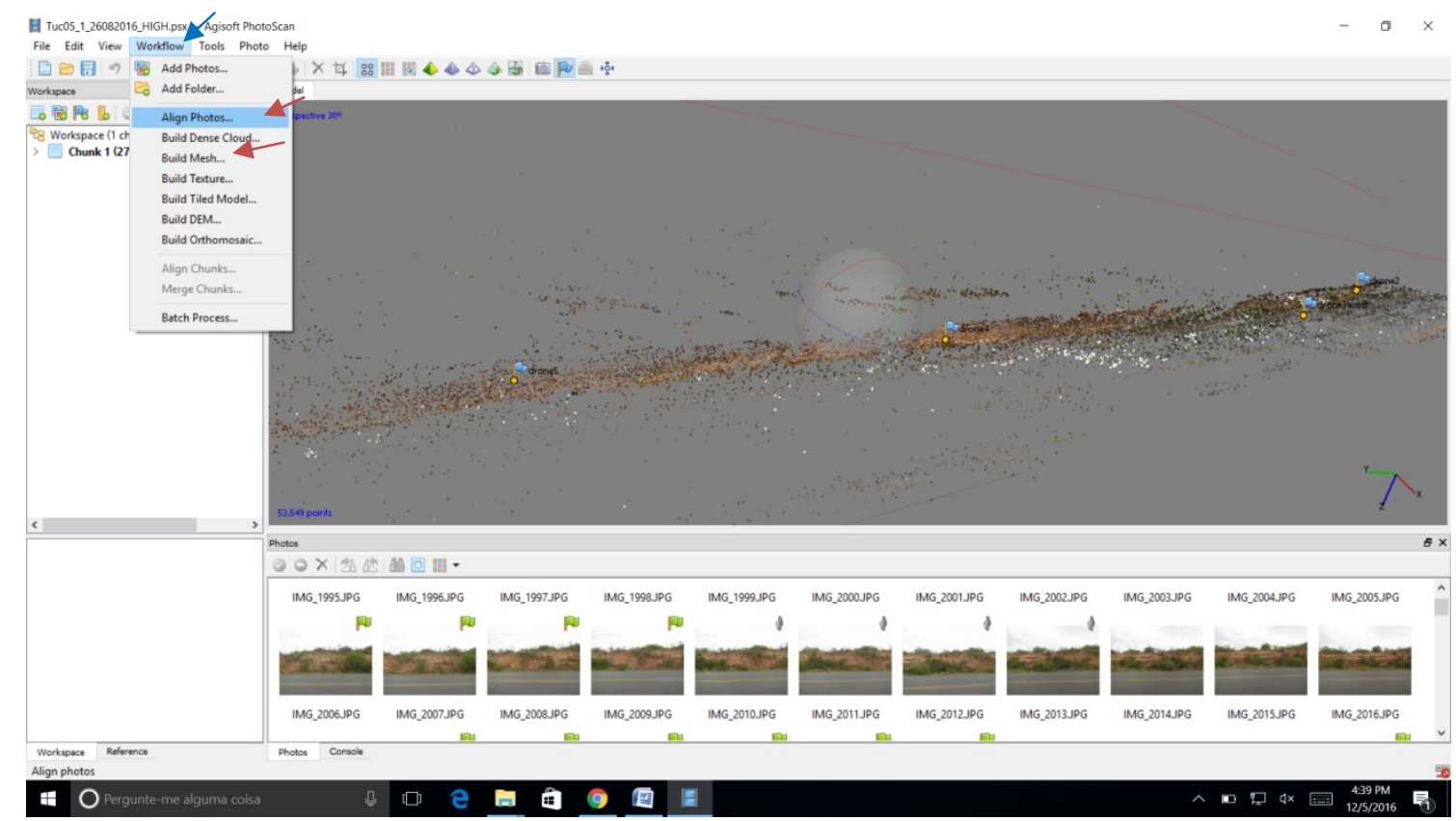

Figura 34 Alinhamento da câmera e malha (setas vermelhas), na "aba" workflow (seta azul) e nuvem de pontos esparsos 


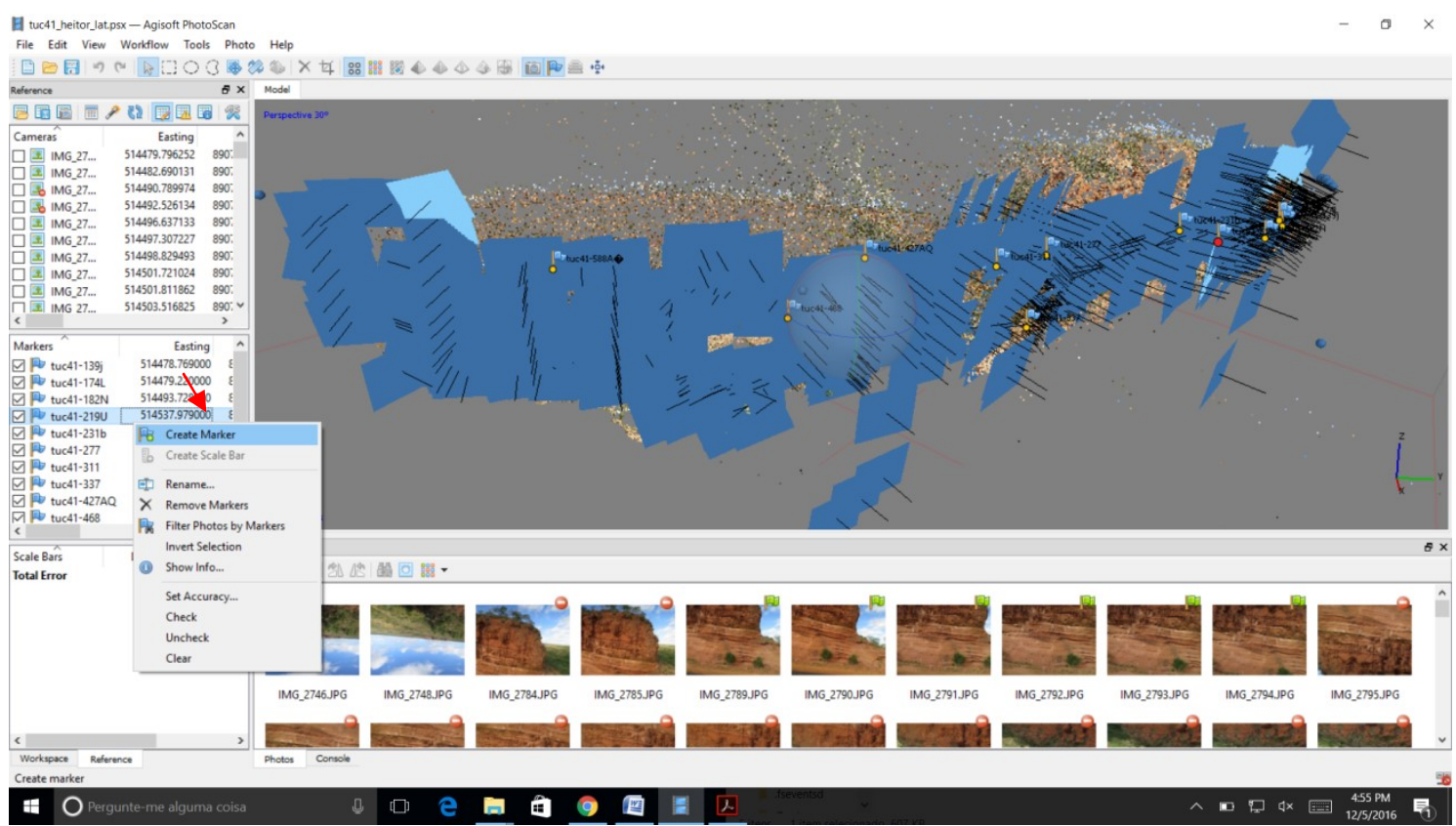

Figura 35 Localização estimada da câmera (quadrado azul) e criação dos pontos de controle (seta vermelha)

Feito o modelo de nuvem esparsa de pontos é necessária a criação da malha (mesh) na aba workflow (figura 31). Essa etapa reconstruirá a geometria do modelo 3D do afloramento, além de preparar o arquivo para a inserção dos pontos de controle.

Os pontos de controle são inseridos para melhorar a precisão das coordenadas UTM no modelo 3D, já que as utilizadas até o momento faziam uso apenas do GPS da câmera fotográfica que neste trabalho não supre a precisão necessária (distâncias verticais entre amostras atingem pontualmente até $10 \mathrm{~cm}$ ). Para essa melhora é necessária maior precisão possível dos pontos de controle a serem adquiridos. Portanto, os pontos adicionados possuem precisão na ordem de $0.1 \mathrm{~mm}$ em x, y e z, coletados pelo DGPS.

Segundo o manual do programa photoscan, a quantidade mínima de pontos de controle para geração de um bom modelo é entre 10 e 15 pontos de controle, igualmente espaçados. Logo, utilizou-se 10 pontos de apoio no afloramento TUC05 e 13 pontos de apoio no afloramento TUC41.

A inserção dos pontos no software é feita pelo reference, na "aba" markers, adicionando as coordenadas remetentes a cada ponto (figura 35). 
Posteriormente, os pontos de controle devem ser reconhecidos e ajustados em todas as fotografias com a maior precisão possível. Essa etapa é de suma importância, pois a precisão do reconhecimento servirá de referência para o ajuste de coordenadas do modelo. Para facilitar esta atividade, os pontos de controle foram escolhidos em campo e marcações in situ foram feitas anteriormente a aquisição das fotos.

Posteriormente à localização dos pontos de apoio foi necessária a otimização da câmera, corrigindo distorções diversas, como por exemplo, a distorção da própria lente.

Após a otimização da câmera, a nuvem densa deve ser gerada conforme a qualidade computacional do usuário. Nuvens densas mais detalhadas, programadas na opção high, necessitam de equipamentos muito potentes para o processamento (para a criação da nuvem densa deve selecionar-se a opção build dense cloud, na "aba" workflow) (figura 6.6.1-1). Neste trabalho foi utilizada uma Workstation para a geração da nuvem densa de alta qualidade. Porém, resultados ótimos podem ser gerados com a nuvem densa na qualidade médium, a qual necessita de uma máquina com 16 GB de memória RAM.

A nuvem densa é o principal resultado para o trabalho em questão, pois a partir dela podem ser retiradas coordenadas, no caso UTM, de qualquer local do afloramento com a precisão desejável. Devido à baixa qualidade de imagem da nuvem densa quando aproximada, a técnica para a demarcação exata das superfícies foi a análise primeiramente em 2D, no ortomosaico, utilizando o Qgis, e posteriormente em 3D, na nuvem densa (figura 36). Uma vez demarcada, a superfície ou geometria desejada deve ser "cortada" do restante do modelo exportando-a em TXT (file>export points). 


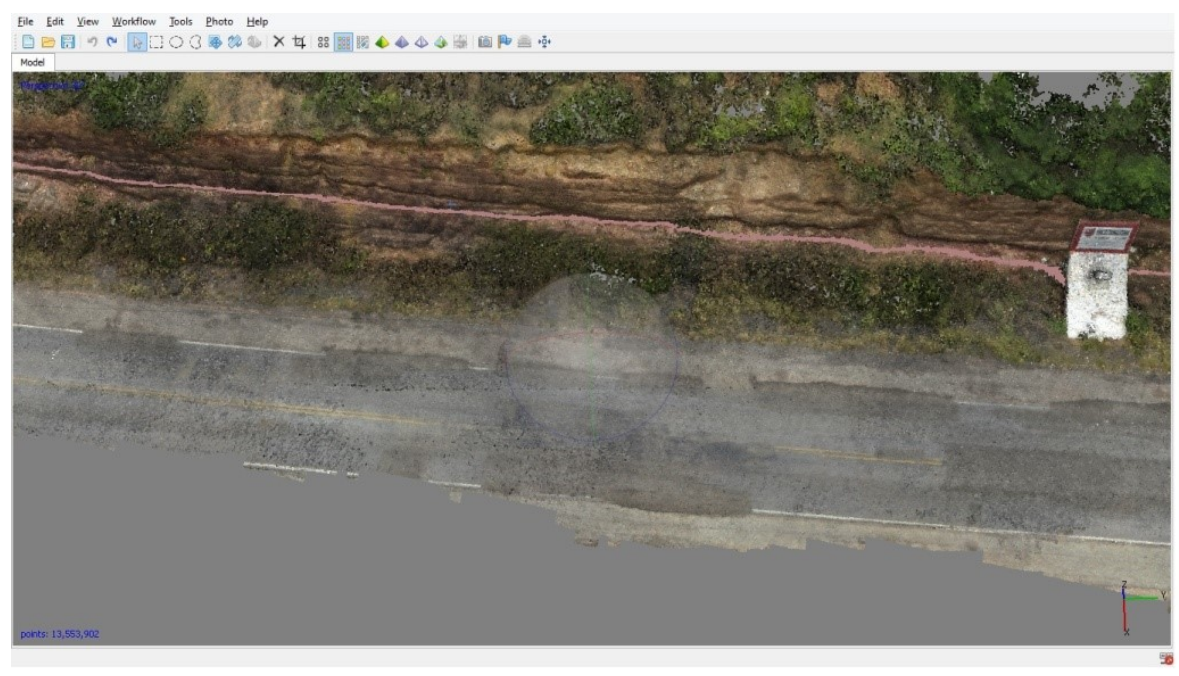

Figura 36 Demarcação no modelo 3D das principais superfícies sedimentares interpretadas no afloramento TUC 05

\subsection{Modelagem geológica}

A modelagem foi utilizada para maior representatividade dos afloramentos estudados com base nos dados petrofísicos adquiridos. Modelos prévios, apenas de permeabilidade, foram gerados no SGEMS, software livre de geoestatística, mas modelos mais robustos, de elementos arquiteturais e fácies, populados com permeabilidade foram gerados no RMS (Reservoir Management Software), da empresa Roxar. As principais etapas para geração do modelo geológico utilizaram o mesmo workflow apresentado pelo trabalho de Vipond (2005) (figura 37).

A primeira etapa da criação do modelo foi a importação das principais superfícies sedimentares do afloramento, obtidas pelo Photoscan para o modelo digital como pontos. A importação foi efetuada como horizontes calculados, no formato "txt.". Esse processo necessitou de edições dentro do software RMS, devido à grande e desnecessária quantidade de pontos representativos das superfícies provenientes dos pixels da nuvem densa. A grande quantidade de pontos atrapalha na próxima etapa, na qual os pontos são interpolados gerando superfícies. As superfícies, por sua vez, constituem o modelo estratigráfico e funcionam como delimitadoras das principais 
superfícies sedimentares, as quais serviram de guias para o modelo de fácies e petrofísico.

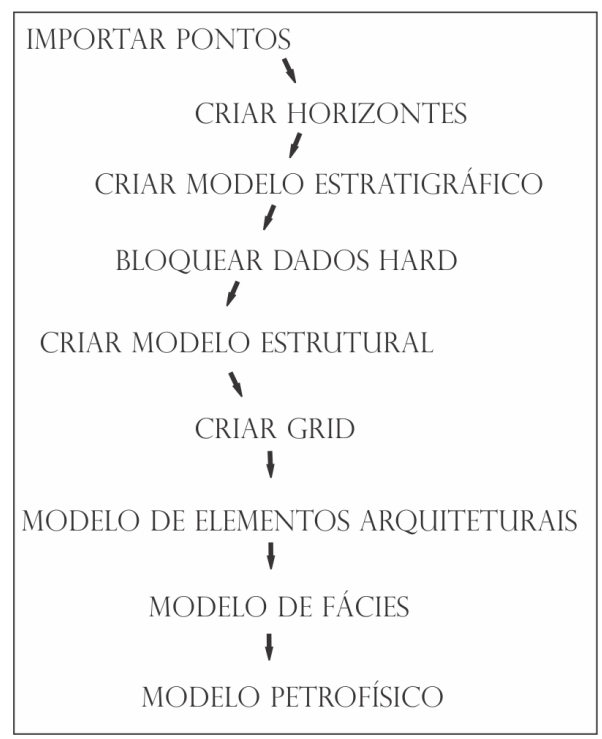

Figura 37 - Fluxograma da modelagem geológica em afloramentos

Posteriormente a criação do modelo estratigráfico importaram-se os poços virtuais, os quais se tratam de sessões estratigráficas descritas em afloramento, por amostragem aleatória. A importação foi feita utilizando o formato RMS WELLS, na qual o poço virtual ou seção estratigráfica foi importada como trajetória do poço, com dados de: arquitetura depocional, fácies, porosidade, permeabilidade horizontal e permeabilidade vertical.

Para a modelagem e simulação dos parâmetros geológicos foi necessária a criação do modelo estrutural, e do grid, composto por células de $1,0 \mathrm{~m}$ nos eixos $\mathrm{x}$ e y e $0,10 \mathrm{~m}$ no eixo $\mathrm{z}$.

Com o intuito de manter os valores reais nos locais amostrados (hard data) bloquearam-se os mesmos, utilizando a ferramenta Block Wells. Feito isso os variogramas foram gerados e modelados para utilização da simulação indicadora, gerando primeiramente modelos de elementos arquiteturais e, secundariamente, fácies sedimentares (baseado no resultado do modelo de elementos arquiteturais). 
Criado o modelo de fácies, o mesmo foi populado com valores de permeabilidade (adquiridos em campo), baseado em variogramas particulares para cada fácies, dentro de cada horizonte.

\section{Resultados obtidos}

Neste item serão apresentados os resultados das análises realizadas em campo e em laboratório nos arenitos da Formação São Sebastião. Para melhor organização do trabalho os resultados obtidos no trabalho foram divididos em: (6.1) análise de fácies, associação de fácies e elemento arquitetural; (6.2) análise petrográfica; (6.3) análise de permoporosidade; (6.4) petrofácies; e, (6.5) modelagem geológica.

\subsection{Análise de fácies, associação de fácies e elemento arquitetural}

As análises de fácies (tabela 3) e associações de fácies foram realizadas durante os trabalhos de campo, agrupando-as em corpos estratigráficos delimitados por diferentes geometrias, continuidade lateral e vertical, e diferentes superfícies: erosivas, planas, irregulares, côncavas, de mergulho sutil ou relativamente alto, separando sets, cosets ou elementos arquiteturais, de primeira a terceira ordem seguindo a proposta de Allen (1983).

\subsubsection{Fácies Sedimentares}

Seções colunares foram levantadas nos dois afloramentos, onde se realizou as descrições das fácies sedimentares. As seções colunares encontram-se detalhadas nos apêndices A e B.

Foram caracterizadas seis fácies sedimentares nos afloramentos estudados. 
A fácies denominada como Afp caracteriza-se subordinadamente por pelitos, mas majoritariamente por arenitos muito finos a médios com estratificação plano paralela apresentando ou não grânulos. Geralmente esta fácies apresenta-se em estratos de espessuras $0,1 \mathrm{~m}$ até $2,5 \mathrm{~m}$, e comprimentos de 4,0 $\mathrm{m}$ até dezenas de metros, com geometrias lenticulares. Essa fácies foi interpretada como fluxo de alta velocidade em regiões com lâmina d'água pouco espessa.

A fácies Afr é composta por arenitos muito finos a médios portadores de marcas onduladas (ripples) geralmente ocorrendo em estratos de espessuras de $0,1 \mathrm{~m}$ até $1,5 \mathrm{~m}$, e comprimentos de 4,0 a centenas de metros. As geometrias associadas a depósitos menos contínuos (menores que 10,0 m) são tabulares. Porém, as associadas a continuidades laterais na escala de dezenas de metros apresentam-se lenticulares. Esta fácies foi interpretada como desaceleração do fluxo.

A fácies Afc caracteriza-se por arenito fino a médio com grânulos esparsos, dispostos em cosets de cruzadas tabulares e/ou acanaladas, de espessuras menores que $0,20 \mathrm{~m}$ e comprimentos variados de dezenas a centenas de metros, apresentando em algumas localidades baixo ângulo de mergulho. Essa fácies foi interpretada como fluxo intermediário entre as fácies Afr e Amcc.

A fácies Amcu foi descrita como arenito médio-grosso com concentração variável de grânulos e seixos dispostos em séries únicas de cruzadas tabulares, de grande porte (maiores que $1,50 \mathrm{~m}$ ) com continuidade lateral de 10,0 $\mathrm{m}$ até 50,0 $\mathrm{m}$. Essa fácies foi interpretada como resultado de avalanches provenientes da alta quantidade de sedimento previamente colocado sobre as formas de leito.

A fácies Amcc compõe-se por arenito médio-grosso com concentração variável de grânulos e seixos, dispostos em cosets de cruzadas tabulares e/ou acanaladas com aproximadamente $0,40 \mathrm{~m}$, com continuidade lateral de dezenas a centenas de metros. Essa fácies foi interpretada como resultado de diferentes sobreposições de formas de leito, sobre altas taxas de vazão do rio. 
A fácies Acon foi descrita como arenito fino a médio-grosso com concentração variável de grânulos e seixos, portadores de estruturas convolucionadas com espessura de 0,2 $\mathrm{m}$ até 4,0 m. Essa fácies foi interpretada como resultado de abalos sísmicos e/ou escapes de fluidos.

Após a distinção das fácies e principais superfícies limitantes, as associações de fácies foram agrupadas em cinco diferentes elementos arquiteturais (figuras 38 a 45, obs: as legendas dos fotomosaicos encontram-se na página posterior ao croqui TUC41.4). 
Tabela 3 - Fácies descritas na Formação São Sebastião nos afloramentos TUC05 e TUC41

\begin{tabular}{|c|c|c|c|}
\hline Código de fácies & Fácies & Estruturas sedimentares & Interpretação \\
\hline Afp & $\begin{array}{l}\text { Pelito a arenito médio, apresenta ou não } \\
\text { grânulos esparsos }\end{array}$ & Laminação plano paralela & $\begin{array}{l}\text { processos de fluxo de alta velocidade em regiões com lâmina } \\
\text { d'água pouco espessa ou, no caso dos pelitos, fluxo muito } \\
\text { baixo e deposição por decantação }\end{array}$ \\
\hline Afr & $\begin{array}{l}\text { Arenito muito fino a médio, apresenta ou } \\
\text { não grânulos }\end{array}$ & Ripples & desaceleração do fluxo no rio \\
\hline Afc & $\begin{array}{l}\text { Arenito fino a médio com grânulos } \\
\text { esparsos }\end{array}$ & $\begin{array}{l}\text { Cosets de cruzadas tabulares e/ou } \\
\text { acanaladas menores que } 0,20 \mathrm{~m} \text {, } \\
\text { localmente apresentam baixo ângulo } \\
\text { de mergulho }\end{array}$ & $\begin{array}{l}\text { processos de fluxo com velocidade intermediária entre } \\
\text { aquelas geradoras das fácies Afr e Amcc. }\end{array}$ \\
\hline Amcu & $\begin{array}{l}\text { Arenito médio-grosso com concentração } \\
\text { variável de grânulos e seixos na base do } \\
\text { foreset e no foreset }\end{array}$ & $\begin{array}{l}\text { Séries únicas de cruzadas tabulares, } \\
\text { de grande porte (maiores que } 1,5 \mathrm{~m} \text { ) }\end{array}$ & $\begin{array}{l}\text { processos de avalanches provenientes da alta quantidade de } \\
\text { sedimento previamente colocado sobre as formas de leito }\end{array}$ \\
\hline Amcc & $\begin{array}{l}\text { Arenito médio-grosso com concentração } \\
\text { variável de grânulos e seixos na base do } \\
\text { foreset e no foreset }\end{array}$ & $\begin{array}{l}\text { Cosets de cruzadas tabulares e/ou } \\
\text { acanaladas com espessura } \\
\text { aproximadamente } 0,40 \mathrm{~m}\end{array}$ & $\begin{array}{l}\text { resultado de diferentes sobreposições de formas de leito, } \\
\text { sobre altas taxas de vazão do rio }\end{array}$ \\
\hline Acon & $\begin{array}{l}\text { Arenito fino a médio-grosso com } \\
\text { concentração variável de grânulos e } \\
\text { seixos }\end{array}$ & Estruturas convolucionadas & resultado de abalos sísmicos e/ou escapes de fluidos \\
\hline
\end{tabular}




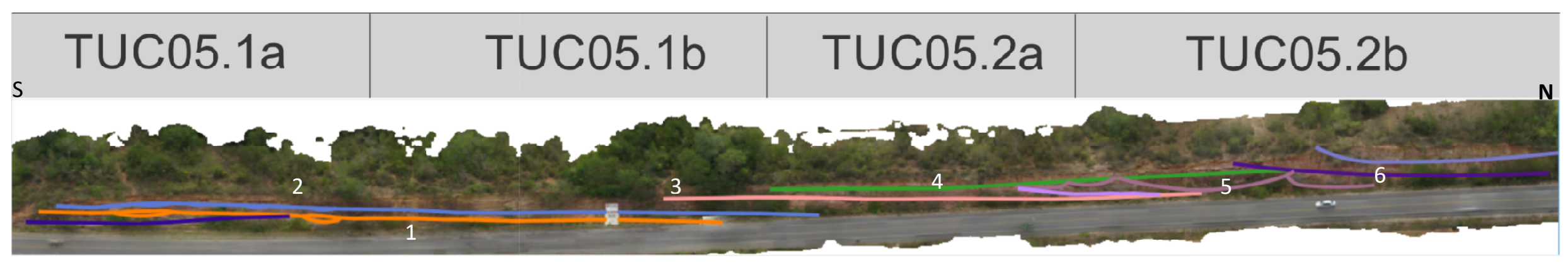

Figura 38 - Legenda após o mosaico TUC41.4

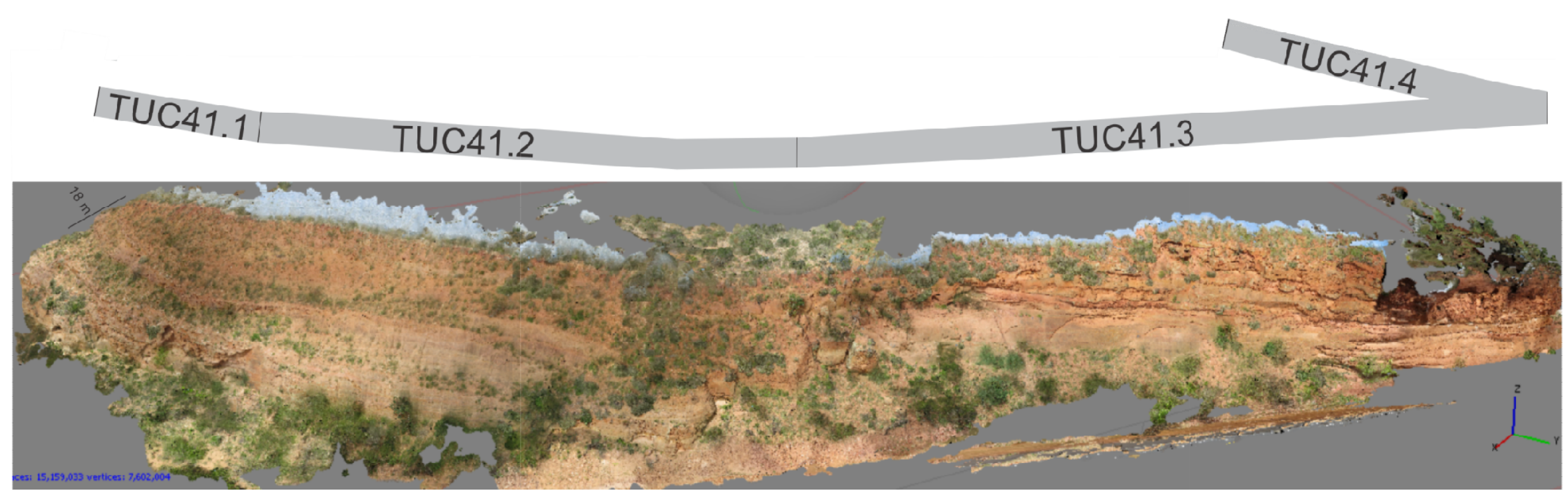

Figura 39 - Legenda após o mosaico TUC41.4 


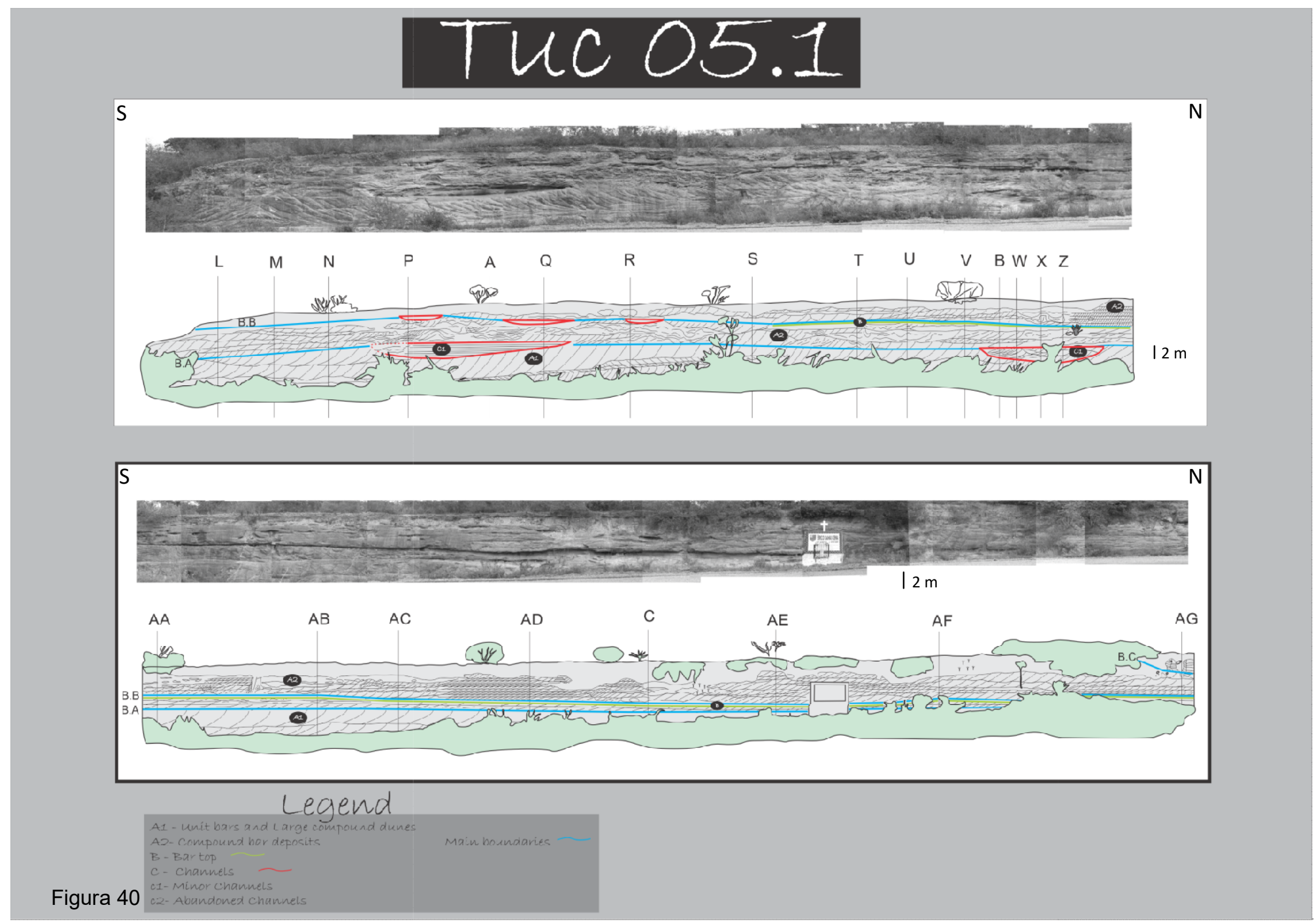




\section{Tuc 05.2}
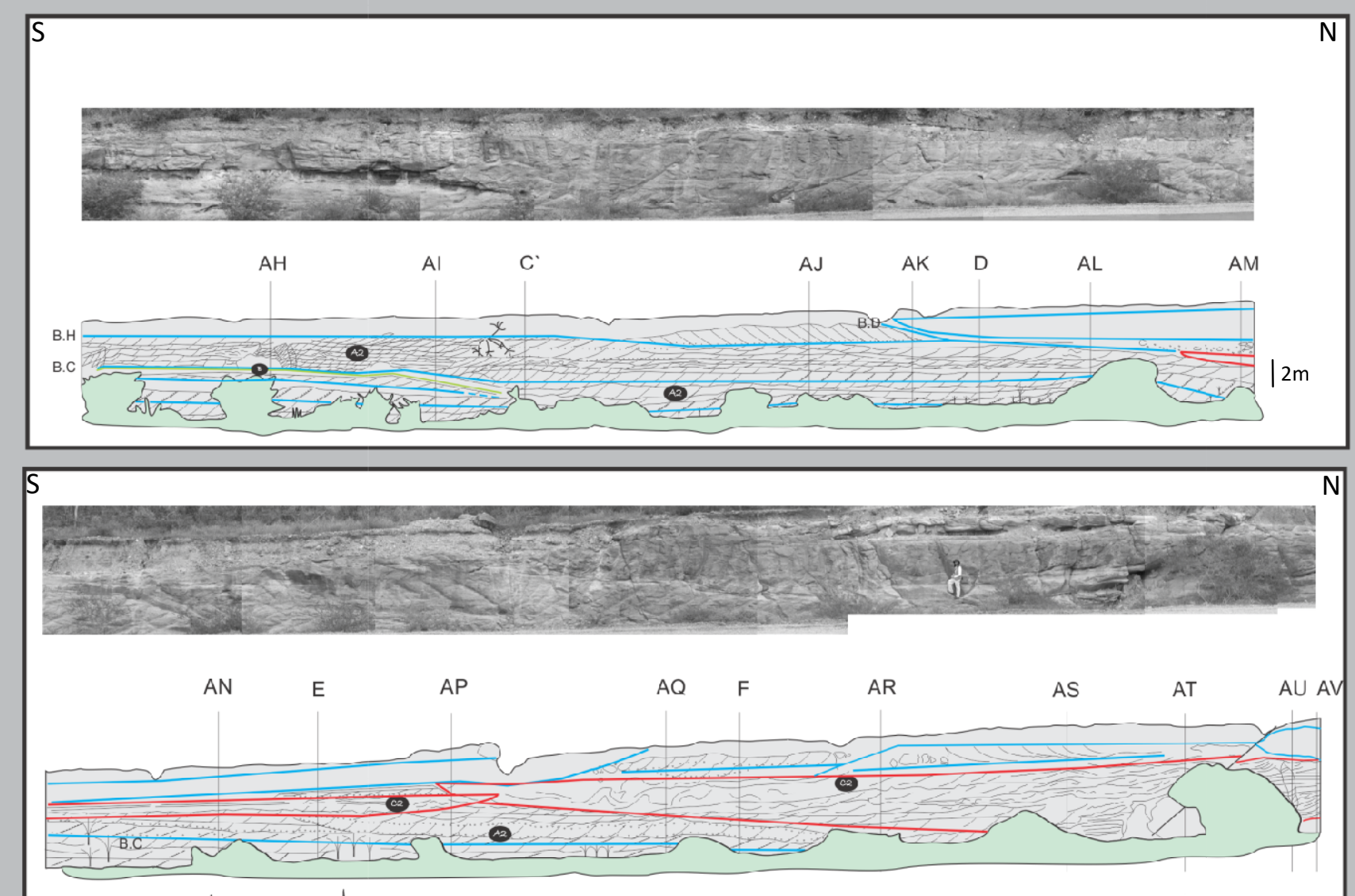

A1- unit bars ana cogehd

Figura 41

11- unit bars and Large compound dunis
A2- compound bar deposits

- Chanuels - 


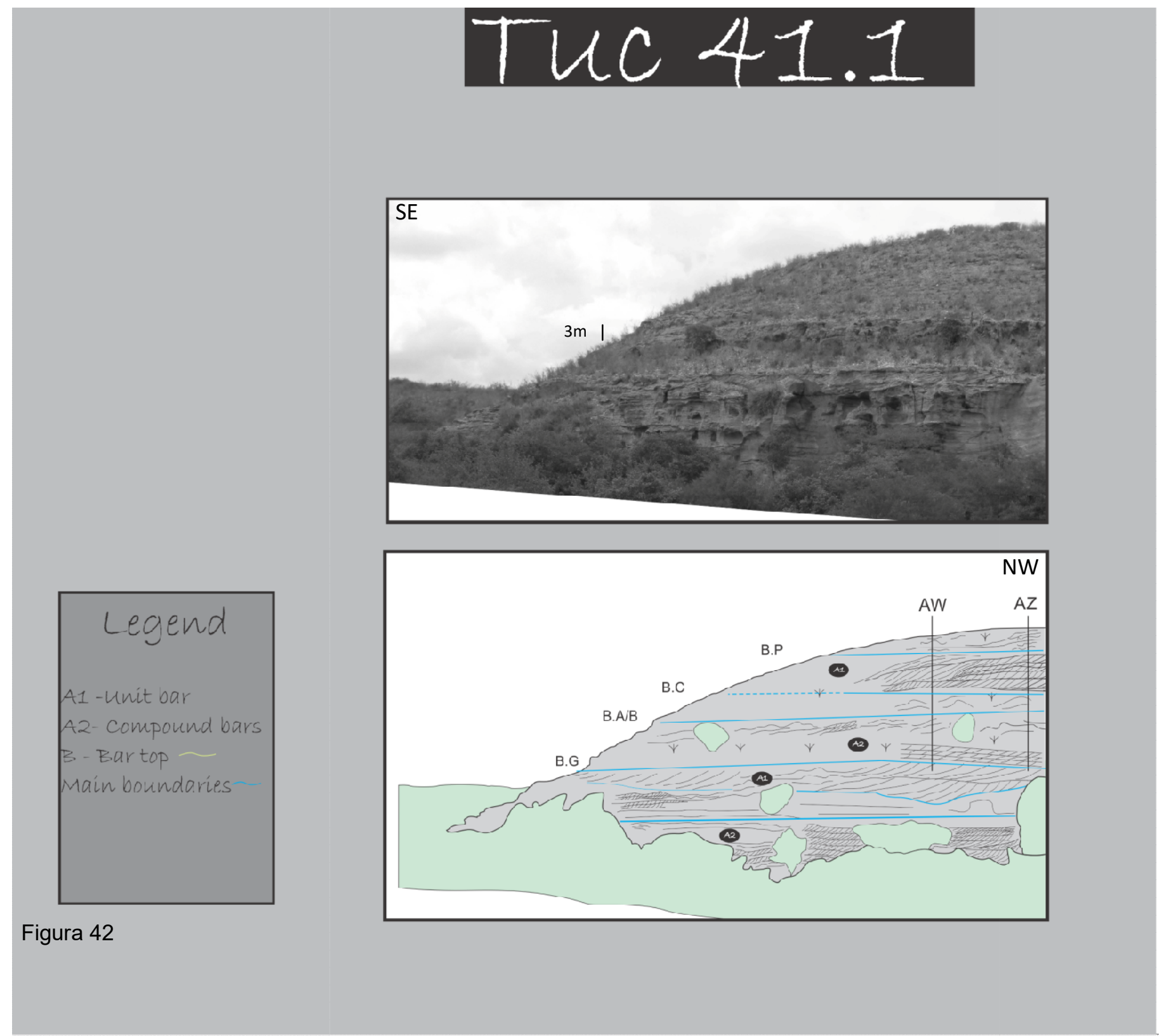




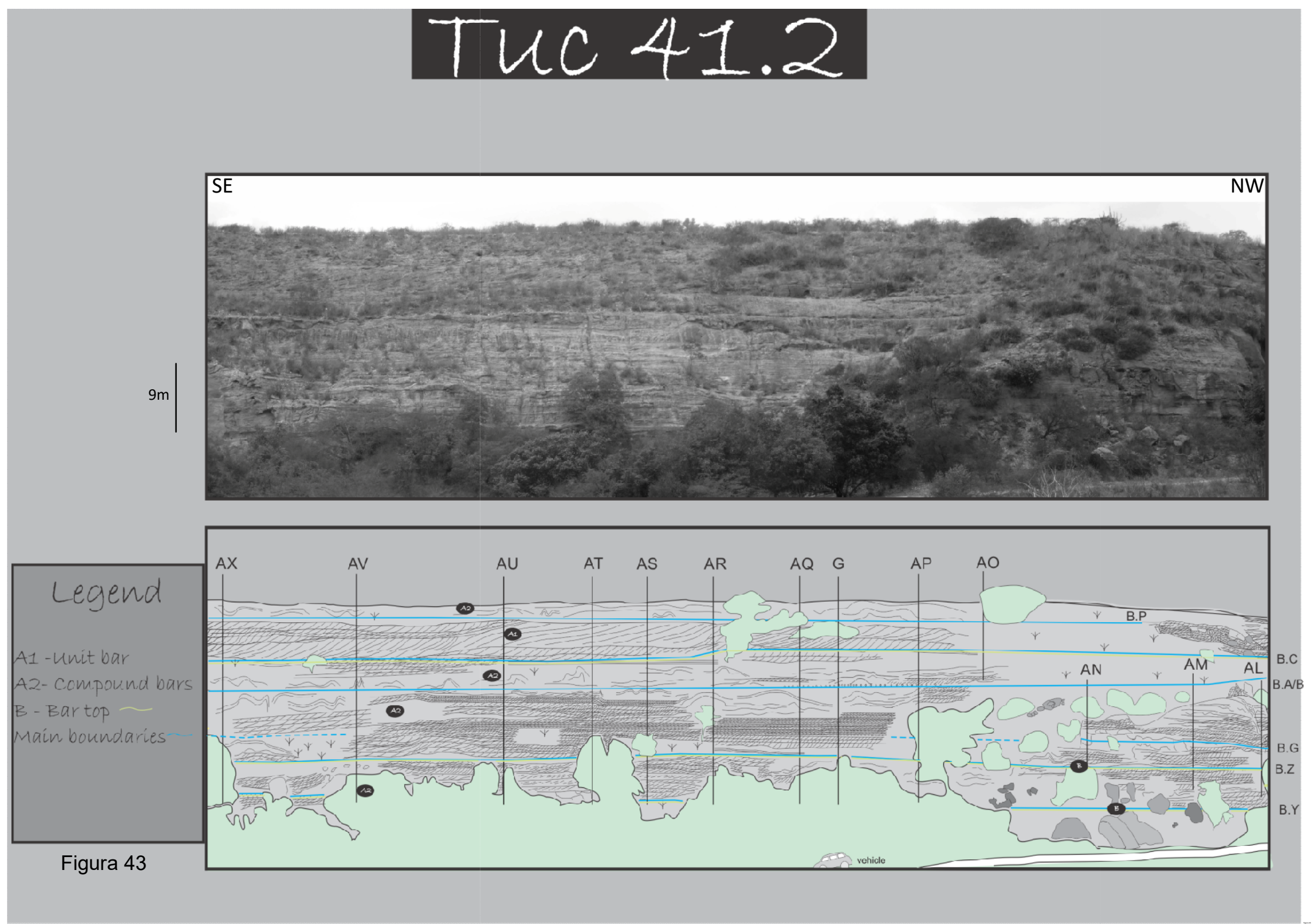




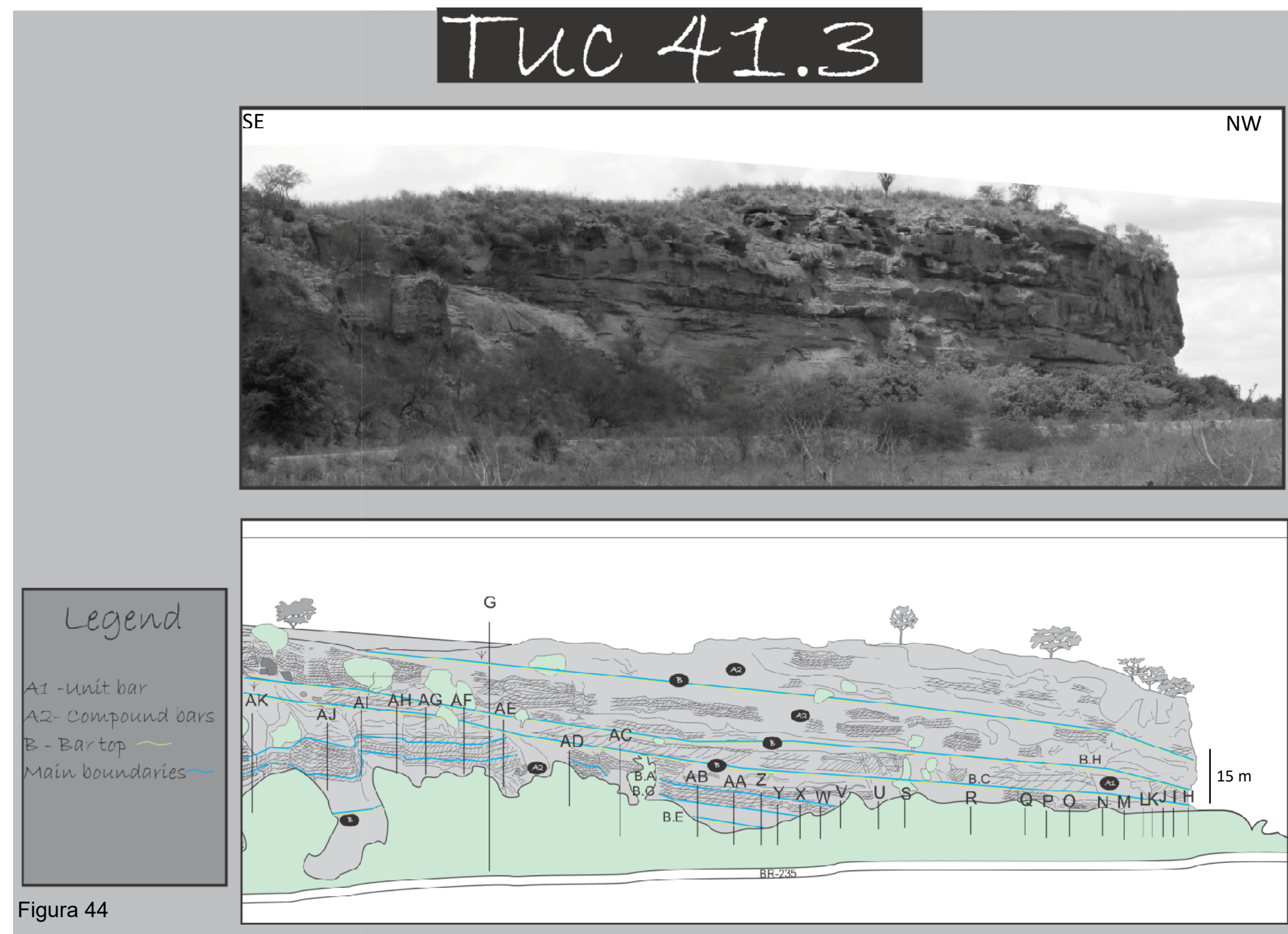



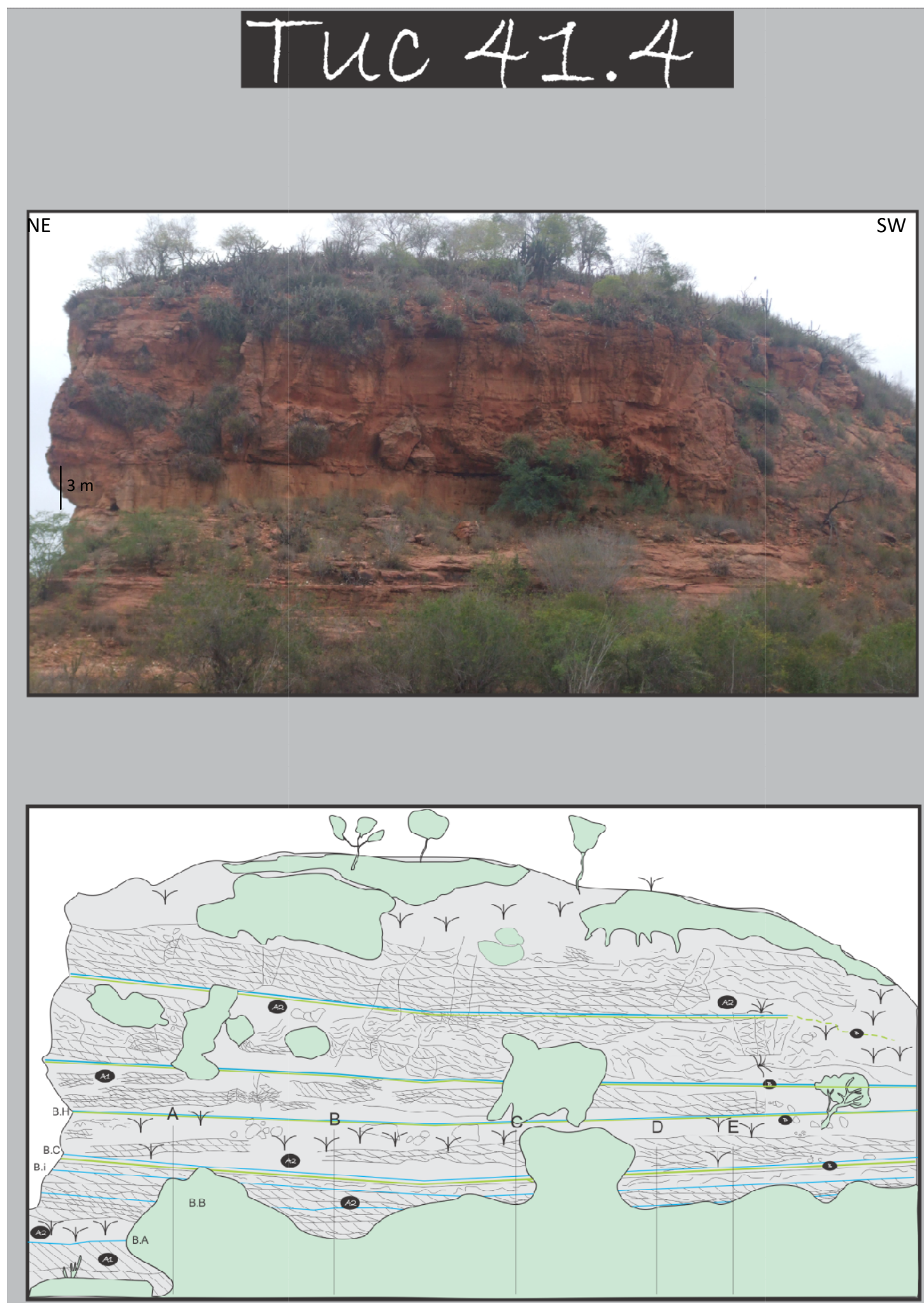

Figura 45

Legend

A1-unitzar B-Bartop

A2-Comsound bar Mainboundaries 
Figura 38- Croqui total e posicionamento dos croquis detalhados do afloramento TUC05. Superfície 1 (ou A) erosiva de terceira ordem, colocando barra composta sobre barra unitária. Essa superfície também é resultado da reativação do sistema trativo, após período inativo, representado por canais abandonados de pequeno porte (sobre barras as unitárias). Superfície 2 (ou B) erosiva sobre topos de barras (de barras compostas) delimitando base de nova barra composta. Supefície 3 (ou C) erosiva, delimitando a base de nova barra composta, preservando apenas localmente topos de barra. Superfície 4 (ou H) de reativação de barra composta. Superfície 5 delimitadora de canal abandonado. Superfície 6 de escavação, delimitadora de canal abandonado de maior porte que o delimitado pela superfície 5

Figura 39 - Croqui total e posicionamento dos croquis detalhados do afloramento TUC41

Figura 40 - Fotomosaico TUC05.1, contendo as principais superfícies sedimentares (descritas na figura 38), elementos arquiteturais (barras, topos de barra, canais menores) e locais das seções de campo ( $L, M, N, P, A, Q, R, S, T, U, V, B, W, X, Z, A A, A B, A C, A D, C, A E, A F$ e AG), as quais constam no apêndice A. Superfícies na cor vermelho delimitam canais abandonados de pequeno porte (obs: as estratificações cruzadas da figura possuem mergulho contrário no plano de visão comparada às feições do afloramento, geradas pela escavadeira, durante a construção da estrada)

Figura 41 - Fotomosaico TUC05.2 do afloramento TUC05, contendo as principais superfícies sedimentares (descritas na figura 38), elementos arquiteturais (legenda na figura) e locais das seções (AH, Al, C', AJ, AK, D, AL, AM, AN, E, AP, AQ, F, AR, AS, AT, AU, AV) de campo, as quais constam no apêndice A. Superfícies limitantes dos canais abandonados são representados pela cor vermelha

Figura 42 - Fotomosaico TUC41.1, contendo as principais superfícies sedimentares, elementos arquiteturais (legenda na figura) e locais das seções (AW e AZ) de campo, as quais constam no apêndice B. Superfície P (possívelmente superfície H do mosaico TUC41.3 e TUC41.4) erosiva, localizada no topo da barra unitária. Superfície $C$ erosiva, na base de barra unitária, a qual está sobre barra composta. Superfície A/B de superimposição de barras compostas. Superfície $\mathrm{G}$ limitante do topo de barra unitária. Essa desaparece lateralmente devido à superimposição de formas de leito que ocorrem internamente, na barra composta

Figura 43 - Fotomosaico TUC41.2, contendo as principais superfícies sedimentares, elementos arquiteturais (legenda na figura) e locais das seções (AL, AM, $\mathrm{NA}, \mathrm{AO}, \mathrm{AP}, \mathrm{G}, \mathrm{AQ}, \mathrm{AR}, \mathrm{AS}, \mathrm{AT}, \mathrm{AU}, \mathrm{AV}$ e AX) de campo, as quais constam no apêndice B. Superfície $\mathrm{P}$ (possívelmente superfície $\mathrm{H}$ do mosaico TUC41.3 e TUC41.4, localizada no topo da barra unitária. Superfície $C$ erosiva na base de barra unitária, a qual está sobre o topo de barra (de barra composta) 
preservado localmente. Superfície A/B de superimposição de barras compostas. Superfície G, pouco contínua, localiza-se entre elementos arquiteturais de barras compostas. A continuidade dessa superfície é resultado das sobreposições de formas de leito, gerando cosets da fácies Amcc. Superfície Z representa a reativação do fluxo trativo de barras compostas sobre topo de barra, localmente erosiva

Figura 44 - Fotomosaico TUC41.3, contendo as principais superfícies sedimentares (na cor azul), elementos arquiteturais (legenda na figura) e locais das seções $(H, I, J, K, L, M, N, O, P, Q, R, S, U, V, W, X, Y, Z, A A, A B, A C, A D, A E, G, A F, A G, A H, A I, A J$ e AK ) de campo, as quais constam no apêndice B. Superfícies de retomada/aumento do fluxo trativo, sobre topos de barra, de barra unitária (superfície $\mathrm{H}$ ), e de barra composta (superfície C). Superfície A erosiva. Superfície G, erosiva, ocorre associada com lag de seixos. Superfície E (possívelmente superfície Z), representa a reativação do fluxo trativo de barras compostas sobre topo de barra, localmente erosiva

Figura 45 - Fotomosaico TUC41.4, contendo as principais superfícies sedimentares (na cor azul), elementos arquiteturais e locais das seções (A, B, C, D e E) de campo, as quais constam no apêndice B. Superfícies de retomada/aumento do fluxo trativo, sobre topos de barra, de barra unitária (superfície H), e de barra composta (superfície C).. Superfície i erosiva, de segunda ordem (menor hierarquia que as demais), entre cosets de arenito médio-grosso (fácies Amcc) (base) e convolutas de arenito médio a fino (fácies Acon) (topo).Superfície B erosiva entre barras compostas. Superfície A erosiva entre barras unitárias (base) e barras compostas (topo) 


\subsubsection{Associações de fácies e elementos arquiteturais}

Com o levantamento das fácies sedimentares e suas interrelações foram interpretados cinco elementos arquiteturais: barras unitárias, barras compostas, topos de barra, preenchimento de canais pequenos e canais abandonados.

A descrição dos elementos arquiteturais baseou-se inicialmente no trabalho sobre arquitetura deposicional de Figueiredo (2013) para a Formação São Sebastião. Neste trabalho foram realizadas reinterpretações de algumas fácies, associações de fácies e elementos arquiteturais, com os estudos realizados em maior detalhe nos afloramentos TUC05 e TUC41.

\section{Barras}

Na Formação São Sebastião, as barras unitárias e compostas são os elementos arquiteturais mais heterogêneos, tanto na geometria do elemento, como na distribuição de fácies. Estes elementos arquiteturais comumente apresentam coloração avermelhada a amarelada e composição majoritariamente de quartzo arenitos, como também analisado por Figueiredo (2013), através de contagem de seixos, com proveniência majoritária de quartzo de veio.

\section{Barras unitárias}

Os elementos arquiteturais de barras unitárias são tipicamente formados por geometrias lenticulares sigmoidais, mas localmente apresentam tendência a geometria tabular. A geometria desses corpos é complexa devido à grande quantidade de superfícies limitantes internas, representadas por superfícies de primeira e segunda ordem e entre elementos arquiteturais, mediadas por superfícies de terceira ordem. Já a continuidade lateral desses corpos 
apresenta-se maior que 400 m de extensão, com espessura variando entre 2 a 12 metros.

A associação de fácies (AF) encontrada nesse elemento arquitetural é composta pelas fácies Amcu, Amcc, Acon e Afc. Esta AF possui na base a fácies Amcu, de arenitos médios a grossos com grânulos e muitos seixos na base dos foresets, com estratificações cruzadas em grande maioria tabulares, mas acanaladas também são encontradas. Essas fácies diminuem a granulometria gradualmente para jusante. Os estratos apresentam-se em séries únicas, dispostos em sets com espessuras próximas de $1,5 \mathrm{~m}$ ou maiores, com cruzadas mergulhando normalmente em alto ângulo e ocasionalmente em médio ângulo, mediadas por superfícies de primeira ordem (figura 48). Entre esses estratos apresentam-se superfícies de reativação horizontais a subhorizontais ou também de alto ângulo. A fácies Amcu comumente passa lateralmente para estruturas convolucionadas (fácies Acon), geralmente mal selecionada.

Na base dessa AF também são encontradas, com menos freqüência, as fácies Amcc, de arenitos médios-grossos dispostos em cosets de estratificações cruzadas tabulares ou acanaladas com grânulos e seixos geralmente concentrados nos foresets e na base deste (figura 49A). Quando encontrada na base do elemento arquitetural, essa fácies apresenta-se pouco espessa, não maior que $0,5 \mathrm{~m}$ e continuidade lateral de $10,0 \mathrm{~m}$ a 20,0 m. A Amcc apresenta duas formas de interrelação com a fácies Amcu; (i) passa verticalmente, mediada por superfícies erosivas de alto ou baixo ângulo, para as fácies Amcu com cruzadas de maior porte, ultrapassando 1,5 m; e (ii) migra lateralmente a partir da fácies Amcu, mediada por superfícies erosivas de alto ângulo. A fácies Amcc também migra lateralmente, com contatos transicionais (predominante) ou abruptos (subordinada), para fácies Acon. As transições laterais das fácies Amcu e Amcc para convolutas (fácies Acon) não possuem mudanças significativas de granulometria.

Sotopostos aos arenitos médios-grossos da fácies Amcu ou Amcc, basais dessa AF, encontram-se superfícies erosivas, de terceira ordem. Essas superfícies são irregulares, portadoras de baixo mergulho e concavidade 
praticamente incipiente, separando esse elemento arquitetural dos corpos de topos de barra ou mesmo barras compostas.

Sobrepostos às fácies basais dessa AF apresentam-se as fácies Afc, com espessuras de sets gradualmente mais finas, compostas por arenitos médios dispostos em cosets com estratificações cruzadas tabulares e/ou acanaladas de pequeno porte, podendo apresentar baixo ângulo de mergulho (Afc) (figura 49C).

Esta AF apresenta-se, por vezes, ausente da fácies Afc. Isso resulta em duas possíveis sucessões verticais colocando as fácies Amcu, Amcc ou Acon, por superfícies de terceira ordem, em contato com as AFs de outros elementos arquiteturais. A primeira sucessão possível é o contato gradacional para arenitos médios a finos, portadores de ripples (Afr) dos topos de barra. A segunda é o contato com AFs pertencentes às barras compostas, por superfícies erosivas de baixo ângulo. 


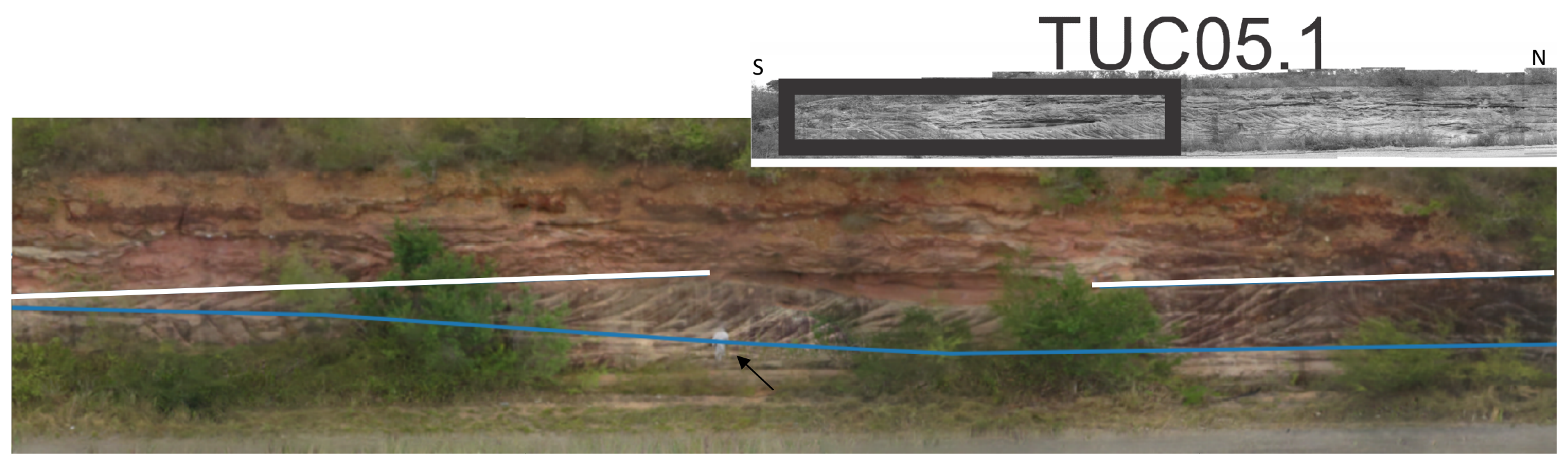

Figura 46 - Geometria lenticular e superfícies de barra unitária localizada no início do afloramento TUC05, de sul para norte. Superfície 1 (ou A) (cor branca) e superfície de menor hierarquia, de reativação de barra unitária (cor azul) (quadrado preto representa o mesmo local em menor detalhe) (seta preta indica escala)

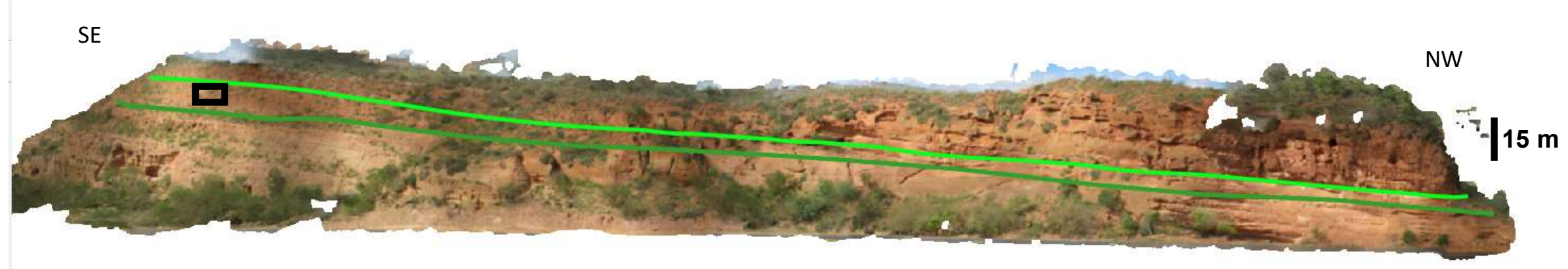


Figura 47- Geometria e principais superfícies limitantes (ambas erosivas) de barra unitária, no afloramento TUC41. Quadrado preto indica localização da figura 48
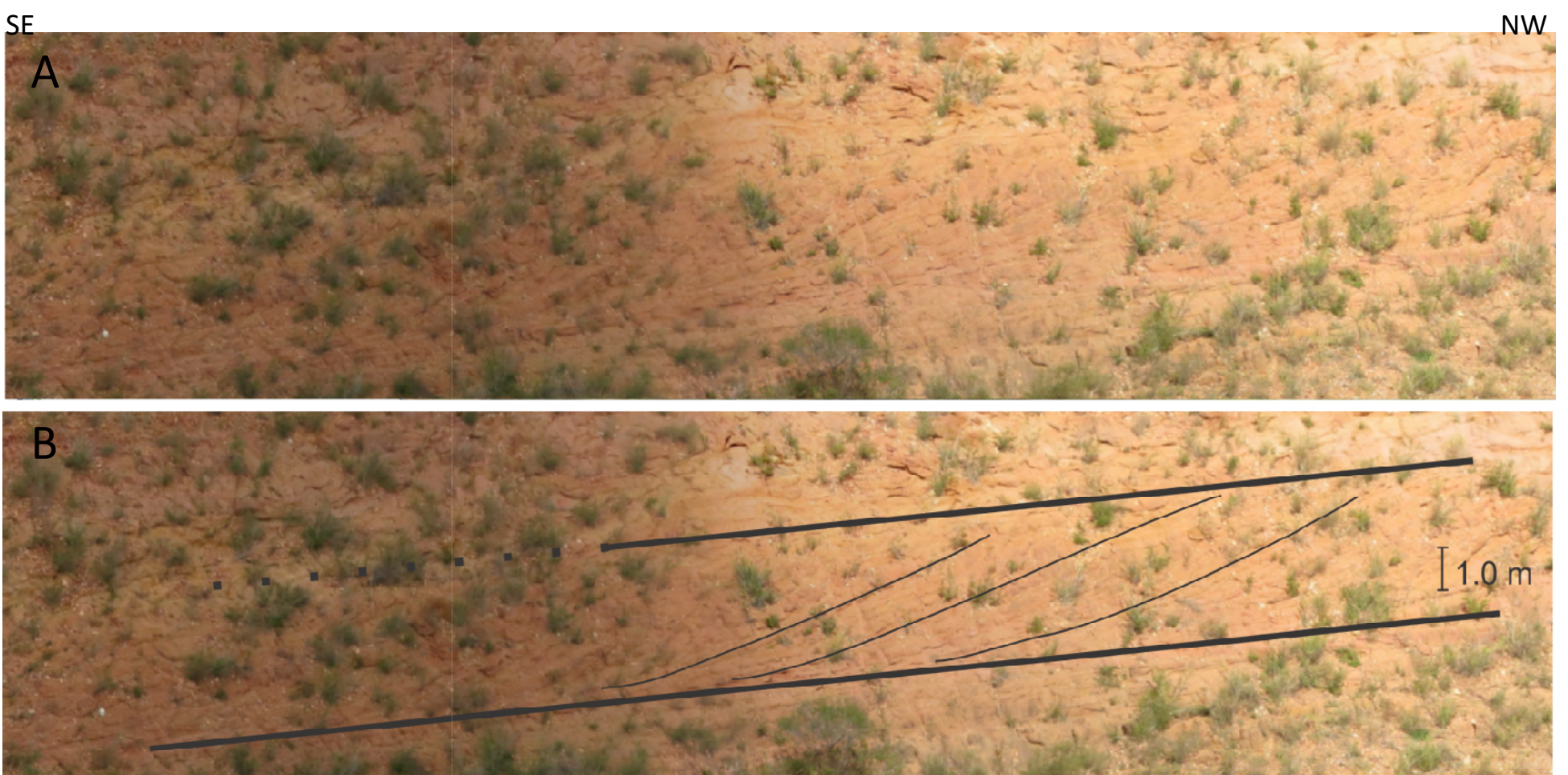

Figura 48 - A) Fotografia retirada por VANT e (B) croqui da fácies Amcu, no afloramento TUC41, mostrando set com geometria tabular de arenito médiogrosso com estratificação cruzada tangencial na base de grande porte. Essa fácies é muito comum nos EA de barra unitária 


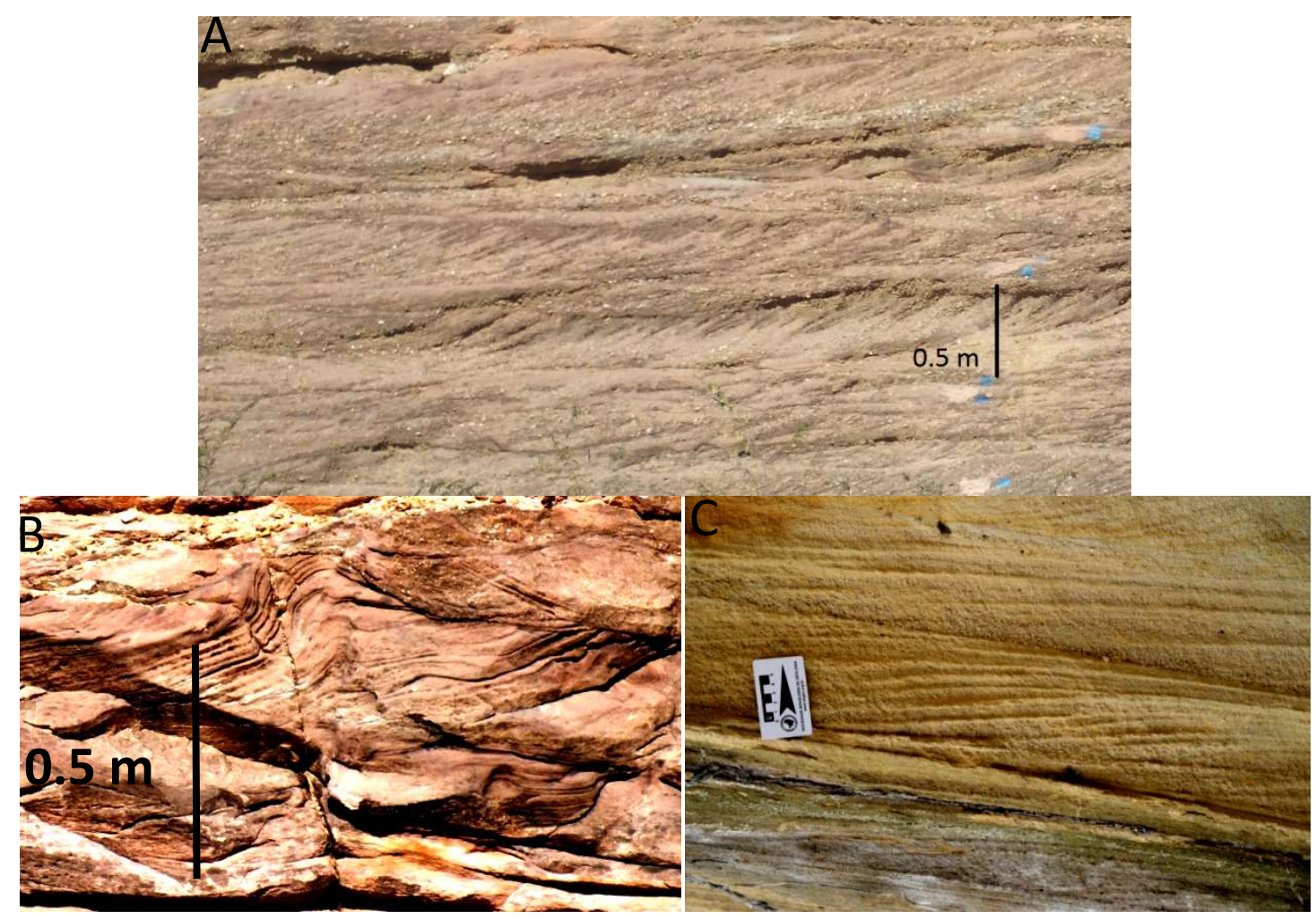

Figura 49 - A) Arenito médio-grosso com estratificações cruzadas, dispostas em cosets com grânulos e seixos nos foresets e na base dos mesmos (fácies Amcc), localizado no afloramento TUC05

B) Arenito médio com estrutura convoluta (fácies Acon), localizado no afloramento TUC05 topo da sucessão de fácies de barras compostas no afloramento TUC05

C) Arenito médio com estrutura cruzada em pequenos cosets com ângulo de mergulho menor que a média analisada (fácies Afc), localizado no afloramento TUC41

\section{Interpretação}

As associações de fácies pertencentes às barras unitárias foram interpretadas como mesoformas que resultam da migração periódica dos sedimentos transportados pelo rio. Isso é resultado do possível aumento no fluxo e certa continuidade no transporte, carregando sedimento sobre coluna d' água próxima ao tamanho das formas de leito. A principal feição dessa arquitetura é a migração para séries únicas grandes, com grande concentração de seixos na base dos foresets, interpretadas como frentes de avalanche. Essas são ocasionadas pela grande espessura da forma de leito que devido 
sua altura, desestabiliza-se durante o fluxo. Além disso, a pequena manifestação de fácies finas, com cruzadas de pequeno porte (Afc), é resultado da menor variação de descarga durante a deposição dessa arquitetura comparada às barras compostas.

As estruturas convolutas foram interpretadas como provenientes das liquefações, por escapes de fluidos, deformando a camada superior inconsolidada, durante a acreção, os quais podem ter o gatilho relacionado ao tectonismo. Outra gênese possível para essas estruturas é a perturbação das estratificações sem tectonismo nenhum associado, apenas durante as pequenas variações de descarga apresentadas pelo rio. Segundo Dzulynski \& Smith (1963) e Owen (1987), as estruturas convolutas podem estar associadas: à cargas de sedimento depositadas abruptamente sobre 0 estrato inconsolidado, tectonismo ou movimento de água subterrânea.

Figueiredo (2013) interpretou as mesmas estruturas como barras unitárias, devido principalmente à grande espessura da estratificação cruzada, e as reativações culminando em fácies de avalanche, com migrações para frentes únicas. O presente trabalho concorda em parte com esta interpretação, tendo-se reinterpretado algumas barras unitárias propostas por Figueiredo (2013) como canais abandonados, devido à espessas sucessões de arenitos finos a muito finos com marcas onduladas. 

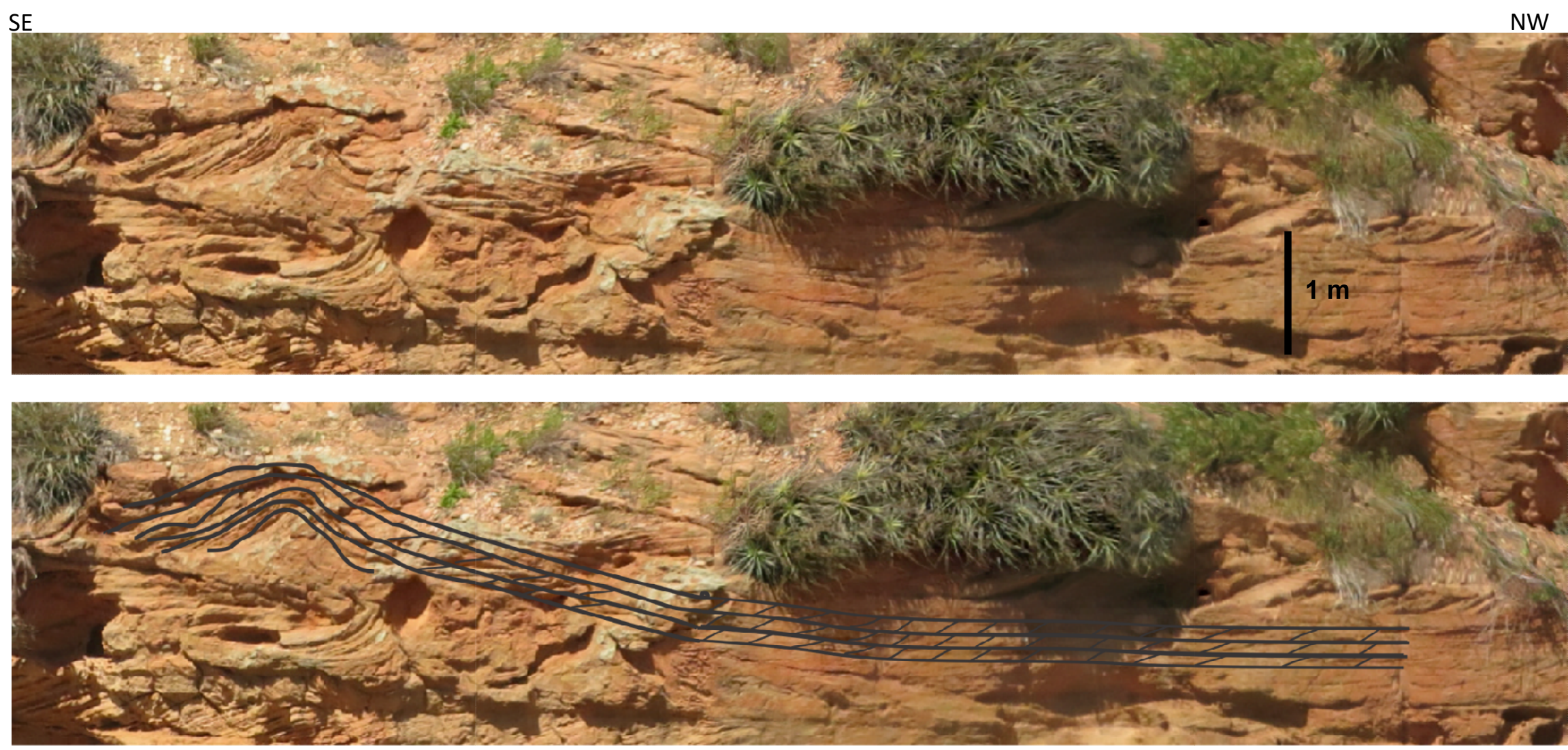

Figura 50 - Estrutura cruzada composta em cosets (Amcc) variando lateralmente para fácies convoluta (Acon). Essa figura apresenta-se a sudoeste dos afloramentos estudados, não representado nos croquis anteriores. 


\section{Barras compostas}

As barras compostas possuem geometria localmente tabular, na escala de 5 a 10 metros de comprimento. Porém, quando analisadas em corpos mais contínuos, a espessura afina-se localmente cerca de um a dois metros e posteriormente voltam a assumir forma tabular, caracterizando geometrias muito irregulares, tendendo a lenticulares. A geometria dessas formas é mais complexa que as barras unitárias, devido à maior quantidade de superfícies erosivas de segunda ordem internas e truncamentos. A continuidade lateral desses corpos é da ordem de centenas de metros, ultrapassando até $500 \mathrm{~m}$ de exposição, enquanto que a espessura varia de $3,0 \mathrm{~m}$ (quando truncadas por superfícies erosivas sobrepostas), até $16 \mathrm{~m}$ (figura 51).

A AF encontrada nesse elemento arquitetural é composta pelas fácies Afc, Amcc e Acon, com granulometria geralmente mais fina que nas barras unitárias. Esta AF possui na base arenitos médios-grossos, com estratificações cruzadas tabulares ou acanaladas dispostos em cosets, com espessura média próxima a 0,4 m (Amcc) (figura 49A) e alta concentração de grânulos e seixos nos foresets (menor concentração que nas barras unitárias). Intraclastos e lags de seixos podem ser encontrados no bottomset. Os estratos dessas fácies, limitados por superfícies de segunda ordem, são levemente inclinados em relação à superfície basal de terceira ordem (limitadora do elemento arquitetural). Ao longo dessa fácies podem ser observadas superfícies erosivas internas, geralmente de baixo ângulo, de menor hierarquia, entre cosets. Também são comuns trucamentos, superfícies de reativação e, principalmente de superimposição de formas de leito, essa última muito frequente nesse elemento. Por vezes, a fácies Amcc transiciona lateralmente para arenitos grossos com grânulos e seixos de estrutura convoluta (fácies Acon) (figura 49B). Essa passagem pode ocorrer abruptamente, mas também gradualmente, diminuindo gradualmente a espessura entre bottom e o topset e aumentanto 0 ângulo de mergulho do estrato até perder totalmente a estrutura da cruzada e convolucionar (figura 50). 


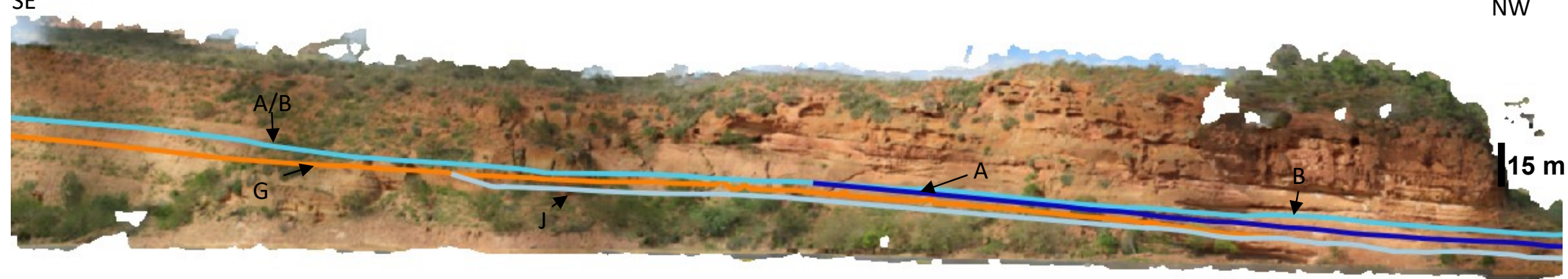

Figura 51- Geometria e principais superfícies limitantes de barra composta do afloramento TUC41.Superfície J é erosiva e ocorre associada com intraclastos, junta-se posteriormente à superfície $\mathrm{G}$ (as descrições das demais superfícies encontram-se nas legenda das figuras 42 a 45)

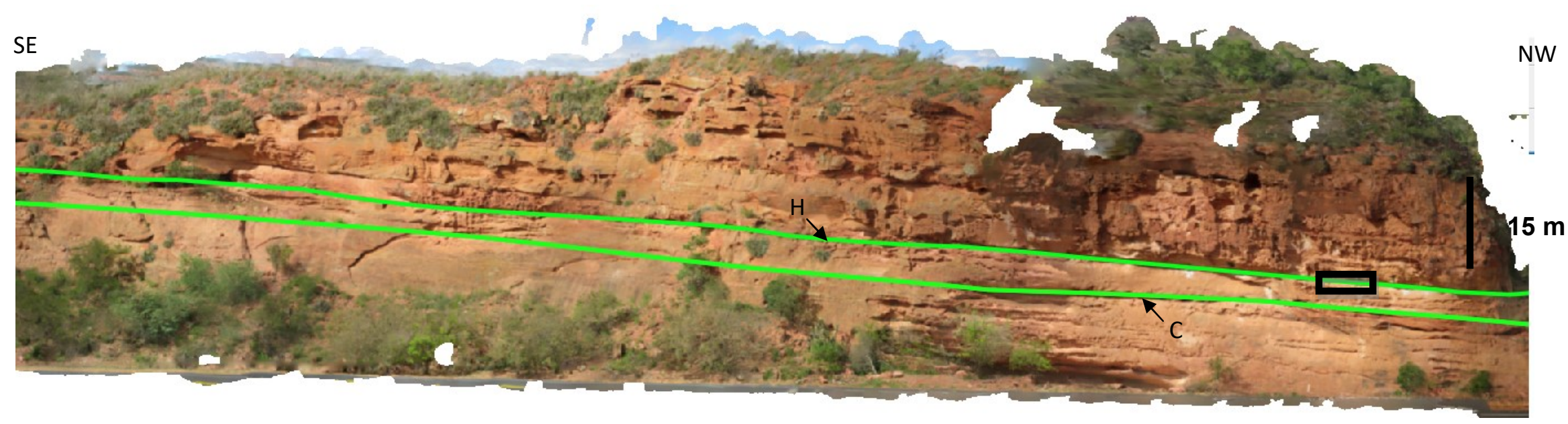

Figura 52- - Continuidade lateral maior que $150 \mathrm{~m}$, nos dois topos de barra destacados no afloramento TUC 41, próximos às superfícies C (basal) e H (as descrições das superfícies encontram-se nas legenda das figuras 42 a 45). Destaque para localização da figura 53 (quadrado preto) 
Sotoposto à fácies basal (Amcc ou localmente Acon) dessa AF encontram-se superfícies erosivas, irregulares, de terceira ordem, que comumente erodem os topos de barra ou barras unitárias, mergulhando suavemente, com ângulo dificilmente maior que $5^{\circ}$. Também foram encontradas superfícies de reativações internas nas barras compostas.

Continuando a AF desse elemento, a fácies Amcc basal (por vezes Acon), verticalmente tende a diminuir tanto a granulometria como a espessura dos cosets para o topo. Na maioria dos locais, essas diminuições são graduais, até que a fácies Amcc transicione para a fácies Afc (figura 49C) composta por arenitos médios (subordinados) a finos (predominantes), com espessura de cosets próximos a $0,20 \mathrm{~m}$, portadores de cruzadas, tabulares ou acanaladas, de menor ângulo que as fácies Amcc. Assim como nas fácies Amcc, as fácies Afc também podem gradar lateralmente (bruscamente ou gradualmente) para estruturas convolutas (Acon). Porém, anteriormente, entre ou posteriormente a gradação granodecrescente das fácies Amcc para Afc, a fácies Acon podem estar associadas, bruscamente, mediadas por superfícies de segunda ordem. A granulometria da fácies Acon comporta-se conforme a fácies sotoposta a ela, mantendo a tendência de afinamento para o topo. Nesse contexto, grandes extensões da fácies Acon podem ser observadas.

Sobresposta às fácies de topo da AF das barras compostas (Afc ou Acon média a fina) podem ser encontrados: topos de barra, por contatos gradacionais (afinando para o topo), superfícies de reativações de barras compostas, ou mesmo barras unitárias, por superfícies erosivas de terceira ordem.

\section{Interpretação}

As associações de fácies de barras compostas foram interpretadas como macroformas, com wavelenght no mínimo duas vezes maior que as barras unitárias, como depósitos ativos não periódicos. O processo de agradação vertical, erosões e, principalmente, sobreposições de formas de leito 
(característico desse elemento arquitetural), resultam em complexas e diferentes geometrias de cosets de cruzadas tabulares ou acanaladas, mediadas por superfícies de diferentes hierarquias. A diminuição da espessura e do ângulo de mergulho dos estratos cruzados do topo em relação às da base, observado com certa continuidade, foi atrelada à diminuição do fluxo e alta coluna d'àgua durante o processo de agradação das formas de leito. As estratificações cruzadas lateralmente alternando para convolutas foram interpretadas, do mesmo modo que nas barras unitárias, como resultado de liquefações sob sedimentos não consolidados, perturbações durante 0 transporte no rio ou pela influência de sismos.

As barras compostas foram interpretadas segundo Bridge e Lunt (2006) como depósitos não periódicos, resultado de complexas interações entre diferentes formas de leito. Já o processo de granodecrescência para o topo também foi observado por (Li et al., 2005) nas barras compostas nos depósitos fluviais na bacia de Datong.

Segundo Hjellback (1997) os processos de geração das barras compostas evoluem da sobreposição de diversas dunas e barras, limitados sempre por superfícies basais de terceira ou quarta ordem de Miall (1992) que são de mesma hierarquia das superfícies limitantes das barras unitárias.

Figueiredo (2013) também interpretou os mesmos depósitos como barras compostas. Adicionalmente, comparou os cosets e suas paleocorrentes às superfícies das barras compostas, e o resultado tende a acreções à jusante. Esse fato fez Figueiredo (2013) relacionar esses depósitos com braid bars, classificando-os como downstream accrecion compound bars.

\section{Topos de barra}

Os topos de barra apresentam coloração marrom avermelhada com tom levemente rosado, muitas vezes acompanhada por brilho micáceo. A seleção 
granulométrica desses depósitos comumente é melhor que os depósitos de barras e barras unitárias, mas podem apresentar grânulos esparsos.

A geometria dessa arquitetura apresenta-se tabular, por vezes lenticular, assemelha-se aos depósitos do tipo sheet, descritos por Miall (1996), com espessuras variando de $0,10 \mathrm{~m}$ a $1,5 \mathrm{~m}$. A continuidade lateral é a principal característica a ser analisada na geometria desse depósito. Essa pode apresentar-se contínua por centenas de metros, ultrapassando $200 \mathrm{~m}$, como no afloramento TUC41 (figura 52 e 53). Porém, corpos menos contínuos (4.0 m) e com extensão menor que $10 \mathrm{~m}$ também foram observados.

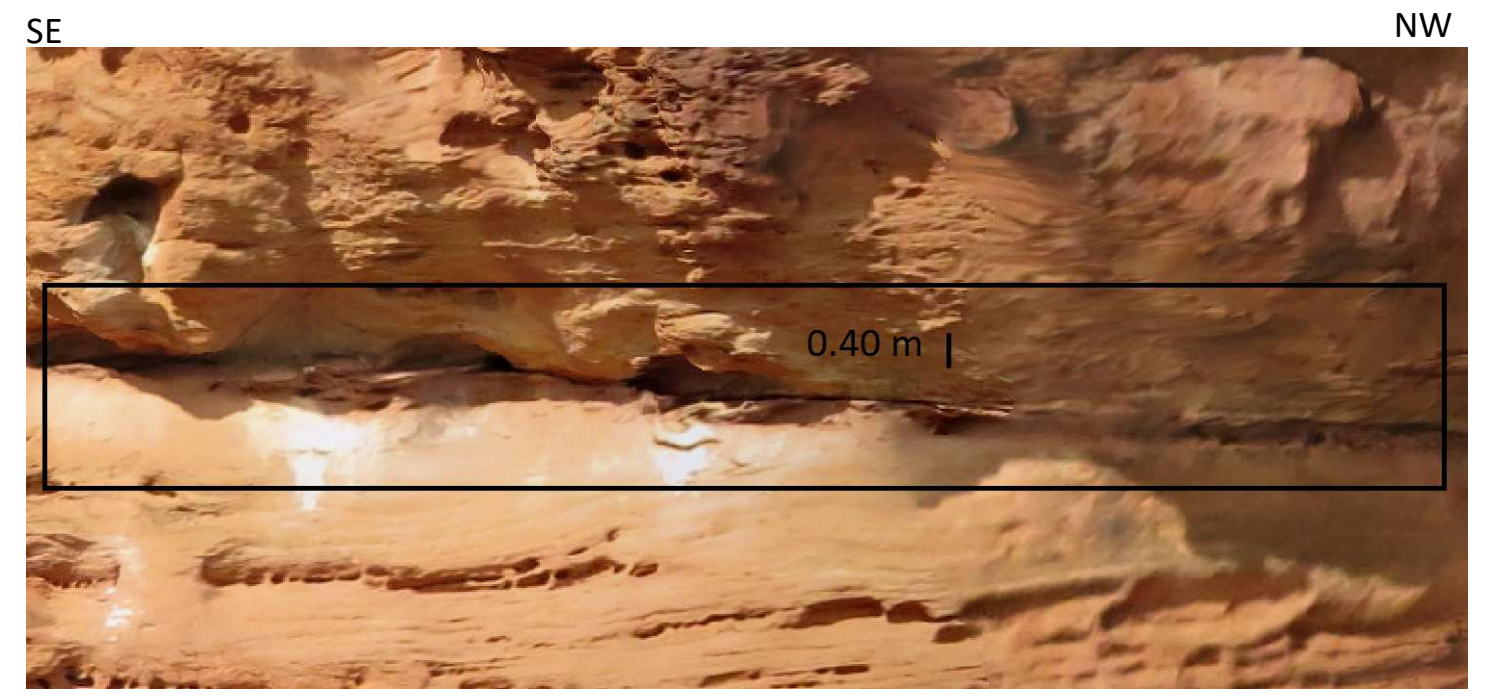

Figura 53 - Topo de barra em detalhe no afloramento TUC41, composto por arenito médio a fino, com espessura próxima de $0,20 \mathrm{~m}$ (essa figura está localizada em menor detalhe no quadrado preto da figura 52)

As fácies características desse elemento arquitetural são arenitos finos, subordinadamente arenitos médios, principalmente com estruturas climbing ripples (fácies Afr), de espessuras centimétricas (figura 54). Além dessas estruturas, camadas convolucionadas (fácies Acon) ou camadas de arenitos (figura 48 B) finos com laminações plano paralelas (fácies Afp) também podem compor subordinadamente os topos de barra.

Lateralmente os topos de barra podem apresentar contatos abruptos erosivos. Em contato com essas superfícies erosivas encontram-se fácies de 
barras compostas (Afc e Amcc), ou mesmo de fácies barras unitárias (Afc, Amcu ou Amcc).

Como já comentado, sotopostos aos topos de barras são encontrados depósitos de barras compostas ou unitárias, por contato gradacional. Esses depósitos (das barras compostas) são constituídos por arenitos médios-finos, com cosets de espessura decimétrica e ângulo de mergulho relativamente baixo (fácies Afc). Os topos de barra também ocorrem sobre depósitos de barras unitárias, por contato gradacional.

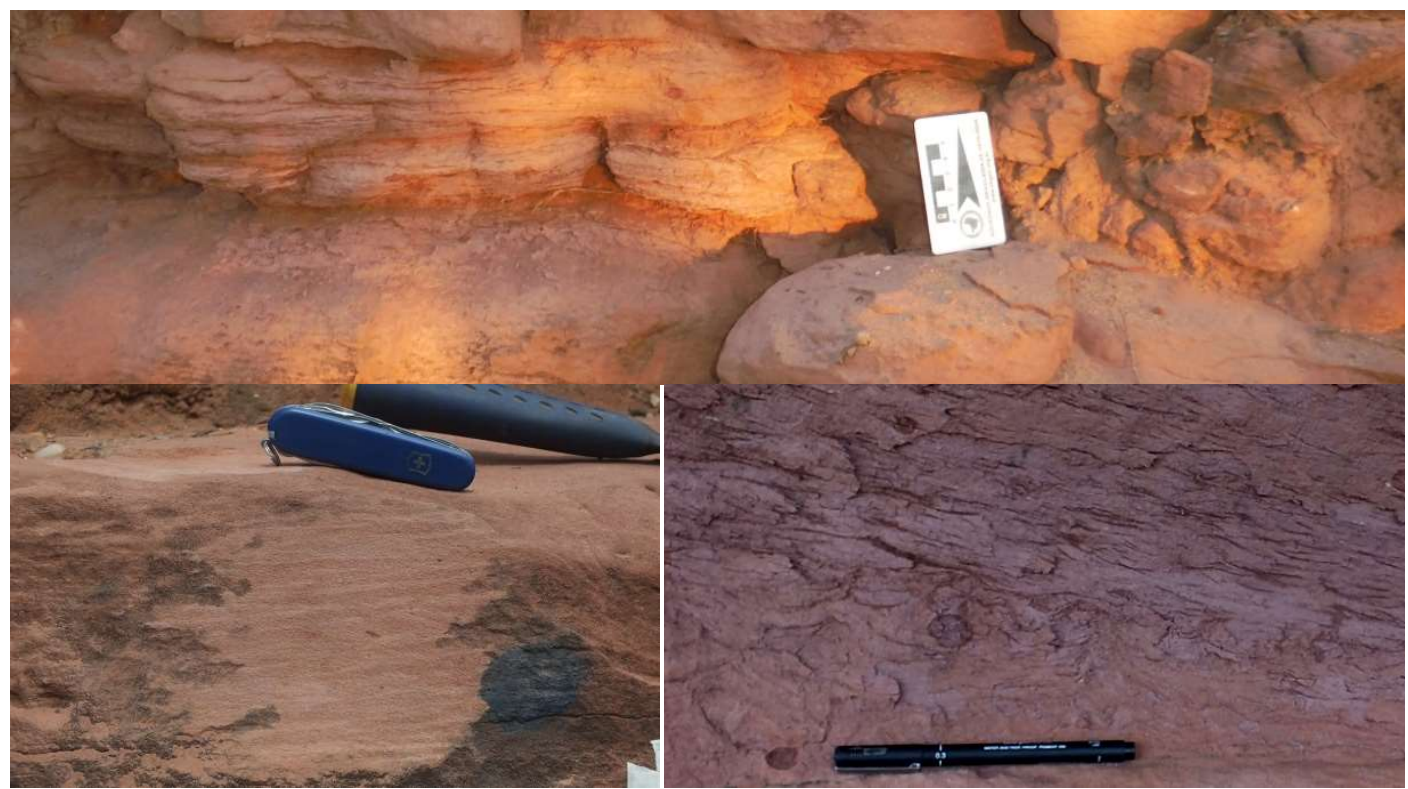

Figura 54 - Estruturas climbbing ripples (marcas onduladas) em arenitos finos (fácies Afr), tipicamente encontrados em topos de barra, ou mesmo canais abandonados

Sobrepostos aos topos de barra encontram-se fácies basais de barras compostas ou unitárias, marcados por superfícies erosivas de terceira ordem.

Sobre algumas barras não ocorre a preservação dos topos de barra devido à erosão total das mesmas pelas barras unitárias e/ou barras compostas, ou mesmo a não deposição desse elemento.

\section{Interpretação}


Esse elemento arquitetural foi interpretado como desaceleração gradual do fluxo e resultado da diminuição da taxa de sedimentos trasportados. Grande quantidade de ripples e depósitos trativos de fluxo rápido com pequenas espessuras de lâmina d'água (representados pelas plano paralelas) representam essas condições. Além disso, a não deposição dos topos de barra em alguns locais foi interpretada como o fluxo contínuo no rio, sem diminuições significativas do stream power.

Segundo Bristow (1996), a preservação dos topos de barra é relacionada à avulsão do canal principal, diminuindo o fluxo local, resultando na deposição e não erosão do topo de barra por sedimentos do canal principal (Bristow 1996).

Lunt \& Bridge (2007) atribuem a não preservação dos topos a sobreposição de fluxos mais enérgicos, colocando esses depósitos em processos de migração a jusante novamente.

Figueiredo (2013) classificou os topos de barra como fácies portadoras de estruturas ripples pouco espessas com grande continuidade lateral, assim como nesse trabalho. Porém, alguns depósitos, aqui classificados como de topo de barra, mais espessos, por volta de 1,0 m, e menos contínuos, por volta de $5.0 \mathrm{~m}$, com geometria lenticular, encontrados principalmente próximos ao baixo de Cícero Dantas, no afloramento TUC05, foram interpretados pelo mesmo autor como planícies de inundação.

\section{Preenchimento de canal}

Os depósitos desse EA possuem coloração rosada a avermelhada e seleção granulométrica boa. Esse elemento arquitetural possui geometria com poucas irregularidades, delimitado por superfícies erosivas côncavas, preenchidas por sedimentos predominantemente finos. Os depósitos de preenchimento de canal possuem espessura máxima, no centro da geometria, de $1,8 \mathrm{~m}$ a $2,5 \mathrm{~m}$, com continuidade lateral de 8,0 a $10,0 \mathrm{~m}$ (figura 55A). 
Sotopostos aos preenchimentos de canais encontram-se, por superfícies erosivas de base de canal (côncavas), de terceira ordem, a fácies Amcu de barras unitárias.

O canal A possui preenchimento de arenitos finos, com laminação plano paralela (fácies Afp) e uma superfície de reativação interna (figura 55B).

Já o preenchimento do canal $B$ é composto por uma $A F$, com as fácies Afc e Acon. Na base, apresenta-se uma variação da fácies Afc, composta por arenito fino micáceo, disposto em estratificações cruzadas de baixo ângulo, com intraclastos. Essa fácies passa verticalmente, por meio à superfície erosiva, para convolutas de granulometria média (fácies Acon) (figua 55C).

Lateralmente aos preenchimentos de canais nota-se o contato brusco, pelas próprias superfícies de terceira ordem, limitantes desse elemento arquitetural, com AFs de barras unitárias.

Sobrepostos aos preenchimentos de canais, por superfícies de terceira ordem horizontais a subhorizontais, encontram-se AFs basais de barras compostas (fácies Amcc e, subordinadamente Acon). 

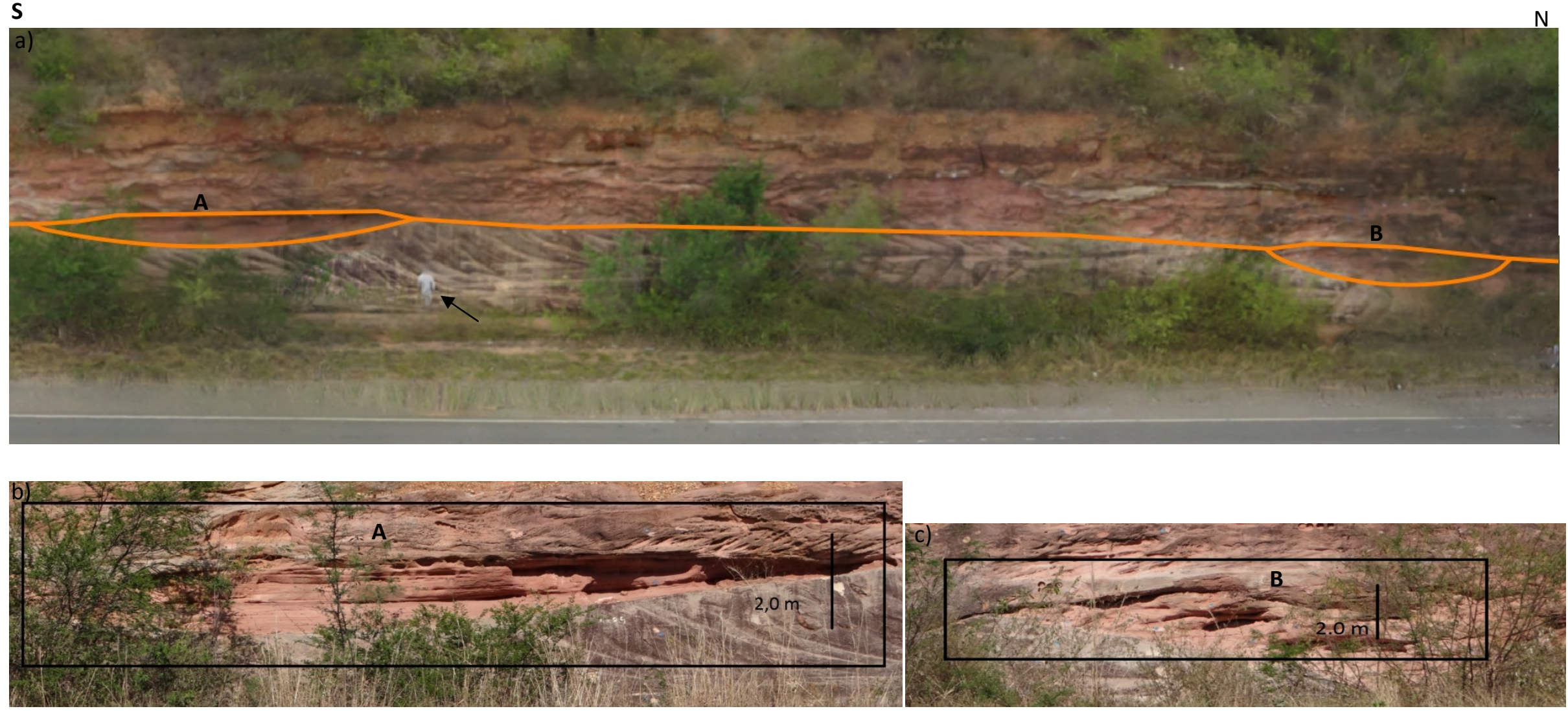

Figura 55 - a) Imagem aérea, adquirida por VANT, com interpretação dos preenchimentos de canais, do afloramento TUC05 (parte 1a) (superfície 1 ou A erosiva em laranja, descrita com mais detalhe na legenda da figura 38) (seta preta indica escala).

b) Imagem de detalhe da geometria do preenchimento de canal (A) da esquerda, preenchido por arenitos finos com laminação plano paralela (Afp)

c) Imagem de detalhe da geometria do preenchimento de canal (B) da direita, preenchido na base por arenitos finos micáceos, com cruzadas de baixo ângulo na base (Afc), e no topo, separado por superfície erosiva, arenitos médios com estrutura convolula (Acon) 


\section{Interpretação}

Esses depósitos foram interpretados como canais abandonados, de menor porte (devido a continuidade lateral e profundidade). Os preenchimentos de canais possivelmente corriam em condições de menor descarga do rio, escavando topos das barras e posteriormente eram preenchidos com sedimentos predominantemente finos.

Um desses canais, observados mais a sul do afloramento TUC05 (canal A), possui fácies semelhantes às interpretadas por Li et al. (2015) como CHf. Esses são descritos pelos autores como canais abandonados preenchidos sobre baixa energia por arenitos laminados, sem trends de granulometria ascendente, homogêneos. Por outro lado o canal localizado a norte do anterior (B) foi preenchido por variações maiores de energia, apresentando estratificações cruzadas de baixo ângulo.

\section{Canais abandonados}

Os canais abandonados possuem coloração rosada, por vezes micácea. A geometria característica desse depósito trata-se de formas côncavas, preenchidas (figura 56). Diferentemento dos depósitos de preenchimento de canal; possuem espessura de $3,0 \mathrm{~m}$ a 4,0 m, com continuidade lateral de 15,0 a 25,0 m. Esse elemento arquitetural é composto por uma associação de fácies (AFca) ou somente pela fácies Afp.

A AFca é composta pelas fácies Afp, Afr, Afc e Acon. Na base encontram-se arenitos médios, dispostos em estratificações cruzadas acanaladas (fácies Afc) que, de forma gradacional, passam lateralmente para arenitos médios de estruturas convolutas (fácies Acon). Sobreposta à fácies Afc encontram-se, por contato abrupto, mediado por superfície erosiva de segunda ordem, arenitos médios a finos, micáceos e convolutos (fácies Acon). Sobre as fácies Acon encontram-se arenitos finos micáceos, com estrutura 
ripple (fácies Afr) ou estrutura plano paralela (fácies Afp). A fácies Afr pode gradar lateralmente para estruturas convolutas de mesma granulometria (fácies Acon).

A superfície basal da AF descrita, de terceira ordem, limitadora desse elemento arquitetural, possui forma côncava, marcada por irregularidades e diminuição brusca da espessura para as periferias, diferente dos EA de preenchimentos de canal.

Lateralmente, essa AF possui contatos por superfícies erosivas de terceira ordem, com AFs de barras compostas. Adicionalmente, também apresenta contato lateral com canais abandonados de maiores dimensões. Esses canais possuem superfícies limitantes erosivas de escavação que mergulham mais sutilmente e com maior comprimento de onda que os canais abandonados descritos anteriormente. $O$ preenchimento desse canal abandonado é homogêneo, preenchido por pelitos de laminação plano paralela (fácies Afp), de coloração roxa esbranquiçada, em níveis contínuos (figura 56). Esse depósito também se assemelha aos CHf descritos por Li et al. (2005). Não foi possível identificar a sucessão de fácies sotoposta ao canal preenchido por pelitos devido às condições do afloramento.

\section{Interpretação}

Esses depósitos foram interpretados como canais abandonados. Porém, de maior hierarquia quando comparados aos preenchimentos de canais devido a maiores dimensões tanto de continuidade lateral como de profundidade.

Interpretou-se a deposição da AF desse elemento arquitetural como preenchimento de escavações (realizadas sobre barras compostas) (fácies Afc), ocasionada pela posterior diminuição gradual do fluxo. Essa diminuição culminou no abandono do canal e preenchimento por arenitos finos, com estrutura convoluta e plano paralelas (fácies Afp) ou ripples (fácies Afr). O 
contato lateral com superfícies escavadas preenchidas por níveis contínuos de pelito favoreceu essa interpretação.

As superfícies preenchidas homogeneamente pelas fácies Afp foram interpretadas como canais abandonados de maior porte devido ao mergulho mais sutil e maior comprimento de onda da superfície basal limitadora desse depósito. Adicionalmente, esse canal estaria mais próximo à possível planície de inundação, consequentemente mais longe do fundo do canal e atrelado a menores condições de fluxo que os demais canais abandonados. Isso se deve ao fato dos sedimentos mais grossos acima da superfície $\mathrm{C}$ e em todo afloramento encontrarem-se mais a sul, os quais representariam o fundo do canal.

Segundo Toonen et al. (2012) o preenchimento da arquitetura de canais abandonados é dividida em dois estágios. O primeiro relacionado ao início do abandono, quando o canal ainda está parcialmente ativo, e outro quando o canal já está totalmente abandonado. O primeiro estágio, nos depósitos analisados, possivelmente estaria relacionado às fácies com estratificações cruzadas (fácies Afc) e o segundo às ripples (fácies Afr).

Segundo Brigde \& Lunt (2006) o processo de abandono é comum em rios entrelaçados, principalmente quando o fluxo de montante é impedido pelas barras que antecedem o canal em questão, gerando abandonos locais.

Lojka et al. (2016) descreveram relações entre barras e canais abandonados, argumentando que depósitos fluviais dificilmente preservam todo o sistema. O autor interpretou as associações de fácies de canais ativos e abandonados como altas variações de descarga na área de estudo.

Figueiredo (2013) interpretou essa AF como barra unitária. Contradizendo Figueiredo (2013), no atual trabalho essa interpretação foi modificada devido à granulometria muito fina e extensa presença de ripples. Já o canal preenchido por pelitos foi interpretado por Figueiredo (2013) como planície de inundação. Neste trabalho, devido à forma erosiva e côncava da superfície basal desse depósito, e a continuidade lateral do depósito 
relativamente baixa para planícies de inundação, optou-se pela classificação de canal abandonado. 


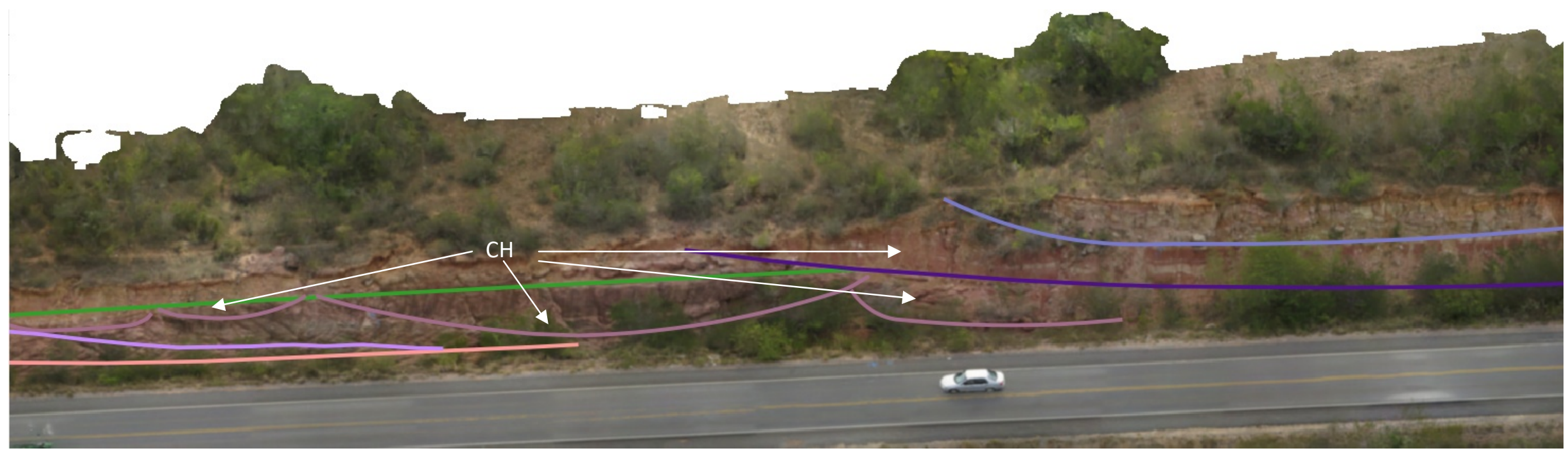

Figura 56 - Geometria de canais abandonados preenchendo superfícies 5, côncavas (destacadas na cor roxo). Contato lateral com a superfície 6, limitadora (na cor azul marinho) do canal abandonado de maior porte. Superfície 3 (ou C), basal de barra composta (na cor salmão) 


\subsection{Petrografia}

A análise petrográfica envolveu análises composicionais, de maturidade mineralógica e textural, granulometria, grau de seleção, arredondamento, empacotamento e contatos de grão. Tendo-se apresentado os resultados separamemente para cada elemento arquitetural dos dois afloramentos estudados.

\subsubsection{Composição mineralógica}

Foram realizadas análises petrográficas em 48 lâminas delgadas para composição mineralógica. Os arenitos da Formação São Sebastião destacamse pela proveniência muito matura, com grande quantidade de quartzo e fragmentos quatzosos, provenientes de quatzitos ou quartzo de veio.

Entre as amostras analisadas, 94\% das amostras foram classificadas como quartzo arenitos e $6 \%$ como arenitos subfeldspáticos. O arenito menos maturo entre todos analisados possui $92 \%$ de quartzo (figura 57 ).

Levando em conta os elementos arquiteturais, não se nota segregação mineralógica evidente entre os elementos arquiteturais. Porém, os depósitos de topo de barra apresentam-se levemente menos maturos. 


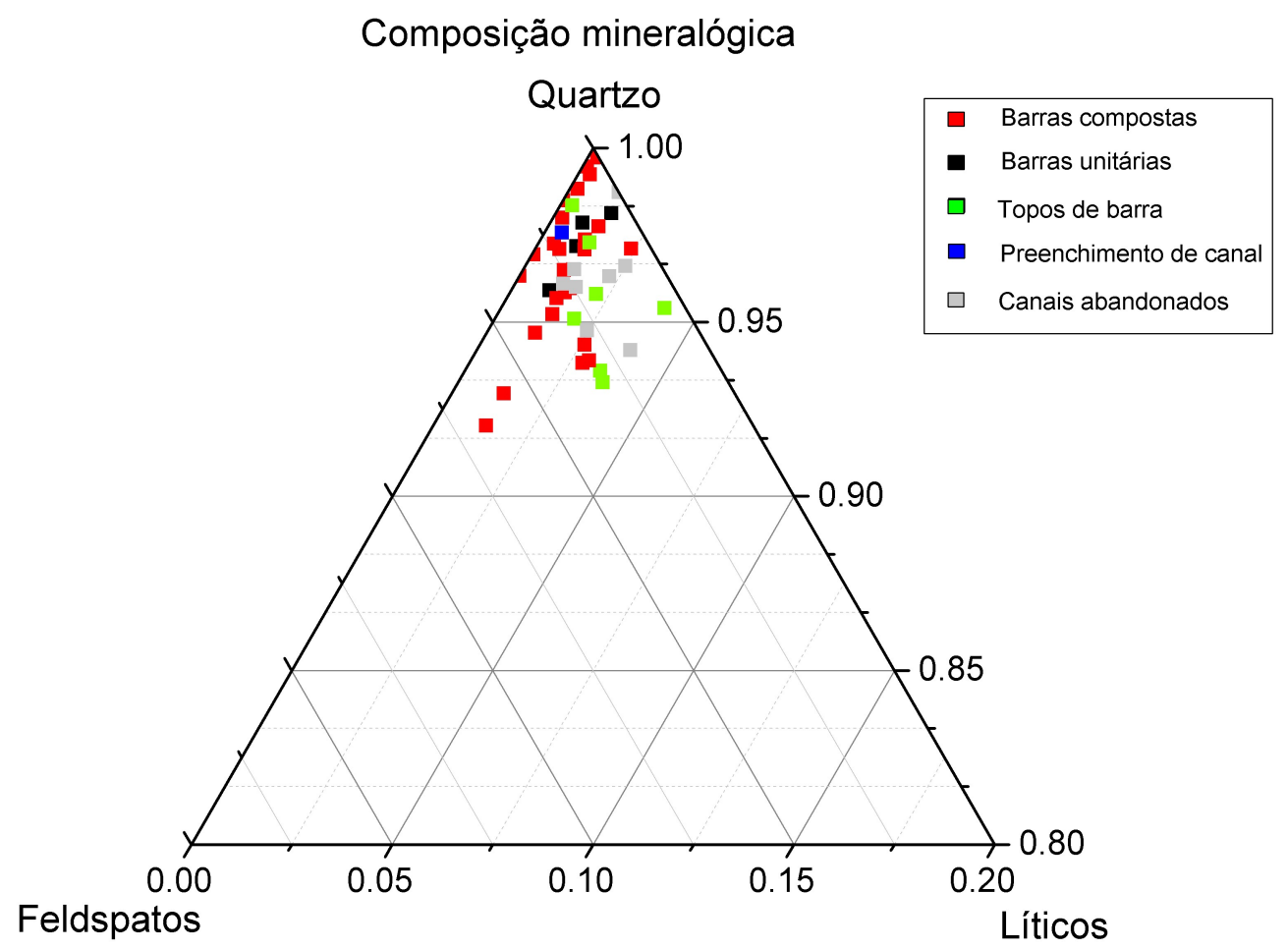

Figura 57 - Diagrama ternário evidenciando alta maturidade na composição mineralógica dos arenitos da Formação São Sebastião (48 amostras analisadas, amostras dos afloramentos TUC05 e 41)

Comparando os dois afloramentos estudados, o grau de maturidade é semelhante (figura 58). Em ambos os afloramentos, os minerais líticos mais observados tratam-se de filitos e raramente clastos de rochas vulcânicas, além de feldspatos microclínios (figura 59 A e B). Micas e intraclastos argilosos ocorrem com certa frequência, principalmente em fácies de arenitos finos (figura 59 C e D). 
A Composição mineralógica - TUC05

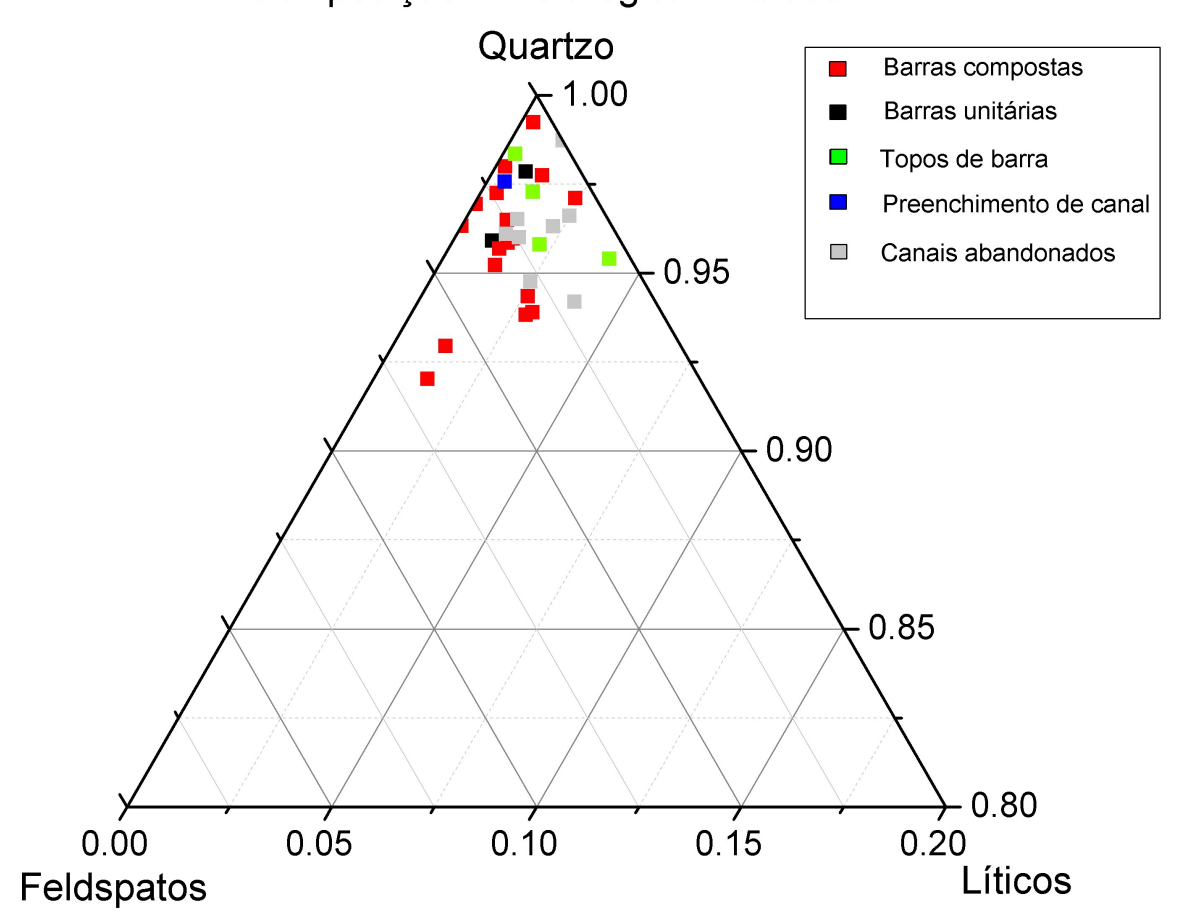

B $\quad$ Composição mineralógica - TUC41

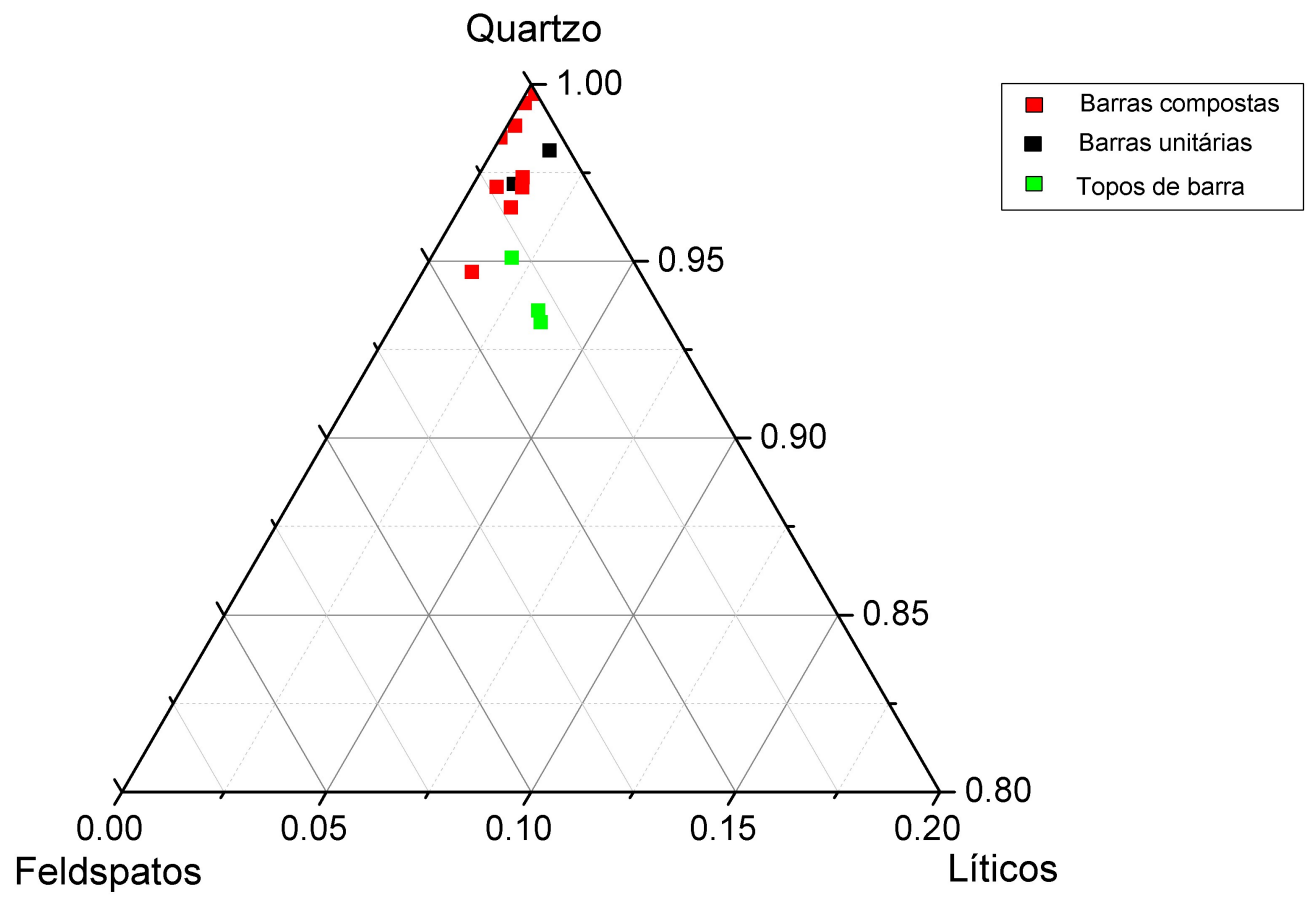

Figura 58 - A) Diagrama ternário de composição mineralógica dos arenitos da Formação São Sebastião no afloramento TUC-05 (32 amostras analisadas). B) Diagrama ternário com composição mineralógica dos arenitos da Formação São Sebastião no afloramento TUC-41 (16 amostras analisadas) 

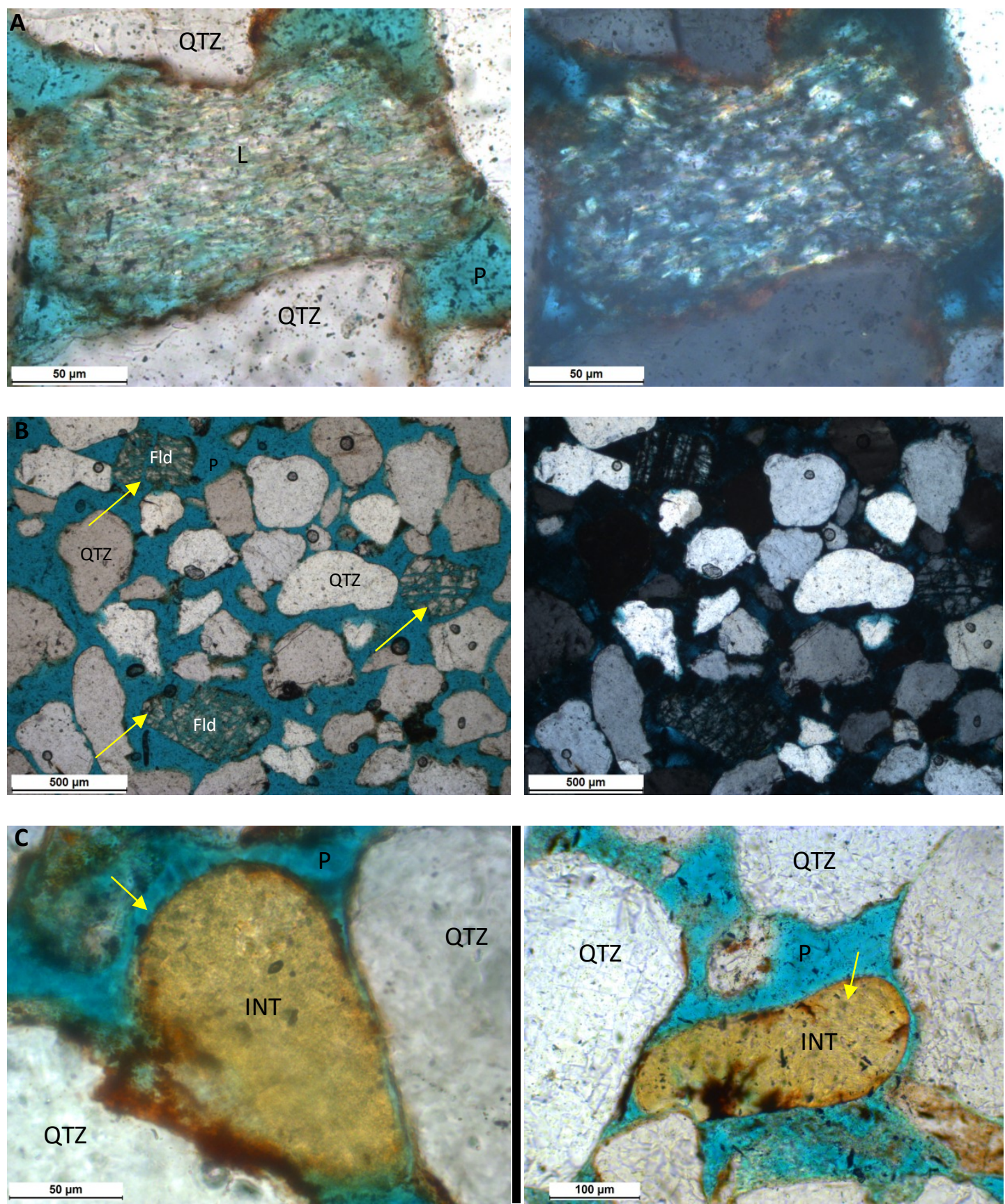

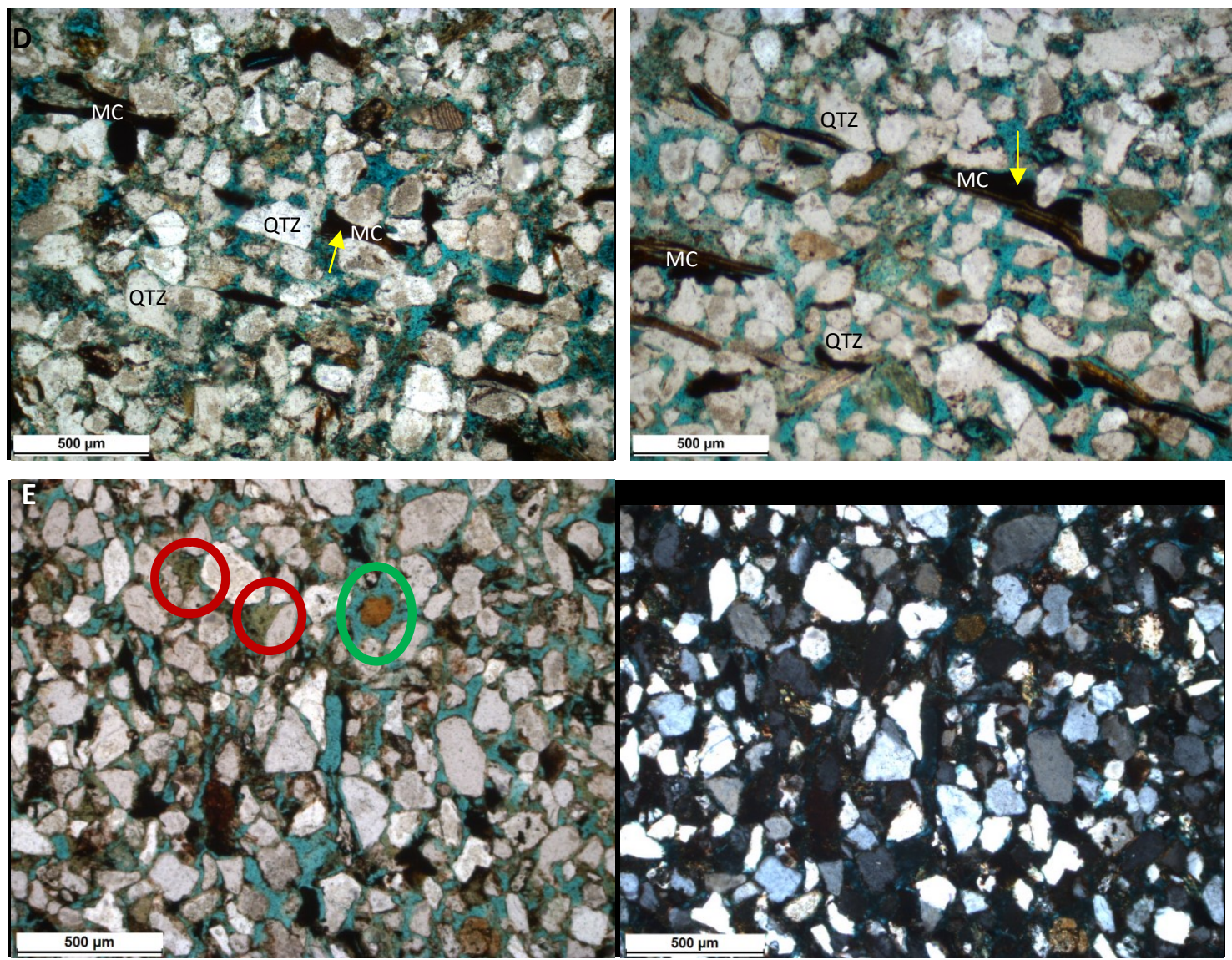

Figura 59- A) Micrografias em detalhe de grão lítico de filito, com filossilicatos, presente nos arenitos da fácies F5 da Formação São Sebastião (micrografia da esquerda obtida com nicois paralelos, enquanto a da direita cruzados).

B) Micrografias dos grãos do arcabouço com feldspatos parcialmente dissolvidos, apontados pelas setas (micrografia da esquerda obtida com nicois paralelos, enquanto a da direita cruzados).

C) Micrografias em detalhe de grãos argilosos (intraclastos), apontados pelas setas (ambas micrografias com nicois paralelos).

D) Micrografias da fácies F2 com micas detríticas, oxidadas, orientadas devido ao fluxo, apontadas pelas setas (ambas micrografias com nicois paralelos).

E) Micrografia de argila estrutural comportando-se como um grão de quartzo do arcabouço (círculo verde) e fragmentos argilosos compactados obstruindo gargantas de poro (círculos vermelhos) (micrografia da esquerda possui nicois paralelos, enquanto a da direita cruzados).

Legenda para todas as micrografias : QTZ = quartzo; Fld = feldspato; L; fragmento lítico; INT = intraclasto argiloso; $\mathrm{MC}=$ mica (biotita); $\mathrm{P}=$ poro 
Apesar da pequena quantidade de grãos líticos e feldspáticos, os arenitos da Formação São Sebastião possuem micas e fragmentos argilosos (colocados a parte na classificação) em quantidade considerável.

As micas ocorrem em 61 (62\%) amostras de um total de 96 amostras. A concentração das micas é variável, visto que em: 20 (21\%) lâminas, apesar de existentes, compõem cerca de 5\% dos poros da seção; 24 (25\%) compõem cerca de $10 \%$ dos poros; nove (9\%) compõem cerca de $25 \%$; e, $8(8 \%)$ compõem $50 \%$ ou mais (figura $60 \mathrm{~A}$ ).

Já os fragmentos argilosos, no total de 47 amostras analisadas, possuem distribuição de: 19 (40\%) amostras com concentrações menores que $2 \%$; $15(31 \%)$ amostras entre $2 \%$ e $4 \%$; sete $(15 \%)$ amostras entre $4 \%$ e $6 \%$; quatro (8\%) amostras entre $6 \%$ e $8 \%$; e, $2(4 \%)$ amostras entre $8 \%$ e $10 \%$. A moda é a concentração até $2 \%$ em cada lâmina (figura 60 B).

Ambas as distribuições apresentam padrão lognormal com assimetria positiva, ou seja, pequena quantidade de amostras com valores relativamente altos.

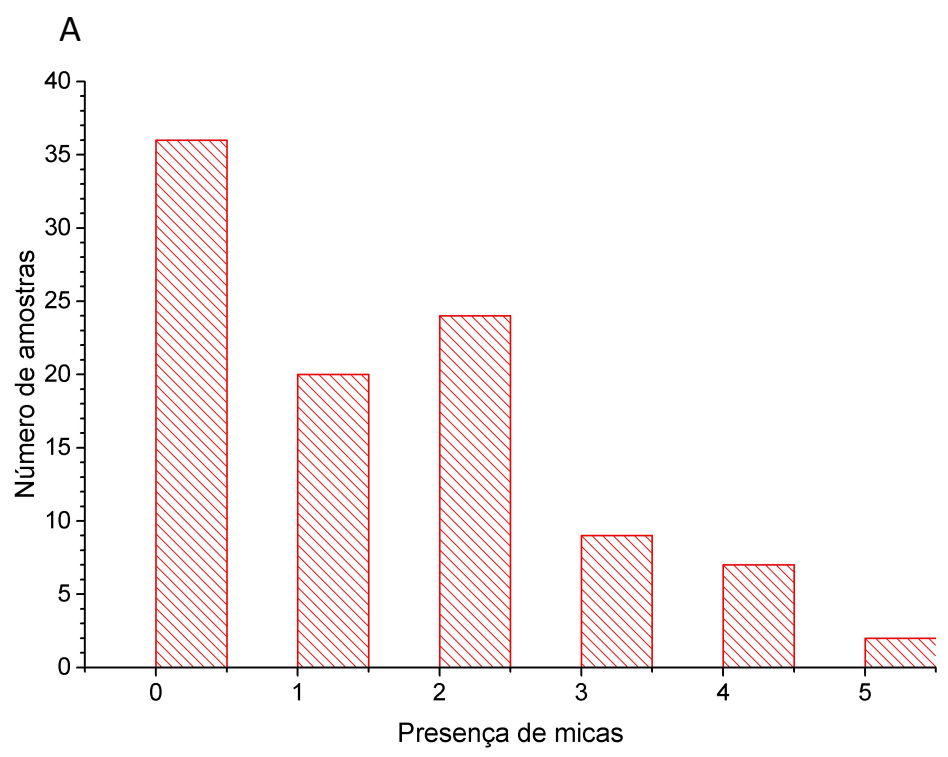




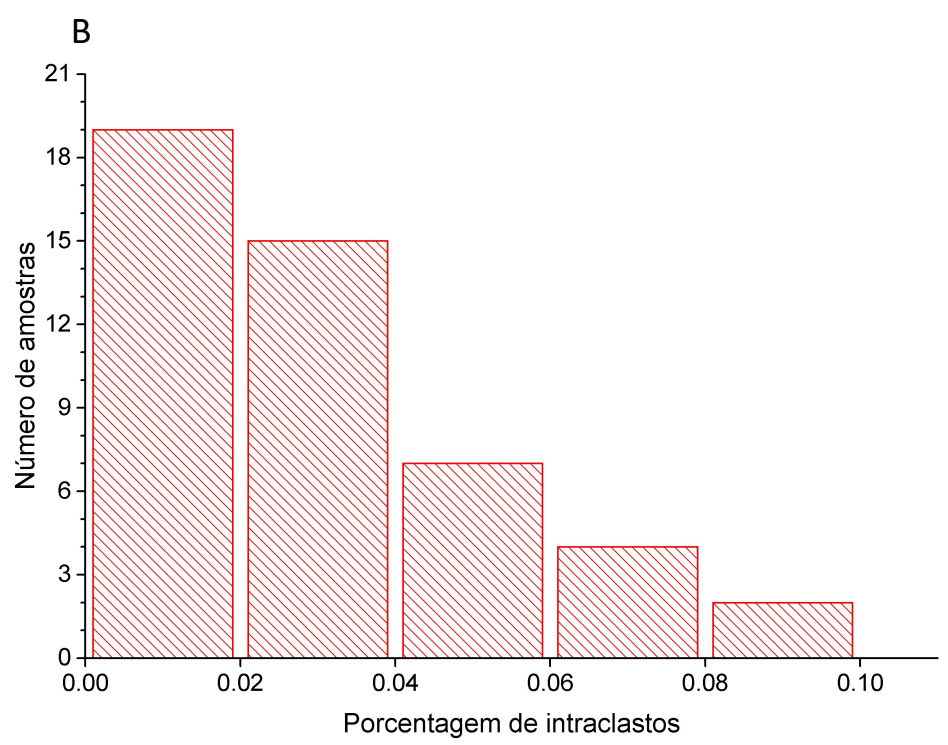

Figura 60- A) Histograma da presença de micas nos arenitos da Formação São Sebastião. No eixo $\mathrm{x}$ a classificação 0 representa constituinte inexistente; 1 - existente, presente em aproximadamente $5 \%$ dos poros; 2 - presente em aproximadamente $10 \%$ dos poros; 3 presente em aproximadamente $25 \%$ dos poros; 4 - presente em aproximadamente $50 \%$ dos poros; 5 - presente em aproximadamente $75 \%$ dos poros; 6 - presente aproximadamente $90 \%$ dos poros. ( $\mathrm{n}=$ número de amostras analisadas)

B) Histograma da presença de fragmentos argilosos em relação ao total dos grãos nos arenitos da Formação São Sebastião

Tanto as micas quanto os fragmentos argilosos (intraclastos) mostram correlação com os elementos arquiteturais (figura 61 A e B). As barras, compostas e unitárias são os depósitos com menor acumulação desses minerais. A moda nos depósitos de barras unitárias e compostas é a ausência de micas em ambas e mediana $1 \%$ e $2 \%$ para fragmentos argilosos, respectivamente.

Os topos de barra possuem moda e mediana para concentração de micas igual ao fator dois (2) (10\% dos poros), e mediana maior que $5 \%$ para os intraclastos. Nos depósitos de preenchimento de canal foi analisada apenas a presença de micas, a qual possui moda igual ao fator três (3) (25\%) e mediana entre dois (2) e três (3). 
Os canais abandonados caracterizam-se por presença de micas com moda igual a quatro (4) (50\%) e mediana igual a dois (2). Já os fragmentos argilosos apresentam-se com mediana igual a $4,5 \%$.
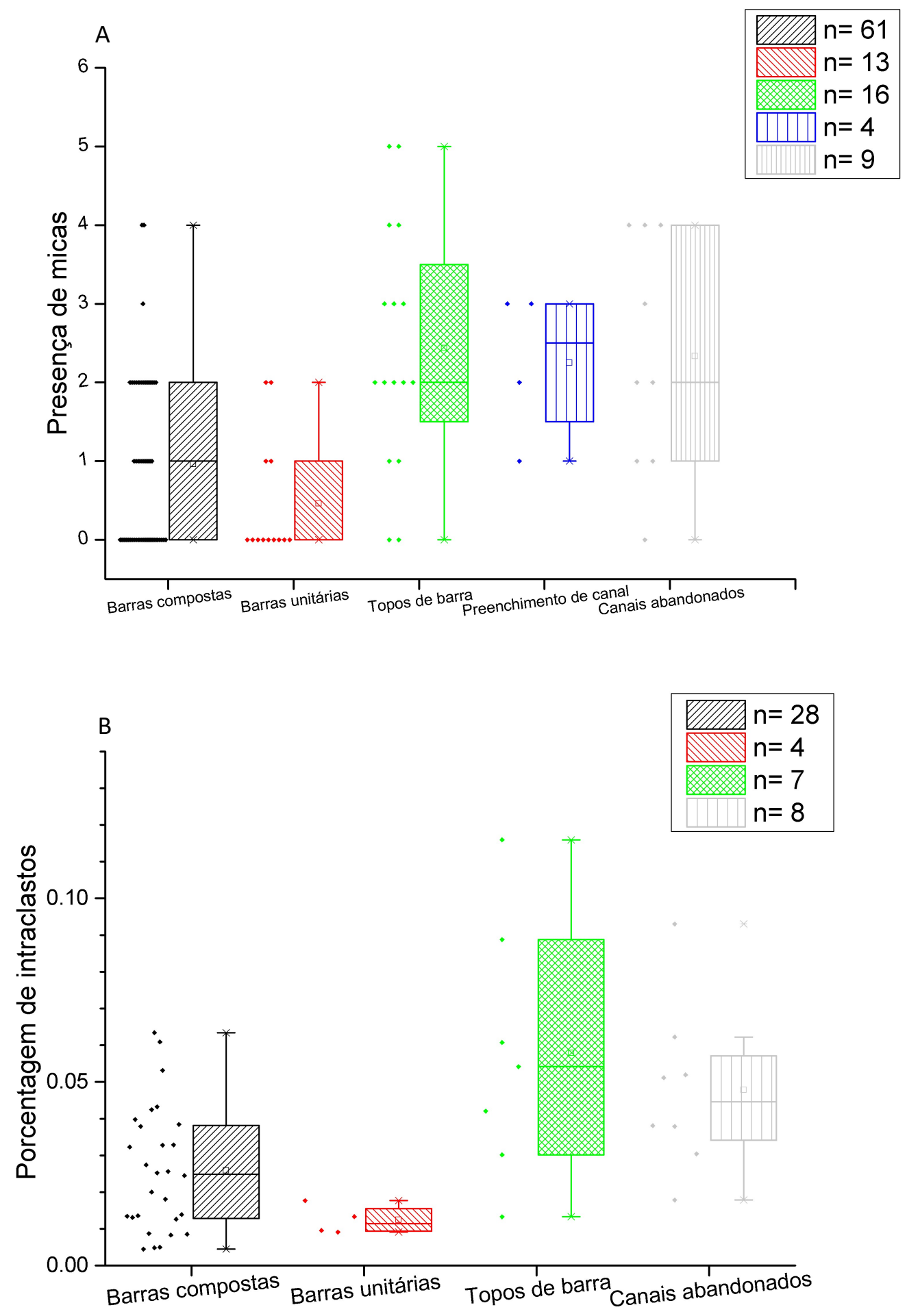

Figura 61- A) Box plots dos elementos arquiteturais pela concentração de micas nos afloramentos da Formação São Sebastião. No eixo y a classificação 0 representa constituinte inexistente; 1 - existente, presente em aproximadamente $5 \%$ dos poros; 2- presente em 
aproximadamente $10 \%$ dos poros; 3 - presente em aproximadamente $25 \%$ dos poros; 4 presente em aproximadamente $50 \%$ dos poros; 5 - presente em aproximadamente $75 \%$ dos poros; 6 - presente aproximadamente $90 \%$ dos poros. ( $n=$ número de amostras analisadas)

B) Box plots dos elementos arquiteturais pela porcentagem de intraclastos argilosos obtidos em contagem para composição dos arenitos da Formação São Sebastião ( $n=$ número de amostras analisadas)

As diferenças das concentrações de fragmentos argilosos e micas nos dois afloramentos estudados apontam para uma concentração levemente superior nos depósitos do afloramento TUC05 (figura 62 A e B). A maior concentração pode ser constatada com confiança nos depósitos de barras compostas (detentoras de maior quantidade nas amostras analisadas). A mediana para os intraclastos argilosos mostra-se próxima a 1\% nos depósitos de barra composta do TUC41 e por volta de 3\% nos depósitos de mesma arquitetura do TUC05. Já a concentração de micas possui moda igual ao fator dois (2) no TUC05 e inexistente (0) no TUC41.

A análise de fragmentos argilosos nos topos de barra mostra-se dificultada pela pequena quantidade de amostras analisadas (sete lâminas delgadas). Porém, levando em conta o maior valor alcançado em três amostras, no TUC05 a porcentagem é próxima a 12\%, e 9\% no TUC41. Já as micas possuem mediana de fatores e três (3) e dois (2) no TUC05 e TUC41, respectivamente.

A moda apresentada para a presença de micas e fragmentos argilosos, considerando todas as amostras mostra-se muito baixa (figura 60). Isso se deve ao fato da maioria das lâminas de amostras analisadas serem pertencentes ao EA de barras (elementos depositados durante energia relativamente alta): $72 \%$ na primeira e $68 \%$ na segunda análise. 

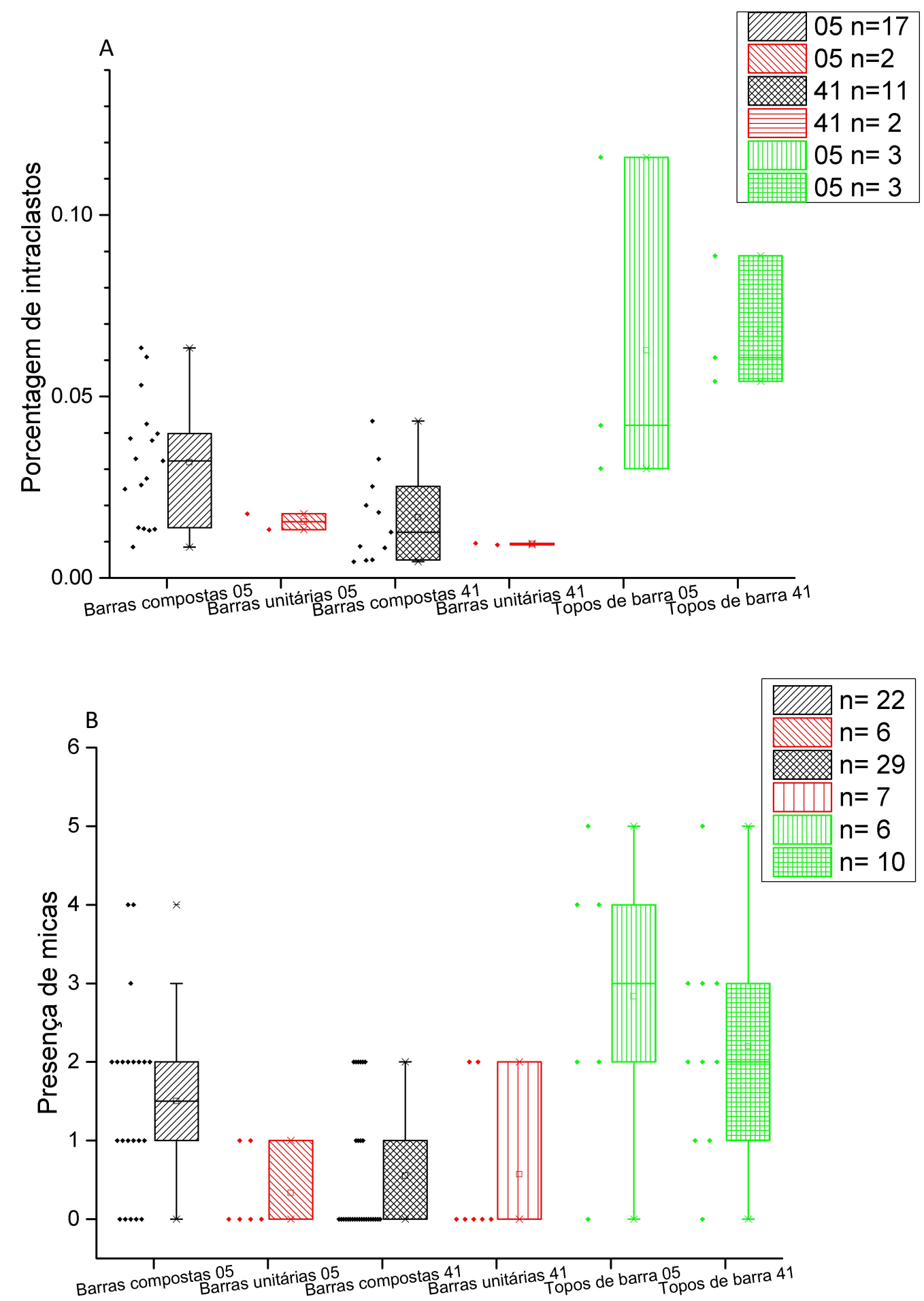

Figura 62 - A) Box plots dos elementos arquiteturais dos afloramentos TUC05 e TUC41 pela porcentagem de fragmentos argilosos, na Formação São Sebastião ( $n=$ número de amostras analisadas).

B) Box plots dos elementos arquiteturais dos afloramentos TUC05 e TUC41 pela presença de micas, na Formação São Sebastião. No eixo y a classificação 0 representa constituinte inexistente; 1 - existente, presente em aproximadamente $5 \%$ dos poros; 2- presente em aproximadamente $10 \%$ dos poros; 3 - presente em aproximadamente $25 \%$ dos poros; 4 - 
presente em aproximadamente $50 \%$ dos poros; 5 - presente em aproximadamente $75 \%$ dos poros; 6 - presente aproximadamente $90 \%$ dos poros. ( $n=$ número de amostras analisadas)

\subsubsection{Análise granulométrica e seleção granulométrica}

As análises granulométricas (com base na escala de Wentworth (1992)) dos afloramentos apontaram granulometria e seleção granulométrica variável nos arenitos da Formação São Sebastião (figura 63). A moda é igual a 2,4 $\Phi$ (areia fina média), variando entre 3,1 e 1,4 $\Phi$, correspondente a areia muito fina até areia média-grossa, respectivamente.

As seleções granulométricas, representadas pelo desvio padrão da granulometria, apresentam moda 0,7 $\Phi$ (moderadamente selecionado) variando de 0,4 $\Phi$ até 1,2 $\Phi$, indicando seleção correspondente entre muito bem selecionado a pobremente selecionado.

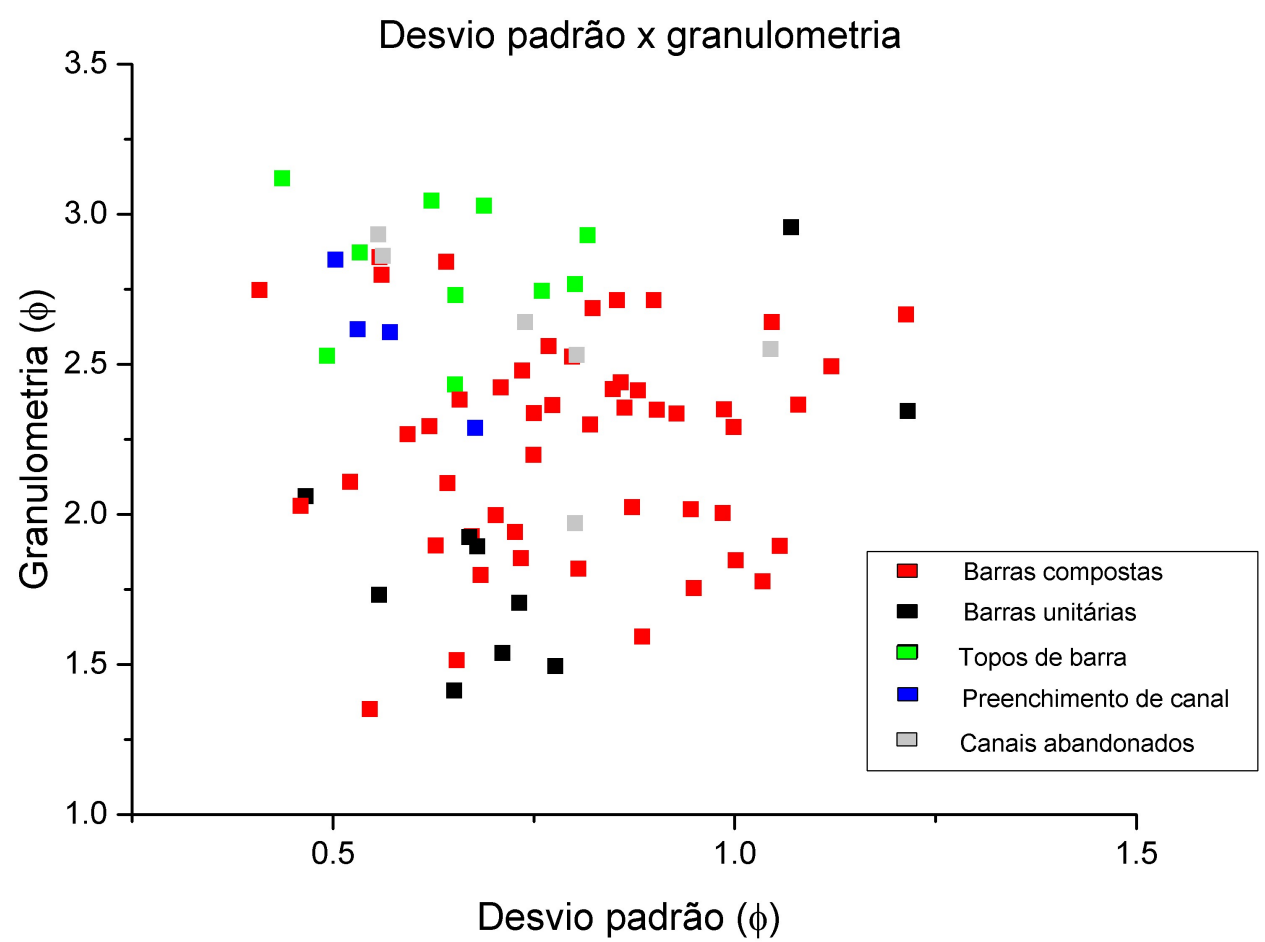

Figura 63- Scatter plot de granulometria por desvio padrão distinguindo os elementos arquiteturais da Formação São Sebastião (82 amostras analisadas) 
A granulometria varia nas barras compostas e unitárias de 1,4 a 3,0 $\Phi$ (areia média a areia fina), com mediana 2,3 Ф (areia média-fina) nas compostas e 1,8 $\Phi$ nas unitárias (areia média). Nos topos de barra varia de 2,4 a 3,1 $\Phi$ (areia fina media a muito fina), com mediana 2,8 $\Phi$ (areia fina a muito fina). Já nos preenchimentos de canais varia de 2,3 a 2,9 Ф (areia media-fina a fina-muito fina), com moda 2,6 Ф (areia fina). Os canais abandonados possuem granulometria de 1,9 a 2,9 $\Phi$ (areia média a fina-muito fina) (figura $64 \mathrm{~A}$ ).

Entre os elementos arquiteturais, os detentores das melhores seleções granulométricas são primeiramente os preenchimentos de canais (média $=0,52$ $\Phi)$, seguidos dos topos de barra (médiana=0,65 $\Phi$ ), barras unitárias (mediana $=0,70 \Phi$ ), canais abandonados (mediana=0,78 $\Phi$ ) e barras compostas (média $=0,80 \Phi$ ) (figura $64 \mathrm{~B}$ ).

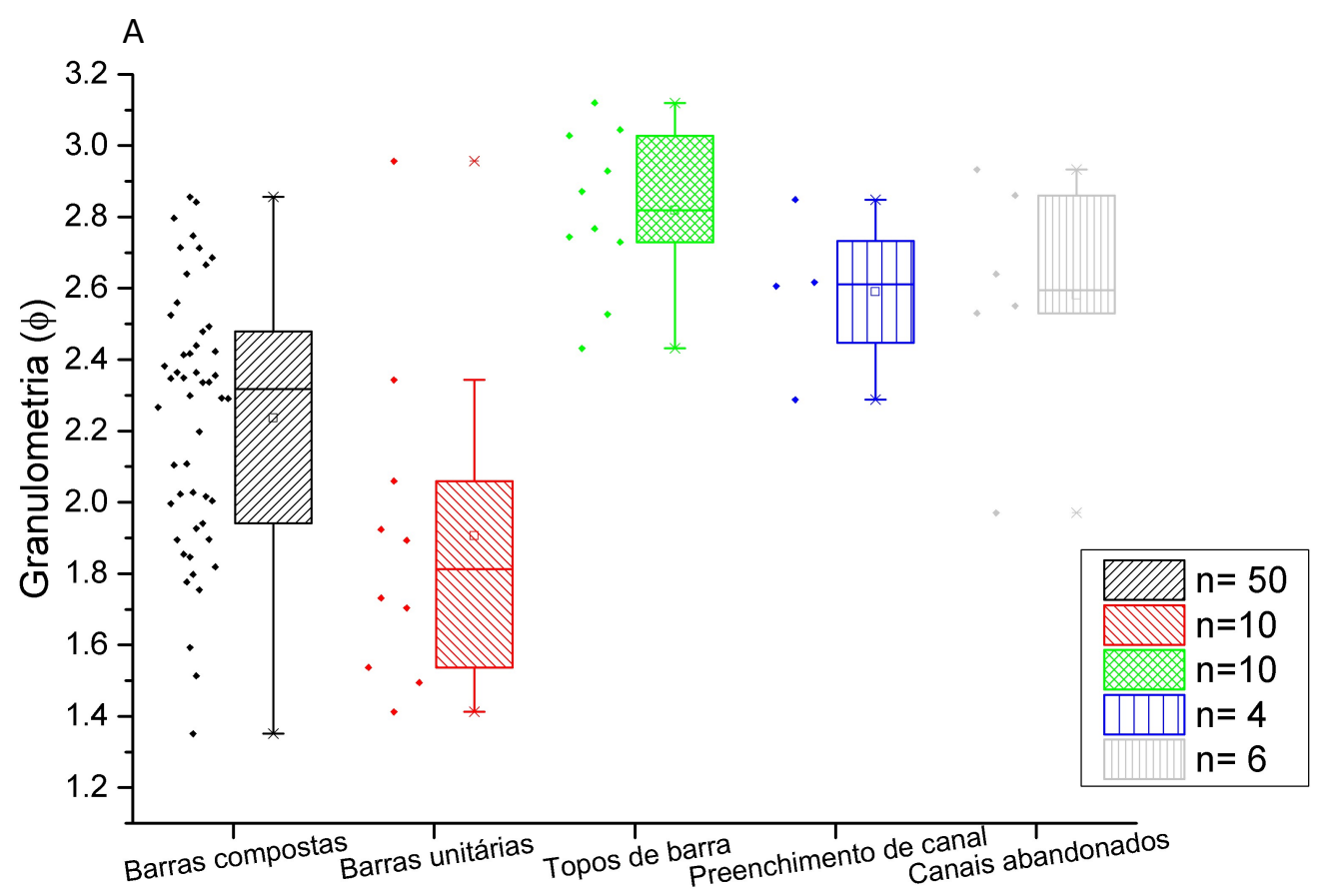




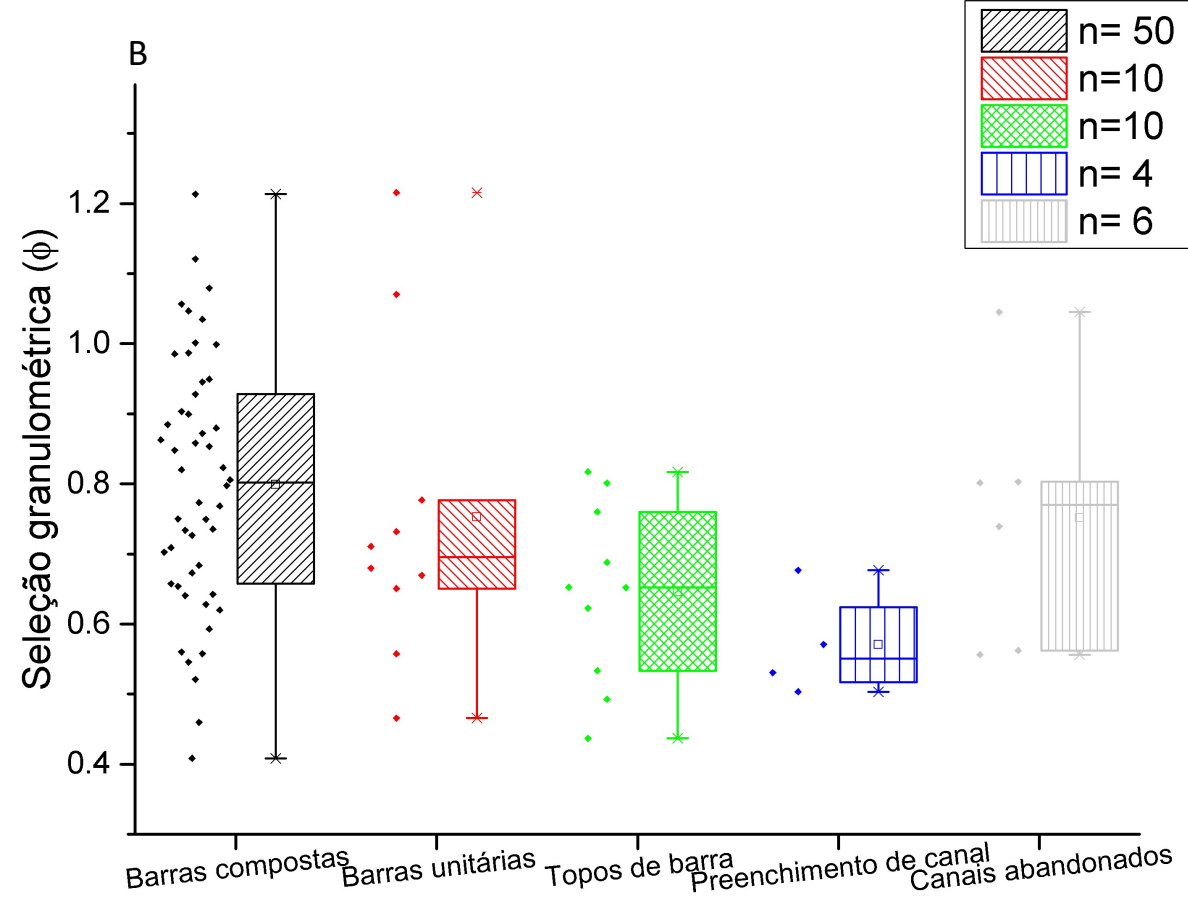

Figura 64 - A) Box plots dos elementos arquiteturais em função da granulometria dos arenitos da Formação São Sebastião ( $n=$ número de amostras analisadas)

B) Box plots dos elementos arquiteturais em função da seleção granulométrica dos arenitos da Formação São Sebastião ( $n=$ número de amostras analisadas)

As granulometrias das barras, tanto unitárias como compostas, são as mais variáveis entre os elementos arquiteturais. As porções basais possuem granulometrias medias-grossas, depositadas com maior cisalhamento de fundo e maior coluna d' água. Para o topo, gradam para fácies com granulometria variável de média a fina, depositadas com grande influência do grain fall, resultado da diminuição da velocidade de fluxo no canal. Essa variação é melhor explicitada nas barras compostas, resultado da tendência finning upward mais expressiva.

A granulometria dos canais abandonados, assim como das barras, possui variação de granulometria, também notada nas análises de campo. Apresenta variação entre granulometria muito fina até granulometrias médias. As correspondentes a areia média seriam transportadas quando os canais estavam em processo de abandono. Já as mais finas seriam remetentes ao 
período em que o transporte realizava-se, predominantemente, por suspensão e deposição por decantação, quando o canal já se encontrava abandonado.

A granulometria dos topos de barra e preenchimentos de canais mostrase fina, sem variação expressiva, reflexo da baixa energia deposicional, característica desses elementos arquiteturais.

\subsubsection{Arredondamento}

O arredondamento dos grãos nos arenitos da Formação São Sebastião apresentam variações desde desprezíveis, até amostras com arredondamentos altos, com mais de $60 \%$ dos grãos arredondados a muito bem arredondados. $A$ curva de distribuição da totalidade das amostras aproxima-se de uma distribuição normal (figura 65).

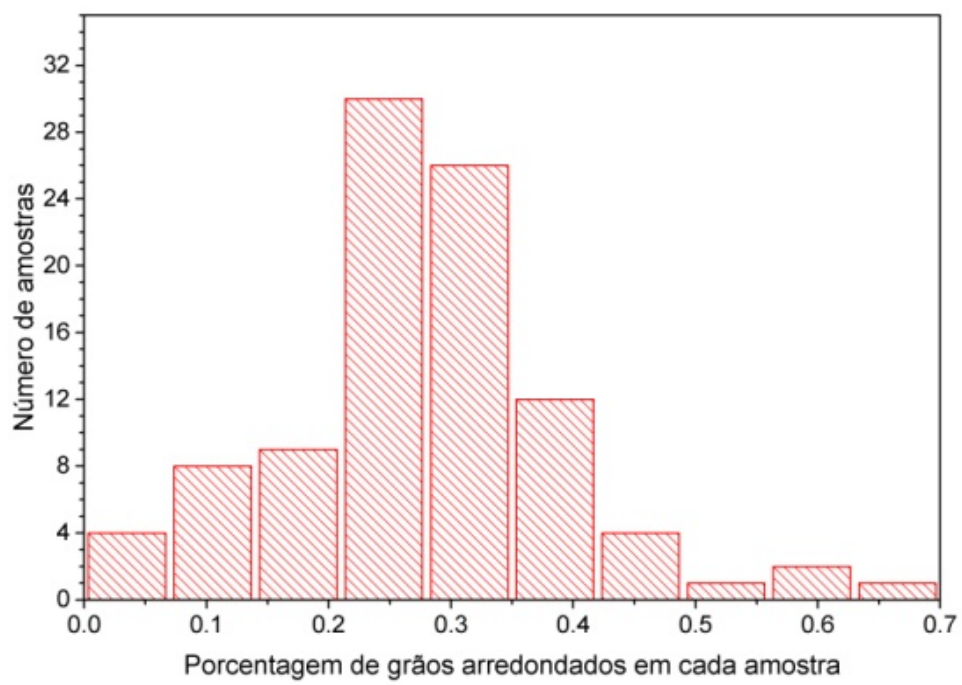

Figura 65 - Histograma do arredondamento dos arenitos da Formação São Sebastião

Assim como na seleção granulométrica, o arredondamento foi agrupado conforme os elementos arquiteturais (figura 66). Os depósitos de barras unitárias são detentores da maior mediana de arredondamento, representando $32 \%$ de grãos arredondados por amostra, seguidos dos depósitos de barra 
composta (30\%). Já os topos de barra e depósitos de preenchimento de canal apresentam mediana menor que $25 \%$ de grãos arredondados. As amostras de canais abandonados possuem o pior arredondamento que os demais (menor de $20 \%$ ).

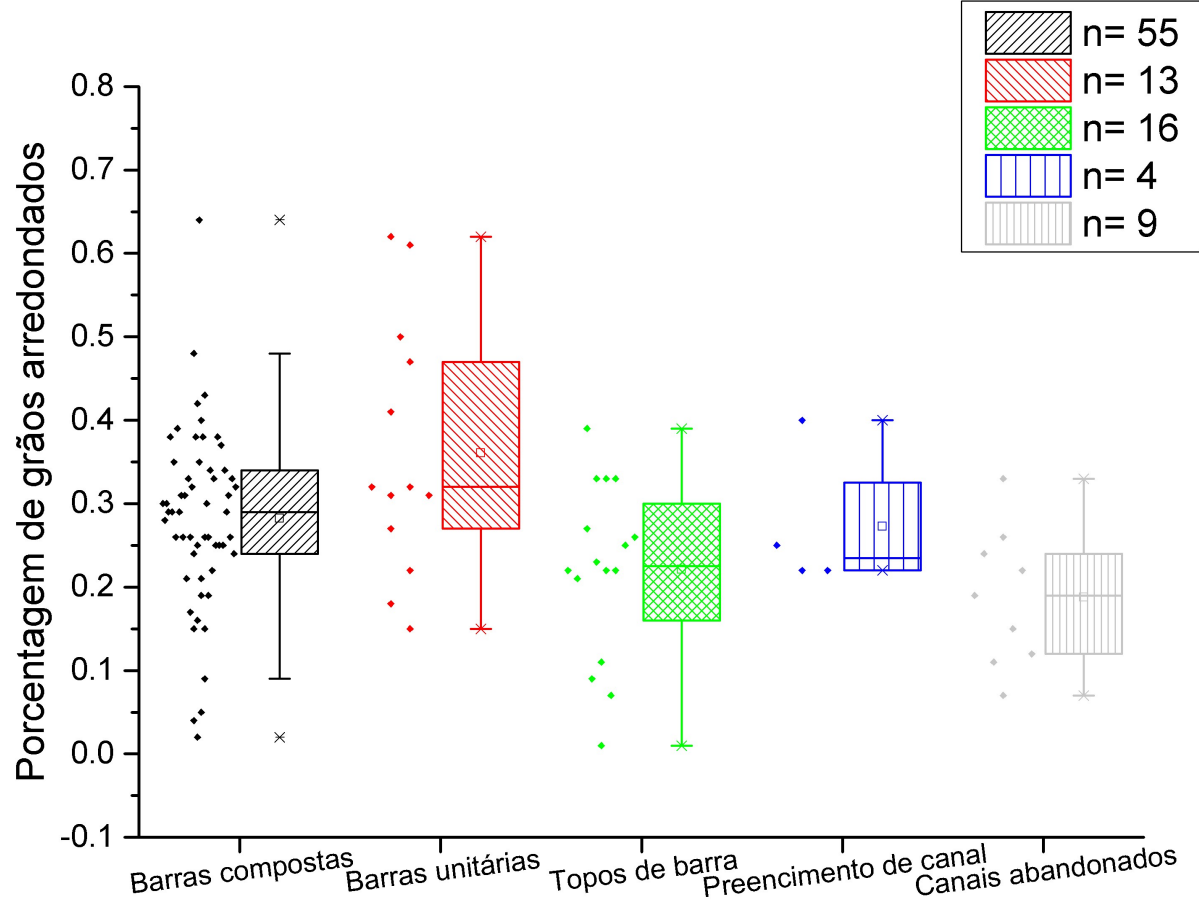

Figura 66 - Box plots dos elementos arquiteturais em função do arredondamento dos arenitos da Formação São Sebastião ( $\mathrm{n}=$ número de amostras analisadas)

Analisando os dois afloramentos separadamente o padrão já comentado é mantido. A maior porcentagem de grãos arredondados é encontrada nas barras unitárias. No afloramento TUC05 os topos de barra apontam uma mediana maior que no TUC41. Porém, a dispersão dos valores no TUC41 é maior, chegando a $40 \%$ dos grãos arredondados, mas também com valores mínimos próximos de zero (figura 67). 

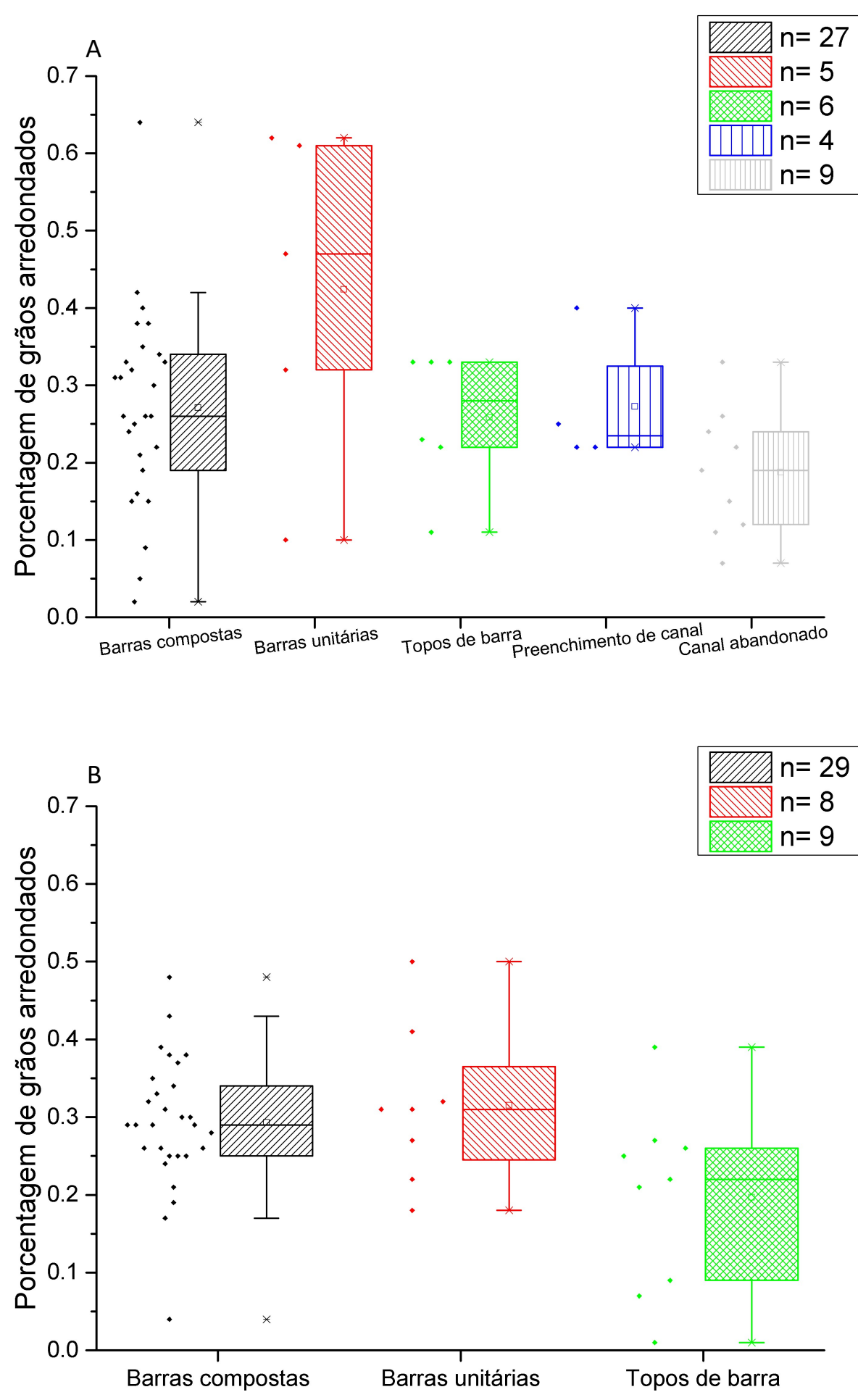

Figura 67 - A) Box plots dos elementos arquiteturais em função do arredondamento dos arenitos da Formação São Sebastião no afloramento TUC05 ( $n=$ número de amostras analisadas)

B) Box plots dos elementos arquiteturais em função do arredondamento dos arenitos da Formação São Sebastião no afloramento TUC41 (n= número de amostras analisadas) 
O arredondamento das amostras é função da abrasão contínua, controlada pelo tempo e energia em que o sedimento foi retrabalhado, ou seja, é uma variável influenciada pelo tempo e tipo de transporte, assim como a granulometria e o grau de seleção. Além disso, o meio também influencia nessa variável, devido à viscosidade, mas nesse estudo o meio é sempre aquoso, tratando-se de depósitos fluviais.

O arredondamento em rochas de granulometria areia média a grossa (maior que 1,5 Ф) mostra-se com mediana de $25 \%$ dos grãos arredondados. As granulometrias arenito médio a fino (entre 1,5 e 2.0 Ф) apresentam mediana de $31 \%$ e média de $35 \%$. Já os arenitos finos a médios (entre 2,0 e 2,5 Ф), apresentam médiana e média de $31 \%$ e de $30 \%$, respectivamente. Os arenitos finos a muito finos (maior que 2,5 Ф) possuem arredondamento com mediana de $22 \%$ e média de $17 \%$. Logo, o arredondamento é maior nas amostras com granulometria mediana, nos depósitos de arenito médio a fino e arenito fino a médio (figura 68).

O pior arredondamento entre as amostras de granulometrias finas pode ser resultado de pequena energia entre o choque dos grãos, representada pela física por quantidade de movimento. Isso ocorre devido ao mecanismo de transporte predominantemente ser a suspensão e menor massa dos grãos finos. Além disso, o ambiente aquoso atenua o choque entre os grãos. 


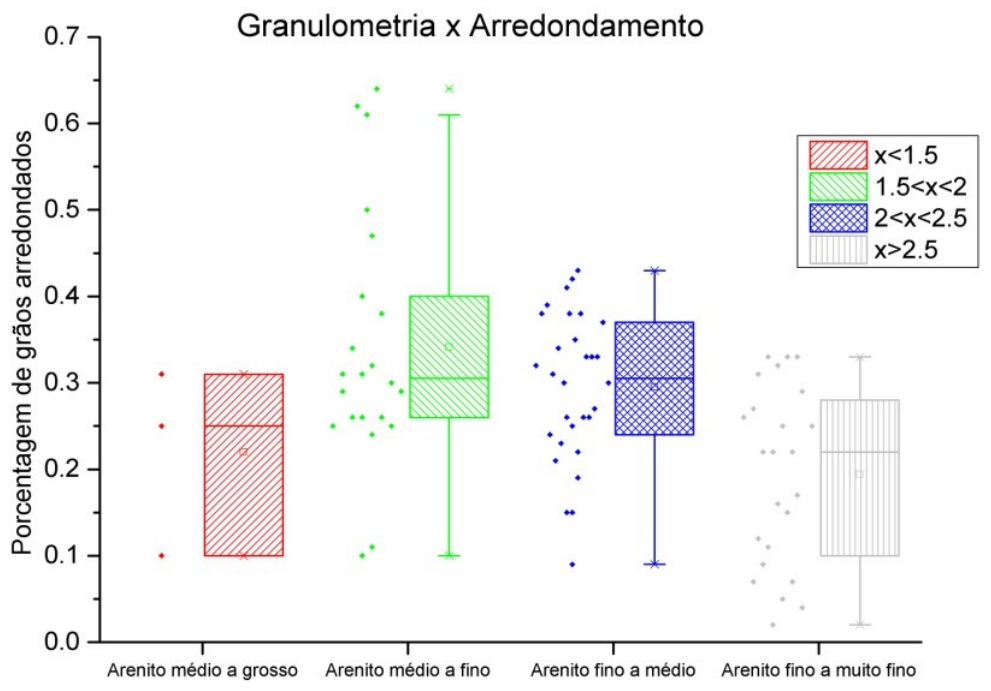

Figura 68 - Box plots da granulometria em função do arredondamento dos arenitos da Formação São Sebastião ( $\mathrm{n}=$ número de amostras analisadas)

A seleção granulométrica quando comparada ao arredondamento apresenta relação parecida à granulometria. Os extremos das variáveis utilizadas no eixo x são menos arredondados que os valores medianos (figura 69). Os arenitos bem selecionados (com desvios padrões menores que $0,55 \Phi$ ) possuem mediana de $19 \%$ dos grãos arredondados. Os moderadamente selecionados (com desvios padrões entre 0,55 e 0,9Ф) apresentam mediana de $30 \%$. Já os arenitos mal selecionados (com desvios padrões maiores que 0,9 Ф) apresentam mediana de $27 \%$ de grãos arredondados. As amostras bem selecionadas manifestam valores mais baixos de arredondamento que as demais amostras. A dispersão dos valores influentes na média das amostras moderadamente selecionadas é notável, com valores muito altos, próximos de $65 \%$, e valores baixos, próximos de $5 \%$. 


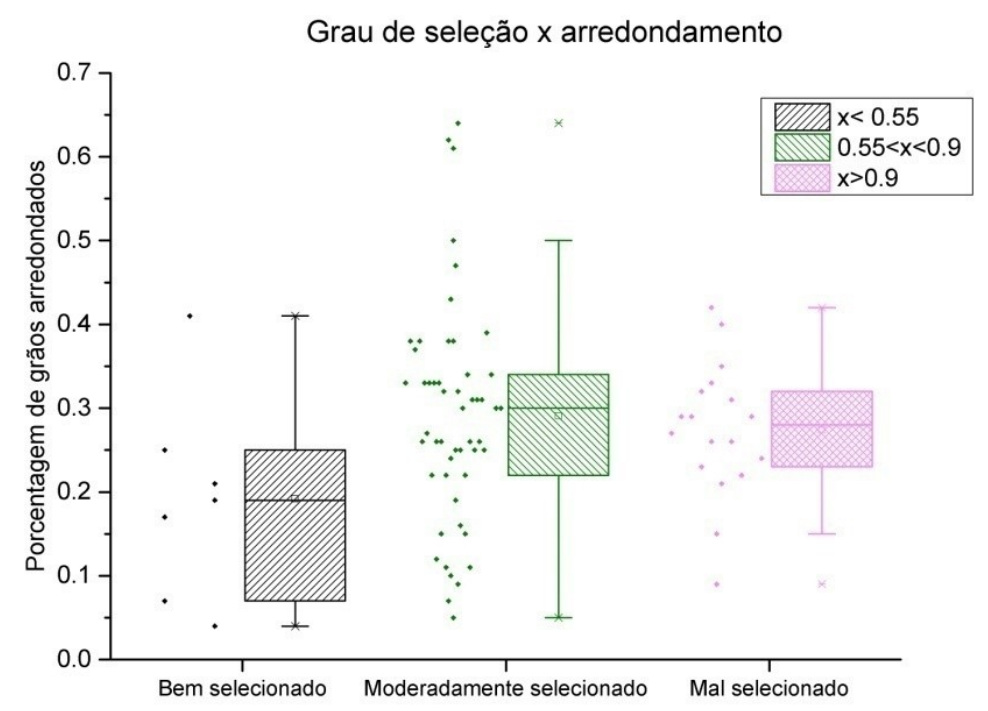

Figura 69 - Box plots do grau de seleção em função do arredondamento dos arenitos da Formação São Sebastião (77 amostras analisadas)

\subsubsection{Empacotamento e contatos de grãos}

O índice de empacotamento (Kahn, 1956) das rochas da Formação São Sebastião nos afloramentos estudados possui distribuição aproximadamente lognormal, com assimetria positiva, caso considere-se a pequena quantidade de amostras com o empacotamento extremamente aberto (índice até 0,15 ) como aberto (figura 70A). A moda dos valores de índice de empacotamento é entre 0,15 e 0,20 .

Já os contatos de grãos possuem distribuição próxima a distribuição normal (figura 70B). O mais frequente caracteriza-se pelo predominante contato pontual, mas com presença considerável de contato planar $(n=32)$. 0 segundo tipo de contato de grão mais frequente caracteriza-se pelo contato pontual e planar. Porém, com predominância de contato planar $(n=30)$. 0 terceiro é o contato pontual predominante, com presença considerável de grãos flutuantes $(n=20)$. 

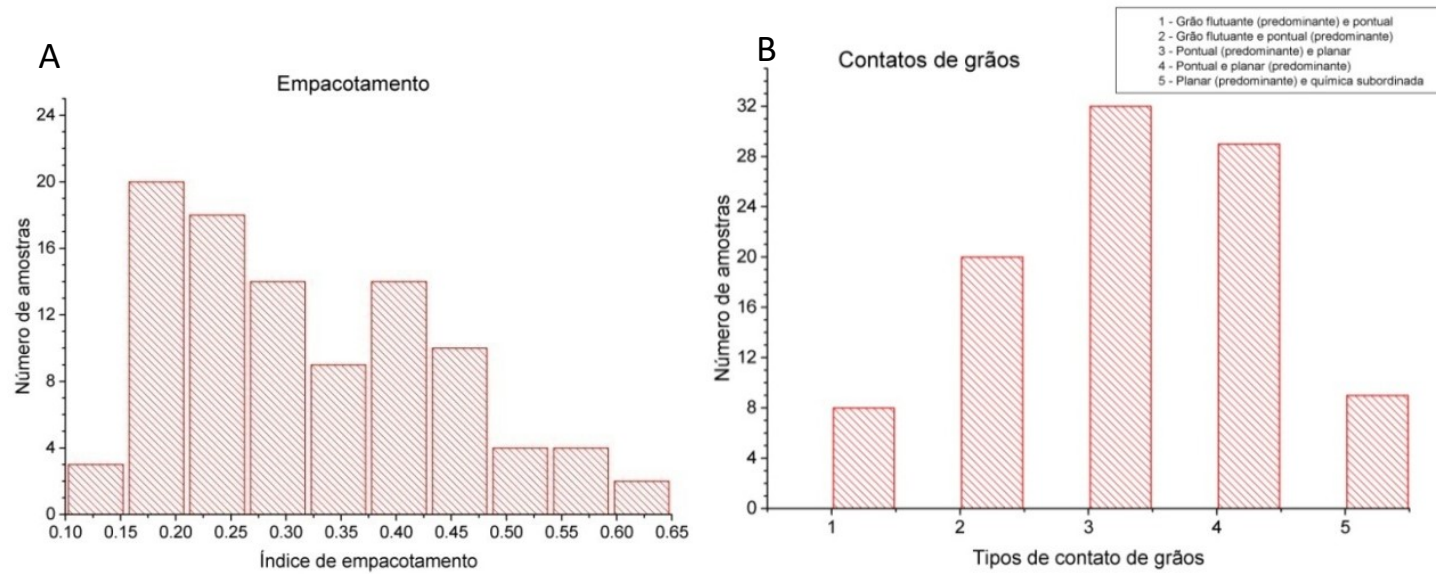

Figura 70 -A) Histograma do índice de empacotamento (Kahn, 1956) nos afloramentos TUC05.

B) Histograma do tipo de contato de grãos nos afloramentos TUC05 e TUC41. No eixo x a classificação 1 representa "contato de grão flutuante" (predominante) e pontual; 2- grão flutuante e pontual (predominante); 3- pontual (predominante) e planar; 4- pontual e planar; e, planar (predominante) e química subordinada

O empacotamento e os contatos de grãos, apesar de possuírem formas de distribuição distintas, quando divididos por elementos arquiteturais, possuem certa semelhança (figura $71 \mathrm{~A}$ e B).

As barras, unitárias e compostas, seguidas dos canais abandonados caracterizam-se por valores menores de empacotamento e contatos de grão. Os empacotamentos são muito abertos nesses elementos (mediana igual a $0,26,0,27$ e 0,24 , respectivamente) (figura $71 \mathrm{~A}$ ). Os contatos de grãos nos três elementos mencionados são predominantemente pontuais, mas com contatos flutuantes, subordinados nas unitárias, e planares, subordinados nas compostas e nos canais abandonados.

Os topos de barra e preenchimento de canais possuem os maiores valores de empacotamento e contatos de grãos. Os empacotamentos são normais a abertos nos topos de barra e nos preenchimentos de canais (mediana igual a 0,44 e 0,36 , respectivamente).

Os contatos de grãos nos topos de barra caracterizam-se, em sua maioria, por contatos pontuais (predominantes) e planares, ou contatos planares (predominantes) com presença pontual de compactação quimica. Já 
nos preenchimentos de canais, $75 \%$ das amostras apresentam-se em sua maioria com contatos pontuais e planares (predominantes).
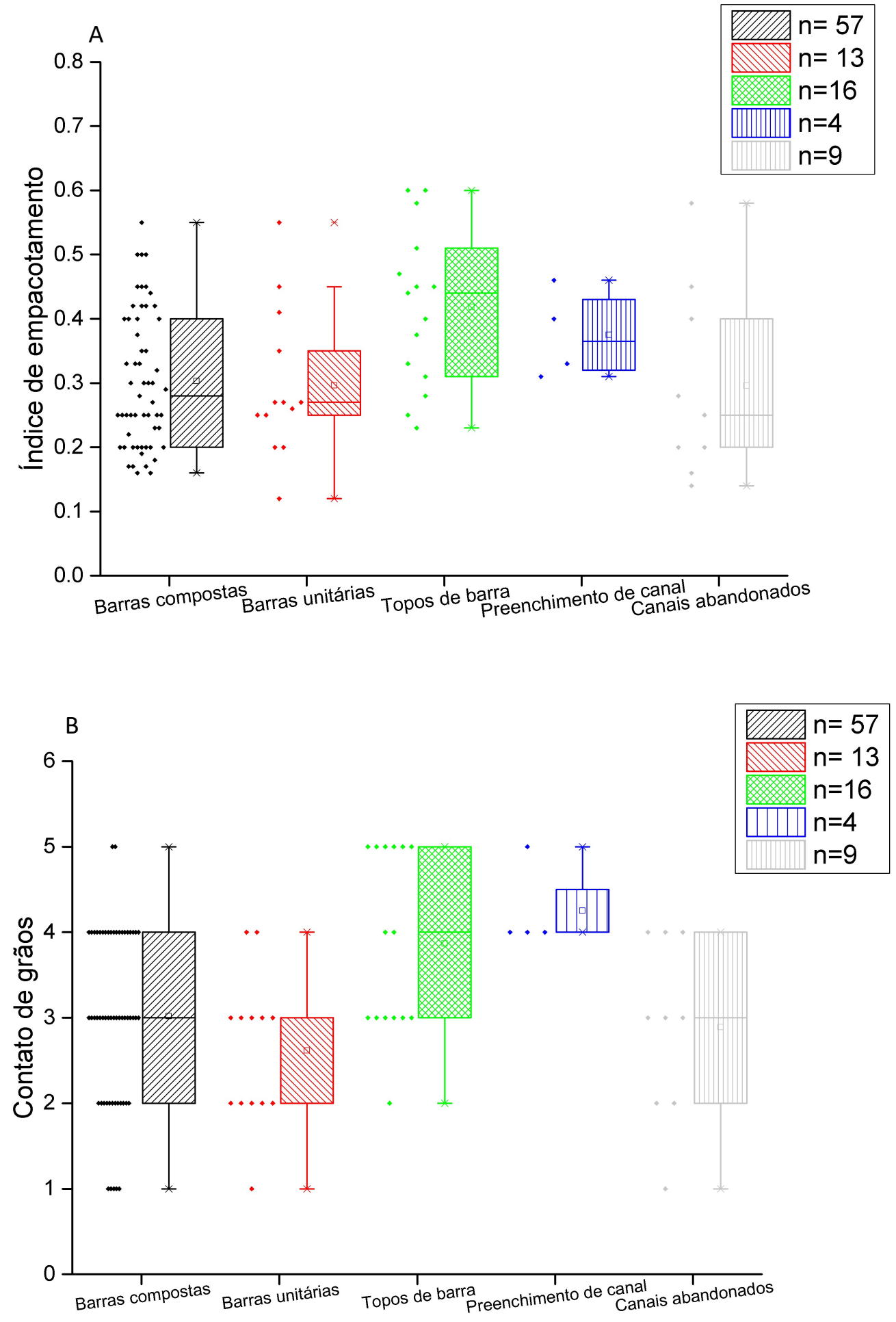

Figura 71 - A) Box plots dos elementos arquiteturais em função do índice de empacotamento (Kahn, 1956) (n= número de amostras analisadas) 
B) Box plots dos elementos arquiteturais em função do índice dos contatos de grão predominantes. No eixo y a classificação 1 representa "contato de grão flutuante" (predominante) e pontual; 2- grão flutuante e pontual (predominante); 3- pontual (predominante) e planar; 4- pontual e planar (predominante); e, 5-planar (predominante) e presença pontual de química subordinada ( $\mathrm{n}=$ número de amostras analisadas)

Quando analisadas as barras unitárias e compostas, e os topos de barra de cada afloramento separadamente nota-se maior índice de empacotamento e maiores fatores de contatos de grãos nos depósitos do afloramento TUC05 (figura $71 \mathrm{~A}$ e B). As barras compostas do afloramento TUC05 possuem mediana de empacotamento igual a 0,30 , e moda quatro (4) de fator de contato de grão, enquanto as do TUC41 apresentam mediana 0,24 e fator três (3) como moda de contato. Já os topos de barras do afloramento TUC05 e TUC41 possuem médias de índices de empacotamento iguais a 0,52 e 0,38 respectivamente. Os contatos de grãos apresentam moda com fator cinco (5) no TUC05 e moda fator três (3) no afloramento TUC41.

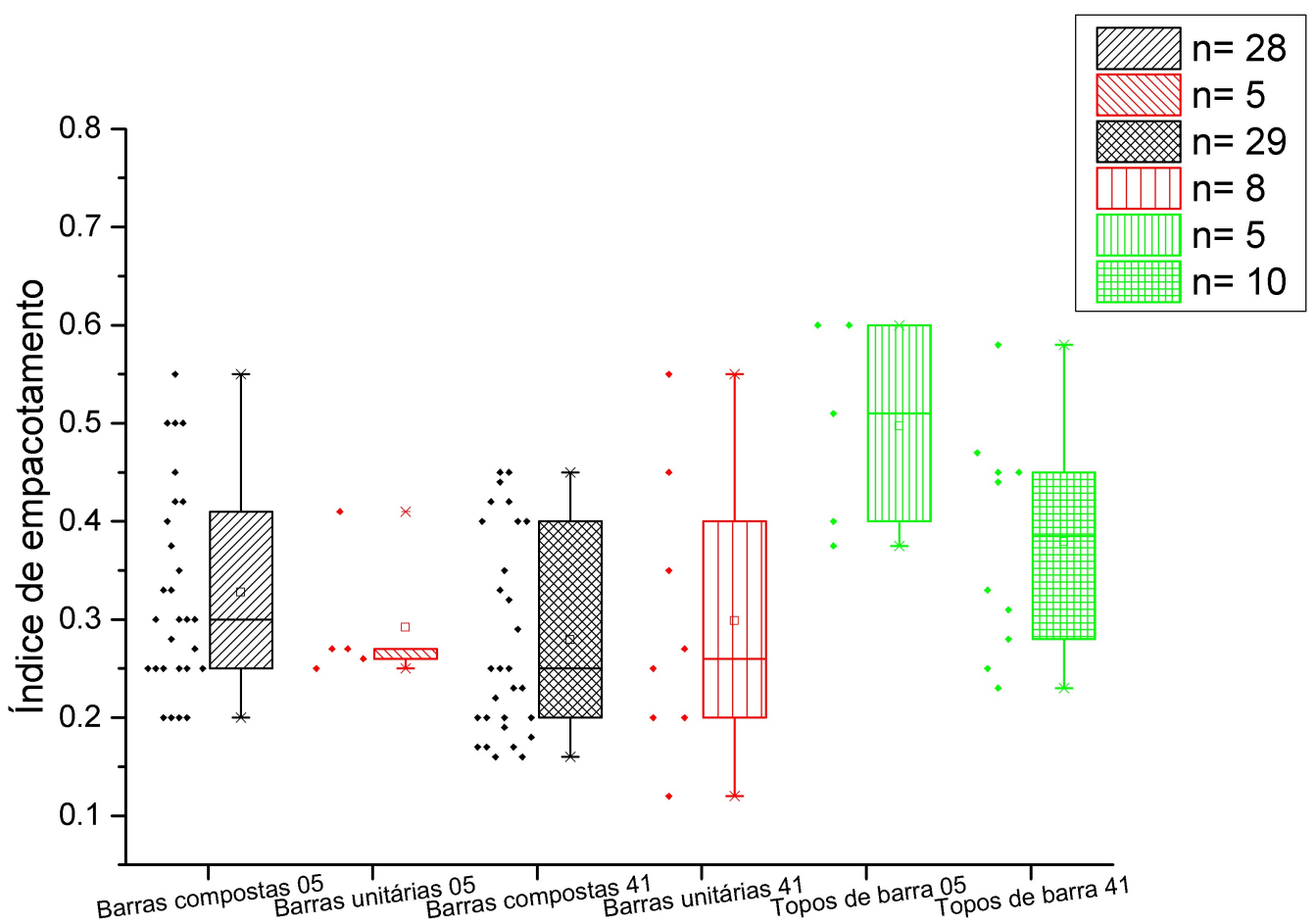




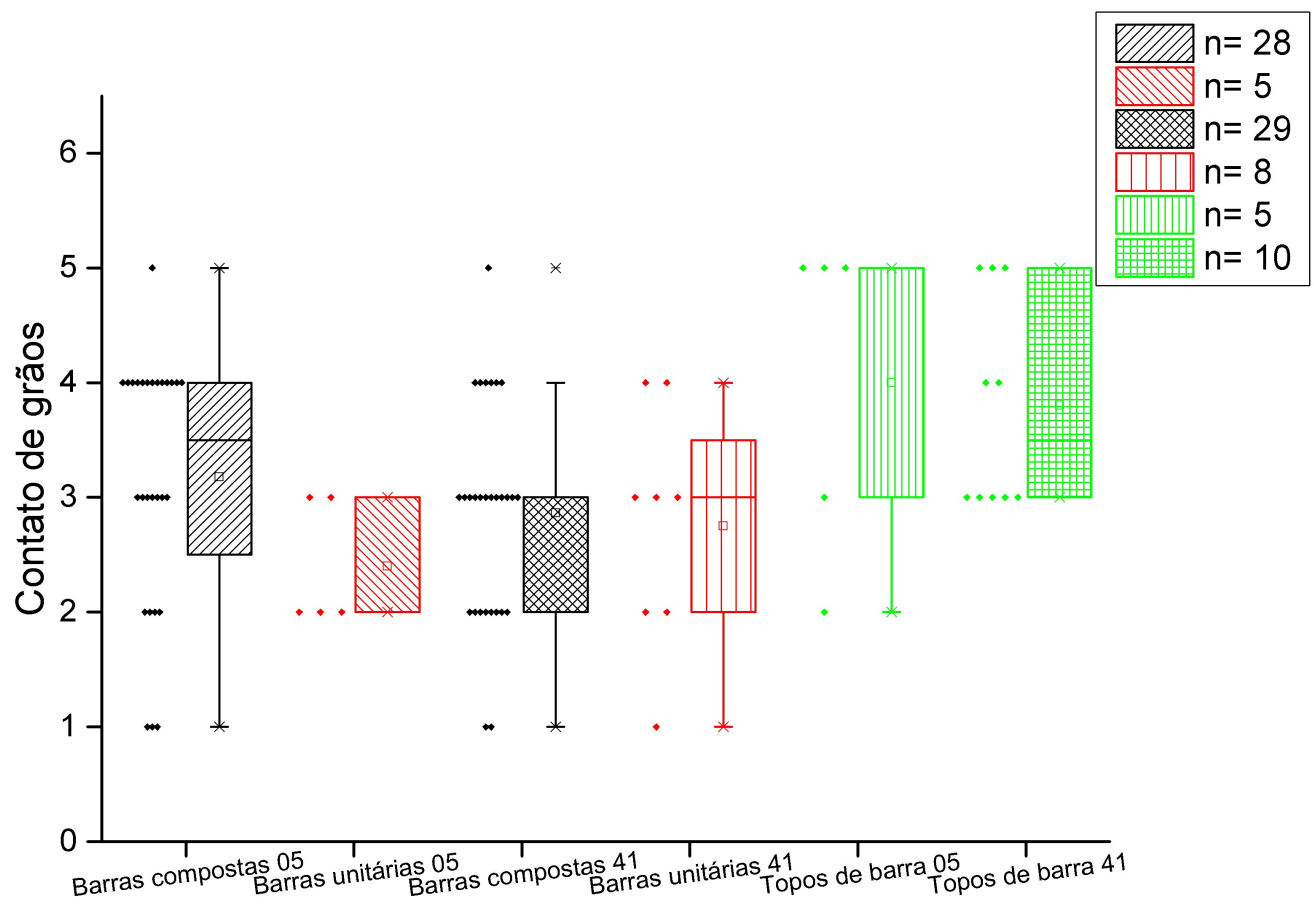

Figura 72 - A) Box plots dos elementos arquiteturais de cada afloramento em função do índice de empacotamento (Kahn, 1956) ( $n=$ número de amostras analisadas).

B) Box plots dos elementos arquiteturais de cada afloramento em função do índice dos contatos de grão predominantes. No eixo y a classificação 1 representa "contato de grão flutuante" (predominante) e pontual; 2- grão flutuante e pontual (predominante); 3- pontual (predominante) e planar; 4- pontual e planar (predominante); e, 5-planar (predominante) e presença pontual de química subordinada ( $\mathrm{n}=$ número de amostras analisadas)

\subsubsection{Pseudomatriz}

Pseudomatrizes mostram-se muito presentes nas rochas dos afloramentos estudados, da Formação São Sebastião (figura 73). A ocorrência dessa textura deve-se a compactação somada à presença de grãos dúcteis, sem a presença de cimentos eodiagenéticos pervasivos. Foram encontradas feições características de pseudomatriz em diferentes estágios, desde apenas o dobramento parcial do grão, como pseudomatrizes totalmente disseminadas. O argilomineral encontrado nessas texturas trata-se, na grande maioria dos casos, de caulinita. 

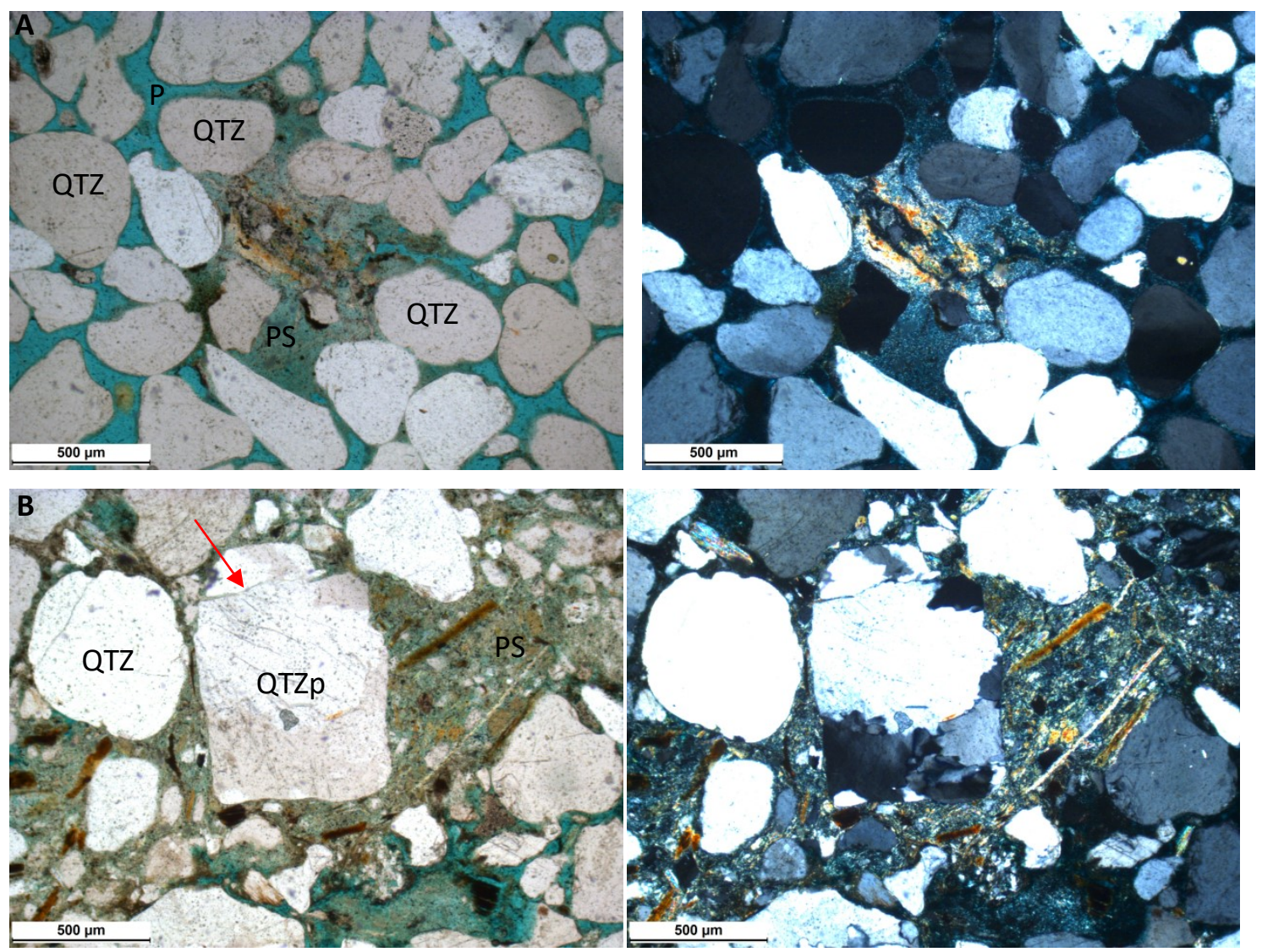

Figura 73 - A) Micrografia de pseudomatriz com resquício do grão precursor e grãos de quartzo do arcabouço (micrografia da esquerda obtida com nicois paralelos, enquanto a da direita cruzados).

B) Micrografia de pseudomatriz sem resquício do grão precursor e grãos de quartzo do arcabouço, inclusive um grande grão de quartzo policristalino pode ser notado (seta vermelha) (micrografia da esquerda obtida com nicois paralelos enquanto a da direita cruzados).

Legenda para todas as micrografias : $\mathrm{QTZ}=$ quartzo; $\mathrm{Qtzp}=$ quartzo policristalino; $\mathrm{PS}=$ pseudomatriz; e $\mathrm{P}=$ poro

Essa textura ocorre em 78 (79\%) amostras do total de 98 . Em 12 lâminas (12\%), compõem cerca de $5 \%$ dos poros; em 28 seções delgadas (28\%) compõem cerca de $10 \%$ dos poros; em 23 lâminas (23\%) compõem cerca de $25 \%$ dos poros; nove amostras (9\%) compõem $50 \%$ dos poros; quatro lâminas (4\%) compõem cerca de $75 \%$ ou mais dos poros preexistentes; e duas laminas (2\%) compõem cerca de 90\%. A moda para a presença de pseudomatriz é a presença em $10 \%$ dos poros preexistentes da lâmina, ou seja, fator igual a dois (2) (figura 74). 


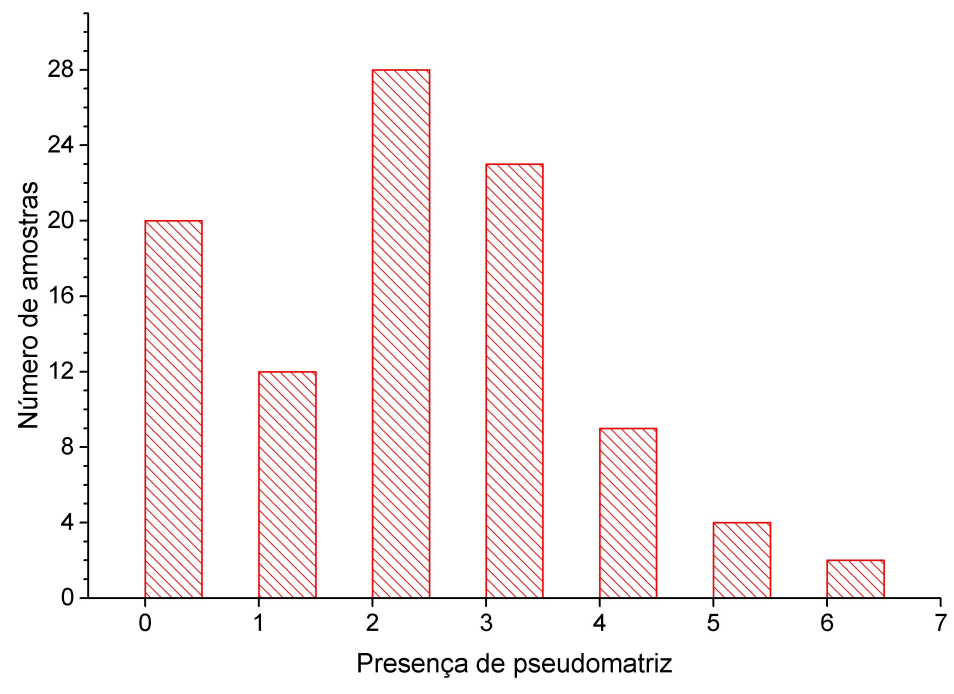

Figura 74 - Histograma do índice da presença de pseudomatriz nos afloramentos da Formação São Sebastião. No eixo x a classificação 0 representa constituinte inexistente; 1 - existente, presente em aproximadamente $5 \%$ dos poros; 2- presente em aproximadamente $10 \%$ dos poros; 3 - presente em aproximadamente $25 \%$ dos poros; 4 - presente em aproximadamente $50 \%$ dos poros; 5- presente em aproximadamente $75 \%$ dos poros; 6 - presente aproximadamente $90 \%$ dos poros. ( $n=$ número de amostras analisadas)

Considerando os elementos arquiteturais, as pseudomatrizes manifestam-se em menor concentração nas populações das amostras de barra unitária. Esse elemento tem como moda a ausência de pseudomatriz, seguido dos depósitos de barras compostas, com mediana igual ao fator dois (2) (10\% nos poros) (figura 75).

Os demais elementos arquiteturais apresentam pseudomatriz em todas as amostras. Os topos de barra possuem moda igual ao fator dois (2), mas $38 \%$ das amostras apresentam valores iguais ou maiores que o fator quatro (4). Os dados dos depósitos de preenchimento de canal, pela pequena quantidade de amostras dificultam a análise, com mediana entre os fatores dois (2) e três (3). Já os canais abandonados apresentam moda igual ao fator três (3) com $66 \%$ das amostras apontando o mesmo fator (figura 75). 


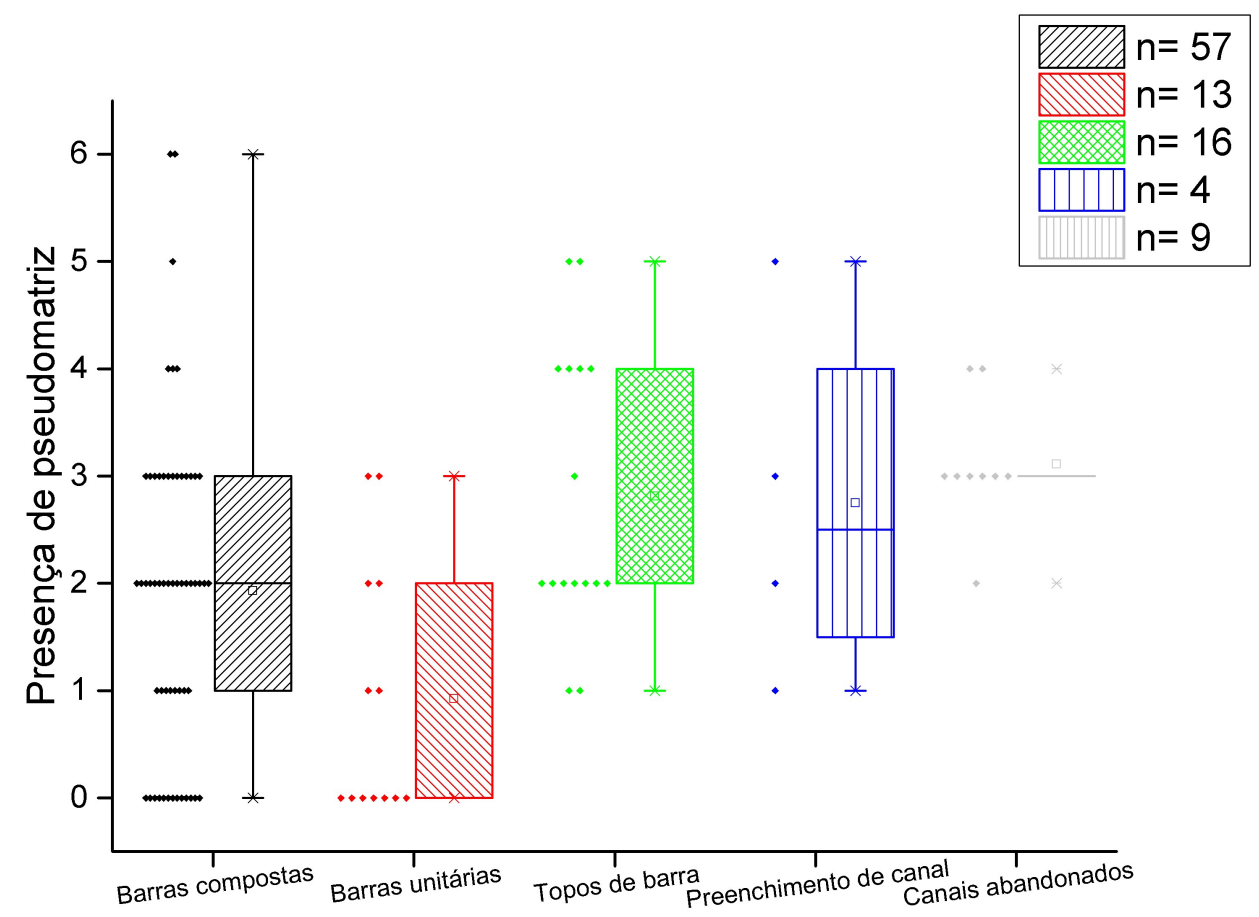

Figura 75 - Box plots dos elementos arquiteturais em função da presença de pseudomatriz. No eixo y a classificação 0 representa constituinte inexistente; 1 - existente, presente em aproximadamente $5 \%$ dos poros; 2 - presente em aproximadamente $10 \%$ dos poros; 3 presente em aproximadamente $25 \%$ dos poros; 4 - presente em aproximadamente $50 \%$ dos poros; 5 - presente em aproximadamente $75 \%$ dos poros; 6 - presente aproximadamente $90 \%$ dos poros. ( $n=$ número de amostras analisadas)

No afloramento TUC05 as amostras mostram-se mais ricas em pseudomatriz que no afloramento TUC41. A mediana das barras unitárias no TUC05 é igual ao fator um (1) e no TUC41 a moda é a ausência desse elemento. As barras compostas possuem moda de fator dois (2) no TUC 05, enquanto no TUC41 a moda é a ausência. O mesmo comportamento mostrado nas barras reflete-se nos topos de barra dos dois afloramentos, com medianas de fator quatro (4), no TUC05 e dois (2), no TUC41. A moda para esse elemento está entre fatores quatro (4) e cinco (5) no afloramento TUC05 e dois (2) no afloramento TUC41 (figura 76). 


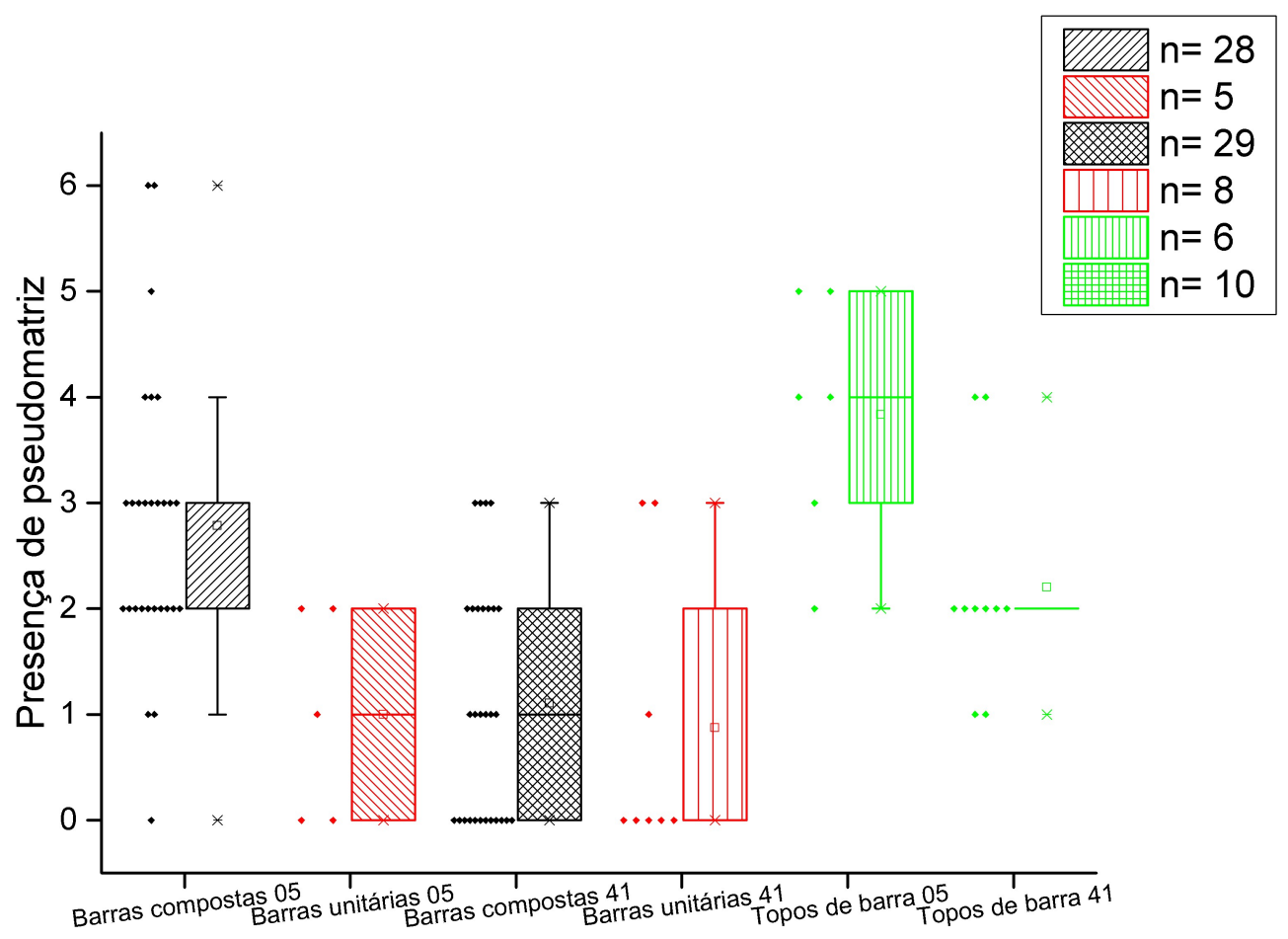

Figura 76 - Box plots dos elementos arquiteturais de cada afloramento em função da presença de pseudomatriz. No eixo y a classificação 0 representa constituinte inexistente; 1 - existente, presente em aproximadamente $5 \%$ dos poros; 2 - presente em aproximadamente $10 \%$ dos poros; 3- presente em aproximadamente $25 \%$ dos poros; 4 - presente em aproximadamente $50 \%$ dos poros; 5 - presente em aproximadamente $75 \%$ dos poros; 6 - presente aproximadamente $90 \%$ dos poros. ( $n=$ número de amostras analisadas)

\subsubsection{Argila infiltrada}

As argilas infiltradas foram constatadas em diversas amostras da Formação São Sebastião (figura 77). Foram encontradas feições característiscas de argilas infiltradas (possivelmente esmectitas) como coatings irregulares (figura $80 \mathrm{~A}$ ), ridges and bridges (figura $80 \mathrm{~A}$ ), e descolamento das mesmas das paredes dos grãos (figura $80 \mathrm{~B}$ ). Essa última textura pode ser resultado pela perda de água, diminuindo o volume da argila (shirinkage).

Determinar o período de ocorrência da argila infiltrada neste trabalho é muito complicado devido à baixa compactação e manifestação em alta frequência de contatos flutuantes. Ocorrências pós-compactacionais são mais 
frequentes. Essa textura foi aqui interpretada, devido ao contexto geral, como pós-compactacional (telodiagenética).
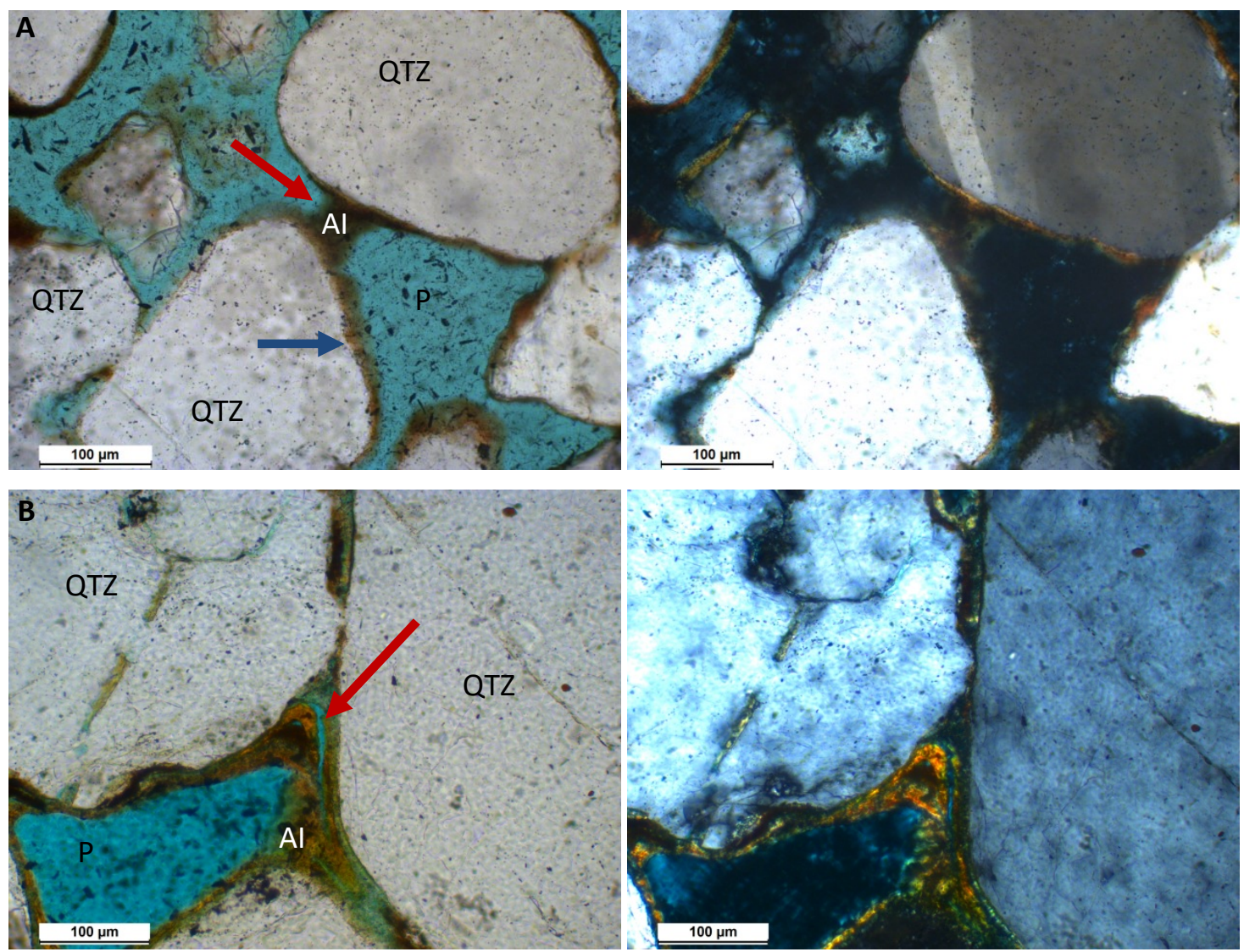

Figura 77 - A) Micrografia de coatings irregulares de argila infiltrada, possivelmente esmectita, (seta azul) e estrutura bridges (seta vermelha) (micrografia da esquerda obtida com nicois paralelos enquanto a da direita cruzados).

B) Micrografia de estrututura shrinkage (seta vermelha) (micrografia da esquerda obtida com nicois paralelos enquanto a da direita cruzados)

Legenda para micrografias: $\mathrm{QTZ}=$ quartzo; $\mathrm{Al}=$ argila infiltrada; $\mathrm{e} \mathrm{P}=$ poro

Essa textura ocorre em 48 amostras do total de 95 (50\%). Em nove lâminas $(9 \%)$ as argilas infiltradas compõem cerca de $5 \%$ dos poros preexistentes; 20 amostras (21\%) compõem cerca de $10 \%$ dos poros; 11 lâminas (12\%) compõem cerca de $25 \%$; quatro lâminas (4\%) compõem $50 \%$ dos poros preexistentes; e, quatro lâminas (4\%) compõem cerca de $75 \%$ ou mais dos poros preexistentes. A moda para a presença de argila infiltrada, quando esta se manifesta, é a presença de em $10 \%$ dos poros preexistentes da lâmina, ou seja, igual a dois (2) (figura 78). 


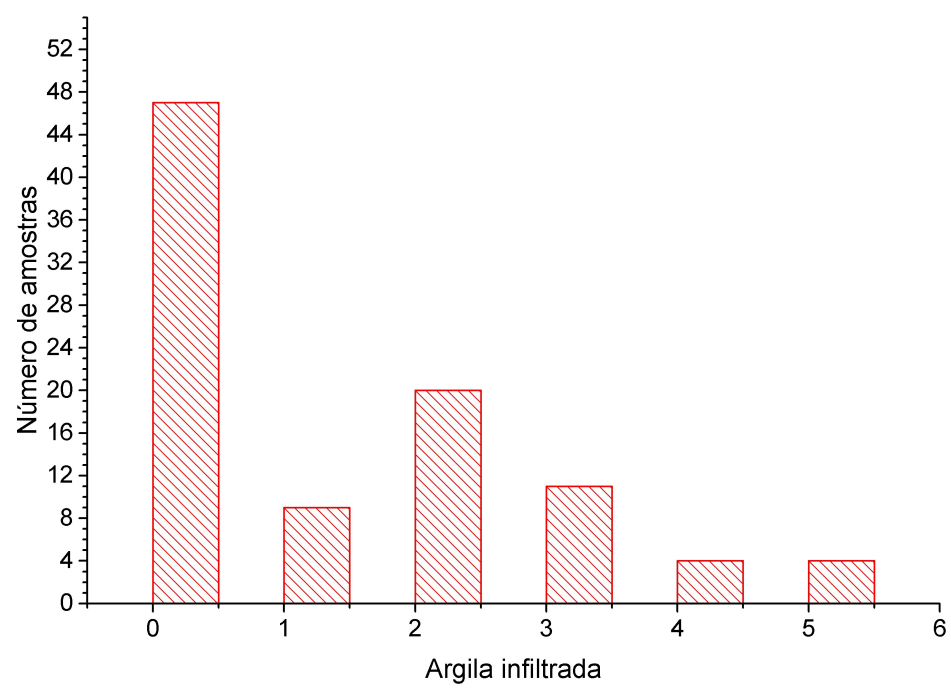

Figura 78 - Histograma do índice da presença de argila infiltrada nos afloramentos da Formação São Sebastião. No eixo x a classificação 0 representa constituinte inexistente; 1 existente, presente em aproximadamente $5 \%$ dos poros; 2- presente em aproximadamente $10 \%$ dos poros; 3 - presente em aproximadamente $25 \%$ dos poros; 4 - presente em aproximadamente $50 \%$ dos poros; 5 - presente em aproximadamente $75 \%$ dos poros; 6 presente aproximadamente $90 \%$ dos poros. ( $\mathrm{n}=$ número de amostras analisadas)

A ocorrência de argila infiltrada, diferentemente dos demais componentes até aqui analisados, não mostram relação direta com os elementos arquiteturais. A ocorrência dessa textura é muito baixa, com moda zero (0) em todos os EAs e médias entre fatores um (1) e dois (2) nas barras e topos de barra (figura 79).

Embora exista uma dispersão muito grande nas barras e nos topos de barras, quando esse componente se manifesta nos topos de barra, tende a ocorrer em maiores concentrações que nas barras (três amostras com fator (3)). 


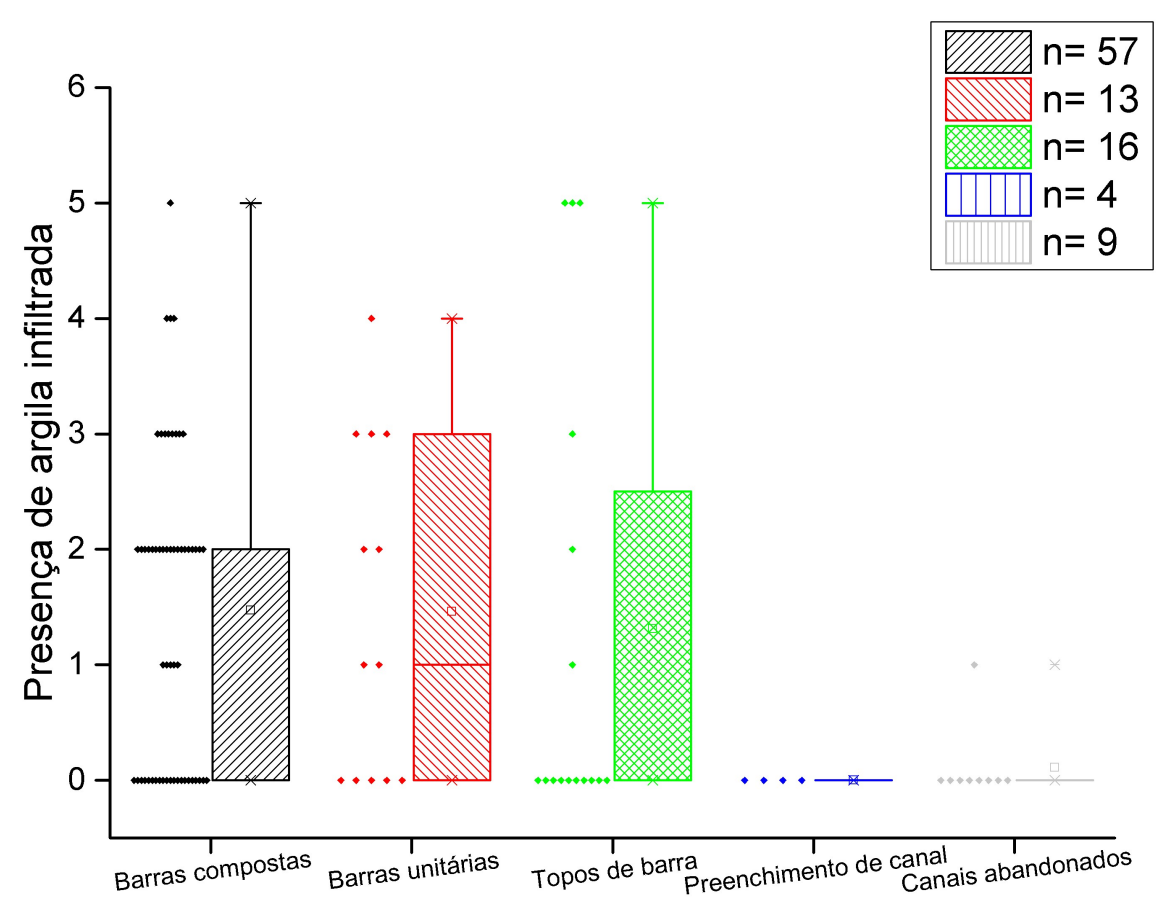

Figura 79 - Box plots dos elementos arquiteturais em função da presença de argila infiltrada. No eixo y a classificação 0 representa constituinte inexistente; 1 - existente, presente em aproximadamente $5 \%$ dos poros; 2 - presente em aproximadamente $10 \%$ dos poros; 3 presente em aproximadamente $25 \%$ dos poros; 4 - presente em aproximadamente $50 \%$ dos poros; 5 - presente em aproximadamente $75 \%$ dos poros; 6 - presente aproximadamente $90 \%$ dos poros. ( $\mathrm{n}=$ número de amostras analisadas)

Analisando os afloramentos separadamente, nota-se maior concentração de argila infiltrada no afloramento TUC41 (figura 80). A moda nas barras, compostas e unitárias, do afloramento TUC41, é igual a dois (2) e três (3), respectivamente. Nos topos de barra apresentam-se tanto em altas concentrações iguais a cinco (5), como ausentes. 


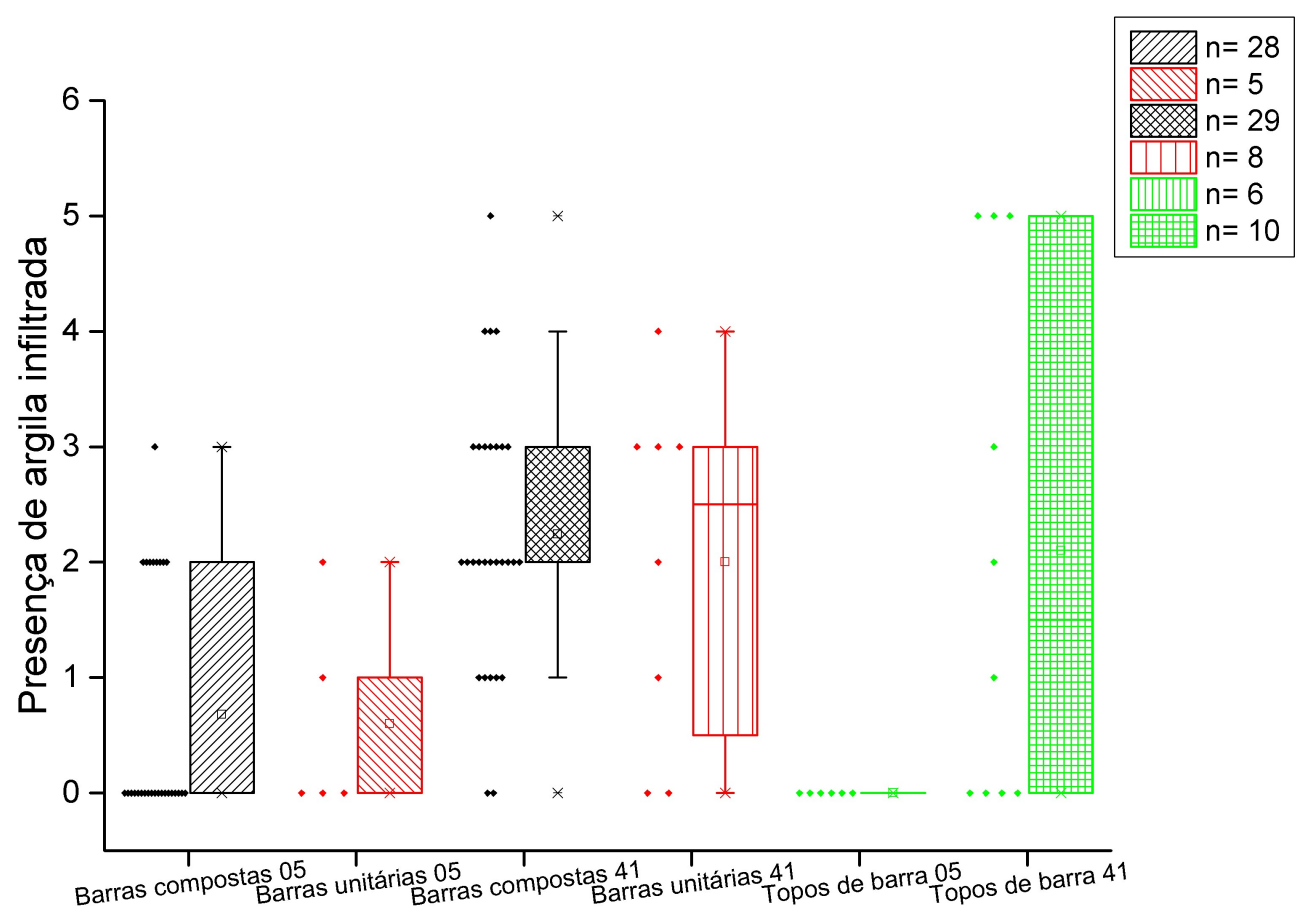

Figura 80 - Box plots dos elementos arquiteturais de cada afloramento em função da presença de argila infiltrada. No eixo y a classificação 0 representa constituinte inexistente; 1 - existente, presente em aproximadamente $5 \%$ dos poros; 2- presente em aproximadamente $10 \%$ dos poros; 3 - presente em aproximadamente $25 \%$ dos poros; 4 - presente em aproximadamente $50 \%$ dos poros; 5 - presente em aproximadamente $75 \%$ dos poros; 6 - presente aproximadamente $90 \%$ dos poros. ( $n=$ número de amostras analisadas)

A baixa presença de argila infiltrada mostrada no histograma de população total deve-se principalmente às amostras do afloramento TUC05, onde ocorrem restritamente, com apenas uma amostra apresentando fator maior que dois (2) (figura 78). Porém, no afloramento TUC-41 mostram-se frequentes, apresentando por vezes até fator cinco (5).

\subsubsection{Cimentos subordinados}

Nas análises petrográficas observou-se a ocorrência de cimentos pouco expressivos. Entre eles estão: sobrecrescimentos de quartzo, argilas diagenéticas e sobrecrescimentos de feldspatos. 
Os sobrecrescimentos de quartzo são recorrentes em reservatórios siliciclásticos (Burley et al., 1989). Porém, esse tipo de cimentação manifestase raramente nas amostras da Formação São Sebastião. Esse ocorrem apenas em grãos isolados que não possuem contatos com outros grãos. Devido à ínfima quantidade de compactação química entre grãos de quartzo e pequena ocorrência desse cimento é muito difícil a interpretação deste.

As argilas diagenéticas também não ocorrem em grande quantidade nas rochas analisadas, mas possuem maior ocorrência que os sobrecrescimentos de quartzo. Elas manifestam-se na forma de pore-lining (figura 81), com coloração esbranquiçada, pré-compactacional (ocorrem entre as superfícies de contato entre os grãos), com birrefringência baixa. Localmente, os argilominerais de baixa birefringência aparecem substituídos por argilas portadoras de maior birrefringência, possivelmente esmectita (figura 81). Para melhores afirmações sobre a classificação exata dos argilominerais, seriam necessárias análises de MEV e difração de raios $X$.

Os sobrecrescimentos de feldspato encontrados são pouco frequentes. Tratam-se de sobrecrescimento de feldspato potássico, onde o mesmo possui composição nitidamente mais pura que o mineral do arcabouço da rocha, ocorrendo anteriormente às argilas infiltradas (figura 82). O sobrecrescimento é, possivelmente, resultado da dissolução de feldspatos detríticos (liberando sílica e potássio). 

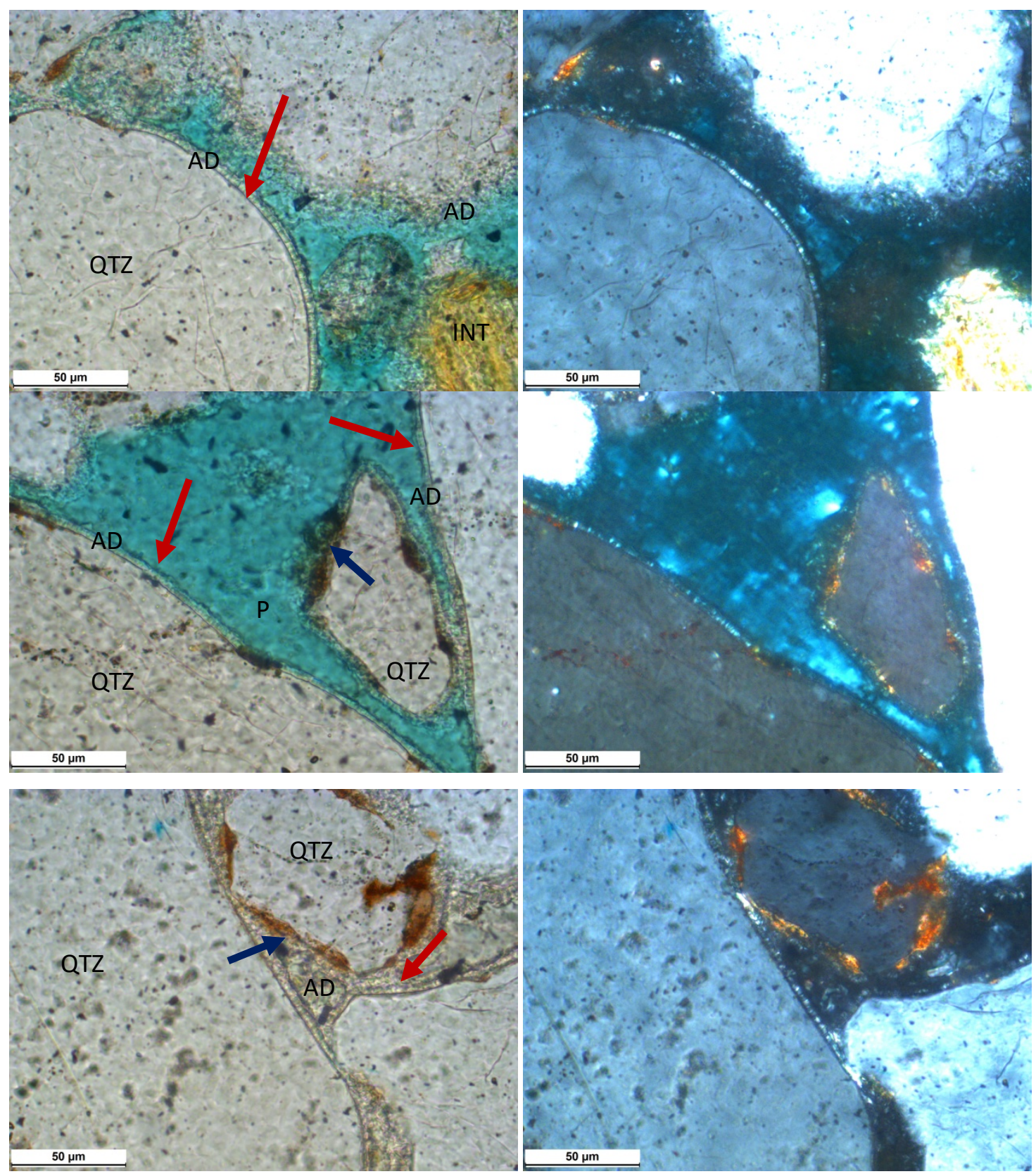

Figura 81 - Micrografias de coating pore-lining de argila diagenética pré compactacional (seta vermelha), substituída, possívelmente, por esmectita (seta azul) (micrografia da esquerda obtida com nicois paralelos enquanto a da direita cruzados) $(\mathrm{QTZ}=$ quartzo; $\mathrm{AD}=$ argila diagenética; INT = intraclasto argiloso; e, $\mathrm{P}=$ poro) 

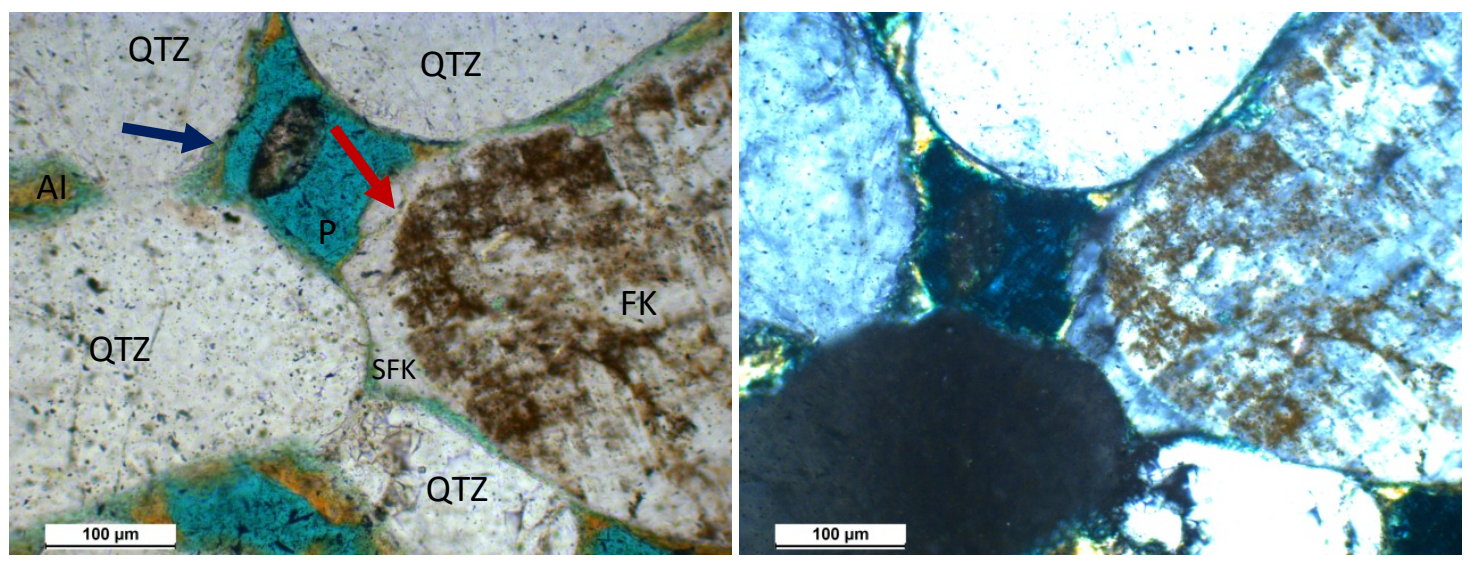

Figura 82 - Micrografias de sobrecrescimento de feldspato alcalino (seta vermelha). Notam-se também coatings irregulares de argila infiltrada pós compactacional (seta azul) (micrografia da esquerda obtida com nicois paralelos enquanto a da direita cruzados) ( $Q T Z$ = quartzo; $\mathrm{Al}=$ argila infiltrada; FK = feldspato potássico; SFK = sobrecrescimento de feldspato potássico; e P $=$ poro)

\subsubsection{Porosidade}

Os poros encontrados na Formação São Sebastião, por meio a contagem modal, foram separados em primários intergranulares e intragranulares. (figura $83 \mathrm{~A}, \mathrm{~B}, \mathrm{C}$ e D).

Nas seções estudadas, as porosidades intragranulares, em sua grande maioria, caracterizam-se por grãos dissolvidos (figura 83 B, C e D), e localmente são encontradas porosidades provenientes, possivelmente, de tectonismo rúptil (figura $83 \mathrm{E}$ ). Além disso, as porosidades intragranulares são locais, ou seja, apenas onde grãos de feldspato, líticos ou argilosos foram dissolvidos. Isso se explica pelo fato da grade maioria dos constituintes do arcabouço (próximo a 90\%) serem representados por quartzo na Formação São Sebastião. O quartzo é dificilmente dissolvido em reservatórios, pois é solúvel apenas em condições muito básicas, com pH maior que nove (Pettijohn et al., 2012). 


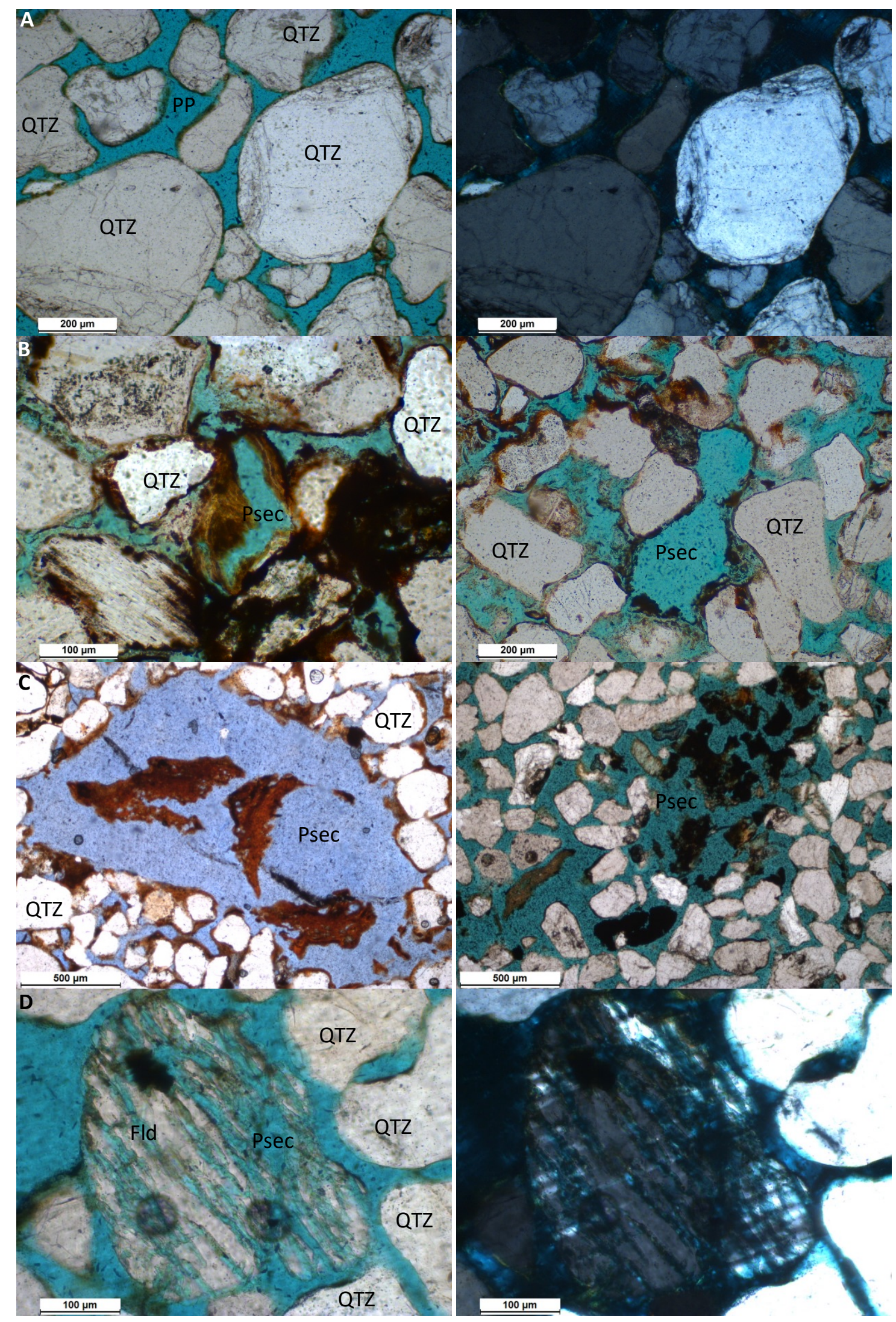




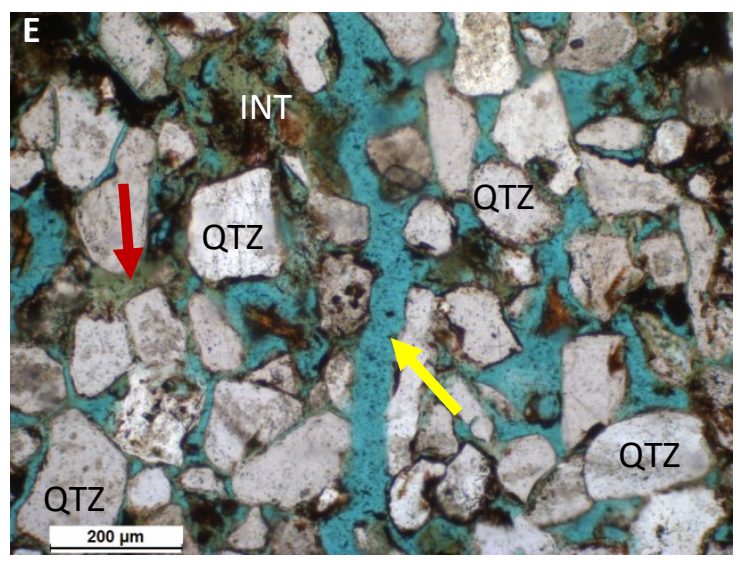

Figura 83 - A) Micrografia de porosidade intergranular (micrografia da esquerda obtida com nicois paralelos, enquanto a da direita cruzados)

B) Micrografia de porosidade secundária proveniente da dissolução parcial (direita) de fragmento argiloso e dissolução total (esquerda) (micrografias obtidas com nicos paralelos)

C) Micrografias de dissoluções parciais (micrografias obtidas com nicois paralelos).

D) Micrografia de dissolução parcial de grão de feldspato (micrografia da esquerda obtida com nicois paralelos, enquanto a da direita cruzados).

E) Micrografia de dissolução de mineral placóide ou produto de microfratura (seta amarela). Nota-se também fragmentos argilosos compactados obstruindo poros (seta vermelha) (micrografia obtida com nicois paralelos)

Legenda para as micrografias : $\mathrm{QTZ}=$ quartzo; $\mathrm{PP}=$ poro primário; $\mathrm{Psec}=$ poro secundário; Fld = feldspato; e INT = intraclasto argiloso

A porosidade intergranular por si só varia desde zero até $24 \%$ pela análise quantitativa. A distribuição das amostras apresenta-se muito dispersa, com moda próxima a $3 \%$, observada em oito amostras. Porém, valores como $10 \%$ são encontrados em seis amostras. Porosidades intergranulares iguais a $5 \%, 11 \%$ e $15 \%$ estão representadas cada uma por cinco amostras (figura 84 ).

Já a porosidade intragranunlar varia de zero até $16 \%$. A moda concentra-se em valores próximos entre $2 \%$ e quatro $4 \%$, representada por 15 amostras. Porosidades intragranulares muito baixas, até $2 \%$ também são significativas na distribuição, representadas por 12 amostras (figura 84) 


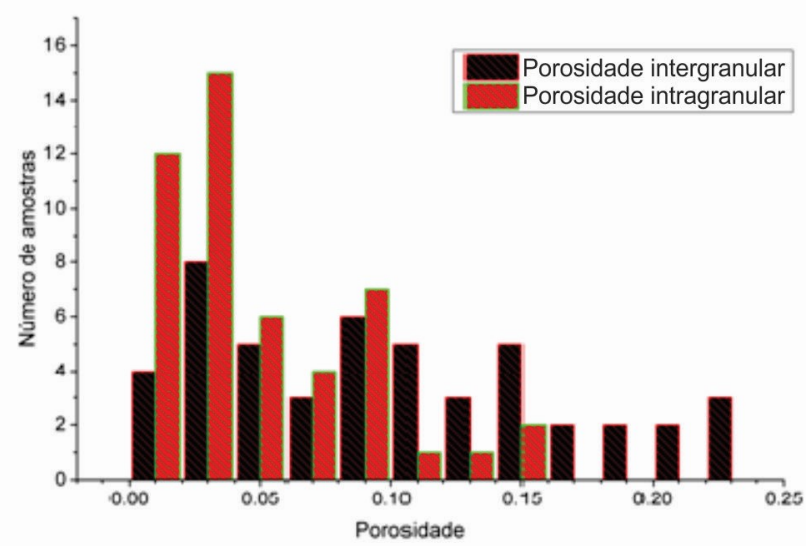

Figura 84 - Histograma discriminado porosidade intergranular e intragranular com intervalo de dois por cento para cada bin , nos afloramentos da Formação São Sebastião.

$\mathrm{Na}$ maior parte das amostras a porosidade intergranular mostra-se superior à intragranular, com exceção de algumas amostras do afloramento TUC41 (figura 85).

Nota-se a distinção entre as amostras dos dois afloramentos. No afloramento TUC05 predominam as amostras com maior porosidade intergranular, e porosidade intragranular relativamente baixa. Já no TUC41 são apresentados maiores valores de porosidade intragranunlar (próximo a 10\%), com valores intermediários de porosidade intergranular.

As porosidades intergranulares e intragranulares são exponencialmente inversamente proporcionais apresentando fator de correlação $r^{2}=0,833$. Com essa relação é possível afirmar que em altas porosidades intergranulares, a porosidade intragranular tende a assumir valores baixos. 


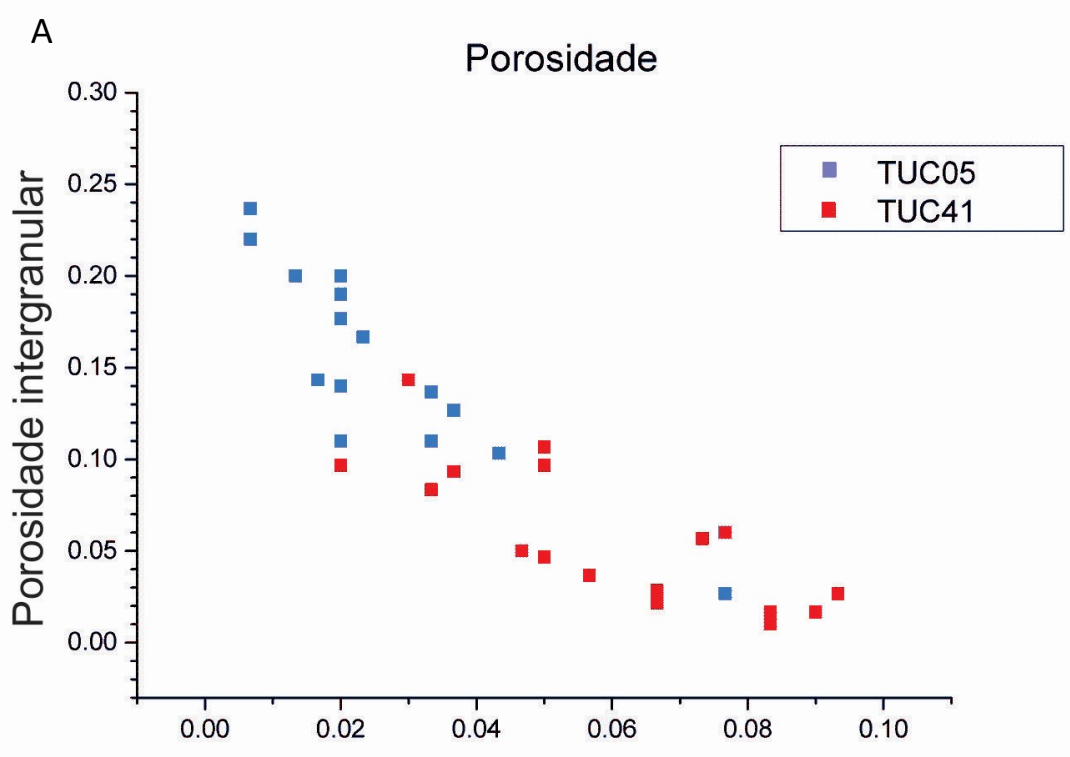

Porosidade intragranular

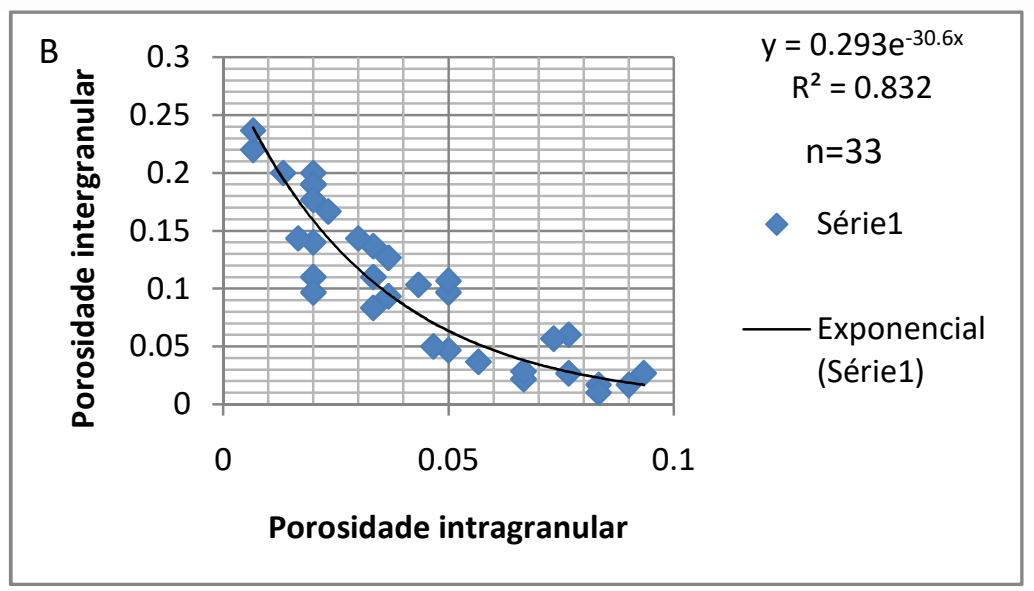

Figura 85 - Scatter plot da porosidade intragranular pela porosidade intergranular nos afloramentos TUC05 e TUC41 da Formação São Sebastião. B) Scatter plot da porosidade intragranular pela porosidade intergranular com fator de correlação $\left(r^{2}=0,832\right)$, nos afloramentos da Formação São Sebastião ( $n=$ número de amostras analisadas)

\subsection{Permoporosidade}

Os resultados de permoporosidade foram adquiridos pelo método a gás e por um método alternativo. Para a porosidade, o método alternativo foi a aquisição por imagem. Já para a permeabilidade, o alternativo foi 0 permeâmetro de campo. 


\subsubsection{Análises de porosidade}

As análises de porosidade foram realizadas pelos métodos a gás em 85 amostras, dos afloramentos TUC05 e TUC41. Também foram realizadas análises por imagem, em 178 lâminas delgadas.

\subsubsection{Análise de porosidade a gás}

As análises de porosidade a gás foram executadas em direções horizontais e verticais. A moda obtida está entre $23 \%$ e $24 \%$, representada por 12 amostras (14\% do total). A porosidade máxima obtida foi igual $31,9 \% \mathrm{e}$ mínima de $16,7 \%$ (figura 86 ).

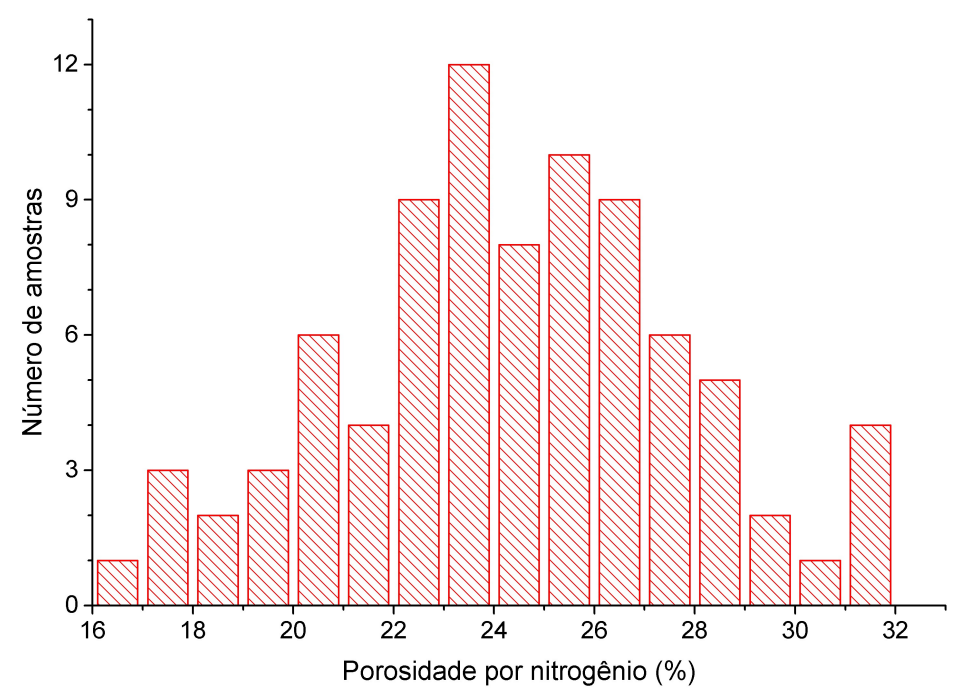

Figura 86 - Histograma da porosidade obtida por meio a injeção de gás nitrogênio nas rochas da Formação São Sebastião.

Realizando-se análises em relação à arquitetura deposicional, a maior porosidade foi obtida nos preenchimento de canais, seguido pela barras unitárias, barras compostas e topos de barra. Nas barras unitárias, a mediana atingiu valor de $25,5 \%$, chegando localmente a $31,9 \%$, enquanto nas 
compostas a mediana atingiu valor de $23,8 \%$, com valor máximo de $31,6 \%$ e valor mínimo $16,8 \%$. Para os depósitos de topo de barra, a mediana tem porosidade próxima a $22,8 \%$, com valor mais alto de $25,0 \%$ e valor mais baixo de $16,7 \%$. Para os depósitos de preenchimento de canal o valor mais alto foi $26,8 \%$ e mais baixo $24,0 \%$ (figura 87 ).

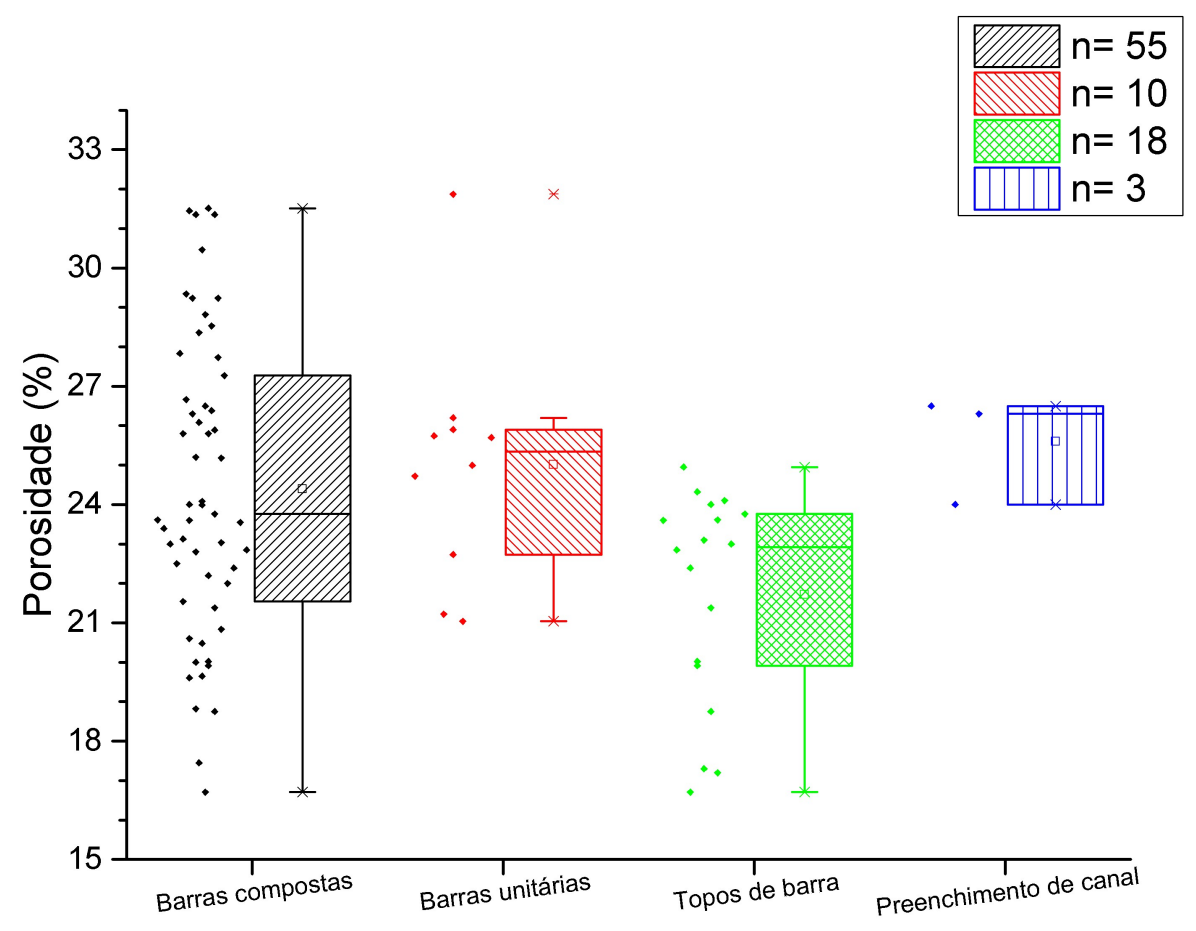

Figura 87 - Box plots dos elementos arquiteturais em função da porosidade obtida pelo método de gás nitrogênio nas amostras da formação São Sebastião ( $n=$ número de amostras analisadas)

As razões para altas porosidades apresentadas nas barras unitárias são atreladas principalmente às estruturas sedimentares de estratificações cruzadas tabulares, predominantes nesse elemento arquitetural, como também à melhor segregação granular, arredondamento e baixa presença de pseudomatriz e micas. Os parâmetros geológicos mais influentes na porosidade dos afloramentos da Formação São Sebastião serão comentados com detalhe na análise dos resultatos. 
Analisando separadamente os afloramentos, nota-se que o afloramento TUC41 possui porosidades maiores que o afloramento TUC05, tanto para depósitos de barra como para topos de barra (figura 88).

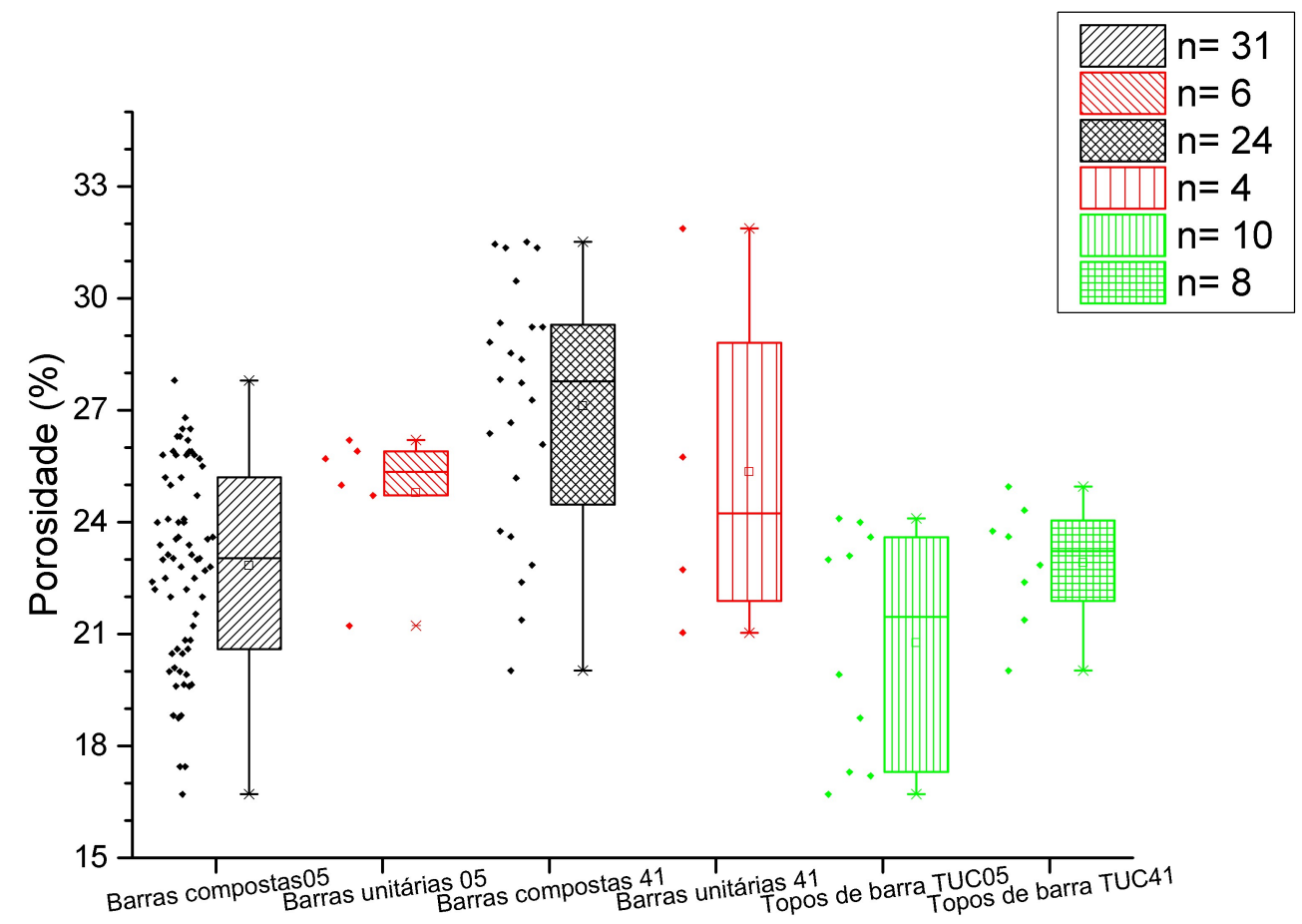

Figura 88 - Box plots dos elementos arquiteturais de cada afloramento em função da porosidade obtida pelo método de injeção de gás nitrogênio nas amostras da Formação São Sebastião ( $\mathrm{n}=$ número de amostras analisadas)

\subsubsection{Análise de porosidade em lâmina}

As análises de porosidade obtidas em lâmina delgadas foram realizadas tanto em direções horizontais quanto verticais. Os valores aqui apresentados referem-se à mediana da porosidade visual de 30 fotografias somada ao desvio padrão (erro) (figura 89 A) e apenas a mediana (figura 89 B).

No primeiro histograma (figura 89 A) a maior frequência concentra-se entre $18 \%$ e $20 \%$, ocorrendo em 27 amostras, representando cerca de $15 \%$ do total. A porosidade máxima obtida foi igual $36 \%$ e mínima de $7 \%$. 
Já no segundo histograma (figura 89 B), a moda está entre 14\% e 16\%, contabilizada em 26 amostras, representando, assim como no primeiro gráfico, $15 \%$ do total. Os valores mínimos e máximos são: $4 \%$ e $29 \%$, respectivamente.
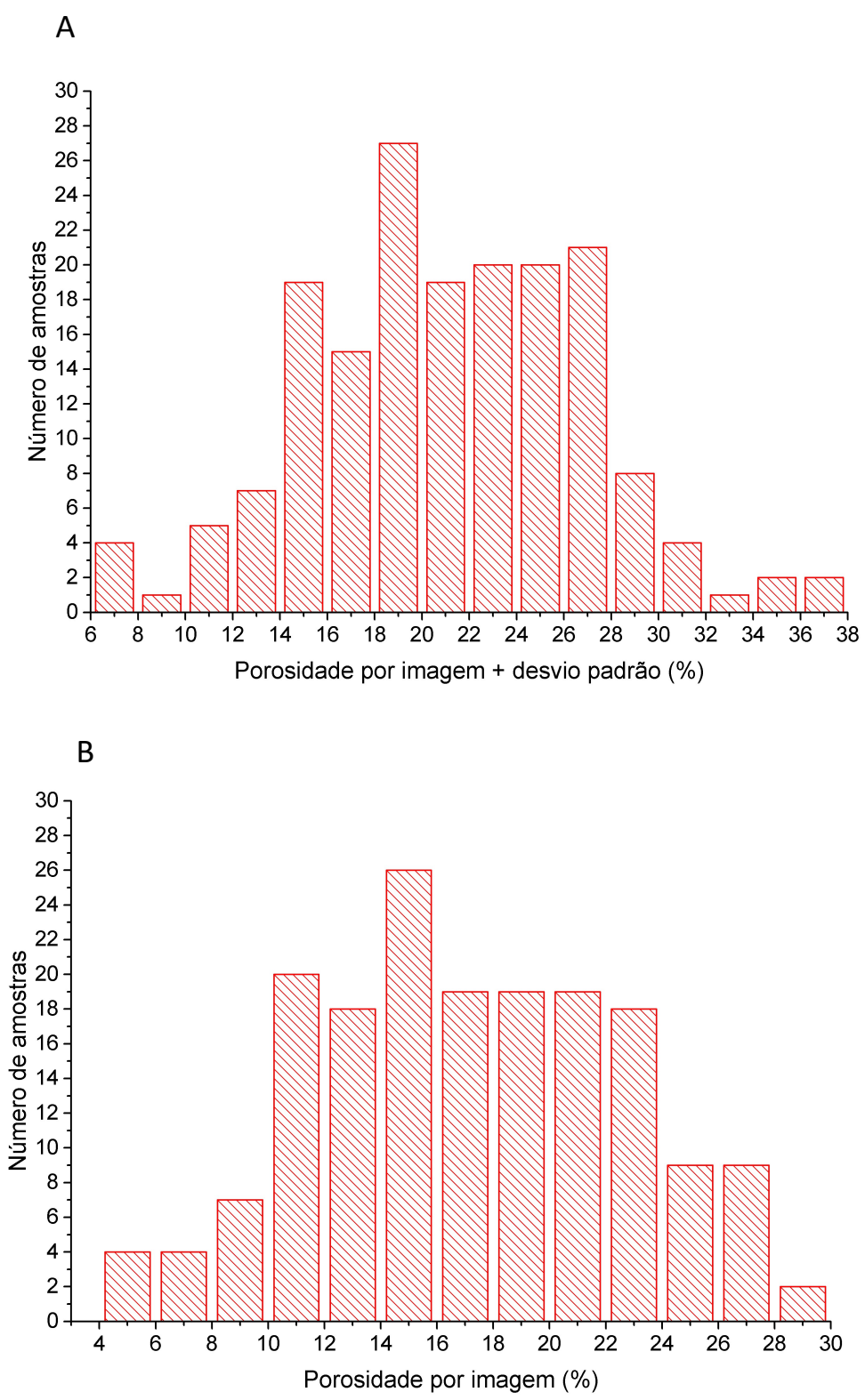

Figura 89 - A) Histograma da mediana da porosidade obtida por imagem pelo software LAS somado ao desvio padrão nas rochas da Formação São Sebastião.

B) Histograma da mediana da porosidade obtida por imagem pelo software LAS nas rochas da Formação São Sebastião 
Realizando-se análise por elemento arquiteturais, observa-se que a mediana da porosidade nas amostras dos depósitos de barra unitária é de $21 \%$, com valor mais alto de $29,45 \%$ e mais baixo de $10,5 \%$. Para as barras compostas, a mediana foi de $19 \%$, com máximo de $28 \%$ e mínimo de $4,5 \%$. Os depósitos de topo de barra obtiveram mediana de $14 \%$, com valor mais alto de $28.8 \%$ e mais baixo de $4,15 \%$. Para os depósitos de preenchimento de canal, a mediana obtida foi de $24.2 \%$, com valor mais alto de $27 \%$ e valor mais baixo de $19,2 \%$. Já os canais abandonados possuem média 16,5\%, com valor máximo de $30,1 \%$ e mínimo $7.5 \%$ (figura 90 ).

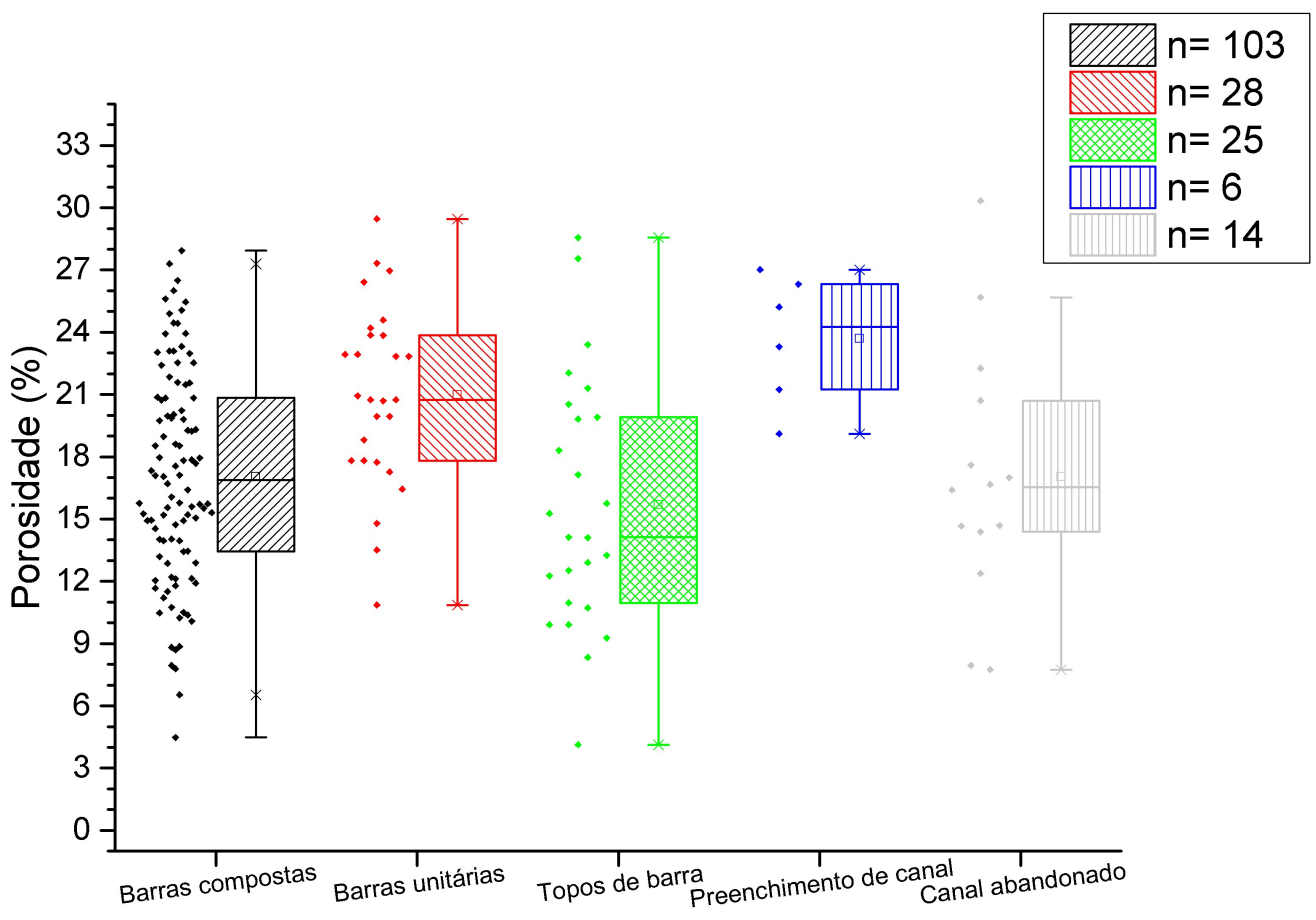

Figura 90 - Box plots dos elementos arquiteturais em função da mediana da porosidade obtida por imagem pelo software LAS, nas amostras da formação São Sebastião ( $n$ = número de amostras analisadas)

\subsubsection{Análises de permeabilidade}

As análises de porosidade foram realizadas pelos métodos a gás em 51 amostras, dos afloramentos TUC05 e TUC41. Também foram realizados ensaios com o permeâmetro de campo, em 1536 locais. As análises foram 
efetuadas em direções horizontais e verticais, mas $80 \%$ dos valores são de permeabilidade horizontal.

\subsubsection{Análise de permeabilidade a gás}

A permeabilidade máxima obtida pelo método a gás foi igual a 16153 $\mathrm{mD}$ e a mínima de $0.016 \mathrm{mD}$ (figura 91). A moda obtida é menor que $250 \mathrm{mD}$, representadas por 29 amostras (38\% do total).

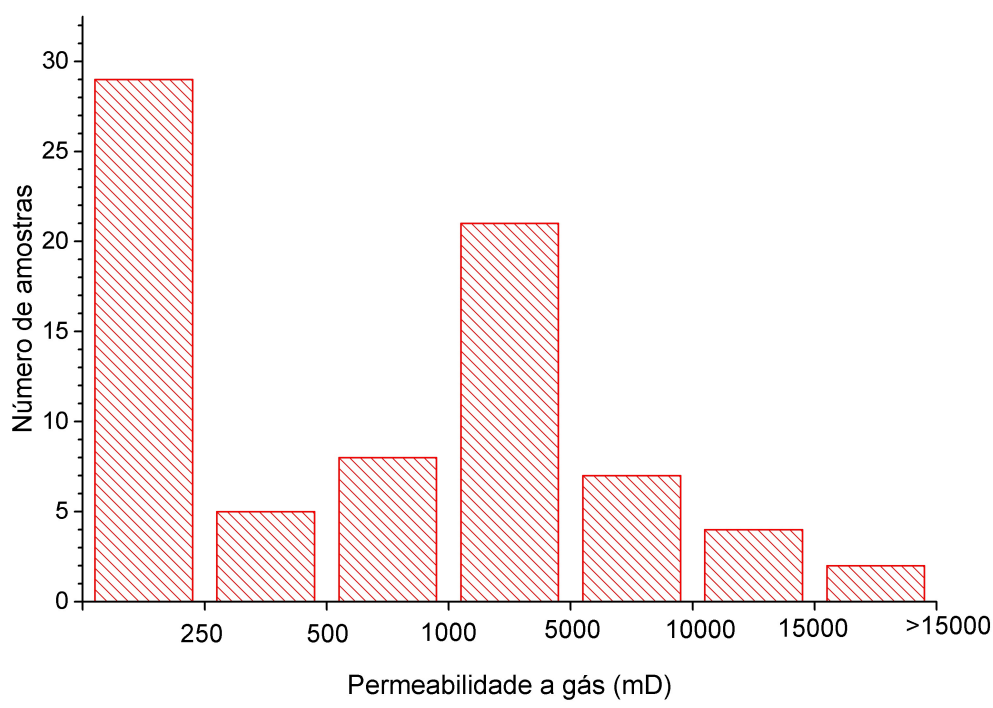

Figura 91 - Histograma da permeabilidade obtida por meio a injeção de gás nitrogênio nas rochas da Formação São Sebastião.

Em relação aos elementos arquiteturais existentes nestes depósitos, a permeabilidade nas barras unitárias foi maior que nas barras compostas, por sua vez maior que nos preenchimentos de canais e topos de barra. Nas barras unitárias a mediana atingiu valor próximo de $4000 \mathrm{mD}$, enquanto nas compostas o valor foi de $3000 \mathrm{mD}$. Para os depósitos de topo de barra a mediana aproxima-se de $30 \mathrm{mD}$, com valor mais alto de $2000 \mathrm{mD}$ e valor mais baixo de 0,016 mD. Para os depósitos de preenchimento de canal três 
amostras foram analisadas e obtiveram praticamente o mesmo valor, entre 150 e $200 \mathrm{mD}$ (figura 92).

A permeabilidade dentro de cada elemento arquitetural é governada por diversos fatores geológicos entre eles: granulometria, estruturas sedimentares, seleção granulométrica, arredondamento, presença de pseudomatriz, argila infiltrada e micas. Esses parâmetros serão comentados detalhadamente na análise dos resultados.

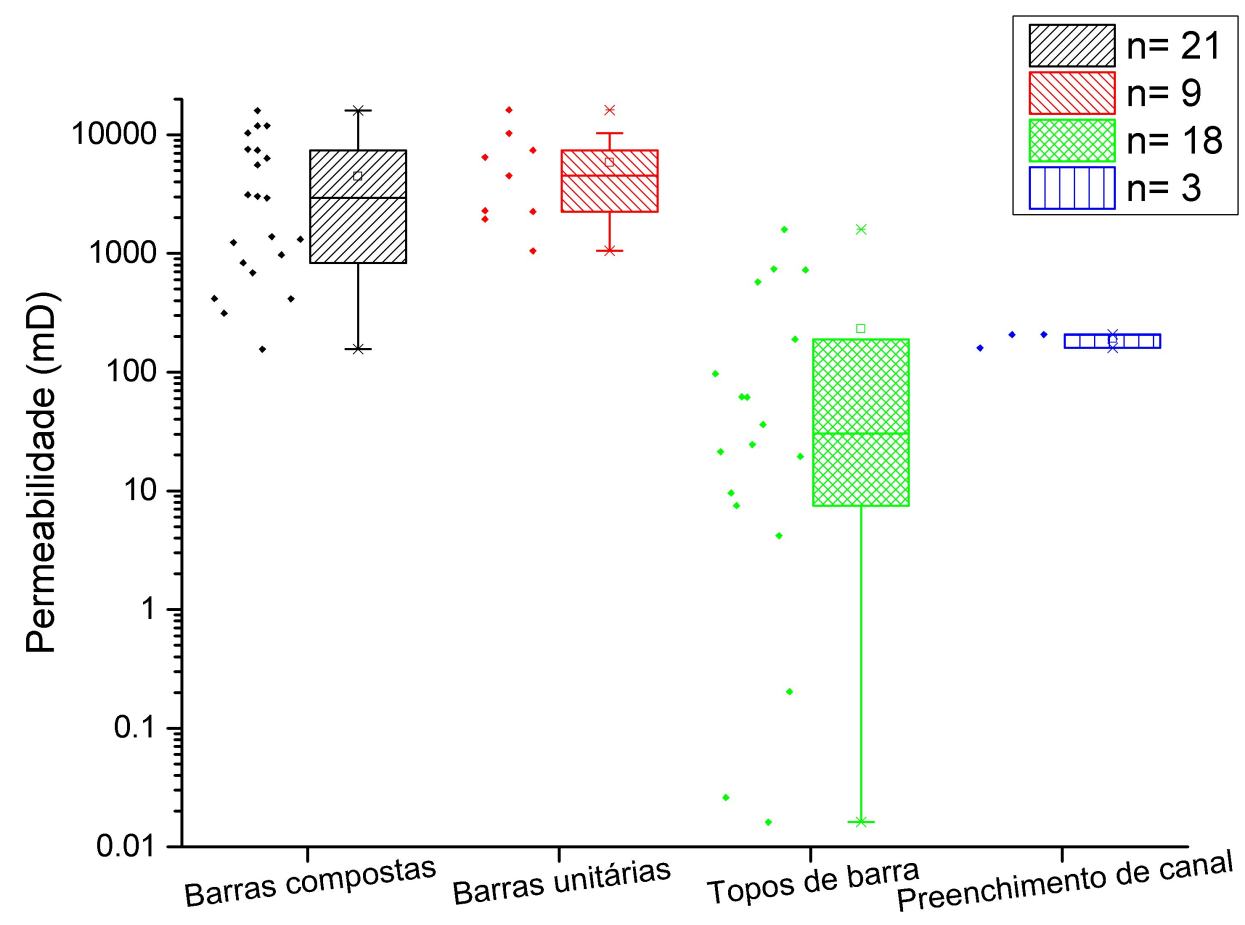

Figura 92 - Box plots dos elementos arquiteturais em função da permeabilidade obtida pelo método de injeção de gás nitrogênio nas amostras da Formação São Sebastião ( $n=$ número de amostras analisadas)

\subsubsection{Ensaios de permeabilidade em campo}

Utilizando a equação obtida para a calibração do permeâmetro de campo, a moda para a permeabilidade encontra-se entre 1000 e $5000 \mathrm{mD}$, representada por 472 ensaios ( $31 \%$ do total). Caso as amostras menores que $1000 \mathrm{mD}$ fossem agrupadas, elas representariam 493 ensaios (32\% do total). 
As permeabilidades máximas obtidas foram maiores que 15000 mD e mínimas próximas de $1 \mathrm{mD}$ (figura 93).

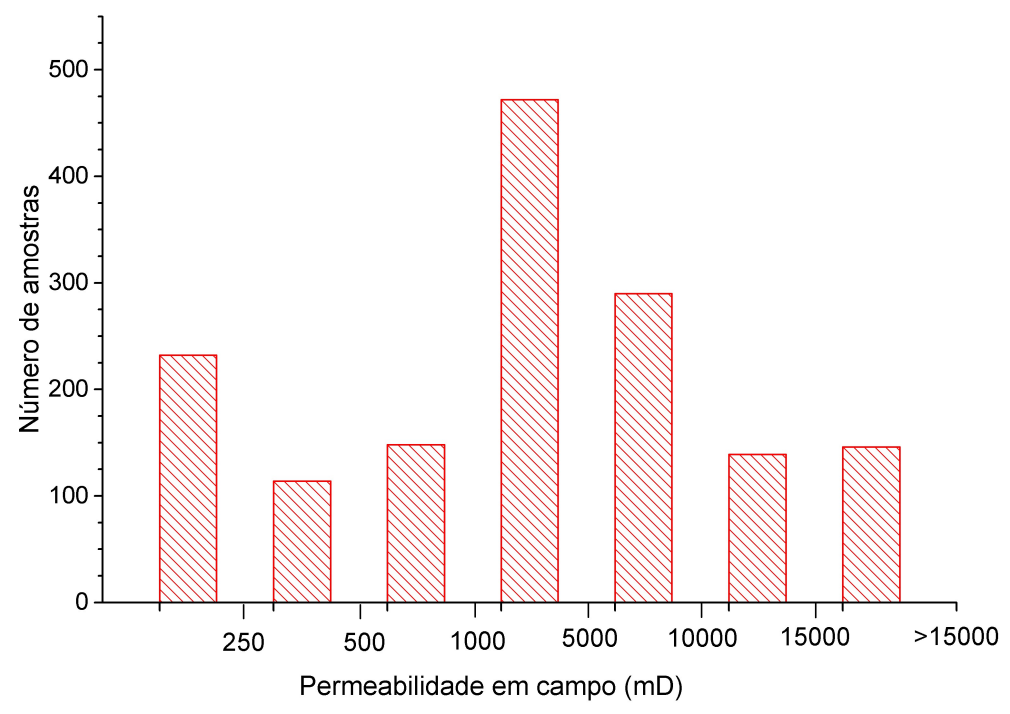

Figura 93 - Histograma da permeabilidade obtida in situ pelo permeâmetro de campo nas rochas da Formação São Sebastião.

A maior permeabilidade foi constatada nos depósitos de barra unitária, seguido pela composta, como nas análises efetuadas em laboratório. Nas barras unitárias a mediana atingiu valor próximo de $6000 \mathrm{mD}$ e valor mínimo próximo de $150 \mathrm{mD}$. Já as compostas apresentaram mediana de $4500 \mathrm{mD}$, com valor mínimo de $2 \mathrm{mD}$. Para os depósitos de topo de barra a mediana tem permeabilidade próxima a $350 \mathrm{mD}$. Nos depósitos de preenchimento de canal a mediana situou-se entre 200 e 300 mD. Já os canais abandonados foram os detentores da menor mediana, $50 \mathrm{mD}$ (figura 94). 


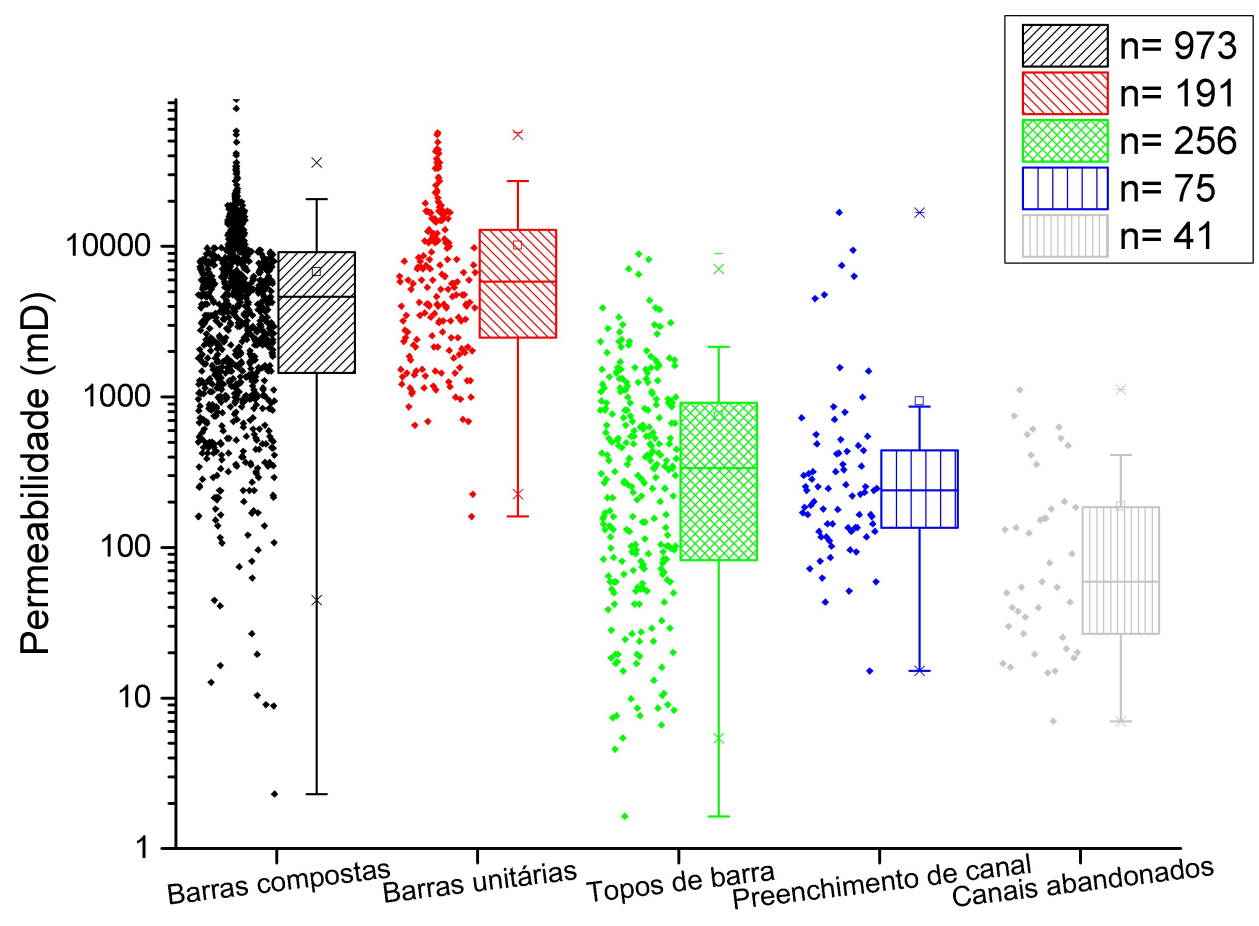

Figura 94 - Box plots dos elementos arquiteturais em função da permeabilidade, obtida in situ, pelo permeâmetro de campo nas rochas da Formação São Sebastião ( $n=$ número de amostras analisadas). Observa-se resultado próximo ao obtido pela análise a gás, com maiores permeabilidades nos depósitos de barras.

Comparando os dois histogramas de permeabilidade (figura 91 e 93), o segundo apresenta maiores valores. Esse fato é resultado de maior razão entre quantidade de amostras mais permeáveis analisadas em campo, por exemplo os depósitos de barras (aproximadamente $70 \%$ do total na análise de campo e $59 \%$ do total na análise a injeção de gás), sobre amostras com menor permeabilidade, como topos de barra.

As medianas obtidas para cada elemento arquitetural nas duas análises são equivalentes, ou seja, mantém-se o padrão de permeabilidade entre os elementos arquiteturais. Esse fato também é resultado do coeficiente de Pearson igual a 0,94, da equação transformadora dos dados ensaios de campo para ensaios de laboratório (item 5.1)

A permeabilidade é muito bem compartimentada entre os elementos arquiteturais, tratando-se, portanto, de um excelente guia para a predição de permeabilidade (figura 92 e 94). Porém, cada elemento arquitetural possui 
variações em quantidades significativas para estudos de reservatório. Logo, serão analisados, no item 7 , os controles deposicionais e diagenéticos dessas variações de permeabilidade, levando em conta a hierarquia da arquitetura deposicional.

\subsection{Petrofácies}

Com base nas descrições petrográficas e diferentes texturas apresentadas, este item dividiu os arenitos estudados em petrofácies (De Ros \& Goldberg 2007). A melhor análise e comparação com permoporosidade e elementos arquiteturais será realizada no item 7.3 .5 e 7.4, respectivamente.

As petrofácies definidas neste estudo foram: arenito rico em pseudomatriz (I), arenito muito micáceo (II), arenito com alta concentração de argila infiltrada (III), arenito com baixa concentração de (menor que 25\%) nos poros de pseudomatriz, micas ou argila infiltrada (IV) e arenito limpo (V). Além das petrófacies mencionadas, deveria ser incluída a petrofácies com arenitos cimentados por argila diagenética, mas devido à existência de apenas uma lâmina no conjunto, ela não será aqui englobada (tabela 4).

Tabela 4- Características diagnósticas das petrófácies utilizadas na Formação São Sebastião

\begin{tabular}{ll}
\hline Petrofácies & Característica diagnóstica \\
\hline I - Arenito rico em pseudomatriz & $\begin{array}{l}\text { Alta concentração de pseudomatriz nos } \\
\text { poros }\end{array}$ \\
II - Arenito muito micáceo & Alta concentração de micas nos poros \\
III - Arenito rico em argila infiltrada & $\begin{array}{l}\text { Alta concentração de argila infiltrada nos } \\
\text { poros }\end{array}$ \\
IV - Arenito "quase limpo” & $\begin{array}{l}\text { Baixa concentração (menor que 25\%) de } \\
\text { qualquer impureza nos poros }\end{array}$ \\
\hline V - Arenito “limpo" & Gargantas de poros limpas, sem obstruções \\
\hline
\end{tabular}


A principal característica da petrofácies I é a quantidade relativamente alta de pseudomatriz. De fato, essa textura possui um alto fator de impotência para o reservatório (item 7.3.2). Com grande quantidade de grãos dúcteis, como intraclastos e feldspatos alterados submetidos um evento de compactação, esses grãos foram compactados e dispersos pelos poros da rocha, obstruindo gargantas de poro, com mineralogia de argilominerais.

A petrofácies II possui alta concentração de micas, as quais obstruem gargantas de poros por si só, devido a sua forma placóide e alongada. Quando compactadas, as micas passam a "dobrar", e assim como as pseudomatrizes, obliterar gargantas de poro (item 7.3.3). Além disso, a disposição das micas tende a ser preferencial, fato que aumenta as heterogeneidades entre as direções horizontais e verticais do reservatório (item 7.4).

A petrofácies III engloba as rochas que possuem mais que alta concentração de argila infiltrada nos poros e fatores menores que dois (2) de micas e pseudomatriz. As argilas infiltradas ocorrem, em sua maioria, na forma de coatings irregulares, os quais não obliteram gargantas de poro, apenas diminuem o raio das mesmas. Devido a esse fato seria menos prejudicial que a existência de pseudomatriz e mica com fator maior que dois (2) (item 7.3.4).

A petrofácies IV caracteriza-se pelos arenitos analisados que não possuem quantidade significativa de elementos que diminuiriam a permoporosidade (menor que $25 \%$ nos poros) conforme as amostras analisadas, ou seja, essa petrofácies possui elementos que diminuem a permeabilidade e porosidade. Porém, a concentração desses não foi significativa para que ocorra um decréssimo significativo das características permoporosas nas amostras analisadas (item 7.3.5). Esses elementos podem se manifestar como: micas, pseudomatriz, ou mesmo argila infiltrada. Em outras palavras, a IV representa arenitos "quase limpos".

Finalmente, a petrofácies V apresenta-se como arenito "limpo", ou seja, ausente da manifestação de argila infiltrada, pseudomatriz e micas. 


\subsection{Modelo de afloramento 3D e modelagem geológica}

A modelagem geológica utilizou-se do resultado gerado pelo processamento das imagens (nuvem densa 3D), identificação das principais superfícies sedimentares, e associações de fácies descritas em campo. Com isso, foram gerados modelos geológicos, entre as principais superfícies, de: elementos arquiteturais e fácies (apêndice $\mathrm{C}$ ao $\mathrm{V}$ ). A amostragem utilizada foi aleatória (apêndice U).

Os pontos (com coordenadas UTM retiradas da nuvem densa) (apêndice C, J, K, L e M), delimitadores das principais superfícies sedimentares foram interpolados, para criação dos horizontes (apêndice D e O). A interpolação utilizada buscou representar a geometria de canais fluviais.

Os horizontes, por sua vez, foram utilizados para criação dos modelos estratigráficos (apêndice $E$ e $P$ ). Nota-se que as irregulariedades das superfícies sedimentares observadas em campo também estão presentes no modelo computacional. As camadas do modelo estratigráfico foram utilizadas para "particionar" a modelagem dentro de cada superfície. O modelo dentro de cada superfície é justificado pela maior similaridade e menor variação (de fácies e características petrofísicas) dentro de uma superfície quando comparada ao afloramento por inteiro. No afloramento TUC05 nota-se horizontes criados representando topos de barras (na cor vermelha). Esses horizontes intermediários, entre as superfícies $C$ e $B, B$ e $A$, e abaixo da $A$, foram criados após a modelagem de elementos arquiteturais. Com a visualização desses corpos, os mesmos foram adicionados no modelo estratigráfico para guiar o modelo de fácies. No afloramento TUC41 essa técnica não foi utilizada devido à grande extensão do afloramento e inviável inclusão de superfícies representantes de todos os topos.

Para a geração do modelo geológico obteve-se um variograma modelado (3D) para cada elemento arquitetural, dentro de cada superfície. Os elementos arquiteturais foram modelados em barras e topos de barra. No afloramento TUC05 também se utilizou o elemento arquitetural de canais 
abandonados. Os apêndices G e R sumarizam as porcentagens de cada elemento arquitetural entre cada superfície modelada.

O modelo de elementos arquiteturais do afloramento TUC 05 apresentou porcentagem de topos de barra de zero até 8,17\%. A maior concentração dos topos foi modelada abaixo da superfície A. É importante frisar que os elementos arquiteturais de preenchimentos de canais presentes nessa superfície foram modelados como topos de barra, o que contribuiu para o aumento de volume nessa superfície. Já os canais abandonados aparecem delimitados pelas superfícies 5 e 6 (apêndice F).

O modelo de elementos arquiteturais do afloramento TUC41 apresentou porcentagem de topos de barra entre as superfícies de 0,52\% até 32,08\%. A maior concentração de topos de barra está abaixo da superfície $C$, onde se apresenta mais contínua (apêndice Q).

Os topos de barra, principais elementos arquiteturais a serem modelados, apresentam espessuras de 0,10 $\mathrm{m}$ a 0,5 $\mathrm{m}$ (uma a cinco células no eixo z) e geometria lenticular, caracterizando corpos muito alongados, com continuidade variável. No afloramento TUC41, por exemplo, o topo de barra abaixo da superfície C apresenta continuidade maior que $200 \mathrm{~m}$. Já no afloramento TUC05 os topos de barra apresentam-se menos contínuos. As superfícies A, B e C possuem topos de barra, mas nenhum deles corta todo o afloramento. Porém, deve-se levar em conta a menor dimensão no plano xy e no eixo z do afloramento TUC 05 , comparado ao TUC 41, fato que evidencia o afinamento e desaparecimento local dos topos de barra.

Posteriormente, a mesma quantidade de variogramas modelados foi obtida para cada fácies (também dentro de cada superfície). Como na indústria do petróleo, as fácies modeladas foram divididas conforme a granulometria (descrita em campo, calibrada pela análise granulométrica em lâmina), em: arenito muito fino, arenito fino, médio-fino, médio e médio-grosso (no modelo do afloramento TUC41 a divisão médio-fino não foi utilizada). A divisão de fácies baseada na granulometria foi utilizada devido à correlação entre granulometria e permeabilidade nas amostras analisadas (descrita com detalhe 
no item 7.2). Os apêndices I e $\mathrm{T}$ sumarizam as porcentagens das fácies modeladas entre cada superfície modelada.

A modelagem de fácies do afloramento TUC05 baseou-se no modelo de elementos arquiteturais. Nos canais abandonados foram modeladas fácies de arenito fino e muito fino, assim como nos depósitos acima da superfície $H$ (interpretados, não existem no afloramento) e nos topos de barra. Já nas barras, encontram-se as distribuições de fácies mais heterogêneas, variando de arenito médio-fino até arenito grosso. A barra com maior concentração de arenitos médio-finos (29\%) e médios (60\%) encontra-se acima da superfície C. Já a barra com maior concentração de arenitos grossos encontra-se abaixo da superfície A (descrita no item 6.1 como barra unitária) (apêndice H).

O modelo de fácies do afloramento TUC41 também se baseou nos modelos de elementos arquiteturais. Nos topos de barra foram modeladas fácies de arenito fino e médio. Já nas barras foram modeladas fácies de arenito médio, médio-grosso e grosso. As células da camada do topo do modelo (sup_acima_h) obtiveram maiores concentrações de arenitos médios-grossos (43\%) e grossos $(56 \%)$ somados. Já a camada com maior concentração de arenitos finos $(2 \%)$ e médios $(27 \%)$ somados foi a localizada abaixo da superfície A. Esse foi classificado como barra composta, com grande quantidade de arenitos médios. A camada abaixo da superfície $C$ (camada com topo de barra mais contínuo) é a detentora em maior quantidade de arenitos finos (21\%) (apêndice S).

Os variogramas discretos horizontais, tanto perpendiculares como paralelos, não obtiveram bons ajustes somente baseados na geoestatística. Portanto, foram ajustados com respaldo das geometrias observadas em afloramento. Já os variogramas verticais, portadores de amostragens contínuas, obtiveram bons ajustes geoestatísticos, representativos das espessuras dos elementos arquiteturais e fácies (apêndice V). 


\section{Análise e discussão dos resultados}

Neste capítulo serão analisados os principais resultados obtidos no trabalho. Primeiramente, serão comparados os resultados na contabilização de porosidade em lâminas delgadas, a qual mostrou diversidades quando comparada aos resultados obtidos pelo método a gás. Em seguida, a permeabilidade e porosidade, variáveis importantes para o estudo de reservatório, serão analisadas conforme os controles deposicionais e diagenéticos. Finalmente, foca-se nos dados mais relevantes para a criação de modelos de reservatório e modelos criados utilizando como análogo a Formação São Sebastião.

\subsection{Resultados das metodologias de porosidade}

Os dados de porosidade obtidos pelo teste de injeção de gás nitrogênio apontaram maiores valores de porosidade quando comparados aos obtidos por imagem (figura $95 \mathrm{~A}$ e $\mathrm{B}$ ). Essa diferença entre os métodos pode estar relacionada a diversos fatores.

A diferença pode ocorrer devido à porosidade medida em lâmina (obtida em 2D) não considerar o arredondamento dos grãos, como comentado no trabalho de Kong et al. (2005) em análises granulométricas. Tridimensionalmente, o arredondamento geraria volume poroso abaixo do grão, não contabilizado nas análises petrográficas, a qual admite toda área abaixo do grão como não porosa.

A diferença relativa entre os resultados das duas análises pode ser observada comparando valores porosos obtidos pelos dois métodos a outra variável correlacionável a porosidade. No caso, foi utilizada a permeabilidade a gás, de acordo com os elementos arquiteturais (figura 95). 
A
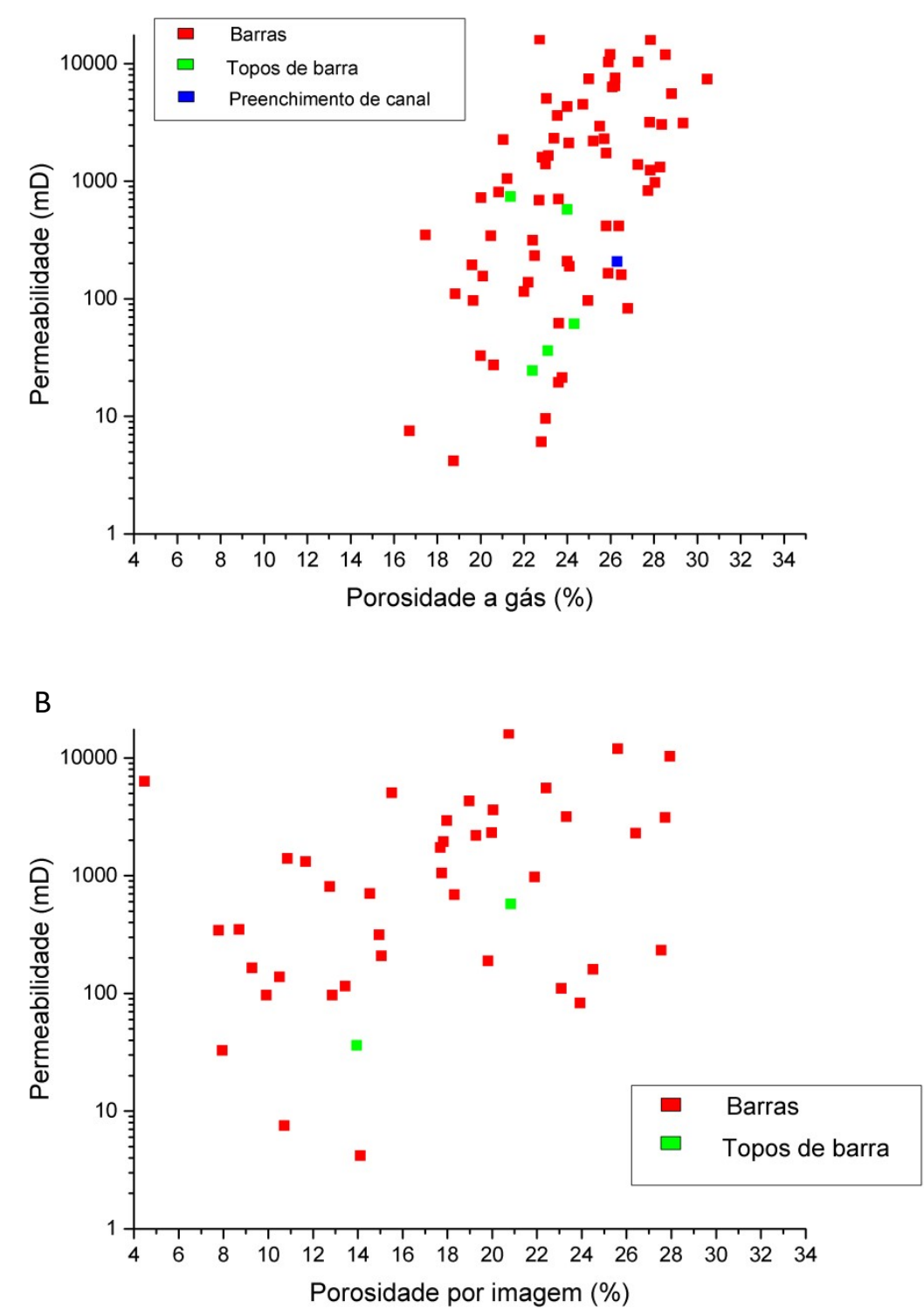

Figura 95 - A) Crossplot da porosidade por imagem (mediana) em função da permeabilidade a gás nas amostras da Formação São Sebastião.

B) Crossplot da porosidade a gás em função da permeabilidade á gás nas amostras da Formação São Sebastião

Tem-se, por exemplo, que o mesmo valor absoluto de permeabilidade, $100 \mathrm{mD}$, está relacionado a valores mínimos de porosidade próximo de $19 \%$, pelo método a gás, e valores mínimos menores que $10 \%$ nas análises por imagem. O salto para valores mais permeáveis (escala de $1000 \mathrm{mD}$ ) ocorre em valores de porosidade entre $21 \%$ e $11 \%$, no gás e na imagem, 
respectivamente. Essa diferença entre porosidades para o mesmo valor de permeabilidade pelos dois métodos se dá pelo tipo de poro habilitado à medição em cada análise.

Os maiores controladores da permeabilidade são macroporos, enquanto os microporos influenciam menos a permeabilidade. $\mathrm{Na}$ análise por imagem o fluido utilizado para impregnação dos poros trata-se de uma mistura com resina, álcool e corante, material muito mais viscoso que o gás de nitrogênio ou hélio. O material mais viscoso, devido a essa característica, adentra os locais mais permeáveis (macroporos) e tem maior dificuldade de fluir pelos microporos (menos permeáveis). Diferentemente, o gás, devido sua menor viscosidade, flui tanto pelos macroporos como pelos microporos. Logo, a viscosidade dos fluidos é outro fator, adicional ao apresentado por Kong et al. (2005) influente na diferença de resultado entre os dois métodos na obtenção de porosidade.

A análise de porosidade fornece o desvio padrão das figuras utilizadas na medição de porosidade, o qual mostra-se maior em amostras com fatores um (1), dois (2), e três (3), de pseudomatriz (tipo de manifestação mais frequente de argilominerais neste trabalho, detentores de microporosidades) (figura 96 A). As concentrações médias imprimem alta heterogeneidade na seção delgada, pois em algumas fotos os poros estão limpos, enquanto outros se encontram repletos de pseudomatriz. Isso resulta em maiores diferenças entre as porosidades medidas por imagem em cada foto, e, consequentemente, aumentando o desvio padrão final fornecido pelo software. Além disso, pelo mesmo motivo, o desvio padrão mostra-se maior em valores nos quais não só a manifestação de pseudomatriz é média, mas também nos valores de porosidades médias, entre $10 \%$ e $20 \%$ (figura 96 B). 

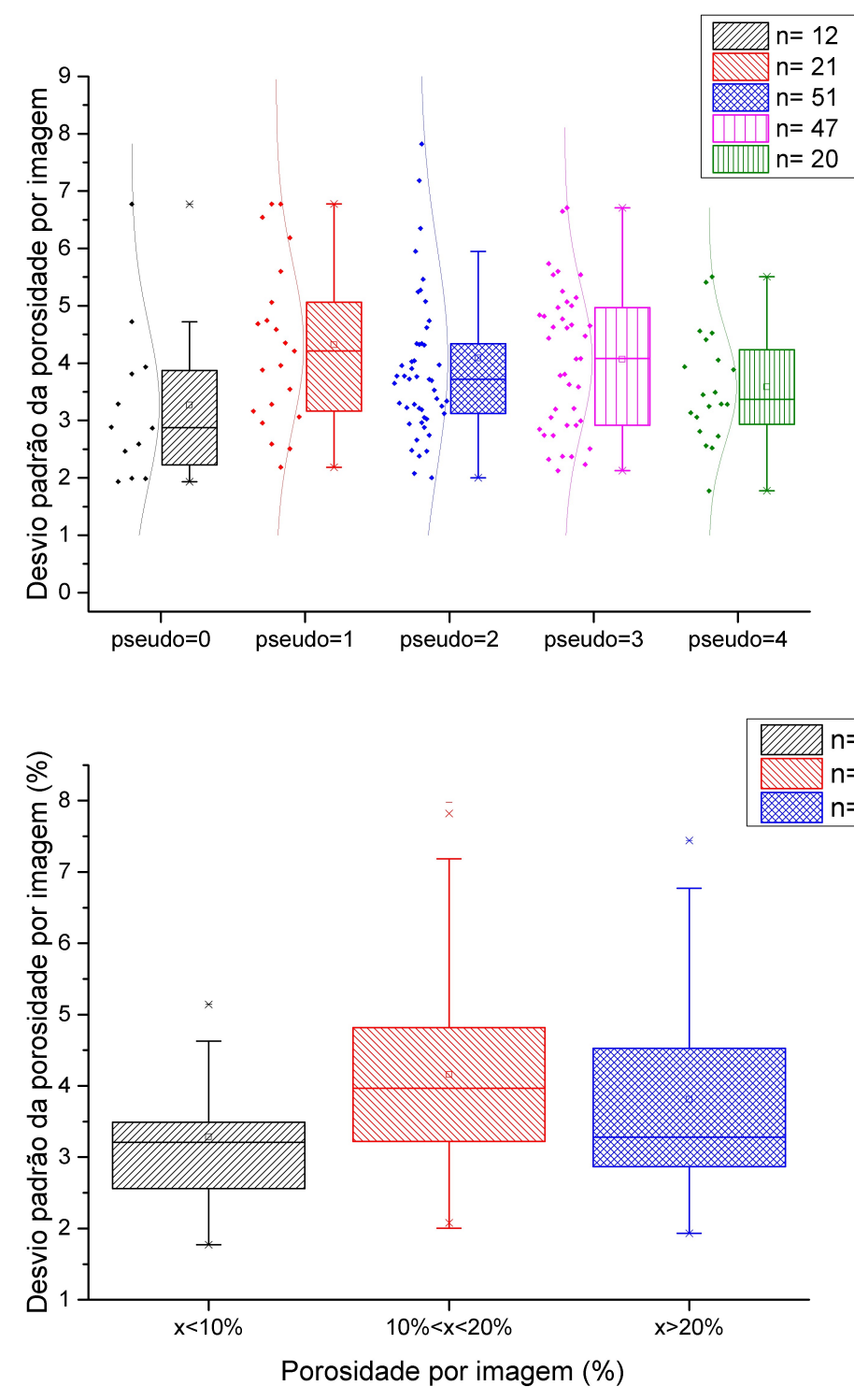

Figura 96 - A) Box plots da quantidade de pseudomatriz em função do desvio padrão da porosidade por imagem, fornecido pelo software LAS, nas amostras da formação São Sebastião. No eixo x a classificação 0 representa constituinte inexistente; 1 - existente, presente em aproximadamente $5 \%$ dos poros da lâmina; 2- presente em aproximadamente $10 \%$ dos poros da lâmina; 3- presente em aproximadamente $25 \%$ dos poros da lâmina; 4presente em aproximadamente $50 \%$ dos poros da lâmina; 5- presente em aproximadamente $75 \%$ dos poros da lâmina; 6- presente aproximadamente $90 \%$ dos poros da lâmina.

B) Box plots dos intervalos de porosidade em função do desvio padrão da porosidade por imagem, fornecido pelo software LAS, nas amostras da formação São Sebastião

O desvio padrão apresentado por seção delgada não é diretamente correlacionável à diferença entre a porosidade fornecida pela lâmina e a 
porosidade obtida na análise a gás, mas sim às heterogeneidades de porosidade, adquiridas pelas fotos. Esse fato pode ser facilmente explicado com a análise em uma amostra somente com microporos. Em todas as fotografias a porosidade atribuída pela imagem será zero ou baixíssima, culminando em um baixíssimo desvio padrão, o que não significa, necessariamente, uma boa relação com a porosidade total medida pelo gás.

A estatística do desvio padrão aumenta quando a amostra analisada possui muitas zonas de heterogeneidades, ou seja, locais em que a pseudomatriz ocorre em altas concentrações e em locais onde a mesma não ocorre. Isso resultará em diferença maior de porosidade visual medida entre as fotos, acarretando maior desvio padrão, já que a porosidade por imagem se refere à contabilização apenas de macroporos. Por outro lado, na porosidade a gás as microporosidades foram medidas. Como resultado disso, o método de imagem possuiu moda deslocada para valores mais baixos que os obtidos por gás $(23 \%-24 \%$ contra $14-16 \%)$ e valores mínimos menores (16\%-17\% contra $4 \%-6 \%$ ) (figura 86 e 89 B).

Neste contexto, tentativas de correlações diretas entre a análise a gás e por imagem foram efetuadas sem sucesso. Para melhor correlação, seriam necessárias quantificações mais precisas da concentração da textura causadora das heterogeneidades ( no caso deste trabalho, a pseudomatriz).

Apesar das disparidades entre as heterogeneidades apresentadas nas fotos, diferentes tipos de porosidades habilitadas à medição, diferenças de viscosidade entre os fluidos e estimativas $2 \mathrm{D}$ contra $3 \mathrm{D}$, algumas similaridades podem ser notadas. As distribuições de porosidades apresentam semelhanças nos histogramas, ambas com tendência a normal. Além disso, as estimativas apresentadas entre porosidade e elementos arquiteturais para as duas análises mostram-se equivalentes, com valores de porosidades maiores nos EA de preenchimentos de canais, seguidos pelas barras unitárias, barras compostas e topos de barra (figura 87 e 90). Logo, apesar das deficiências, a análise de porosidade por imagem mostrou-se satisfatória para a realização deste trabalho que utiliza comparações de valores absolutos de porosidade entre 
grupos de amostras, como por exemplo, fácies, elementos arquiteturais, intervalo de granulometria e entre outros.

\subsection{Controles deposicionais na qualidade de reservatórios}

Os depósitos fluviais são divididos, nos estudos de reservatórios, basicamente em rios meandrantes e entrelaçados (Reinick \& Singh, 1980). Os afloramentos estudados na Formação São Sebastião, por mais que essa classificação seja considerada inadequada e esteja perdendo força entre os especialistas, convergem para a interpretação de um sistema fluvial do tipo entrelaçado. Essa interpretação foi em parte sugerida por Figueiredo (2013), conforme a carga de transporte do rio, variando predominantemente entre areia, grânulos e seixos, mas com argila e silte em determinadas regiões.

$\mathrm{Na}$ indústria petrolífera interpretam-se depósitos de rios entrelaçados como verdadeiras "caixas de areia isotrópicas", caracterizando reservatórios do tipo sheet sandstones ( $\mathrm{SH}$ types), ou quebra-cabeça (Galloway \& Hobday, 1996; Friend, 2009). Porém, a diversidade de elementos arquiteturais descritos nesse estudo implica em grande variação na qualidade de reservatório. Os EA caracterizam as heterogeneidades de maior escala nesse trabalho e foram detalhados separadamente no item 6.1.

As barras unitárias possuem geometria lenticular, por volta dos $400 \mathrm{~m}$ de continuidade lateral, mas também chega pontualmente a corpos com apenas 50 m. As associações de fácies contêm estruturas com estratificações cruzadas tabulares de grande porte $(1,5 \mathrm{~m})$, migrando para sets únicos, com convolutas e acanaladas associadas, portadoras de granulometrias médiasgrossas, com grande e moderada concentração de grânulos e seixos. Dentro desse elemento arquitetural foram constatadas gradações ocasionais para fácies com cruzadas de menor porte e granulometria média a fina, predominantemente média.

Já as barras compostas possuem geometria também lenticular, mas mais complexa que as barras unitárias, com irregularidades das superfícies 
sedimentares que imprimem variações de espessura entre as superfícies internas. A continuidade lateral é maior que as barras unitárias, ultrapassando os 500 m. A associação de fácies é composta por estratificações cruzadas de menor porte que as barras unitárias, dispostos em cosets (de 0,4 m), com acanaladas e convolutas associadas (fácies Amcc e Acon). Além disso, possuem tendência granodecrescente mais forte que nas unitárias, portando, em média, fácies com granulometria mais fina que as barras unitárias (figura 64 A). Os três demais elementos arquiteturais englobam associações de fácies de menor turbulência e menor velocidade de fluxo.

Os canais abandonados possuem cruzadas acanaladas com granulometria média, mas predominam ripples e estratificações convolutas de granulometria média a fina. Os topos de barra possuem associações de fácies formadas principalmente por ripples e convolutas de granulometria fina. Já os preenchimentos de canais possuem fácies plano paralelas predominantemente, e, convolutas e cruzadas de baixo ângulo associadas.

Considerando a porosidade dos elementos arquiteturais, os mais porosos são os depósitos de preenchimento de canais (24\%), seguidos pelas barras unitárias $(21 \%)$, barras compostas $(19 \%)$, canais abandonados $(16 \%) \mathrm{e}$ topos de barra (14\%) (figura 90). Já a permeabilidade é maior nas barras unitárias $(6000 \mathrm{mD})$, seguidas pelas barras compostas $(4500 \mathrm{mD})$, topos de barra $(350 \mathrm{mD})$, preenchimento de canais $(240 \mathrm{mD})$ e canais abandonados (50mD) (figura 94).

Nota-se que a melhor porosidade e permeabilidade não se encontram no mesmo elemento arquitetural, provando a não correlação direta entre esses dois atributos. O detentor da melhor porosidade, os preenchimentos de canais, possui permeabilidades muito baixas comparadas às barras unitárias e compostas. Adicionalmente, possuem permeabilidades próximas ao detentor da pior média de porosidade, os topos de barra. Devido a essas disparidades observa-se a complexidade da relação entre porosidade e permeabilidade, a qual não é uma correlação logarítmica simples, como colocadas por diversos autores, como Kupecz et al. (1997). 
A disparidade entre porosidade e permeabilidade nos elementos arquiteturais está ligada a diversas variáveis deposicionais, utilizadas na classificação das fácies sedimentares que, por sua vez, são utilizadas na definição de elementos arquiteturais. Estas variáveis, como: granulometria, estrutura sedimentar, seleção granulométrica, e arredondamento, serão discutidas a seguir.

Vale ressaltar que variáveis influentes na permeabilidade podem não ser influentes na porosidade e vice-versa. Além disso, o fator de influência de uma determinada variável pode ser maior na porosidade e menor na permeabilidade e vice-versa, ou mesmo igualmente influente em ambas. Esse controle muito complexo das características permoporosas dificulta a predição desses atributos.

\subsubsection{Granulometria}

A granulometria mostrou grande correlação com a permeabilidade, em todos os elementos arquiteturais (figuras 97 e 98). Por outro lado, os dados levantados no presente trabalho mostram que a porosidade não possui nenhuma influência da granulometria (figura 99). Isso ocorre tanto dentro de um elemento arquitetural, por exemplo as barras compostas (figura $99 \mathrm{~B}$ ), quanto na totalidade dos dados (figura $99 \mathrm{~A}$ ), contrariando em parte trabalhos como de Ogolo et al (2015), no qual a porosidade cresce com a diminuição da granulometria.

No geral, com exceção da variação de granulometria fina a muito fina nos depósitos de preenchimentos de canais, as fácies de granulometrias mais grossas apresentam maiores permeabilidades (figura 97 e 98). Isso se deve à maior quantidade de macroporos na trama dos depósitos grossos, nos quais o diâmetro das gargantas de poro é maior que nos depósitos finos.

Paralelo a esse fato, as maiores permeabilidades são apresentadas pelas barras unitárias, seguidas pelas barras compostas, detentoras das 
maiores medianas de granulometria entre os elementos arquiteturais. Porém, a granulometria não se correlaciona sem erros com a permeabilidade. Os depósitos de topos de barras possuem as granulometrias mais finas, mas permeabilidades superiores a elementos arquiteturais de granulometria mais grossa (preenchimento de canais e canais abandonados) (figura 94). Esse fato aponta, possivelmente, a manifestação de outra variável deposicional na permeabilidade.

Do mesmo modo que maiores granulometrias dentro de cada elemento arquitetural significam maiores permeabilidades, intervalos maiores de granulometria, dentro de um elemento arquitetural, correspondem a maiores variações de permeabilidade. As barras compostas, por exemplo, compõem os depósitos com maior variação de granulometria (1,4 Ф a 2,9 Ф) (figura 64 A) e, consequentemente permeabilidade ( $2 \mathrm{mD}$ até maior que $10000 \mathrm{mD}$ ) (figura 94).

Entretanto, a granulometria da rocha não influencia diretamente na porosidade (figura 99). Esse fato pode ser explicado pelo simples fato da porosidade ser uma relação volumétrica adimensional.
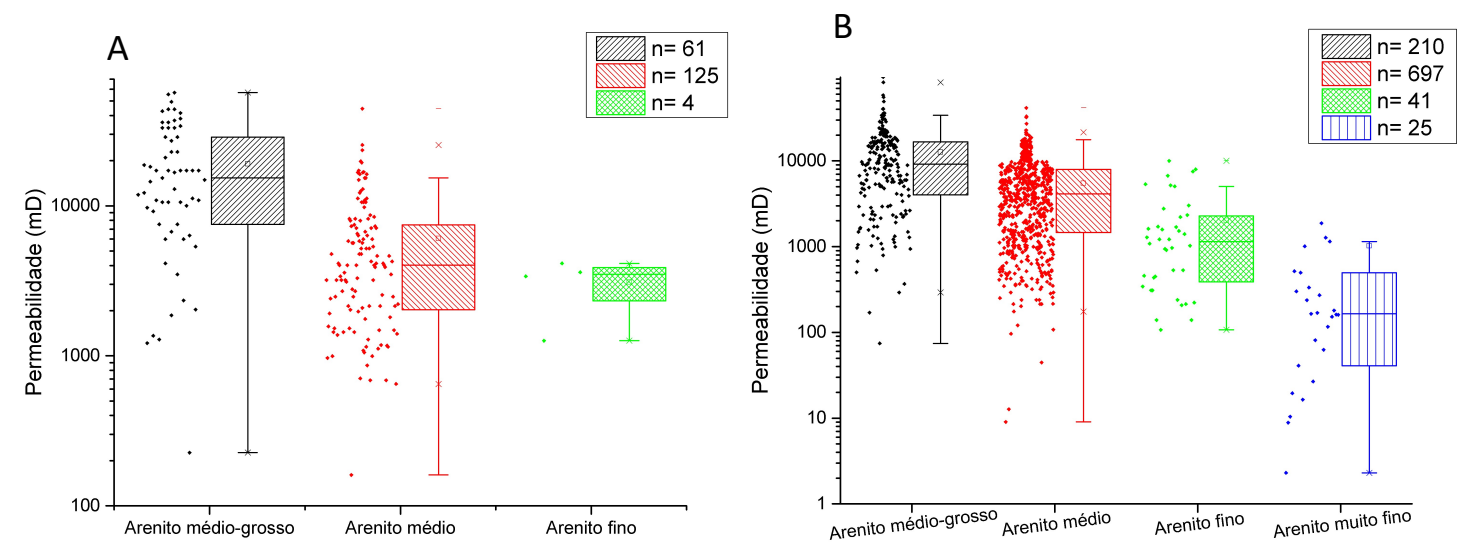

Figura 97 - A) Box plots das diferentes granulometrias, nos depósitos de barra unitária, pela permeabilidade, nos arenitos da formação São Sebastião.

B)Box plots das diferentes granulometrias, nos depósitos de barra composta, pela permeabilidade, nos arenitos da formação São Sebastião.

A 

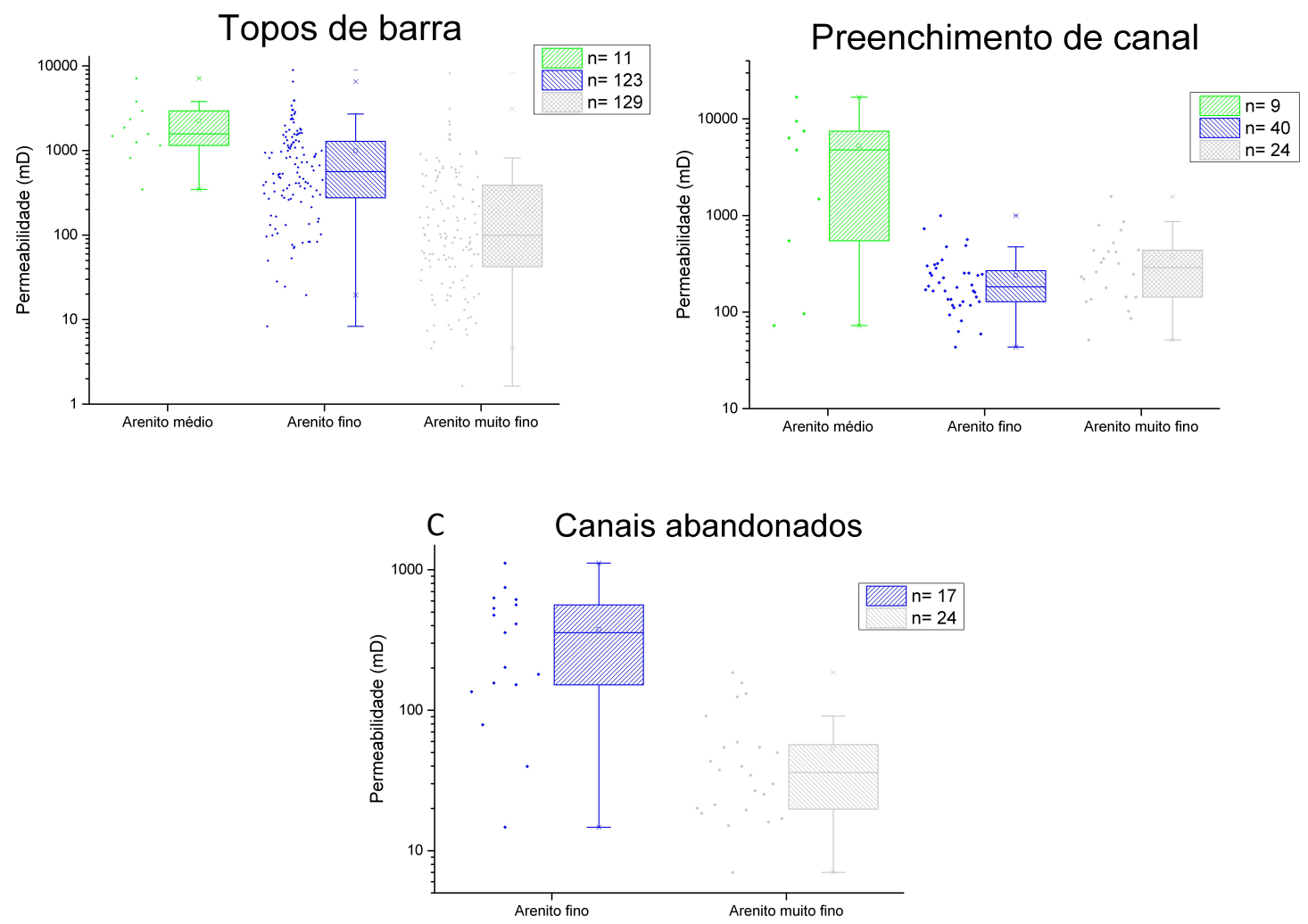

Figura 98 - A) Box plots das diferentes granulometrias, nos depósitos de topo de barra, pela permeabilidade, nos arenitos da formação São Sebastião

B) Box plots das diferentes granulometrias, nos depósitos de preenchimento de canal, em função da permeabilidade, nos arenitos da formação São Sebastião.

C) Box plots das diferentes granulometrias, nos depósitos de canais abandonados, em função da permeabilidade, nos arenitos da formação São Sebastião.
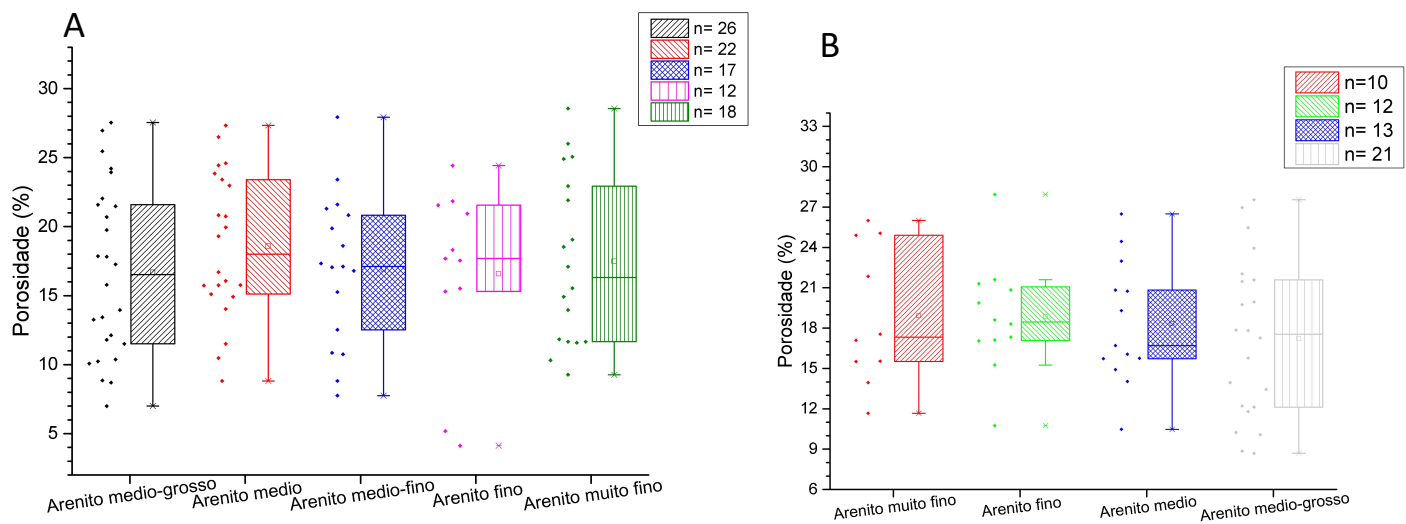

Figura 99 - A) Box plots de mediana da porosidade por imagem em função da granulometria

B) Box plots da granulometria em função da porosidade dentro do elemento arquitetural barras compostas 


\subsubsection{Estrutura sedimentar}

Uma das principais variáveis geológicas utilizadas na descrição de fácies, juntamente com a granulometria, é o tipo de estrutura sedimentar presente na rocha. A estrutura indica as condições de fluxo em que a mesma foi depositada. Remetida à granulometria, a estrutura sedimentar mostra bom controle sobre a permeabilidade (figura 100 a 104). A porosidade, por sua vez, também mostrou-se influenciada pela estrutura, porém, independentemente da granulometria analisada (figura 105).

Analisando as estruturas das arquiteturas (remetentes às granulometrias) nos depósitos de barras unitárias e compostas, as cruzadas tabulares mostram-se sempre com permeabilidades superiores quando comparadas às demais. As cruzadas tabulares apresentam medianas maiores que $10000 \mathrm{mD}$ nos arenitos médios-grossos e maiores que $3800 \mathrm{mD}$ nos arenitos médios. As cruzadas acanaladas e as convolutas possuem medianas relativamente próximas $(5000 \mathrm{mD}$ nos arenitos médios-grossos e próximos a $3000 \mathrm{mD}$ nos arenitos médios), mas as convolutas podem alcançar valores muito baixos de permeabilidade $(200 \mathrm{mD}$ nos arenitos grossos e $10 \mathrm{mD}$ nos arenitos médios). As cruzadas de baixo ângulo possuem permeabilidades menores (próximas a $1000 \mathrm{mD}$ em arenitos médios) que as já comentadas nas barras, sendo apenas mais permeáveis que as estruturas ripples $(550 \mathrm{mD}$ em arenitos médios) (figuras 100 e 101).

Porém, nos topos de barra, as cruzadas de baixo ângulo possuem permeabilidade levemente superior $(900 \mathrm{mD})$ quando comparadas às convolutas $(750 \mathrm{mD})$. As convolutas tanto nesse elemento, como nos canais abandonados, possuem a mediana desse atributo superior às ripples (figuras 102 e 103).

As laminações plano paralelas, analisadas apenas nos preenchimentos EA de canais, mostram-se mais permeáveis $(450 \mathrm{mD})$ que as convolutas $(160 \mathrm{mD})$ dentro desse elemento (figura104). Esse fato revela o menor fator de 
influência da estrutura na permeabilidade em relação à granulometria, pois as convolutas com grossas granulometrias possuem maiores permeabilidades associadas.

Valores maiores de permeabilidade nas fácies com estruturas de cruzadas tabulares, quando comparados aos valores das fácies acanaladas, ocorrem devido à melhor segregação granular nas formas de leito de crista reta. As cruzadas tabulares apresentam menor quantidade de grãos transportados pelo grain fall, os quais são responsáveis pela formação da cruzada acanalada ao invés da estrutura tabular no meio aquoso, segundo Reesink \& Bridge (2007). Os grãos transportados por suspensão geralmente são menores que os outros grãos do arcabouço, colocando-se entre grãos maiores, debilitando a segregação granular e permeabilidade local. Destaca-se que a segregação granular representa a organização textural da estrutura, enquanto seleção granulométrica é o desvio padrão das granulometrias.

Já as convolutas podem ser divididas em duas subestruturas, uma delas com segregação granular média e outra variando de baixa a ausente. Esse fato possivelmente é herança da intensidade e modo de perturbação do depósito, o qual anteriormente se trataria de uma estratificação cruzada. A maior variação de segregação granular dessa estrutura é refletida na maior variação de permeabilidades (com anomalias baixas), em diferentes granulometrias (figuras 100, 101, 102 e 104). Segundo Dzulynski \& Smith (1963) as estruturas convolutas, quando associadas à granulometria mais fina tendem a convolucionar mais, acarretando maior perturbação da seleção granulométrica.

Seguindo o raciocínio dos autores Dzulynski \& Smith (1963) e adicionando os resultados obtidos deste trabalho, as estruturas convolutas finas teriam a permeabilidade debilitada pela maior convolução, além da granulometria fina (também influencia negativamente a permeabilidade). Porém, a convolução e diferentes intensidades de convolução são notadas em todas as granulometrias da formação São Sebastião. Adicionalmente, as estruturas convolutas nas fácies finas apresentam melhores permeabilidades que as ripples (figura 102 e 103). 
As fácies com estratificações cruzadas de baixo ângulo, depositadas sobre menores velocidades de fluxo que as cruzadas basais das barras, possuem menor segregação granular (Reinick \& Singh, 1980). Esse fato não ocasionaria descolamento dos grãos do slip face, diminuindo a freqüência do processo de avalanche. Logo, o "avalanche sorting", descrito por Taira \& Scholle (1979), muito comum nas barras unitárias, seria menos efetivo na segregação granular.

As ripples possuem energia trativa baixa para a separação dos grãos, com grande atuação do grain fall. Logo, a segregação granular é menor nessa estrutura que nas demais, justificando a menor permeabilidade.

A porosidade é mais alta nas fácies com estratificações cruzadas tabulares (como a permeabilidade) (19\%) e nas fácies com plano paralelas $(20 \%)$, seguido pelas fácies com estratificações cruzadas acanaladas e convolutas (17\%), e, posteriormente, pelas ripples (11\%) (figura 105). Essa hierarquia de maiores e menores porosidades, assim como já comentada para a permeabilidade, ocorre devido ao tipo de transporte de grão e velocidade de fluxo, responsáveis pela geração das estruturas sedimentares. A permeabilidade encontrada nos preenchimentos de canais (mediana máxima próxima a $400 \mathrm{mD}$ ) não é muito alta como nas fácies com cruzadas tabulares devido à granulometria (fina) em que foram analisadas.

A constatação da maior porosidade nas fácies com estruturas plano paralelas, assim como a maior permeabilidade sobre as convolutas (que apresentam medianas próximas às acanaladas) nos depósitos de preenchimentos de canais, e a alta permoporosidade nas fácies com cruzadas tabulares, apontariam essas como as fácies sedimentares mais favoráveis para rochas reservatórios (no caso da permeabilidade admitindo-se mesma granulometria e elemento arquitetural).

Porém, outras variáveis deposicionais e diagenéticas, devem ser analisadas antes dessa afirmação. 

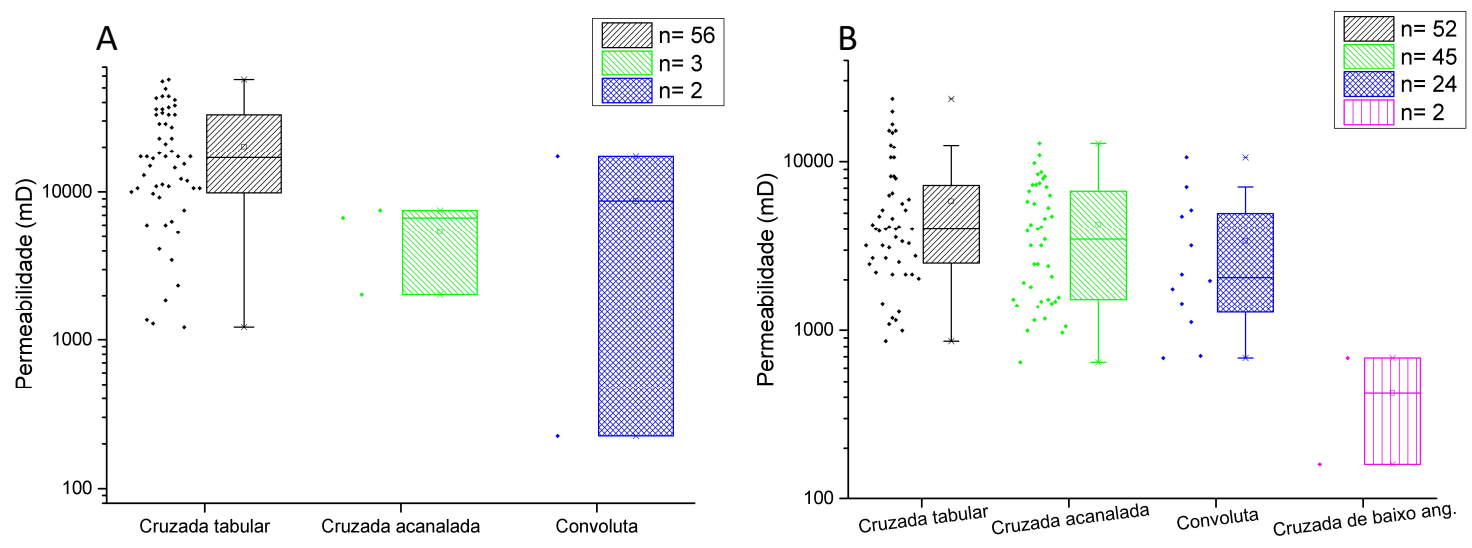

Figura 100 - A) Box plots das estruturas sedimentares nos arenitos médios-grossos, nos depósitos de barra unitária, em função da permeabilidade.

B) Box plots das estruturas sedimentares nos arenitos médios, nos depósitos de barra unitária, em função da permeabilidade
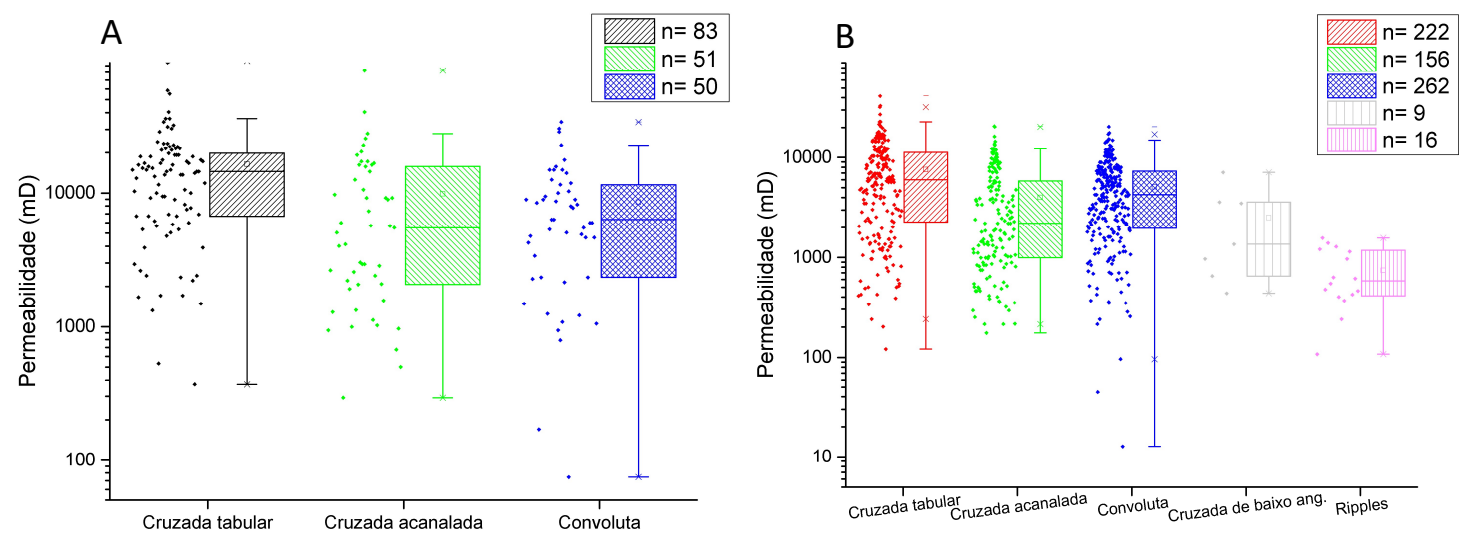

Figura 101 - A) Box plots das estruturas sedimentares nos arenitos médios-grossos, nos depósitos de barra composta, em função da permeabilidade.

B) Box plots das estruturas sedimentares nos arenitos médios, nos depósitos de barras compostas, em função da permeabilidade
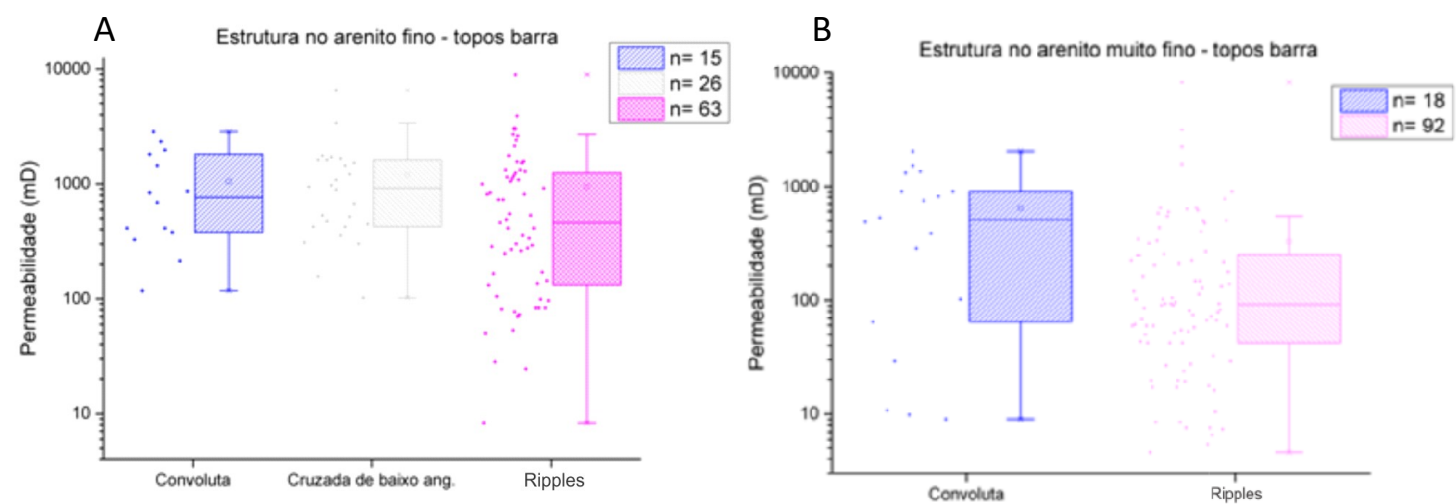

Figura 102 - A) Box plots das estruturas sedimentares nos arenitos finos, nos depósitos de topo de barra, em função da permeabilidade. 
B) Box plots das estruturas sedimentares nos arenitos muito finos, de topos de barra, em função da permeabilidade

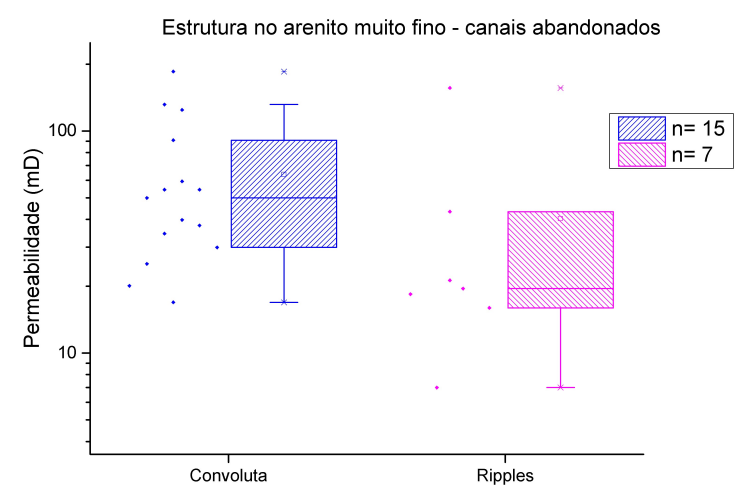

Figura 103 - Box plots das estruturas sedimentares nos arenitos muito finos, nos canais abandonados, em função da permeabilidade
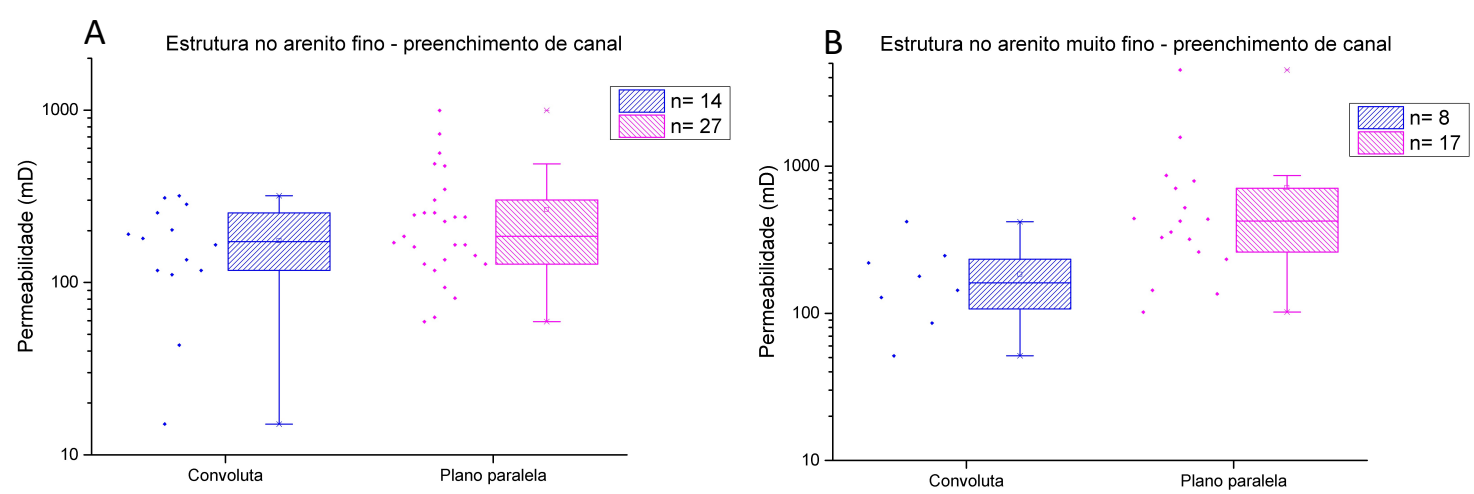

Figura 104 - A) Box plots das estruturas sedimentares nos arenitos finos, dos preenchimentos de canais, em função da permeabilidade.

B) Box plots das estruturas sedimentares nos arenitos muito finos, dos preenchimentos de canais, em função da permeabilidade

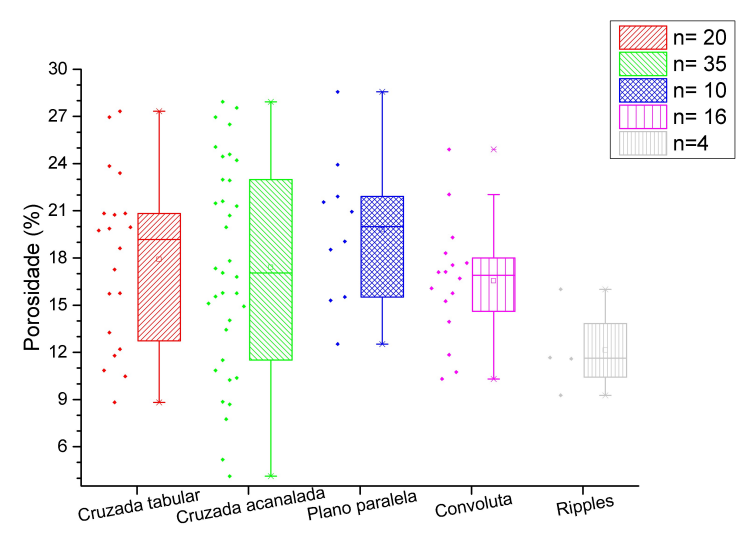

Figura 105 - Box plots de mediana da porosidade obtida por imagem, em função da estrutura sedimentar nas amostras da formação São Sebastião. 


\subsubsection{Seleção granulométrica}

A velocidade de fluxo deposicional (influente nas estruturas geradas durante a deposição) também determina outra variável deposicional: a seleção granulométrica. Porém, o controle desta não ocorre pelo módulo da velocidade de fluxo deposicional, mas sim pela sua taxa de variação (Boggs 2012).

Segundo Bridge (2003), as barras são os elementos arquiteturais nos quais se encontra maior variação de energia, devido aos diferentes mecanismos de transporte e deposição. Nos rios entrelaçados, essa diferença é ainda maior, resultado da alta variação do stream power.

Neste trabalho, nos depósitos de barra unitária, pela menor frequência da associaição de fácies finning upward que nas barras compostas, predominam sedimentos mais grossos, culminando em melhor seleção frente às barras compostas e canais abandonados.

Toonen et al (2012) discute o processo de abandono de canais apontando processos de abandonos graduais, o que resultaria em grandes variações de granulometria e baixa seleção granulométrica no perfil vertical.

As barras compostas, como já comentadas, possuem forte tendência à diminuição de granulometria para o topo, semelhante, mas em menor magnitude, aos canais abandonados. Para esses elementos, a seleção granulométrica é pior que nos demais elementos arquiteturais (próximo de 0,8 $\Phi$ para ambos) (figura 64B). Esse fato explicar-se-ia pela alta variação da energia de fluxo. Por parte dos canais abandonados, ocorrem fluxos de maior energia antes do abandono, ou durante reativações esporádicas, e fluxos de menor energia após o total abandono. Já nas barras, a variação atribui-se a diferentes espessuras de coluna d'água durante o transporte, ou até mesmo diferentes gradientes hidráulicos do rio (Reeinick \& Singh, 1980).

Além disso, os sedimentos das arquiteturas de granulometrias mais grossas tendem a sofrer ciclos de transportes mais curtos que os sedimentos 
finos, apesar de mais enérgicos. Nos depósitos analisados esse fator resulta na melhor seleção dos topos de barra e preenchimento de canal. Ressalta-se que a seleção granulométrica é o desvio padrão das granulometrias, enquanto a segregação granular representa a organização textural observada na estrutura.

Comparada a seleção granulométrica aos elementos arquiteturais, principais fatores no controle de porosidade e permeabilidade até aqui, nota-se a perturbação da relação entre a seleção granulométrica e a permeabilidade (figura 106A).

Segundo Boggs (1995), a granulometria possui tendência a correlação negativa com a seleção, ou seja, quanto melhor selecionadas as amostras, menor tende a ser a granulometria. Logo, devido ao alto controle da granulometria sobre a permeabilidade, a relação apresentada entre a permeabilidade e a seleção não se mostra clara.

As fácies com melhor seleção granulométrica mostraram-se, neste trabalho, relacionadas aos depósitos de granulometria mais fina (figura 63) as quais estão acompanhadas de menores gargantas de poro, relacionando-as às menores permeabilidades. Por outro lado, as maiores gargantas de poro estão relacionadas aos depósitos portadores de pior seleção granulométrica, os quais conferem permeabilidade mais baixa que os moderadamente mal selecionados (figura 106A). Por isso, infere-se que a seleção granulométrica influencia na permeabilidade, mas isso ocorre apenas quando não existem diferenças grandes de diâmetros de garganta de poro. Grandes diferenças de gargantas de poro e a alta influência da granulometria na permeabilidade podem inibir a ação da seleção granulométrica como fator controlador da permeabilidade. Esse fato ocorre nessas amostras comparando amostras bem selecionadas e mal selecionadas (figura 106A).

Enquanto a relação entre seleção granulométrica com a permeabilidade pode ser inibida pela granulometria, a porosidade, por não ter relação com o tamanho de grão, explicita correlação com a seleção granulométrica (figura 106B). Isso pode ser explicado por uma trama onde predominam granulometrias de areia média-grossa e alguns grãos de areia muito fina, os quais seriam prejudiciais à porosidade, pois se colocariam entre os poros 
gerados pelos grãos maiores, bem como na permeabilidade, prejudicando fluxos. Porém, para essa afirmação é necessário analisar a relação entre o diâmetro da garganta de poro e quantidade de finos presente na trama. Em gargantas de poro muito grandes, pequenas concentrações de finos tenderiam a não debilitar em grande quantidade o fluxo (notado no grupo dos moderadamente mal selecionados), mas sempre debilitariam a porosidade. Para que a debilitação considerável (que diminuiria a permeabilidade em escalas de grandeza) de gargantas de poros grandes ocorresse seria necessário grande quantidade de finos. Em outras palavras, supõe-se que quanto maior a garganta de poro, maior a quantidade de sedimentos finos necessários para debilitar o fluxo.

Tiab e Donaldson (2004) discutem a importância da seleção granulométrica na porosidade. O resultado comentado pelos autores é a melhor seleção granulométrica acompanhada de maiores valores de porosidade.

Neste trabalho, a granulometria e a seleção granulométria não possuem correlação direta, mas os elementos arquiteturais distinguem-se em grupos (figura 63). Os EA de granulometria predominantemente fina possuem melhor seleção granulométrica. Já os elementos arquiteturais com fácies sedimentares de granulações grossas, como as barras, possuem piores seleções granulométricas (figura $64 \mathrm{~B}$ ).
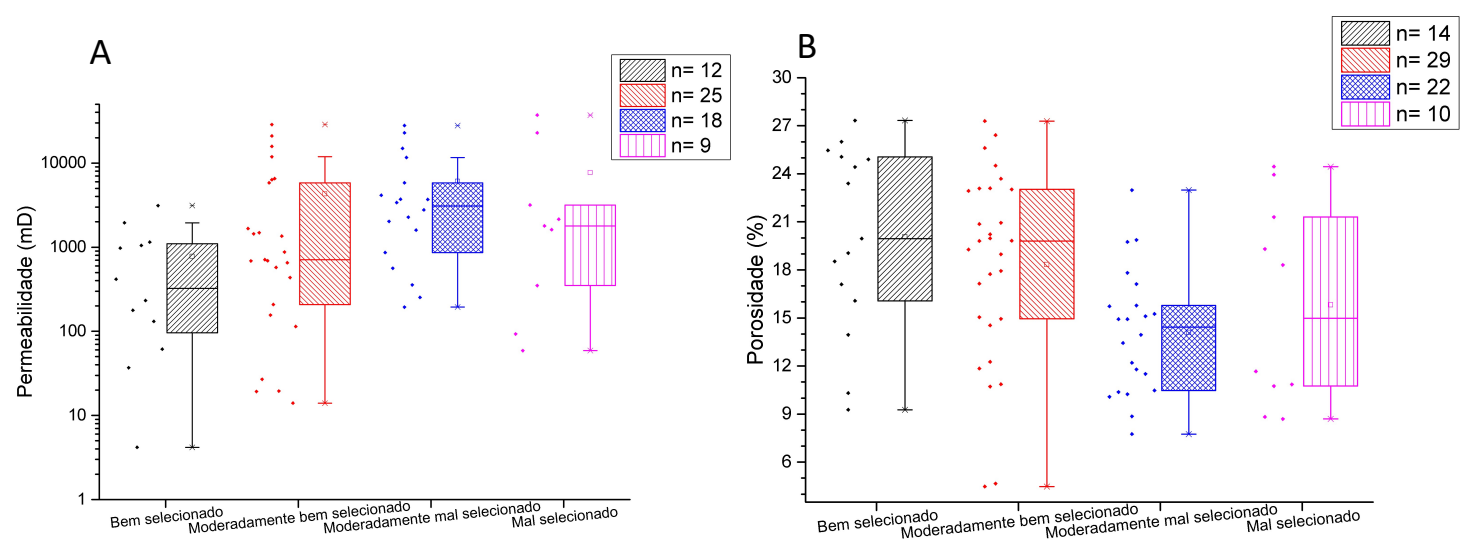

Figura 106 - A) Box plots das diferentes seleções granulométricas em função da permeabilidade, nos arenitos da formação São Sebastião 
B) Box plots de mediana da porosidade por imagem em função da seleção granulométrica nas amostras da formação São Sebastião

\subsubsection{Arredondamento}

Assim como as demais variáveis apresentadas até o momento, o arredondamento também mostrou boa relação quando agrupado em elementos arquiteturais. Porém, as variações das medianas das taxas de arredondamento entre os elementos arquiteturais não são altas (aproximadamente 10\%, de 20\% a 30\% de grãos arredondados) (figura 66).

Com base no sistema deposicional analisado, rios entrelaçados, que corriam segundo Figueiredo (2013) axialmente à abertura do rifte, o transporte seria relativamente longo, proporcionando arredondamento aos grãos. Por outro lado, esses rios poderiam ser pouco estáveis, resultando em pequenos ciclos de transporte. Além disso, o rifte sofria grande influência de outros sistemas fluviais transversais à bacia, descritos como fans, provenientes das ombreiras com paleocorrentes, segundo Freitas (2014), para o interior da bacia. Esses desaguariam nos rios axiais, transportando sedimentos pouco arredondados devido ao pequeno curso de transporte. Adicionalmente, segundo Figueiredo (2013) alguns depósitos da Formação São Sebastião teriam sofrido influência de retrabalhamento eólico. Portanto, a influência de sistemas deposicionais distintos nos elementos arquiteturais, geradores de padrões de arredondamentos diferentes, poderiam ser os responsáveis pelas pequenas variações.

O arredondamento é resultado, segundo Suguio (1973) e Boggs (2012), do contínuo transporte sedimentar. Porém, este atua diferentemente em distâncias curtas e longas de transporte. Em distâncias curtas, diferentes granulometrias possuiriam arredondamentos iguais, já em distâncias longas os sedimentos mais grossos apresentariam maiores taxas de arredondamento. Porém, a relação apresentada pelos autores não considera eventos externos ou interação entre diferentes processos deposicionais, como o que ocorre em bacias sedimentares com influências tectônicas. 
Com base nos resultados, é possível observar o melhor arredondamento nos elementos arquiteturais de granulometria mais grossa, como as barras compostas (30\% dos grãos do arcabouço arredondados) e unitárias ( $32 \%$ dos grãos arredondados) (figura 66). Porém, neste trabalho observa-se que a relação entre granulometria e arredondamento mostra pior arredondamento nas amostras de granulometrias muito finas ( $21 \%$ dos grãos arredondados) e media-grossa (maior granulometria presente) ( $25 \%$ dos grãos arredondados), contrariando em parte a ideia anterior (figura 68). Essa perturbação da correlação esperada (grãos com maior granulometria mais arredondados) pode ser proveniente da atuação de diferentes processos sedimentares no transporte dos grãos, no qual os grãos com granulometria mais grossa sofrem menos transporte, contabilizando menor quantidade de choques $\mathrm{e}$ consecutivamente arredondando menos. Outra hipótese, menos provável, seria a contribuição de um sistema eólico, o qual não arredondaria apenas as granulometrias mais grossas, resultando na correlação esperada (granulometrias mais grossas mais arredondadas).

Por outro lado, no presente trabalho observam-se depósitos de boa seleção granulométrica (e geralmente com predomínio de grãos com menor granulometria) apresentando piores arredondamentos e depósitos mal selecionados (de maior granulometria) com predomínio de grãos mais arredondados (figura 69). Essa correlação, assim como a relação entre elementos arquiteturais e o arredondamento, convergiria para um transporte relativamente longo, no qual os depósitos melhores selecionados, geralmente com menor granulometria, tenderiam a possuir menor arredondamento.

$\mathrm{O}$ arredondamento na literatura mostra-se como fator muito influente nas características permoporosas (Tiab \& Donaldson, 2004; e Pettijohn et al., 1972). Porém, neste trabalho quando comparado à permeabilidade, essas variáveis não mostraram correlação direta. Já a porosidade apresenta correlação baixa. Adicionamente, nota-se que as estruturas sedimentares, as quais apresentam arcabouço com grãos mais arredondados, são as estratificações cruzadas (figura 107). 
O maior arredondamento pertencente às fácies sedimentares com estratificações cruzadas é resultado da maior turbulência e maior quantidade de choque entre grãos durante a formação dessa estrutura. Esse fato não ocorre na formação das ripples, por exemplo, detentoras de maiores taxas de decantação. A importância do arredondamento para a porosidade é traduzida pela ausência de irregularidades nas bordas dos grãos, as quais ocupariam volume poroso no reservatório. Teoricamente, a permeabilidade também seria afetada pelo arredondamento, mas essa relação não foi obtida com os dados deste trabalho.

Paralelamente, corroborando com os dados da bibliografia (Tiab \& Donaldson, 2004; e Pettijohn et al., 1972), os elementos arquiteturais com maior concentração de grãos mais arredondados são os detentores de maior permeabilidade (barras). A relação direta entre permeabilidade e arredondamento pode não ter ficado clara devido à manifestação de outras variáveis, como por exemplo, as amostras com maiores gargantas de poro (granulometria média-grossa), as quais possuem baixo arredondamento.

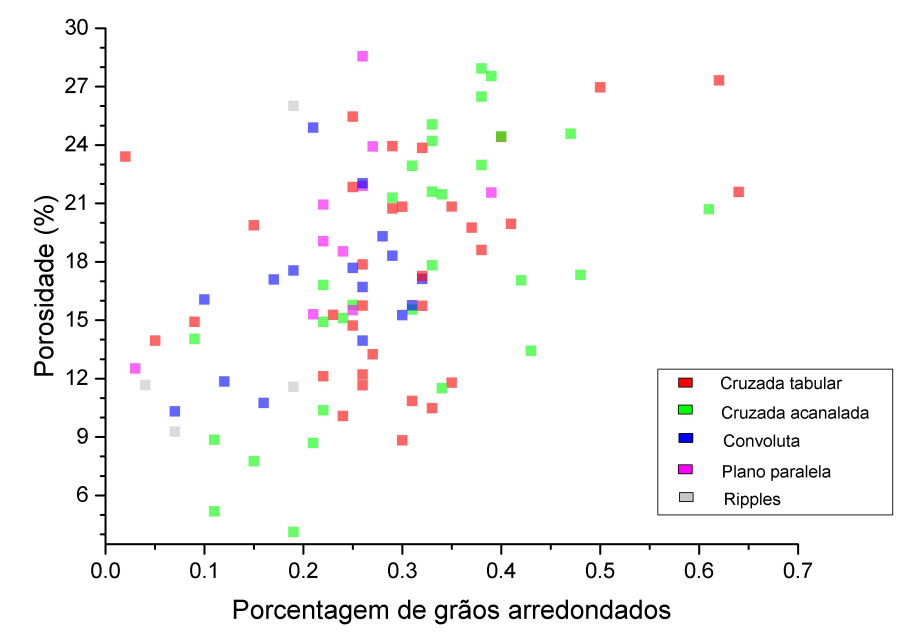

Figura 107 - Box plots de mediana da porosidade obtida por imagem (para diferentes estruturas sedimentares) em função do arredondamento, nas amostras da formação São Sebastião.

Portanto, os controles deposicionais, desde a escala mesoscópica (elementos arquiteturais e fácies) até a escala microscópica (seleção granulométrica e arredondamento) possuem heterogeneidades muito 
importantes e complexas, as quais exercem controle de diferentes maneiras sobre a permoporosidade.

Além disso, no âmbito dos controles deposicionais, também está incluída a composição mineralógica das rochas. A composição mineralógica é dependente da área fonte, velocidade de fluxo e tipo de transporte no sistema deposicional, tempo e distância do transporte. Porém, a mineralogia é muito importante na história diagenética, a qual afeta em grande magnitude a permoporosidade. Logo, será discutida nos controles diagenéticos na qualidade de reservatório.

\subsection{Controles diagenéticos na qualidade de reservatórios}

Os controles diagenéticos são de suma importância na qualidade de reservatório, pois podem mudar drasticamente a permoporosidade gerada pelos processos deposicionais. Os principais fatores responsáveis são: história compactacional atrelada à composição mineralógica, eventos de cimentação, infiltrações de argilas, eventos de dissolução e entre outros. Os principais fatores controladores diagenéticos na qualidade de reservatórios constatados nos depósitos analisados serão apresentados a seguir.

\subsubsection{Composição mineralógica e compactação}

A composição mineralógica é de suma importância para o desenvolvimento de texturas microscópicas controladoras das características permoporosas do reservatório.

Segundo De Ros (1996) e Pettijon et al. (1972) a composição inicial das rochas é de total importância na sua história diagenética. Rochas mais maturas tendem a desenvolver reservatórios com menor quantidade de argilas, enquanto arenitos feldspáticos tendem a desenvolver maior quantidade de 
argila, e rochas com fragmentos vulcânicos desenvolveriam zeólitas, entre outras associações.

Os depósitos da Formação São Sebastião são composicionalmente muito maturos. A pequena quantidade de fragmentos líticos e fedspatos (médias menores que 10\% somados) (mineralogia suscetível ao intemperismo) pode ser correlacionada a um clima árido na região no momento da deposição, com alta taxa de intemperismo (figura 57). Evidências de intemperismo não telodiagenético de grãos feldspáticos nas lâminas descritas reforçam esta hipótese.

Segundo Krynine (1948) é possível obter relações de taxas de intemperismo segundo a composição mineralógica. Quanto maior a presença de fragmentos líticos suscetíveis ao intemperismo, menor seria a taxa de intemperismo.

A maturidade apresentada pelos arenitos da formação São Sebastião revela ótima característica para reservatórios. Porém, ao mesmo tempo, a pequena quantidade de fragmentos líticos pode ser um fator de impotência na obtenção de porosidade secundária durante a mesodiagênese.

A mesma maturidade constatada aqui para os depósitos da formação São Sebastião foi descrita por Figueiredo (2013), em análises macroscópicas, atrelando a grande quantidade de fragmentos quartzosos à proveniência de sedimentos policíclicos Paleozóicos.

Outros componentes do arcabouço englobados separadamente neste trabalho também possuem manifestação na Formação São Sebastião, entre eles micas e intraclastos de argila, os quais têm relação com os elementos arquiteturais (importantes controladores da permoporosidade). A presença de micas certamente é muito prejudicial ao reservatório, pois fecha ou diminui os raios das gargantas de poro (figura 59 D). Já os fragmentos argilosos podem ou não ser prejudiciais ao reservatório. Caso a argila presente no sistema caracterize-se como argila estrutural, sem sofrer compactação, não ocorre interferência negativa no reservatório (figura 59 E). Porém, na maioria dos casos, compactações ínfimas em empacotamentos abertos-normais são 
suficientes para a compactação e dobramento das argilas estruturais, as quais passariam a fechar gargantas de poro (figura $59 \mathrm{E}$ ).

As barras, tanto unitárias quanto compostas, devido à energia de deposição e baixa taxa de decantação, tenderiam a destruir os fragmentos argilosos e não depositar ou depositar pequena concentração de micas. Nas barras compostas, apesar da moda ser a inexistênca de micas, encontra-se maior concentração de micas (na totalidade das amostras) e intraclastos $(2,5 \%$ da composição mineralógica) que nas unitárias (intraclastos igual a $1 \%$ da composição mineralógica) (figura 61). A maior concentração ocorre por estarem sujeitas a maior gama de regimes de fluxo do rio, com diminuições de energia, mesmo que subordinadas, mas mais frequentes (durante a deposição das fácies do topo) que nas barras unitárias.

Com o mesmo raciocínio, os demais elementos arquiteturais, portadores de granulometria mais fina que as barras e menor energia associada (figura 64A), demonstram maior quantidade de micas e fragmentos argilosos (figura 61). Dentre os três restantes, a menor quantidade de fragmentos argilosos ocorre nos canais abandonados (4,5\% da composição mineralógica total), os quais possuem turbulências periódicas durante o transporte, por reativações, ou anteriormente ao abandono total dos canais, com potencial para destruição dos mesmos. Já as arquiteturas de preenchimento de canal (mediana de $25 \%$ dos poros) e topos de barras (mediana de $10 \%$ dos poros, atingindo até mais que $50 \%$ ) são as detentoras de maior concentração micas, e os topos de barras de fragmentos argilosos (próximo de $6 \%$ da composição total). A concentração de micas e intraclastos argilosos, portanto, mostra-se inversamente proporcional à energia do ambiente deposicional de cada arquitetura.

Apesar da boa maturidade textural das rochas analisadas, as micas e intraclastos argilosos, assim como os feldspatos alterados colocar-se-iam aparte dessa característica, tendendo a piorar a qualidade do reservatório. Contudo, esses fragmentos podem sofrer dissolução, como em algumas ocasiões observadas nesse trabalho (figura 83 B, C e D). 
Segundo Smosna \& Bruner (1997), é preciso cautela para afirmações entre qualidade de reservatório e maturidade, pois os grãos dúcteis, como feldspatos alterados e líticos, muitas vezes podem passar por processos de dissolução, aumentando a porosidade secundária.

A concentração de fragmentos argilosos, feldspatos alterados e líticos é superior no afloramento TUC05 (item 6.2.1), o qual possui menor quantidade de porosidade secundária (item 6.2.9). Talvez a maior quantidade de grãos dúcteis nesse afloramento seja resultado de um evento de dissolução não muito eficaz.

Já no afloramento TUC41 a porosidade secundária mostra-se maior, fato que estaria relacionado a um evento de dissolução mais eficaz que no TUC05. Outra hipótese seria a presença de tipos de grãos dúcteis mais instáveis às condições impostas na área do afloramento TUC41, os quais foram dissolvidos.

Os fatores geradores das porosidades secundárias, com a evolução do soterramento e compactação, podem não dissolver os grãos instáveis, mas deformá-los, gerando pseudomatriz. Para a geração de pseudomatriz é necessária a compactação mecânica de grãos dúcteis na trama da rocha (Pettijohn et al 2012).

Os índices de compactação nas amostras analisadas nos dois diferentes afloramentos não são altos, contabilizando grande quantidade de contatos do tipo grãos flutuantes, e baixos índices de empacotamento, além de compactação química praticamente inexistente (figura 70 e 71). Essas características e a ausência de sobrecrescimento de quartzo são características muito favoráveis para reservatórios de hidrocarbonetos, visto que a baixa compactação mantém a porosidade intergranular (Sombra \& Kiang, 1997).

Segundo Gluyas et al. (1993) grandes compactações resultantes de espessas colunas de rocha sobrepostas refletiriam em empacotamentos fechados e contatos de grãos com evidências de compactação química que, por sua vez, estariam relacionadas a sobrecrescimentos de quartzo, o que definitivamente não ocorre nas rochas analisadas. 
É evidente que no mesmo afloramento as taxas de compactação são praticamente iguais. Porém, as diferenças nas taxas analisadas (no mesmo afloramento) resumem-se à relação de grãos de quartzo e grãos dúcteis durante a compactação mecânica. Portanto, a maior taxa resulta no aumento da quantidade de contatos planares, além de empacotamentos mais fechados, encontrados em maior quantidade nos elementos arquiteturais relacionados à menor energia deposicional (preenchimentos de canais, topos de barra e canais abandonados), nos quais também encontra-se maior quantidade de pseudomatriz (figura 71 e 75 ).

Analisando as compactações separadamente, observou-se a maior compactação no afloramento TUC05, assim como a quantidade de intraclastos (figura 61A e 72). Essas diferenças entre os dois afloramentos poderiam ser explicadas pela posição geográfica dos dois afloramentos durante a subsidência mecânica da bacia. Essa subsidência caracteriza-se pelas reativações de falhas normais ou geração destas, resultando em altas taxas de subsidência em curtos períodos de tempo. O afloramento TUC05 localiza-se próximo ao baixo de Cícero Dantas, onde, segundo Magnavita et al (2003), concentraram-se as maiores taxas de subsidência do Tucano e maior espessura de sedimentos depositados. Já o afloramento TUC41 localiza-se próximo a zonas que supostamente sofreram menores taxas de subsidência, associadas possivelmente a menores taxas de decantação que no TUC05. O TUC41 possivelmente foi sujeito a maiores energias deposicionais, refletindo composições com menor concentração de micas $e$ intraclastos e, posteriormente, menor compactação, em função de sobreposições de pacotes sedimentares de menos espessos que no TUC05.

Apesar da inexistência de compactação química, a compactação mecânica foi observada pela presença de grãos dúcteis deformados (ou dobrados), além da não cimentação eodiagenética, correlacionados à geração de pseudomatriz, a qual será comentada na sequência (figura 108). 


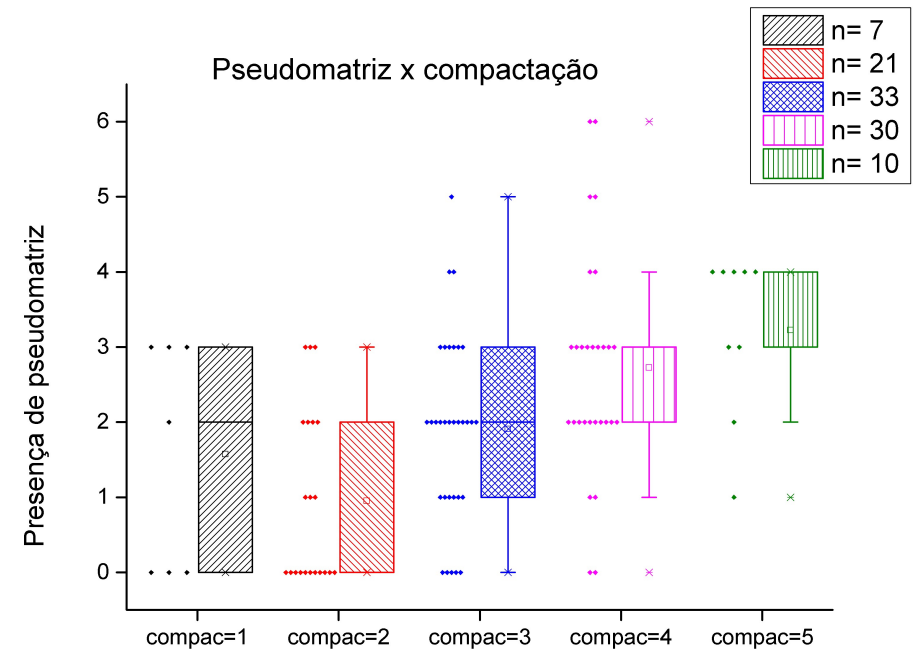

Figura 108 - Box plots da compactação em função da presença de pseudomatriz nos dois afloramentos estudados. No eixo $\mathrm{x}$ a classificação 1 representa "contato de grão flutuante" (predominante) e pontual; 2- grão flutuante e pontual (predominante); 3- pontual (predominante) e planar; 4- pontual e planar; e, planar (predominante) e química subordinada. No eixo y a classificação 0 representa constituinte inexistente; 1 - existente, presente em aproximadamente $5 \%$ nos poros ancestrais da lâmina; 2- presente em aproximadamente $10 \%$ nos poros ancestrais da lâmina; 3 - presente em aproximadamente $25 \%$ nos poros ancestrais da lâmina; 4- presente em aproximadamente $50 \%$ nos poros ancestrais da lâmina; 5- presente em aproximadamente $75 \%$ nos poros ancestrais da lâmina; 6 - presente aproximadamente $90 \%$ nos poros ancestrais da lâmina.

\subsubsection{Pseudomatriz}

As maiores concentrações de pseudomatriz encontram-se nas amostras com maiores compactações, as quais também possuem maior quantidade de grãos dúcteis e, por sua vez estão relacionadas a ambientes deposicionais menos enérgicos. A ausência de "contatos flutuantes" (índice maior ou igual a três (3)) resulta, com base nos dados deste trabalho e condições necessárias, em maior concentração de pseudomatriz (figura 108). Isso se deve ao fato dos grãos do arcabouço tocarem-se, deformando os grãos dúcteis.

A origem da pseudomatriz nos afloramentos deste trabalho, além dos intraclastos argilosos, engloba os feldspatos alterados (possivelmente por interação eodiagenética com água meteórica), presentes em todas as 
arquiteturas, e não relacionados com baixa energia de ambiente deposicional (como os intraclastos) e sim a área fonte. A concentração de feldspatos é maior no afloramento TUC05, assim como a presença de pseudomatriz (figura 58 e 76). A pseudomatriz gerada a partir de grãos de feldspatos alterados pode explicar a grande quantidade dessa textura em algumas amostras de barra (depósitos de energia relativamente alta), as quais possuem menor concentração, ou ausência, de fragmentos argilosos.

Tanto a permeabilidade como a porosidade são fortemente influenciadas pela concentração de pseudomatriz (figura 109). A compactação dos grãos dúcteis promove a desagregação dos mesmos, os quais passam a preencher os poros, diminuindo o volume poroso, obliterando gargantas de poro (afetando negativamente a permeabilidade) e, na maioria das vezes, substituindo macroporos por microporos. Notou-se nas seções delgadas o maior decréscimo da permeabilidade pela pseudomatriz em fácies de granulometrias finas. Isso se deve ao fato dos raios das gargantas de poro dos arenitos finos serem menores, necessitando de menor volume de pseudomatriz para obliteração. Já sobre a porosidade, destaca-se o decréscimo não linear relacionado ao aumento de pseudomatriz, pois a partir do fator três (3) a porosidade diminui em menor gradiente (figura 109 B).

Retornando à relação com os elementos arquiteturais, tendo em vista a diminuição proporcionada pela pseudomatriz nas características permoporosas, a menor ocorrência de pseudomatriz nos depósitos de barra foi interpretada como um dos importantes fatores que contribuem para alta porosidade e permeabilidade desse elemento arquitetural (figura 75 e item 6.3).

Grande quantidade de pseudomatriz também foi constatada: na Bacia do Recôncavo, na Formação Sergi, provenientes de intraclastos de argila (De Ros \& Scherer 2012); na Bacia do Espírito Santo, em reservatórios turbidíticos do Cretáceo, provenientes de feldspatos alterados (Mansurberg et al 2012); no Cretáceo dos EUA (Ketzer \& Morad 2006); na Bacia do Solimões (Lima \& De Ros, 2002); entre outros. Nesses trabalhos a pseudomatriz também exerce influência negativa sobre a porosidade e a permeabilidade, diminuindo a última em escalas de grandeza, como neste trabalho. 

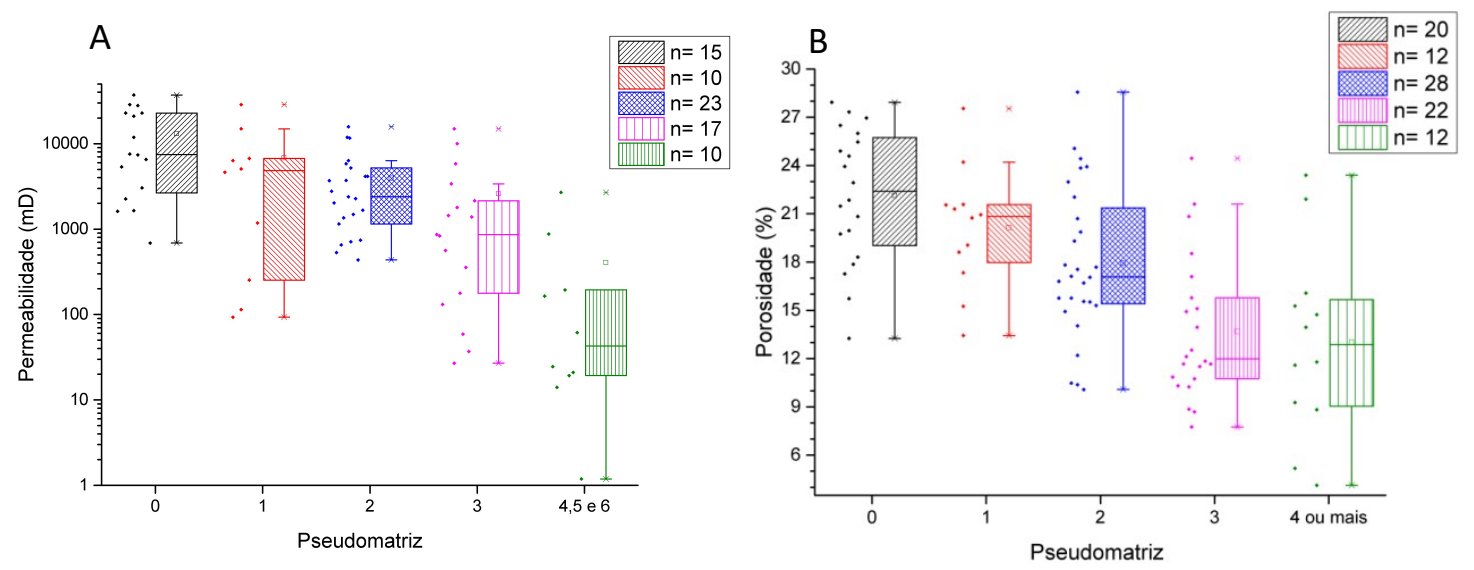

Figura 109 - A) Box plots da presença de pseudomatriz em função da permeabilidade. No eixo $x$ a classificação 0 representa constituinte inexistente; 1 - existente, presente em aproximadamente $5 \%$ dos poros da lâmina; 2- presente em aproximadamente $10 \%$ dos poros da lâmina; 3- presente em aproximadamente $25 \%$ dos poros da lâmina; 4- presente em aproximadamente $50 \%$ dos poros da lâmina, ou mais

B) Box plots de mediana da porosidade por imagem em função da pseudomatriz nas amostras da formação São Sebastião. No eixo x a classificação 0 representa constituinte inexistente; 1 existente, presente em aproximadamente $5 \%$ dos poros da lâmina; 2- presente em aproximadamente $10 \%$ dos poros da lâmina; 3- presente em aproximadamente $25 \%$ dos poros da lâmina; 4- presente em aproximadamente $50 \%$ dos poros da lâmina, ou mais

\subsubsection{Micas}

Grãos de mica, também relacionados aos controles deposicionais, ocorrem em maior quantidade nos elementos arquiteturais com granulometria fina predominante, relacionadas à maior taxa de decantação (figura 61A). Diferentemente das pseudomatrizes, devido ao seu hábito placóide alongado, não necessitam da compactação para influenciar negativamente a permoporosidade. Porém, devido à ductibilidade das mesmas, com a compactação, um único mineral pode obliterar mais de uma garganta de poro. Logo, tanto a permeabilidade como a porosidade são diretamente relacionadas e influenciadas negativamente pela concentração de mica (figura 110) Além disso, a presença de micas no reservatório é responsável por importante anisotropia horizontal-vertical de permeabilidade (discutida no item 7.4). 
A obstrução de poros gerada pelas micas no reservatório também foi constatada nos turbiditos da bacia do Espírito Santo (Mansurberg et al 2012).
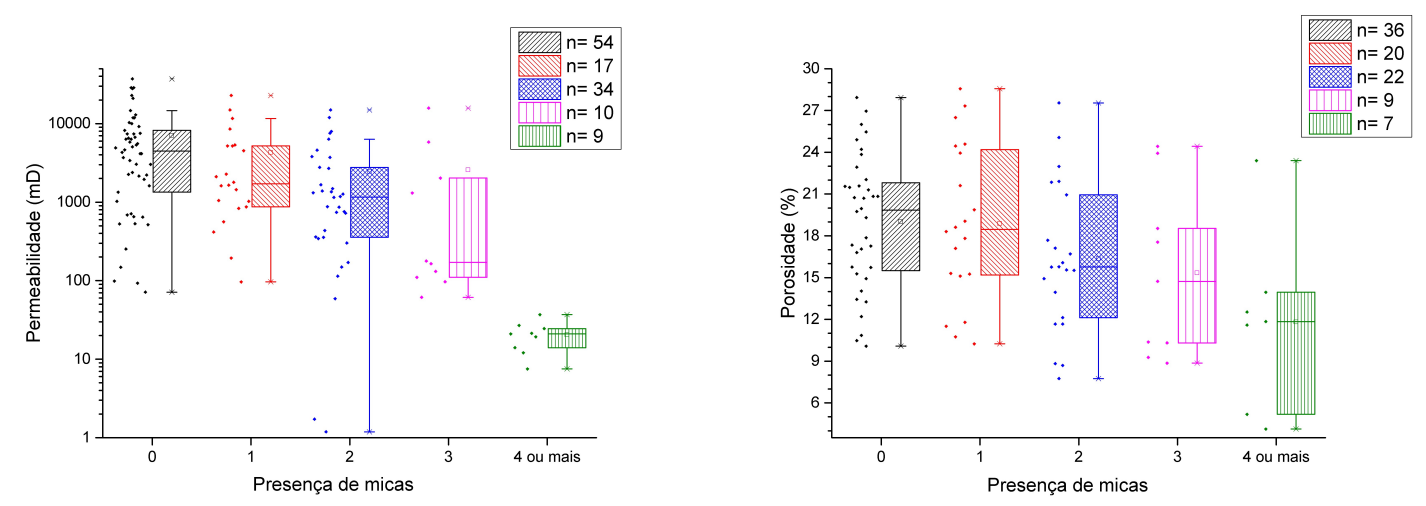

Figura 110 - A) Box plots da presença de micas em função da permeabilidade. No eixo x a classificação 0 representa constituinte inexistente; 1 - existente, presente em aproximadamente $5 \%$ dos poros da lâmina; 2- presente em aproximadamente $10 \%$ dos poros da lâmina; 3- presente em aproximadamente $25 \%$ dos poros da lâmina; 4- presente em aproximadamente $50 \%$ dos poros da lâmina; 5 - presente em aproximadamente $75 \%$ dos poros da lâmina; 6- presente aproximadamente $90 \%$ dos poros da lâmina

B) Box plots de mediana da porosidade por imagem em função da presença de micas nas amostras da formação São Sebastião. No eixo x a classificação 0 representa constituinte inexistente; 1 - existente, presente em aproximadamente $5 \%$ dos poros da lâmina; 2- presente em aproximadamente $10 \%$ dos poros da lâmina; 3- presente em aproximadamente $25 \%$ dos poros da lâmina; 4- presente em aproximadamente $50 \%$ dos poros da lâmina; 5 - presente em aproximadamente $75 \%$ dos poros da lâmina; 6- presente aproximadamente $90 \%$ dos poros da lâmina

\subsubsection{Argilas infiltradas e diagenéticas}

Assim como as pseudomatrizes e micas, as argilas infiltradas e diagenéticas são sinônimos de diminuição na qualidade de reservatórios (Moraes \& De Ros 1990). A ocorrência de argila infiltrada é mais frequente no afloramento TUC41 (figura 80), enquanto a argila diagenética ocorre apenas em área restrita do afloramento TUC05.

As argilas infiltradas apresentam correlação negativa com a porosidade, como esperado. Porém, nota-se que amostras analisadas sem argilas infiltradas são menos porosas que as amostras com argilas infiltradas (figura 
111B). Isso está relacionado com o hábito dessa textura (coatings irregulares e pouco espessos) que não diminui em grande magnitude o volume poroso e, possivelmente, à manifestação de outra textura em maior concentração nessas amostras.

Diferentemente das pseudomatrizes e micas, as argilas infiltradas não obliteram as gargantas de poro, apenas diminuem o raio das mesmas (figura 77), fato que resulta na não correlação negativa com a permeabilidade, pois as principais vias de fluxo não são obstruídas (figura 111A).

Outro importante fator para essa análise é a não manifestação de grandes quantidades de pseudomatriz quando argilas infiltradas apresentam-se no sistema (figura 111C). Constatada essa relação, levantar-se-ia a hipótese das argilas infiltradas impedirem a manifestação de pseudomatrizes, caso as argilas infiltradas fossem eodiagenéticas. Contudo, analisando as características texturais dessas argilas, dúvidas permaneceram a respeito do intervalo de infiltração das mesmas, mas grande parte das evidências petrográficas apontam para infiltração durante a telodiagênese. Esse fato eliminaria a possibilidade da relação comentada entre as texturas.

Diferentemente da Formação São Sebastião, nos trabalhos de Moraes \& De Ros (1990) e De Ros \& Scherer (2012), na Bacia do Recôncavo, na Formação Sergi, onde a argila infiltrada é eodiagenética, ela ocorre fechando totalmente os poros, diminuindo significantemente a permoporosidade.

Apenas quatro lâminas detentoras de argila diagenética foram analisadas petrograficamente e para a porosidade por lâmina, e duas para a permeabilidade. As quatro lâminas possuiam $10 \%$ dos poros preenchidos por argila diagenética. As porosidades resultaram em: 19\% (I); $20 \%$ (II); $24 \%$ (III) e $19 \%$ (IV), sendo que as três primeiras amostras são do afloramento TUC 05 e a ultima do afloramento TUC41. A permeabilidade da amostra II é 7700 mD; e na amostra IV é $2200 \mathrm{mD}$ na direção horizontal e $12 \mathrm{mD}$ na direção vertical. Segundo Pettijohn et al (2012), as argilas diagenéticas influenciam negativamente a permoporosidade do reservatório. Neste trabalho, a pequena quantidade de amostras analisadas inviabilizou maiores discussões. 

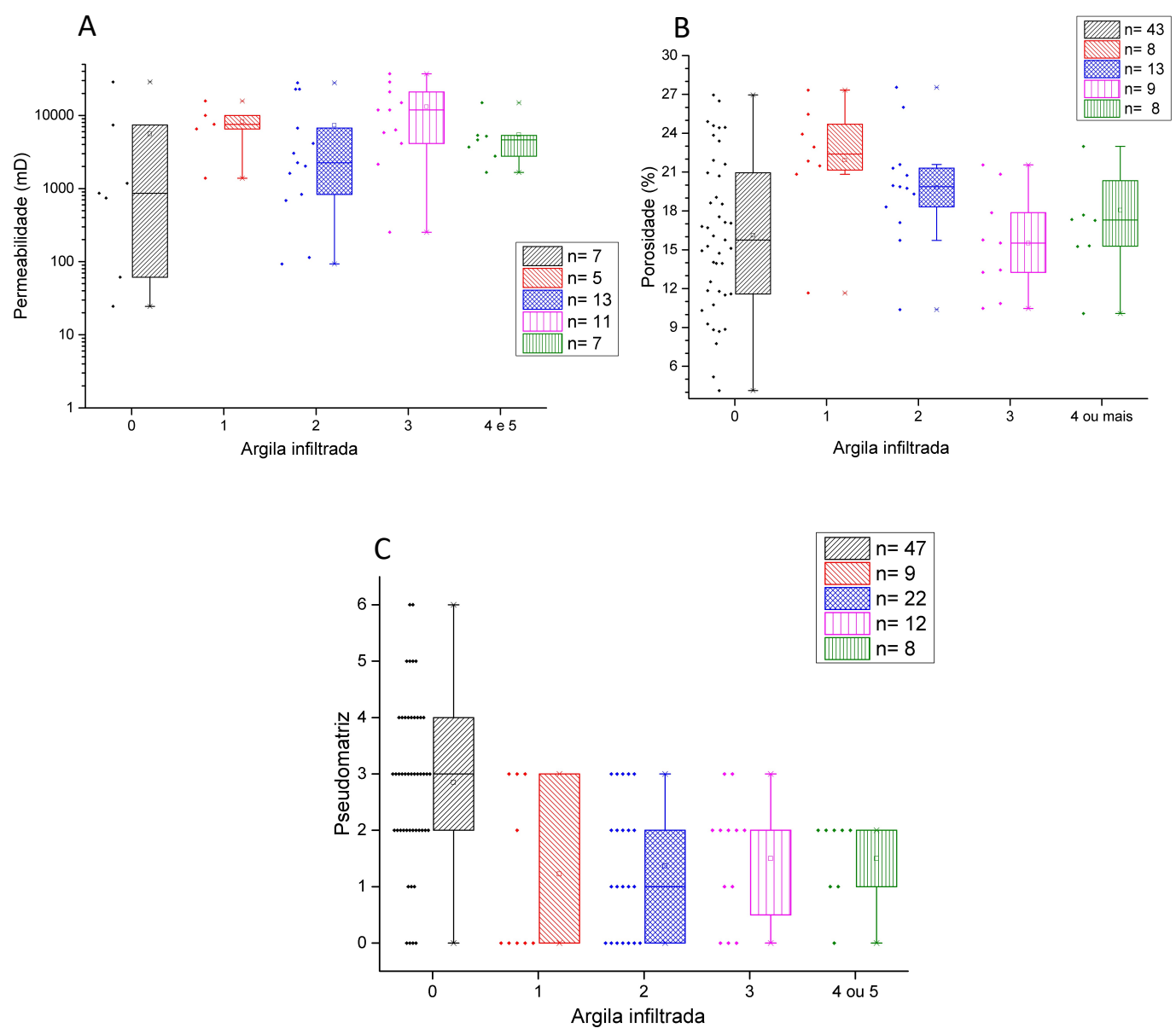

Figura 111 - A) Box plots da presença de argila infiltrada em função da permeabilidade. No eixo $\mathrm{x}$ a classificação 0 representa constituinte inexistente; 1 - existente, presente em aproximadamente $5 \%$ dos poros da lâmina; 2 - presente em aproximadamente $10 \%$ dos poros da lâmina; 3- presente em aproximadamente $25 \%$ dos poros da lâmina; 4- presente em aproximadamente $50 \%$ dos poros da lâmina; 5- presente em aproximadamente $75 \%$ dos poros da lâmina; 6- presente aproximadamente $90 \%$ dos poros da lâmina

B) Box plots de mediana da porosidade por imagem em função da argila infiltrada nas amostras da formação São Sebastião. No eixo x a classificação 0 representa constituinte inexistente; 1 existente, presente em aproximadamente $5 \%$ dos poros da lâmina; 2- presente em aproximadamente $10 \%$ dos poros da lâmina; 3 - presente em aproximadamente $25 \%$ dos poros da lâmina; 4- presente em aproximadamente $50 \%$ dos poros da lâmina; 5- presente em aproximadamente $75 \%$ dos poros da lâmina; 6 - presente aproximadamente $90 \%$ dos poros da lâmina

C) Box plots da presença de argila infiltrada em função da presença de pseudomatriz. . No eixo $\mathrm{x}$ e y a classificação 0 representa constituinte inexistente; 1 - existente, presente em aproximadamente $5 \%$ dos poros da lâmina; 2- presente em aproximadamente $10 \%$ dos poros 
da lâmina; 3- presente em aproximadamente $25 \%$ dos poros da lâmina; 4- presente em aproximadamente $50 \%$ dos poros da lâmina; 5 - presente em aproximadamente $75 \%$ dos poros da lâmina; 6- presente aproximadamente $90 \%$ dos poros da lâmina

\subsubsection{Petrofácies}

As associações de fácies são restringidas a elementos arquiteturais e são ótimos guias para a predição de permoporosidades. Do mesmo modo, as petrofácies agrupam descrições de texturas petrográficas relacionadas a comportamentos composicionais e diagenéticos semelhantes. Essa técnica também proporciona boa previsão das qualidades de reservatório (figura 112).

As petrofácies I, II e III possuem baixas porosidades devido aos fatores maiores que dois (2) de pseudomatriz, micas e argila infiltrada, respectivamente, utilizados para definí-las. Já as petrofácies IV, devido ao menor fator (rochas com pseudomatriz, micas ou argila infiltrada com fatores menores ou iguais a dois (2)), possuem maiores porosidades. Por fim, a petrofácies $\mathrm{V}$ não possui elementos que preencheriam espaços porosos ("arenito limpo"), culminando em maior porosidade. Essa relação é válida devido às amostras estarem em condições de soterramento similares, o que não acarreta em níveis de compactação distintos (figura 112 B).

A grande interferência das petrofácies I e II na permeabilidade se dá pelo tipo de ocorrência da pseudomatriz e das micas. Ambas ocorrem obliterando as gargantas de poro, ocasionando perdas muito grandes de permeabilidade e praticamente impossibilitando a passagem do fluido por determinadas regiões. Porém, nota-se que alguns valores de permeabilidade, tanto nas petrofácies I, quanto na II, apresentam-se maiores que $1000 \mathrm{mD}$. Isso pode ser explicado pela concentração da pseudomatriz em micas e locais restritos, restando caminhos preferenciais com gargantas de poro "limpas". As petrofácies III possuem valores de permeabilidade altos. Isso se deve ao hábito que as argilas infiltradas ocorrem (cutans), não fechando totalmente as gargantas de poro. Esse fator, atrelado à baixa compactação das amostras analisadas explica a alta permeabilidade desse conjunto de amostras. Assim 
como a petrofácies III, a IV também possui altos valores de permeabilidade, mas a distribuição é mais dispersa. Os altos valores de permeabilidade estão associados à pequena quantidade, ou mesmo ausência, das argilas infiltradas, mas principalmente de micas e/ou pseudomatrizes. A dispersão encontrada é resultado de alguns valores baixos de permeabilidade, os quais geralmente são resultado da combinação entre fatores dois (2), tanto de pseudomatriz, como de micas, os quais somados fechariam gargantas de poro em volume relativamente alto. As petrofácies $\mathrm{V}$ apresentam valores de permeabilidade acima de $4000 \mathrm{mD}$, resultado da não diminuição dos raios das gargantas de poro. Logo, apenas valores altíssimos de permeabilidade são associados a essa petrofácies (figura 112 A).
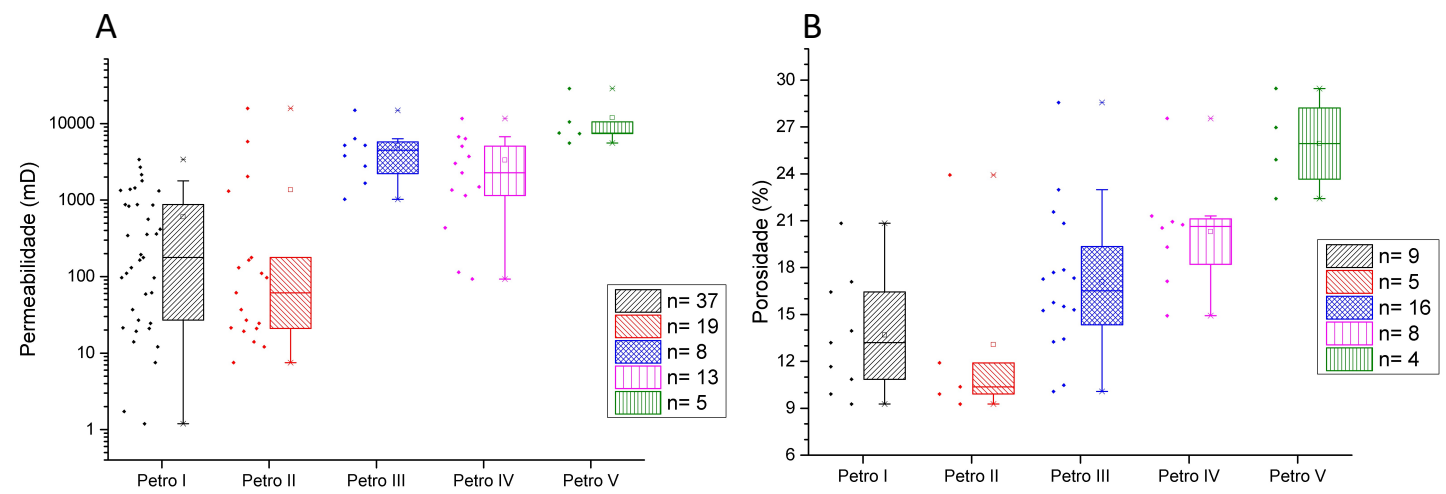

Figura 112 - A) Box plots das diferentes petrofácies pela permeabilidade. Petrofácies I arenito com pseudomatriz; petrofácies II - arenito com micas; petrofácies III - arenito com argila infiltrada; petrofácies IV - arenito com fator menor que dois de pseudomatriz, micas, ou argila infiltrada; petrofácies $V$ - arenito limpo

B) Box plots das diferentes petrofácies pela porosidade. Petrofácies I - arenito com pseudomatriz; petrofácies II - arenito com micas; petrofácies III - arenito com argila infiltrada; petrofácies IV - arenito com fator menor que dois de pseudomatriz, micas, ou argila infiltrada; petrofácies $\mathrm{V}$ - arenito limpo

Portanto, além dos controles deposicionais, diferentes distribuições de permoporosidade estão relacionadas ao controle mineralógico/diagenético. As mais prejudiciais ao reservatório estão relacionadas à alta concentração de micas e pseudomatriz. As restantes podem ser agrupadas como reservatórios rentáveis, devido à distribuição semelhante em relação à permeabilidade (valores maiores que 1000 mD), mesmo apresentando algumas dispersões. 


\subsection{A Formação São Sebastião como análogo de reservatório}

As principais heterogeneidades na Formação São Sebastião estão submetidas tanto aos controles deposicionais (item 7.2) como controles diagenéticos (7.3), guiados majoritariamente pelos elementos arquiteturais e petrofácies, respectivamente. Essas heterogeneidades, com ocorrências em diferentes escalas, mostraram-se correlacionáveis, determinando associações de heterogeneidades portadoras de características para reservatórios mais e menos efetivos (figura 113 e tabela 5).

As melhores características permoporosas e geométricas para os reservatórios encontram-se nos depósitos de barras unitárias e compostas, ocorrendo em conjunto com as petrofácies IV e $\mathrm{V}$, detentoras das permoporosidades mais efetivas. Esse fato revela a influência do controle deposicional na história diagenética (ambas controladoras da qualidade de reservatório) que também ocorre na correlação dos elementos arquiteturais com permoporosidades e petrofácies menos efetivas como reservatório.
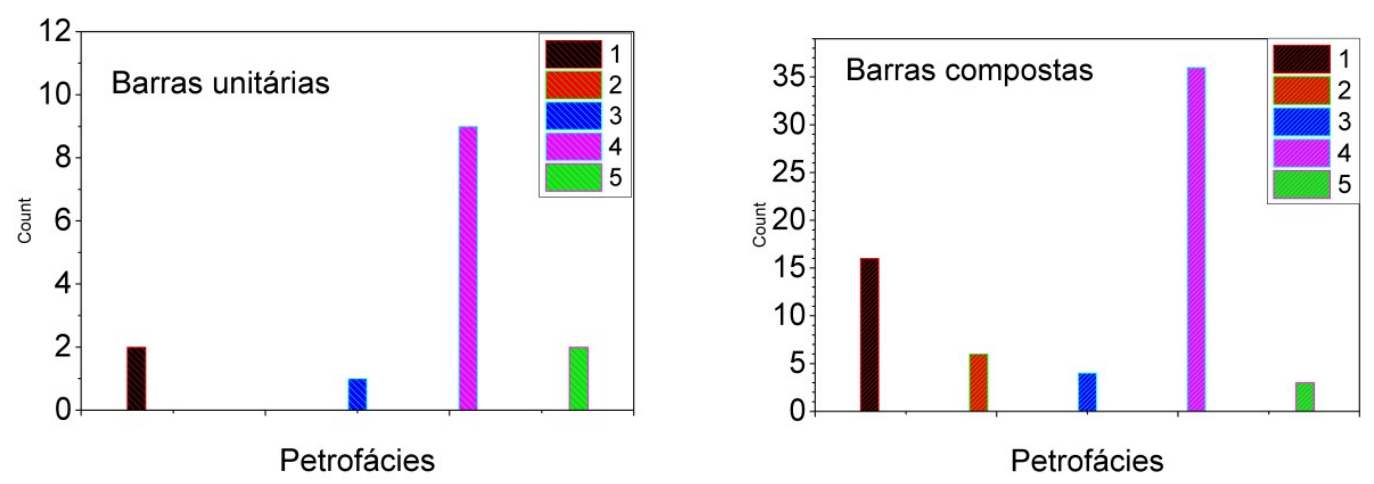


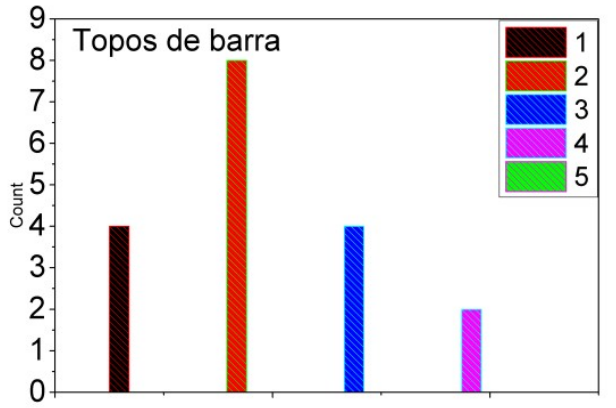

Petrofácies

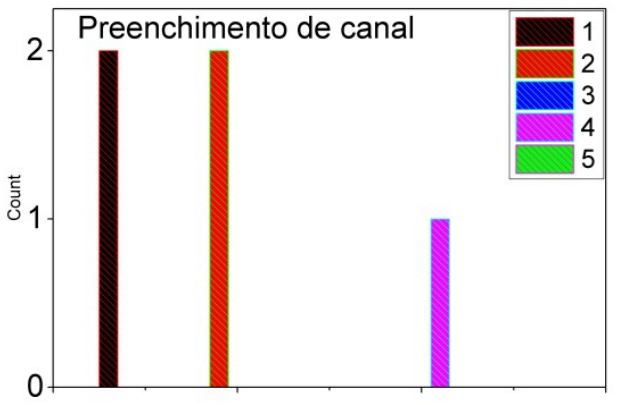

Petrofácies

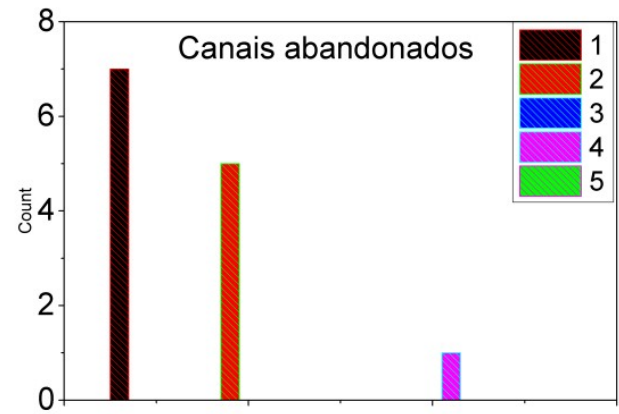

Petrofácies

Figura 113 - Histogramas representativos das frequências das petrofácies dentro de cada elemento arquitetural. 1- Petrofácies com alta concentração de pseudomatriz; 2-petrofácies com alta concentração de micas; 3- petrofácies com alta concentração de argila infiltrada; 4petrofácies com pequena manifestação de elementos prejudiciais ao reservatório; 5-petrofácies sem manifestação de nenhum elemento prejudicial ao reservatório

Tabela 5 - Quantificação da ocorrência de cada petrofácies dentro dos elementos arquiteturais (Petrofácies I - alta concentração de pseudomatriz; petrofácies II - alta concentração de micas; petrofácies III - alta concentração de argila infiltrada; petrofácies IV - pequena manifestação de elementos prejudiciais ao reservatório; petrofácies $\mathrm{V}$ - sem manifestação de elemento prejudicial ao reservatório $)(B C=$ barra composta; $B U=$ barra unitária; $T B=$ topo de barra; $P C$ $=$ preenchimento de canal; e, $\mathrm{CA}=$ canal abandonado $)$.

\begin{tabular}{llllll}
\hline & Petro I & Petro II & Petro III & Petro IV & Petro V \\
\hline BC & $25 \%$ & $9 \%$ & $2 \%$ & $55 \%$ & $9 \%$ \\
BU & $14 \%$ & $5 \%$ & $3 \%$ & $64 \%$ & $14 \%$ \\
TB & $22 \%$ & $44 \%$ & $22 \%$ & $12 \%$ & - \\
PC & $40 \%$ & $40 \%$ & - & $20 \%$ & - \\
CA & $54 \%$ & $38 \%$ & - & $8 \%$ & - \\
\hline
\end{tabular}


A geometria dos depósitos é de suma importância para a efetividade do reservatório e, como mencionado, os corpos mais contínuos, portadores de maior volume que poderia ser saturado em $\mathrm{HC}$, são encontrados nas barras compostas, seguido pelas barras unitárias (item 6.1). Porém, as barras compostas possuem maior probabilidade à ocorrência de fácies finas, assim como cruzadas de baixo ângulo e ripples, fato que diminui a efetividade desses reservatórios em relação às barras unitárias, as quais apresentam granulometrias mais grossas e estruturas portadoras de características permoporosas mais efetivas (cruzadas tabulares de grande porte).

Com base nessas características, as barras unitárias caracterizariam-se por reservatórios menos volumosos, porém mais efetivos e de maior facilidade para a locação de poços injetores e produtores. Em contrapartida, os resevatórios das barras compostas seriam mais volumosos, podendo armazenar maior quantidade de hidrocarbonetos, mas necessitariam de maior estudo para locação dos poços injetores e produtores, devido à maior quantidade de heterogeneidades presentes, podendo acarretar piores fatores de recuperação. A tabela 6 sumariza as principais informações dos reservatórios mais rentáveis da Formação São Sebastião.

Tabela 6 - Principais dados sobre os reservatórios mais efetivos da Formação São Sebastião ( $\mathrm{BC}=$ barras compostas; $\mathrm{e}, \mathrm{BU}=$ barras unitárias)

\begin{tabular}{|c|c|c|c|c|c|}
\hline & Geometria & Granulometria & Estrutura & $\Phi(\%)$ & $\mathrm{K}(\mathrm{mD})$ \\
\hline BC & $\begin{array}{l}\text { Irregulares tendendo a } \\
\text { lenticulares } \\
\text { Emáx }=16,0 \mathrm{~m} \\
\text { Emín }=3,0 \mathrm{~m} \\
\text { Lmáx } ~ 500,0 \mathrm{~m} \\
\text { Lmín }=-\end{array}$ & $\begin{array}{l}\text { Mín = Areia fina } \\
\text { Med = Areia media } \\
\text { Máx = Areia média- } \\
\text { grossa }\end{array}$ & $\begin{array}{l}\text { Cruzadas de } \\
\text { médio- } \\
\text { pequeno } \\
\text { porte e } \\
\text { convolutas }\end{array}$ & $\begin{array}{l}\text { Mín }=3,5 \\
\text { Med }=16,9 \\
\text { Máx }=28,3\end{array}$ & $\begin{array}{l}\text { Mín }=2,5 \\
\text { Med }=5000 \\
\text { Máx }>15000\end{array}$ \\
\hline BU & $\begin{array}{l}\text { Lenticulares } \\
\text { Emáx 12,0 m } \\
\text { Emín = 2,0 m } \\
\text { Lmáx 400,0 m } \\
\text { Lmín 50,0 m }\end{array}$ & $\begin{array}{l}\text { Mín = Areia média } \\
\text { Med = Areia media- } \\
\text { grossa } \\
\text { Máx = Areia média- } \\
\text { grossa }\end{array}$ & $\begin{array}{l}\text { Cruzadas de } \\
\text { grande- } \\
\text { médio porte } \\
\text { e convolutas }\end{array}$ & $\begin{array}{l}\text { Mín }=11,0 \\
\text { Med }=21,0 \\
\text { Máx }=29,8\end{array}$ & $\begin{array}{l}\text { Mín }=170 \\
\text { Med }=6000 \\
\text { Máx }>15000\end{array}$ \\
\hline
\end{tabular}


A mesma importância para os extensos corpos portadores de características efetivas como reservatórios deve ser atribuída às principais zonas de baixa permeabilidade. As principais heterogeneidades atuantes como barreiras de permoporosidade nos afloramentos descritos da Formação São Sebastião, tanto na macro como na microescala, caracterizam-se pelos topos de barra e canais abandonados, acompanhados principalmente pelas petrofácies I e II, e, subordinadamente, pela petrofácies IV (tabela 7).

A geometria dos topos de barra caracteriza-se como lenticular, podendo variar de muito contínua, ultrapassando os 200 m (abaixo da superfície C do afloramento TUC41), ou pouco contínua, na ordem de unidades de metro (no afloramento TUC05).

A geometria dos canais abandonados apresenta-se côncava com variações na continuidade lateral de dezenas a unidades de metro. A granulometria nesses dois elementos arquiturais é predominantemente areia fina, com variações de areia média-grossa nos canais abandonados.

Tabela 7 - Principais dados sobre as anisotropias negativas de permeabilidade da Formação São Sebastião ( $\mathrm{TB}=$ topos de barra; e CA = canais abandondados)

\begin{tabular}{|c|c|c|c|c|c|}
\hline & Geometria & Granulometria & Estrutura & $\Phi(\%)$ & $\mathrm{K}(\mathrm{mD})$ \\
\hline TB & $\begin{array}{l}\text { Lenticulares ou lençóis } \\
\text { Emáx }=1,5 \mathrm{~m} \\
\text { Emín }=0,1 \mathrm{~m} \\
\text { Lmáx } \sim 500 \mathrm{~m} \\
\text { Lmín }=8,0 \mathrm{~m}\end{array}$ & $\begin{array}{l}\text { Mín = Areia muito fina } \\
\text { Med = Areia fina } \\
\text { Máx = Areia média }\end{array}$ & $\begin{array}{l}\text { Ripples e } \\
\text { plano } \\
\text { paralelas }\end{array}$ & $\begin{array}{l}\text { Mín }=4,0 \\
\text { Med }=13,5 \\
\text { Máx }=28,5\end{array}$ & $\begin{array}{l}\text { Mín }=1,5 \\
\text { Med }=200 \\
\text { Máx }=4000\end{array}$ \\
\hline CA & $\begin{array}{l}\text { Côncavas para cima } \\
\text { Emáx } 5.0 \mathrm{~m} \\
\text { Emín }=1,5 \mathrm{~m} \\
\text { Lmáx } \sim 30,0 \mathrm{~m} \\
\text { Lmín } \sim 5,0 \mathrm{~m}\end{array}$ & $\begin{array}{l}\text { Mín = Areia muito fina } \\
\text { Med = Areia fina } \\
\text { Máx = Areia média- } \\
\text { grossa }\end{array}$ & $\begin{array}{l}\text { Ripples e } \\
\text { cruzadas }\end{array}$ & $\begin{array}{l}\text { Mín }=7,8 \\
\text { Med }=16,1 \\
\text { Máx }=29,8\end{array}$ & $\begin{array}{l}\text { Mín }=7 \\
\text { Med }=50 \\
\text { Máx }=1000\end{array}$ \\
\hline
\end{tabular}

Outra importante característica retirada dos análogos para o reservatório é a anisotropia de permeabilidade horizontal-vertical. As diferenças de permeabilidade vertical e horizontal não estariam relacionadas à granulometria, comum para as duas direções. A maior influência na variação da 
permeabilidade horizontal e vertical é a estrutura sedimentar e a presença de minerais micáceos (figura 114 e tabela 8).

A distribuição da maior permeabilidade horizontal sobre a vertical nas fácies com estratificações cruzadas tabulares deve-se ao fato da segregação granular proporcionada pela estrutura sedimentar organizar maiores gargantas de poro na direção horizontal ao acamamento. Nas amostras com grande concentração de fragmentos micáceos (provenientes dos topos de barra), nas fácies com estratificações cruzadas acanaladas e nas fácies convolutas esse padrão foi reconhecido pela média, mas em menores proporções que nas fácies com estratificações cruzadas tabulares (tabela 8). Adicionalmente, foram identificados valores muito altos dessa anisotropia em algumas amostras das fácies de topo de barra, portadoras de micas, e das fácies com estratificações cruzadas (tanto acanaladas como tabulares), mas os mesmos não foram encontrados nas convolutas (figura 114B).

A menor razão e ausência de valores muito altos apresentados para as estruturas convolutas está relacionada à ausência de estruturas sedimentares (atuam como barreira de permeabilidade nessa escala), tanto limites de séries como foresets de cruzadas. Nas fácies micáceas, esse mineral atua como barreira para o fluxo na direção do acamamento. A ausência de componentes que atuam como barreiras de permeabilidade, nessa escala, nas fácies convolutas, faz com que a estrutura comporte-se como isótropa, sem grande diferença de permeabilidade entre as direções horizontais e verticais.

As anisotropias muito altas $\left(\mathrm{K}_{\mathrm{H}}: \mathrm{K}_{\mathrm{V}}>10\right)$ apresentadas pela ocorrência de micas estão relacionadas à superfície específica do hábito placóide do mineral, atuante como barreira de fluxo, diminuindo drasticamente a permeabilidade perpendicularmente à sua direção. A orientação das micas geralmente ocorre na direção subhorizontal, debilitando o fluxo vertical. Porém, notam-se em algumas amostras permeabilidades verticais maiores que as horizontais, manifestadas em fácies com estruturas levemente convolucionadas ou sem orientação preferencial das micas. Contudo, devido à mediana $(x>1)$ e média $(x>4,0)$ da relação $K_{H} / K_{V}$ das fácies com concentração de micas, as mesmas tendem a barrar o fluxo vertical. 

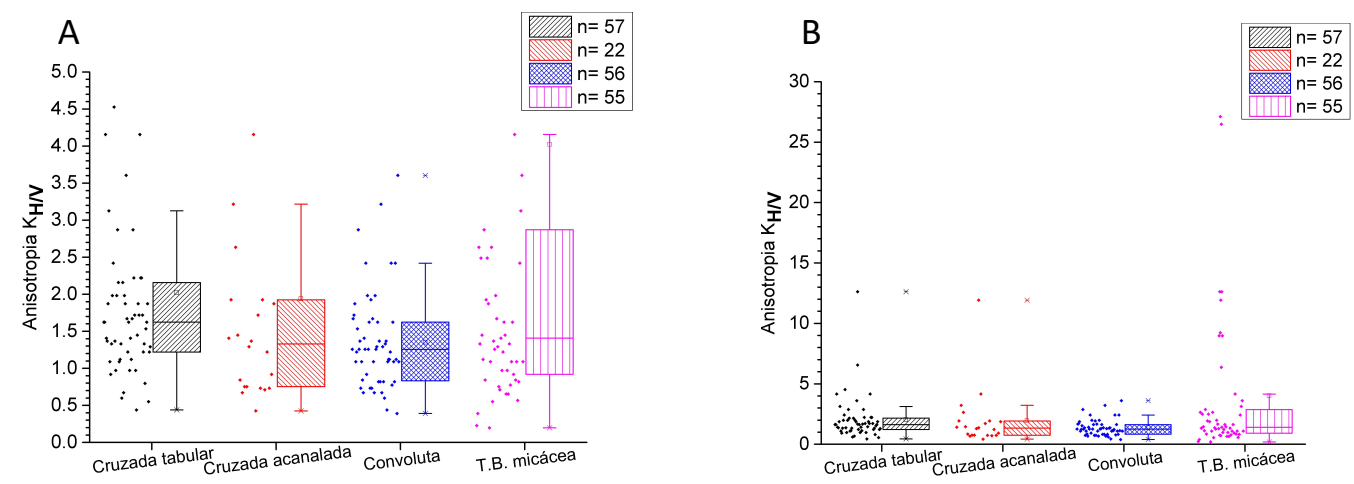

Figura 114 -A)Boxs plots da anisotropia de permeabilidade horizontal-vertical.

B) Mesmos boxs plots apresentados no gráfico A, mas com visão para valores maiores que cinco no eixo y.

Tabela 8 - Anisotropia horizontal-vertical mínima, média e máxima das estruturas mais freqüentes nos reservatórios e nos topos de barras micáceos, da Formação São Sebastião.

\begin{tabular}{llll}
\hline Anisotropia $\mathbf{K}_{\text {H/v }}$ & Mínima & Mediana & Máxima \\
\hline Cruzada tabular & 0,38 & 1,62 & 12,60 \\
Cruzada acanalada & 0,41 & 1,32 & 11,90 \\
Convoluta & 0,42 & 1,25 & 3,75 \\
Topos de barras micáceos & 0,18 & 1,40 & 27,11 \\
\hline
\end{tabular}

Mostra-se aqui a grande importância dos análogos de reservatório observados em afloramento para a exploração e recuperação de hidrocarbonetos, devido principalmente ao baixo custo de aquisição de dados, reconhecimento de sucessões de fácies e geometrias dos reservatórios mais efetivos e principais barreiras de permeabilidade. Além disso, evidencia-se a grande ocorrência da anisotropia relacionada à estrutura sedimentar das fácies, as quais variam em escalas não modeladas na indústria.

\subsection{Modelagem geológica}

Os modelos geológicos utilizados na indústria petrolífera necessitariam de amostragens muito detalhadas para geração de modelos de total representatividade do reservatório, devido à complexa configuração de: arquitetura deposicional, fácies sedimentares, petrografia e permoporosidade 
(comentada nos itens anteriores para os afloramentos estudados). Porém, devido ao alto custo, a amostragem é reduzida, invibializando a construção de modelos baseados totalmente em parâmetros matemáticos e geoestatísticos.

Assim como na indústria petrolífera, a construção do modelo geológico dos afloramentos estudados, baseados somente na amostragem de sessões estratigráficas levantadas em campo não foi satisfatória. As seções foram muito detalhadas, com espaçamento próximo de 5,0 m, mas os variogramas de arquiteturas e fácies resultantes, ajustados geoestatisticamente, geraram apenas ruídos fornecidos pela simulação indicadora seqüencial, devido ao pequeno alcance horizontal, não representando as continuidades observadas em campo e analisadas em escritório (pelas imagens obtidas pelo VANT). Os variogramas verticais demonstraram bons resultados, com alcances refletindo as espessuras reais das associações de fácies observadas em campo. Porém, os variogramas horizontais apresentaram baixa amplitude.

Buscando honrar a técnica geoestatística, em busca de variogramas horizontais mais representativos, foram inseridas informações de seções virtuais, obtidas pela análise das fotos de drone e correlação estratigráfica de fácies conforme as seções levantadas detalhadamente em campo. Como resultado, a inserção das novas seções virtuais aumentou em pequena quantidade a amplitude do variograma horizontal das fácies. Porém, o resultado mostrou-se distante do observado no afloramento.

A amostragem de elevado detalhe em reservatórios e, principalmente, em campos de petróleo em fase inicial de exploração são totalmente inviáveis. Por isso, a importação de inúmeras seções virtuais foi descartada.

A mesma saída utilizada na indústria do petróleo para a construção de variogramas paralelos e perpendiculares foi utilizada. Os variogramas horizontais e perpendiculares do modelo foram ajustados com base na geometria, primeiramente dos elementos arquiteturais e, secundariamente, das fácies dentro de cada elemento arquitetural, observados cuidadosamente em campo e nas imagens aéreas. 
$\mathrm{Na}$ indústria petrolifera, os variogramas horizontais, principalmente na fase inicial de exploração, são ajustados com base em modelos conceituais de análogos de reservatório, retirando destes as principais heterogeneidades de fácies que estão completamente interligadas com as características e anisotropias permoporosas.

O modelo de arquitetura baseou-se nas associações de fácies descritas em campo, modelando barras e topos de barras. Já o modelo de fácies utilizouse das variações de granulometria, as quais são importantes heterogeneidades controladoras da permeabilidade (evidenciado no item 7.2) e de fácil aquisição de dados. As associações de fácies observadas nos afloramentos, entre as superfícies, tendem a apresentar arenitos de maior granulometria na base (com estratificações cruzadas decimétricas a métricas) afinando para o topo (onde concentram-se ripples ou estruturas plano paralelas). Essa tendência foi reproduzida com sucesso nos modelos apresentados (apêndice $\mathrm{H}$ e S). Além disso, no afloramento TUC 05 os topos de barra foram representados de forma não contínua, como constatado no afloramento (apêndice F). No TUC41 a continuidade do topo de barra da superfície $\mathrm{C}$ e a não continuidade da superfície $Z$ e $Y$ também constam nos modelos (apêndice $Q$ ).

Os modelos de fácies foram utilizados como base para os modelos de permeabilidade horizontal (apêndice W ao BB). Nesses modelos as medidas de permeâmetro de campo foram utilizadas como dados hard. Nota-se que tanto no afloramento TUC05, como no afloramento TUC41 as principais barreiras de permeabilidade para o fluxo encontram-se nos topos de barra, mas também em fácies de granulometrias finas pertencentes às barras. Além disso, as menores medianas de permeabilidade estão associadas as camadas com menos topos de barras e fácies finas. Essa tendência corrobora com os resultados obtidos anteriormente, apresentando os topos de barra e as fácies mais finas como principais barreiras de permeabilidade para o reservatório.

\section{Conclusões}


Nos controles deposicionais, concluiu-se que as barras unitárias são os melhores reservatórios, seguidos de perto pelas barras compostas. Os topos de barra, anteriormente pouco descritos na literatura e na indústria petrolífera, manifestam-se como importantes barreiras de permeabilidade. Esse elemento arquitetural encontra-se capeando ótimos reservatórios (barras), por contato gradacional, devido à tendência finning-upward da granulometria. Os canais abandonados também manifestaram anomalias de baixa permeabilidade. Com base nas variáveis analisadas do controles deposicional, concluiu-se que a granulometria foi a maior controladora da permeabilidade, sofrendo influência subordinada da estrutura. Já a porosidade possui como principal controladora a estrutura (sem influência da granulometria), seguida pela seleção granulométrica.

A granulometria mais grossa é mais efetiva para a permeabilidade. Porém, a seleção granulométrica possui pequena parcela de influência. Rochas muito mal selecionadas obtêm pequeno decréscimo na permeabilidade. Já para a porosidade, a seleção granulométrica é de suma importância. A melhor seleção culmina na maior porosidade.

As cruzadas tabulares, assim como as estruturas plano paralelas, são as estruturas mais rentáveis para reservatórios. Isso se deve a melhor segregação granular dessas estruturas, fator altamente relevante para a permeabilidade e porosidade. Já as convolutas e as cruzadas acanaladas possuem valores menores que as demais estruturas. Porém, apresentam permeabilidades e porosidades altas associadas. As convolutas, dependendo do nível de convolução, podem também apresentar permeabilidades e porosidades muito baixas (baixa segregação granular). As cruzadas de baixo ângulo portam características menos efetivas que as mencionadas até o momento, mas são mais efetivas que as ripples. Contudo, é importante salientar que, na permeabilidade as estruturas são apenas controladoras secundárias, enquanto na porosidade são os fatores de maior relevância.

O arredondamento não demonstrou grande controle sobre a permoporosidade. Isso pode ser resultado da pequena variação de arredondamento encontrada nos depósitos analisados. 
A proveniência das rochas analisadas é muito importante na caracterização permoporosa. Esse controle aumenta quando a história diagenética passa a fazer parte dos sistemas controladores. Tanto a presença de intraclastos argilosos, como feldspatos alterados e micas, associados à compactação, são prejudiciais à permoporosidade. Além desses componentes destaca-se, na história diagenética, a argila infiltrada. Essa manifesta altas concentrações nas rochas da formação São Sebastião, principalmente no afloramento TUC41. As argilas infiltradas mostram-se pouco influentes na permeabilidade e agem negativamente na porosidade.

A influência inexistente da argila infiltrada sobre a permeabilidade, comparada aos demais elementos, deve-se à sua forma de ocorrência. As argilas infiltradas ocorrem na forma de coatings irregulares, ou cutans, pouco espessos, sem obliterar as gargantas de poro. Já os demais elementos (micas, feldspatos alterados e intraclastos argilosos), quando compactados, obstruem totalmente as gargantas de poro. Isso resulta na diminuição em escalas de grandeza na permeabilidade.

Por análise geral, concluiu-se que os controles deposicionais estão relacionados aos controles diagenéticos, agindo em conjunto na qualidade de reservatório. Os elementos arquiteturais depositados com maior velocidade de fluxo, como barras unitárias e barras compostas possuem maior energia dissipada e menor taxa de decantação associada. Essa energia acarreta maior segregação granular e, consequentemente: estruturas cruzadas; menores potenciais para preservação e menores concentrações de micas e intraclastos; e, maiores porosidades e permeabilidades. Por outro lado, os canais abandonados e topos de barra são associados às condições de menores velocidades de fluxo, com menor segregação granular, resultando em: estruturas ripples, maiores potenciais para preservação e maiores concentrações de pseudomatriz e micas; e, características permoporosas menos efetivas.

Por fim, conclui-se que a Formação São Sebastião é efetiva como reservatório, caso a mesma estivesse saturada por hidrocarbonetos. Isso se deve às altas medianas de permeabilidade e porosidade. Anisotropias de 
permeabilidade estão presentes tanto entre os elementos arquiteturais como entre fácies nessa Formação. Entre os elementos arquiteturais, as principais anisotropias residem entre as barras e os topos de barra. Já entre as fácies (dentro do possível reservatório de barras), nota-se que a maior diferença entre permeabilidade horizontal e vertical apresenta-se em fácies portadoras de micas. Isso ocorre devido ao hábito do mineral, funcionando como barreira para o fluxo (principalmente vertical). As cruzadas tabulares e acanaladas também apresentam anisotropia de permeabilidade horizontal-vertical. As primeiras possuem índice $\mathrm{K}_{\mathrm{H} / \mathrm{N}}$ maiores que as acanaladas, mas ambas detém pares com valores muito maiores na permeabilidade horizontal. Por outro lado, as convolutas não possuem estruturas sedimentares que funcionam, nessa escala, como barreiras de permeabilidade vertical. Como resultado, as convolutas apresentam-se mais isótropas que as demais estruturas, resultando em valores de permeabilidades horizontais e verticais próximos, sem pares discrepantes, e menor índice $\mathrm{K}_{\mathrm{H} N \mathrm{q}}$ que as cruzadas. 


\section{Bibliografia}

Alexander, J., 1993. A discussion on the use of analogues for reservoir geology. Geological Society, London, Special Publications, 69(1), pp.175-194

Allen, J.R.L. 1983. Studies in fluvialtile sedimentation: bars, bar complexes and sandstone sheets (low-sinuosity braided streams) in the Brownstones (L. Devonian), Welsh Borders. Sedimentary Geology, 33 (4), pp. 237-293.

Almeida, F.D., Hasui, Y., Brito Neves, B. D. e Fuck, R.A., 1977. Províncias estruturais brasileiras. Simpósio de Geologia do Nordeste, 8(1977), pp.363391.

Alsop, D.B., Al Ghammari, M., Al Abri, A., Al Mahrooqi, A., Al Rawahi, H. and Salem, H., 2014. Reservoir architecture of the Gharif Formation outcrops in the Southern Huqf area, Sultanate of Oman. Geological Society, Special Publications, 387(1), pp.111-133.

Ashley, G.M., 1990. Classification of large-scale subaqueous bedforms: a new look at an old problem-SEPM bedforms and bedding structures. Journal of Sedimentary Research, 60(1), pp.160-172.

Ashmore, P.E., 1991. How do gravel-bed rivers braid?. Canadian journal of earth sciences, 28(3), pp.326-341.

Aune, T., 2006. Reservoir Modelling of Delta Front Clinoforms within The Cretaceous Panther Tongue Formation, Western Interior Basin, USA (Master dissertation, UNIVERSITY OF BERGEN), pp.103.

Blais, R.A. and Carlier, P.A., 1968. Applications of geostatistics in ore evaluation. CIM spec, 9, pp. 41-68. 
Bloch, S., Lander, R.H. and Bonnell, L., 2002. Anomalously high porosity and permeability in deeply buried sandstone reservoirs: Origin and predictability. AAPG bulletin, 86(2), pp.301-328.

Boggs Jr, S., 1995. Principles of sedimentology and stratigraphy. Prentice Hall Inc., $774 \mathrm{p}$.

Boggs Jr, S., 2012, Principles of sedimentology and stratigraphy. Pearson Education Ltd., $5^{\text {th }}$ ed., 585 p.

Bowman, A., 2016. Outcrop analogues for hydrocarbon reservoirs in the Columbus Basin, offshore east Trinidad. Geological Society, London, Special Publications, 436(1), pp.151-192.

Brandsæter, I., Mcllroy, D., Lia, O., Ringrose, P. and Næss, A., 2005. Reservoir modelling and simulation of Lajas Formation outcrops (Argentina) to constrain tidal reservoirs of the Halten Terrace (Norway). Petroleum Geoscience, 11(1), pp.37-46.

Bridge, J.S., 2003. Rivers and floodplains: forms, processes, and sedimentary record. Blackwell Publishing, 416p.

Bridge, J.S. and Lunt, I.A., 2006. Depositional models of braided rivers. Braided Rivers, Processes, Deposits, Ecology and Management, Int. Assoc. Sediment. Spec. Pub, 36, pp.11-50.

Bristow, C.S., 1993. Sedimentary structures exposed in bar tops in the Brahmaputra River, Bangladesh. Geological Society, London, Special Publications, 75(1), pp.277-289. 
Burley, S.D., Mullis, J.T. and Matter, A., 1989. Timing diagenesis in the Tartan Reservoir (UK North Sea): constraints from combined cathodoluminescence microscopy and fluid inclusion studies. Marine and Petroleum Geology, 6(2), pp. 98.

Bussab, W.O. and Morettin, P.A., 1987. Estatística básica. Atual Editora, $4^{a}$ edição.

Caers, J., 2005. Petroleum geostatistics. Society of Petroleum Engineers, 88 p.

Caixeta, J.M., Bueno, G.V., Magnavita, L.P. and Feijó, F.J., 1994. Bacias do Recôncavo, Tucano e Jatobá. Boletim de Geociências da PETROBRAS, 8(1), pp.163-172.

Carvalho, M.V., De Ros, L.F. and Gomes, N.S., 1995. Carbonate cementation patterns and diagenetic reservoir facies in the Campos Basin Cretaceous turbidites, offshore eastern Brazil. Marine and Petroleum Geology, 12(7), pp.741-758.

Carver, R.E., 1971. Procedures in sedimentary petrology. Wiley-Interscience, $653 p$.

Castro, J.C., Barrocas, S.L.S. and Lima, H.P., 1981. Fácies, diagênese e modelos de acumulação da Formação Açu, parte emersa da Bacia Potiguar. Cenpes, Petrobras, pp. 24.

Clark, N. J., 1969. Elements of petroleum reservoirs. Society of Petroleum Engineers of AIME, 19-30p.

Cosentino, L., 2001. Integrated reservoir studies. Editions Technip, 310 p. 
Costa, I. P., Milhomem, P., Bueno, G. V., Silva, H. S. R. L. and Kosin, M.D., 2007. Sub-bacias de Tucano Sul e Central. Boletim de Geociências da PETROBRAS, 15(2), pp.433-443.

Cruz, D. A. 2015. Curso de petrofísica. Pesquisa e Desenvolvimento em Geoengenharia e Engenharia de poço, Tecnologias de Recuperação, CENPES, PETROBRAS.

Dalrymple, M., 2001. Fluvial reservoir architecture in the Statfjord Formation (northern North Sea) augmented by outcrop analogue statistics. Petroleum Geoscience, 7(2), pp.115-122.

De Ros, L.F. 1996. Compositional controls in sandstone diagenesis. Acta Universitatis Upsaliensis, Comprehensive Summaries of Uppsala Dissertations from the Faculty of Science and Technology 198. 24 p.

De Ros, L.F. and Goldberg, K., 2007, April. Reservoir petrofacies: a tool for quality characterization and prediction. In: AAPG, Annual Convention and Exhibition, Abstracts Volume, pp. 1.

De Ros, L.F. and Scherer, C.M., 2012. Stratigraphic controls on the distribution of diagenetic processes, quality and heterogeneity of fluvial-aeolian reservoirs from the Recôncavo Basin, Brazil. Int. Assoc. Sedimentol. Spec. Publ, 45, pp.105-132.

De Ros, L.F., Sgarbi, G.N.C. and Morad, S., 1994. Multiple authigenesis of Kfeldspar in sandstones: evidence from the Cretaceous Areado Formation, São Francisco Basin, central Brazil. Journal of Sedimentary Research, 64(4), pp 778-787. 
Destro, N., Alkmim, F.F., Magnavita, L.P. and Szatmari, P., 2003. The Jeremoabo transpressional transfer fault, recôncavo-Tucano rift, NE Brazil. Journal of Structural Geology, 25(8), pp.1263-1279.

Deutsch, C.V., 2002. Geostatistical reservoir modeling: Oxford University Press, New York, 376 p.

Dranfield, P., Begg, S.H. and Carter, R.R., 1987. Wytch Farm oil field: reservoir characterization of the Triassic Sherwood Sandstone for input to reservoir simulation studies. Petroleum geology of north west Europe: London, Graham and Trotman, pp.149-160.

Dzulynski, S. and Smith, A.J., 1963. Convolute lamination, its origin, preservation, and directional significance. Journal of Sedimentary Research, 33(3), pp 616-627.

Ehrlich, R., Crabtree, S.J., Horkowitz, K.O. and Horkowitz, J.P., 1991. Petrography and reservoir physics I: Objective classification of reservoir porosity (1). AAPG Bulletin, 75(10), pp.1547-1562.

Ekeland, A., Pedersen, N., Howell, J., Nemec, W., Keogh, K. and Viste, I., 2008. Modeling of Intra-channel Belt Depositional Architecture in Fluvial Reservoir Analogs from the Lourinha Formation, Portugal. Search and Discovery Article, (50146).

Enge, H.D., Buckley, S.J., Rotevatn, A. and Howell, J.A., 2007. From outcrop to reservoir simulation model: Workflow and procedures. Geosphere, 3(6), pp.469490.

Figueiredo, F.T., 2013. Proveniência e arquitetura de depósitos fluviais das Sub-Bacias Tucano Central e Norte, Cretáceo (BA) (Doctoral dissertation, INSTITUTO DE GEOCIÊNCIAS), $161 \mathrm{p}$. 
Folk, R.L., 1974. Petrology of Sedimentary Rocks. Hemphill, 182 p.

Fossen, H., Schultz, R.A., Torabi, A. and Tveranger, J., 2009. Petrophysically selective compaction bands in Navajo sandstone. In: 2009 Portland GSA Annual Meeting, 41(7), pp 568.

Freitas, B.T., 2014. A Formação Marizal (Aptiano) na Bacia do Tucano (BA): Contribuições à análise da arquitetura de depósitos fluviais e implicações paleobiogeográficas (Doctoral dissertation, INSTITUTO DE GEOCIÊNCIAS), $175 \mathrm{p}$.

Friend, P.F., 2009. Towards the field classification of alluvial architecture or sequence. Modern and Ancient Fluvial Systems (Special Publication 6 of the IAS), p.345.

Füchtbauer, H. and Schmincke, H.U., 1974. Sediments and Sedimentary Rocks, 1, 464 p.

Galloway, W.E. and Hobday, D.K., 1996. Facies characterization of reservoirs and aquifers. In: Terrigenous Clastic Depositional Systems, pp. 426-444.

Germanoski, D. and Schumm, S.A., 1993. Changes in braided river morphology resulting from aggradation and degradation. The Journal of Geology, pp.451466.

Gesicki, A.L.D., Sayeg, I.J., Curti, D.K., Boggiani, P.C. e Giannini, P.C.F., 2009. Determinação quantitativa de parâmetros texturais de arenitos eólicos através 
de análise de imagens digitais de seções delgadas. Revista Brasileira de Geociências, 39(2), pp. 267-275.

Ghignone, J.I., 1972. A evolução estrutural do Recôncavo durante o tempo Candeias. Brazilian Journal of Geology, 2(1), pp.35-50.

Giles, M.R. and De Boer, R.B., 1989. Secondary porosity: creation of enhanced porosities in the subsurface from the dissolution of carbonate cements as a result of cooling formation waters. Marine and Petroleum Geology, 6(3), pp. 261-269.

Glover P.W.J. 2000. Petrophysics. University of Aberdeen, England, 281 p.

Gluyas, J.G., Robinson, A.G., Emery, D., Grant, S.M. and Oxtoby, N.H., 1993, January. The link between petroleum emplacement and sandstone cementation. In Geological Society, London, Petroleum Geology Conference series, 4, pp. 1395-1402.

Gluyas, J. and Cade, C.A., 1997. Prediction of porosity in compacted sands. In: Reservoir Quality Prediction in sandstones and carbonates, pp. 19-28.

Goovaerts, P., 1997. Geostatistics for natural resources evaluation. Oxford University Press on Demand, 483 p.

Graton, L.C. and Fraser, H.J., 1935. Systematic packing of spheres: with particular relation to porosity and permeability. The Journal of Geology, pp.785909. 
Gy, P., 1967. Theory and practice of sampling broken ores. In: Canadian Mining and Metallurgical Bulletin, 60(664) pp. 884.

Hjellbakk, A., 1997. Facies and fluvial architecture of a high-energy braided river: the Upper Proterozoic Seglodden member, Varanger Peninsula, northern Norway. Sedimentary Geology, 114(1), pp.131-161.

Hornung, J. and Aigner, T., 1999. Reservoir and aquifer characterization of fluvial architectural elements: Stubensandstein, Upper Triassic, southwest Germany. Sedimentary Geology, 129(3), pp.215-280.

Howell, J.A., Martinius, A.W. and Good, T.R., 2014. The application of outcrop analogues in geological modelling: A review, present status and future outlook. Geological Society, London, Special Publications, 387(1), pp.1-25.

Hurst, A., Huuse, M., Duranti, D., Vigorito, M., Jameson, E. and Schwab, A., 2016. Application of outcrop analogues in successful exploration of a sand injection complex. Geological Society, Special Publications, 436(1), pp.75-92.

Ingersoll, R.V., Bullard, T.F., Ford, R.L., Grimm, J.P., Pickle, J.D. and Sares, S.W., 1984. The effect of grain size on detrital modes: a test of the GazziDickinson point-counting method. Journal of Sedimentary Research,54(1), pp.103-116.

Jones, F.O. and Owens, W.W., 1980. A laboratory study of low-permeability gas sands. Journal of Petroleum Technology, 32(09), pp.1-631.

Kahn, J.S., 1956. The analysis and distribution of the properties of packing in sand-size sediments: 1 . On the measurement of packing in sandstones. The Journal of Geology, pp.385-395. 
Ketzer, J.M. and Morad, S., 2006. Predictive distribution of shallow marine, lowporosity (pseudomatrix-rich) sandstones in a sequence stratigraphic frameworkexample from the Ferron sandstone, Upper Cretaceous, USA. Marine and petroleum geology, 23(1), pp.29-36.

Klein, C. and Philpotts, A.R., 2012. Earth materials: introduction to mineralogy and petrology. Cambridge University Press, 487 p.

Krynine, P.D., 1948. The megascopic study and field classification of sedimentary rocks. The Journal of Geology, 56(2), pp.130-165.

Koch, G.S. and Link, R.F., 1971. The coefficient of variation; a guide to the sampling of ore deposits. Economic Geology, 66(2), pp.293-301.

Kong, M., Bhattacharya, R.N., James, C. and Basu, A., 2005. A statistical approach to estimate the $3 \mathrm{D}$ size distribution of spheres from 2D size distributions. Geological Society of America Bulletin, 117(1-2), pp. 244-249.

Kozeny, J., Striedieck, W.F. and Wyllie, M.R.J., 1927. Concerning capillary conduction of water in the soil: (rise, seepage and use in irrigation). Petroleum Branch of the American Institute of Mining and Metallurgical Engineers, 136, pp. 271-306.

Kupecz, J.A., Gluyas, J. and Bloch, S., 1997. Reservoir quality prediction in sandstones and carbonates: An overview.

Leddy, J.O., Ashworth, P.J. and Best, J.L., 1993. Mechanisms of anabranch avulsion within gravel-bed braided rivers: observations from a scaled physical model. Geological Society, London, Special Publications, 75(1), pp.119-127.

Li, S., Yu, X., Chen, B. and Li, S., 2015. Quantitative characterization of architecture elements and their response to base-level change in a sandy braided fluvial system at a mountain front. Journal of Sedimentary Research, 85(10), pp.1258-1274. 
Lima, R.D. and De Ros, L.F., 2002. The role of depositional setting and diagenesis on the reservoir quality of Devonian sandstones from the Solimoes Basin, Brazilian Amazonia. Marine and Petroleum Geology, 19(9), pp.10471071.

Lojka, R., Rosenau, N.A., Sidorinova, T. and Strnad, L., 2016. Architecture, paleosols and cyclicity of the Middle-Late Pennsylvanian proximal fluvial system (Nýřany Member, Pilsen Basin, Czech Republic). Bulletin of Geosciences, 91(1), pp. 111-140.

Lundegard, P.D., 1992. Sandstone Porosity Loss - A. Journal of Sedimentary Petrology, 62(2), pp. 250-260.

Lunt, I.A. and Bridge, J.S., 2007. Formation and preservation of open-framework gravel strata in unidirectional flows. Sedimentology, 54(1), pp.71-87.

Luthi, S.M. and Flint, S.S., 2014. The application of outcrop-based research boreholes for reservoir modelling: potential, challenges and pitfalls. Geological Society, London, Special Publications, 387(1), pp.233-246.

Magnavita, L. P., Davison, I. and Kusznir, N. J., 1994. Rifting, erosion, and uplift history of the Recôncavo-Tucano-Jatobá Rift, northeast Brazil. Tectonics, 13(2), pp.367-388.

Magnavita, L., Destro, N., Carvalho, M., Milhomen, P. S. and Souza-Lima, W, 2003. Bacia de Tucano. Fundação paleontológica PHOENIX, pp. 52.

Mansurbeg, H., De Ros, L.F., Morad, S., Ketzer, J.M., El-Ghali, M.A.K., Caja, M.A. and Othman, R., 2012. Meteoric-water diagenesis in late Cretaceous 
canyon-fill turbidite reservoirs from the Espírito Santo Basin, eastern Brazil. Marine and Petroleum Geology, 37(1), pp.7-26.

Martinius, A.W. and Næss, A., 2005. Uncertainty analysis of fluvial outcrop data for stochastic reservoir modelling. Petroleum Geoscience, 11(3), pp.203-214.

Meyer, R. and Krause, F.F., 2006. Permeability anisotropy and heterogeneity of a sandstone reservoir analogue: An estuarine to shoreface depositional system in the Virgelle Member, Milk River Formation, Writing-on-Stone Provincial Park, southern Alberta. Bulletin of Canadian Petroleum Geology, 54(4), pp.301-318.

Miall, A.D., 1977. A review of the braided-river depositional environment. EarthScience Reviews, 13(1), pp.1-62.

Miall, A.D., 1985. Architectural-element analysis: a new method of facies analysis applied to fluvial deposits. Earth-Science Reviews, 22(4), pp.261-308.

Miall, A.D., 1996. The Geology of Fluvial Deposits Springer-Verlag. 582 p.

Miall, A., 2000. Principles of sedimentary basin analysis. Springer-Verlag, 616 p.

Milani, E.J. and Davison, I., 1988. Basement control and transfer tectonics in the Recôncavo-Tucano-Jatobá rift, Northeast Brazil. Tectonophysics, 154(1-2), pp. 4153-5070.

Molenaar, N., 1986. The interrelation between clay infiltration, quartz cementation, and compaction in lower Givetian terrestrial sandstones, northern Ardennes, Belgium. Journal of Sedimentary Research, 56(3), pp. 359-369.

Morad, S. 1998. Carbonate cementation in sandstones: distribution patterns and geochemical evolution. In: Morad, S. (ed), Carbonate Cementation in Sandstones, IAS Special Publication, 26, pp. 1-26. 
Morad, S., Al-Ramadan, K., Ketzer, J.M. and De Ros, L.F., 2010. The impact of diagenesis on the heterogeneity of sandstone reservoirs: A review of the role of depositional facies and sequence stratigraphy. AAPG bulletin, 94(8), pp.12671309.

Morad, S., Ketzer, J.R.M. and De Ros, L.F., 2000. Spatial and temporal distribution of diagenetic alterations in siliciclastic rocks: implications for mass transfer in sedimentary basins. Sedimentology, 47(s1), pp.95-120.

Morad, S., Márfil, R. and PEŇA, J.A., 1989. Diagenetic K-feldspar pseudomorphs in the Triassic Buntsandstein sandstones of the Iberian Range, Spain. Sedimentology, 36(4), pp.635-650.

Moraes, M.A. and De Ros, L.F., 1990. Infiltrated clays in fluvial Jurassic sandstones of Recôncavo Basin, northeastern Brazil. Journal of Sedimentary Research, 60(6), pp. 809-819.

Moraes, M.A. and De Ros, L.F., 1992. Depositional infiltrated and authigenic clays in fluvial sandstones of the Jurassic Sergi Formation, Reconcavo Basin, northeastern Brazil. In: Origin, diagenesis and petrophysics of clay minerals in sandstones, 47, pp. 197-208.

Ogolo, N.A., Akinboro, O.G., Inam, J.E., Akpokere, F.E. and Onyekonwu, M.O., 2015. Effect of Grain Size on Porosity Revisited. In: SPE Nigeria Annual International Conference and Exhibition, Society of Petroleum Engineers, pp. 113.

Olea, R.A., 2000. Geostatistics for Engineers and Earth Scientists. Kluwer Academic Publishers, $303 \mathrm{p}$.

Owen, G., 1987. Deformation processes in unconsolidated sands. Geological Society, London, Special Publications, 29(1), pp.11-24. 
Pettijohn, F.L. 1957. Sedimentary Rocks. Ney York, Harper \& Row Publishers, $719 p$.

Pettijohn, F.J, Portter, P.E. and Siever (1972). Sand and Sandstone, Springer Science \& Business Media, 618 p.

Pettijohn, F.J., Potter, P.E. and Siever, R., 2012. Sand and sandstone. Springer Science \& Business Media.

Pittman, E.D., 1971. Microporosity in carbonate rocks: Geological notes. AAPG Bulletin, 55(10), pp.1873-1878.

Pittman, E.D., 1979. Porosity diagenesis and productive capability of sandstone reservoirs. In: Aspects of diageneis, pp. 159-173.

Powers, M.C., 1953. A new roundness scale for sedimentary particles. Journal of Sedimentary Research, 23(2), pp. 117-119.

Pranter, M.J., Hewlett, A.C., Cole, R.D., Wang, H. and Gilman, J., 2014. Fluvial architecture and connectivity of the Williams Fork Formation: Use of outcrop analogues for stratigraphic characterization and reservoir modelling. Geological Society, London, Special Publications, 387(1), pp.57-83.

Primmer, T.J., Cade, C.A., Evans, J., Gluyas, J.G., Hopkins, M.S., Oxtoby, N.H., Smalley, P.C., Warren, E.A. and Worden, R.H., 1997. Global patterns in sandstone diagenesis: their application to reservoir quality prediction for petroleum exploration. In: AAPG Memoir 69, Reservoir Quality Prediction in Sandstones and Carbonates, pp. 61-77.

Racey, A., Fisher, J., Bailey, H. and Roy, S.K., 2016. The value of fieldwork in making connections between onshore outcrops and offshore models: an example from India. Geological Society, London, Special Publications, 436(1), pp.21-53. 
Reading, H.G. 1986. Facies. In: Sedimentary Environments and Facies, Blackwell, $2^{\text {nd }}$ edition, pp. 4-19.

Reading, H.G. 1996. Sedimentary Environments: Processes, Facies and Stratigraphy. Blackwell, 688 p.

Reesink, A.J.H. and Bridge, J.S., 2007. Influence of superimposed bedforms and flow unsteadiness on formation of cross strata in dunes and unit bars. Sedimentary Geology, 202(1), pp. 281-296.

Reesink, A.J.H. \& Bridge, J.S. 2009. Influence of superimposed bedforms and flow unsteadiness on formation of cross strata in dunes and unit bars - Part 2, further experiments. Sedimentary Geology, 222, pp. 274-300.

Reesink, A.J., Ashworth, P.J., Sambrook Smith, G.H., Best, J.L., Parsons, D.R., Amsler, M.L., Hardy, R.J., Lane, S.N., Nicholas, A.P., Orfeo, O. and Sandbach, S.D., 2014. Scales and causes of heterogeneity in bars in a large multi-channel river: Río Paraná, Argentina. Sedimentology, 61(4), pp.1055-1085.

Reineck, H.E. and Singh, I.B., 1980. Depositional sedimentary environments: with reference to terrigenous clastics. Springer Science \& Business Media, 549 p.

SANTOS, C.C., REIS, C. e PEDREIRA, A.J., 2010. Projeto Bacia do Tucano Central: folha Ribeira do Pombal-SC. 24-ZA-IV: folha Cícero Dantas-SC. 24ZAV.

Santos, C.C. \& Reis, C., 2011. Projeto Bacia do Tucano Central: Folha Caimbé - SC.24-Z-A-I, Folha Jeremoabo - SC.24-Z-A-II.

Santos, C.D., Cupertino, J.A. and Braga, J.A.E., 1990. Síntese sobre a geologia das bacias do Recôncavo, Tucano e Jatobá. Origem e evolução de bacias sedimentares, pp.269-289. 
Scherer, C.M.S. and De Ros, L.F., 2009. Heterogeneidades dos reservatórios Flúvio-eólicos da Formaçao Sergi na Bacia do Recôncavo. Boletim de Geociências da Petrobras, 17, pp.249-271.

Schmidt, V. and McDonald, D.A., 1979. The role of secondary porosity in the course of sandstone diagenesis. In: Aspects of diagenesis, 175-207 p.

Selley, R.C. 1998. Elements of Petroleum Geology. Academic Press, 2nd edition. Academic Press, 2nd edition, 470 p.

Shepherd, R.G., 1989. Correlations of permeability and grain size. Ground water, 27(5), pp.633-638.

Slichter, C.S., 1899. Theoretical investigation of the motion of ground waters (No. 22). US Department of the Interior, Geological Survey, Water Resources Division, Ground Water Branch, 384 p.

Smosna, R. and Bruner, K.R., 1997. Depositional controls over porosity development in lithic sandstones of the Appalachian Basin: reducing exploration risk. In: AAPG Memoir 69: Reservoir Quality Prediction in Sandstones and Carbonates, pp. 249-265.

Sneh, A., 1983. Desert stream sequences in the Sinai Peninsula. Journal of Sedimentary Research, 53(4), pp. 1271-1279.

Sombra, C.L., Arienti, L.M., Pereira, M.J. and Macedo, J.M., 1990. Parâmetros controladores da porosidade e permeabilidade nos reservatórios clásticos profundos do Campo de Merluza, Bacia de Santos, Brasil. Bol. Geoc. Petrobrás, 4, pp.451-466.

Sombra, C.L. and Chang, H.K., 1997. Burial history and porosity evolution of Brazilian Upper Jurassic to Tertiary sandstone reservoirs. In: Reservoir Quality Prediction in sandstones and carbonates, pp. 79-89. 
Sowek, G.A., 2013. Caracterização de heterogeneidades em reservatórios fluviais a partir do estudo de análogo na formação Rio do Rasto, Bacia do Paraná (Master dissertation, UNIVERSIDADE FEDERAL DO PARANA), 77 p.

Stevens, S.S., 1946. On the theory of scales of measurement. Science, 677$680 \mathrm{p}$.

Stuart, W.J., Kennedy, S. and Thomas, A.D., 1988. Influence of structural growth and other factors on the configuration of fluvial sandstones, Permian Cooper Basin. Australian Petroleum Exploration Association Journal, 28, pp.255-265.

Taira, A. and Scholle, P.A., 1979. Origin of bimodal sands in some modern environments. Journal of Sedimentary Petrology, 49(3), pp. 777-786.

Taylor, A.W. and Ritts, B.D., 2004. Mesoscale heterogeneity of fluviallacustrine reservoir analogues: examples from the eocene green river and colton formations, uinta basin, utah, usa. Journal of Petroleum Geology, 27(1), pp.325.

Tiab, D. and Donaldson, E.C., 2004. Petrophysics theory and practice of measuring reservoir rock and fluid transport properties. Elsevier, 2nd edition, $762 \mathrm{p}$.

Toonen, W.H., Kleinhans, M.G. and Cohen, K.M., 2012. Sedimentary architecture of abandoned channel fills. Earth Surface Processes and Landforms, 37(4), pp.459-472.

Viana, C.F., Gama Jr, E.G., Simoes, I.D.A., Moura, J.A., Fonseca, J.D.R. and Alves, R.J., 1971. Revisão estratigráfica da bacia Recôncavo/Tucano. Boletim técnico da Petrobrás, 14(3-4), pp.157-192. 
Vipond, E., 2005, Modelling small-scale heterogeneities in a channelised turbidite system: Digital outcrop study from the Ainsa I Turbidite System.(Master dissertation, UNIVERSITY OF BERGEN), 208 p.

Walker R.G. 1992. Facies, facies models and modern stratigraphic concepts. In: R.G. Walker \& N.P. James (Eds.), Facies Models and Response to Sea-level Change, Geological Association of Canada, pp. 1-14.

Waugh, B., 1978. Authigenic K-feldspar in British Permo-Triassic sandstones. Journal of the Geological Society, 135(1), pp.51-56.

Weber, K.J., 1986. How heterogeneity affects oil recovery. Reservoir characterization, 487, p.544.

Wentworth, C.K., 1922. A scale of grade and class terms for clastic sediments. The Journal of Geology, 30(5), pp.377-392.

Worden, R.H. \& Morad, S. 2003. Clay minerals in sandstones: controls on formation, distribution and evolution. In: Worden, R.H. \& Morad, S. (eds), Clay Mineral Cements in Sandstones, Int. Assoc. Sedimentol. Spec. Publ., 34, pp. 341.

Yamamoto, J.K., 2001. Análise geoestatística. Avaliação e classificação de reservas minerais. São Paulo, EDUSP, pp.69-91.

Yamamoto, J.K. and Landim, P.M.B., 2013. Geoestatistics: concepts and application. Oficina de textos, $215 \mathrm{p}$.

Yangquan, J., Jiaxin, Y., Sitian, L., Ruiqi, Y., Fengjiang, L. and Shengke, Y., 2005. Architectural units and heterogeneity of channel reservoirs in the Karamay Formation, outcrop area of Karamay oil field, Junggar basin, northwest China. AAPG bulletin, 89(4), pp.529-545. 
Young, H.D. and Freedman, R.A., 2008. Física II: termodinâmica e ondas. Addison Wesley, $12^{\mathrm{a}}$ edição.

\section{Apêndices}

Apêndice A - Legenda e seções estratigráficas do afloramento TUC05

Apêndice B - Seções estratigráficas do afloramento TUC41

Apêndice C - A) Nuvem de pontos 3D do afloramento TUC05 inteiro. B) Visão de detalhe da nuvem de pontos do afloramento TUC05

Apêndice D - A) Principais superfícies sedimentares do afloramento TUC05 delimitadas na imagem de drone. B) Principais superfícies sedimentares do afloramento TUC05 no RMS

Apêndice E - Modelo estratigráfico do afloramento TUC05

Apêndice F - Modelo de elementos arquiteturais do afloramento TUC05, utilizando a SIS

Apêndice G - Tabela de porcentagens de elementos arquiteturais entre superfícies do afloramento TUC05

Apêndice $\mathrm{H}$ - Modelo de fácies do afloramento TUC05, utilizando a SIS

Apêndice I - Tabela de porcentagens de fácies entre superficies do afloramento TUC05

Apêndice $\mathrm{J}$ - Nuvem de pontos 3D da frente do afloramento TUC41 (referente ao mosaico tuc41.4)

Apêndice K - Principais superfícies sedimentares do mosaico TUC41.4

Apêndice L - Nuvem de pontos 3D dos mosaicos TUC41.1, TUC41.2, TUC41.3

Apêndice $M$ - Aproximação da nuvem de pontos 3D na lateral do afloramento TUC41(superfícies $\mathrm{C}$ e $\mathrm{H}$ em detalhe)

Apêndice N - Principais superfícies sedimentares da lateral afloramento TUC41, delimitadas na imagem de drone 
Apêndice $\mathrm{O}$ - Principais superfícies sedimentares digitalizadas do afloramento TUC41

Apêndice $P$ - Modelo estratigráfico do afloramento TUC41, com principais superfícies sedimentares descritas

Apêndice Q - Modelo de elementos arquiteturais do afloramento TUC41, utilizando a SIS

Apêndice R - Tabela de porcentagens de elementos arquiteturais entre superfícies do afloramento TUC41

Apêndice S - Modelo de fácies do afloramento TUC41, utilizando a SIS

Apêndice $T$ - Tabela de porcentagem de fácies do modelo entre superfícies do afloramento TUC41

Apêndice U - Amostragem de dados hard utilizados na confecção dos modelos

Apêndice $V$ - Variogramas verticais de fácies

Apêndice W - Modelo de pemeabilidade horizontal, utilizando a SGS, do afloramento TUC05

Apêndice X- Continuação para norte do modelos de pemeabilidade horizontal, utilizando a SGS, do afloramento TUC05

Apêndice $Y$ - Modelo de pemeabilidade horizontal, utilizando a SGS, do afloramento TUC41

Apendice $Z$ - Modelo de permeabilidade horizontal do apêndice $Y$ em detalhe, do afloramento TUC41

Apendice AA - Tabela com a mediana da permeabilidade horizontal adquirida do modelo de permeabilidade do apêndice W (TUC05)

Apendice BB - Tabela com a mediana da permeabilidade horizontal adquirida do modelo de permeabilidade do apêndice Y (TUC41) 
Apêndice A - Legenda e seções estratigráficas do afloramento TUC 05

Planar cross-bed

\section{Legend}

Horizontal bedding or climbing ripples lamination

Trough cross-bed

Convolute bedding

Tangential cross-bed

Heterolithic bedding

Granules and/or pebbles

Massive

Climbing ripple lamination m - Mustone/siltstone

vfs - Very fine sandstone

fs - Fine to medium sandstone

ms - Medium sandstone

mcs - Medium-coarse sandstone

B. X - Main Boundaries

- Tinny Perm Measurements 
TUC05 Sections I

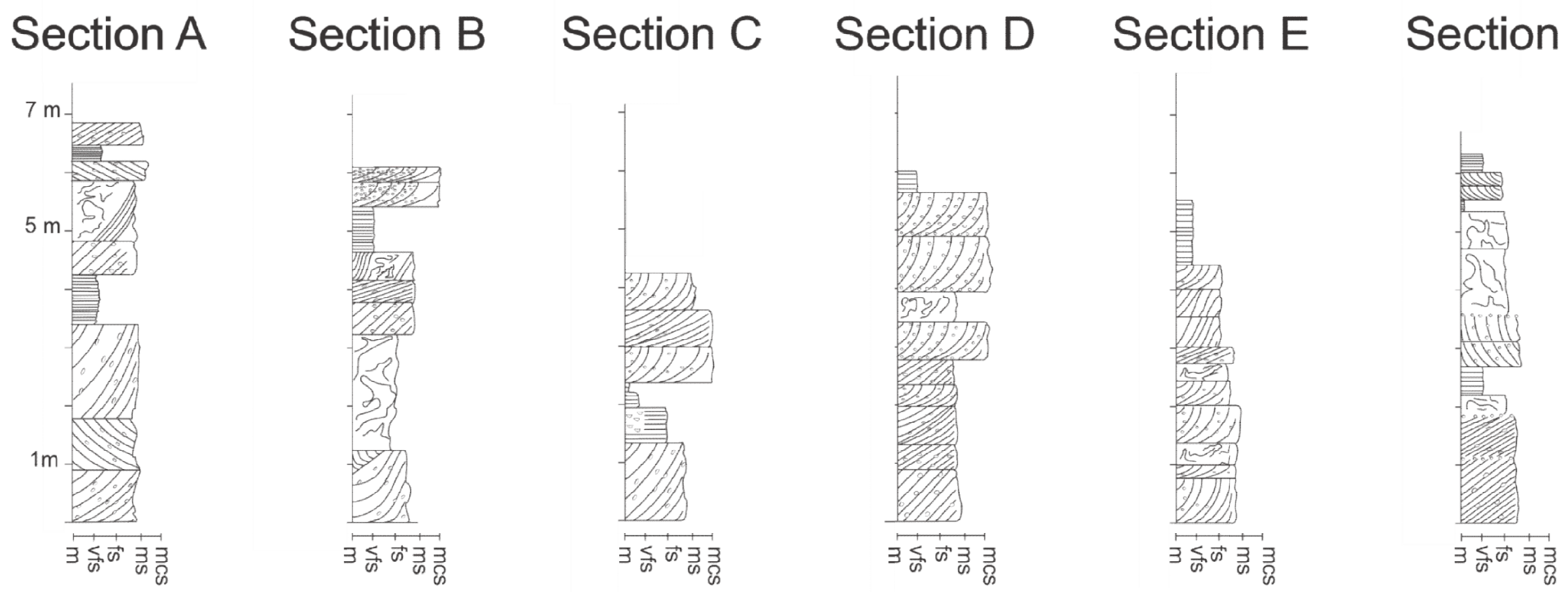


TUC05 Tinny Perm Sections II

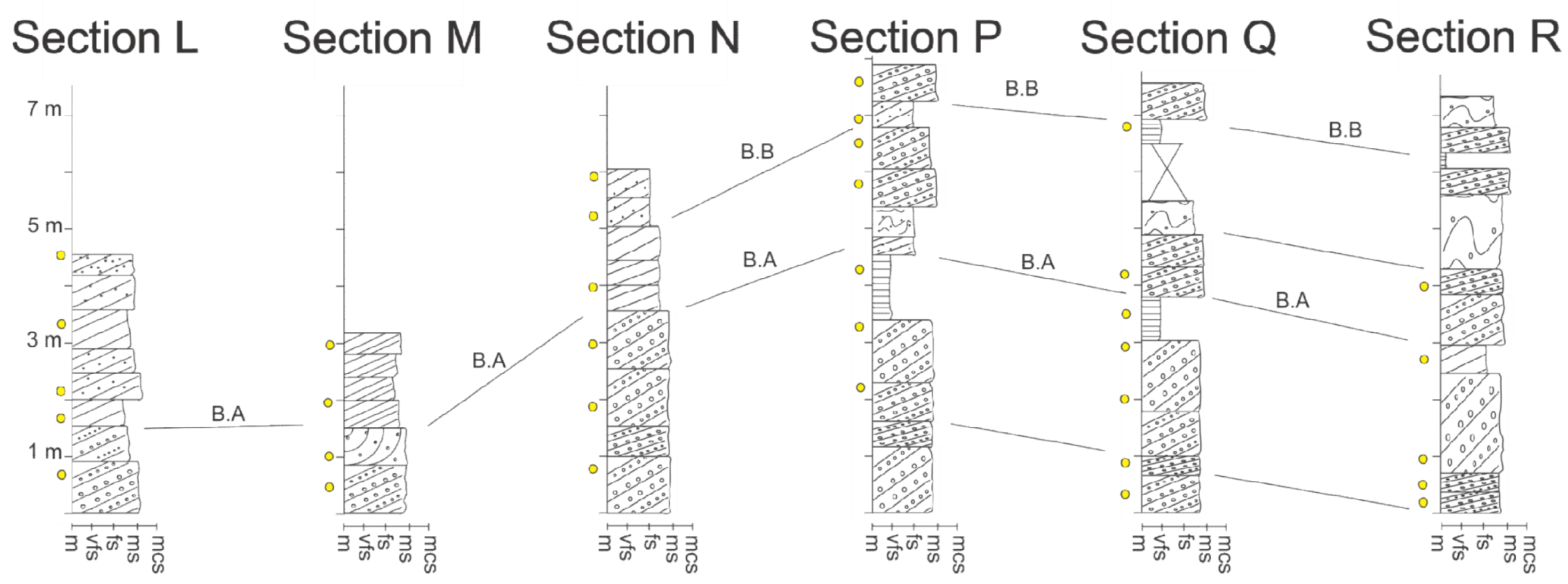




\section{TUC05 Tinny Perm Sections III}

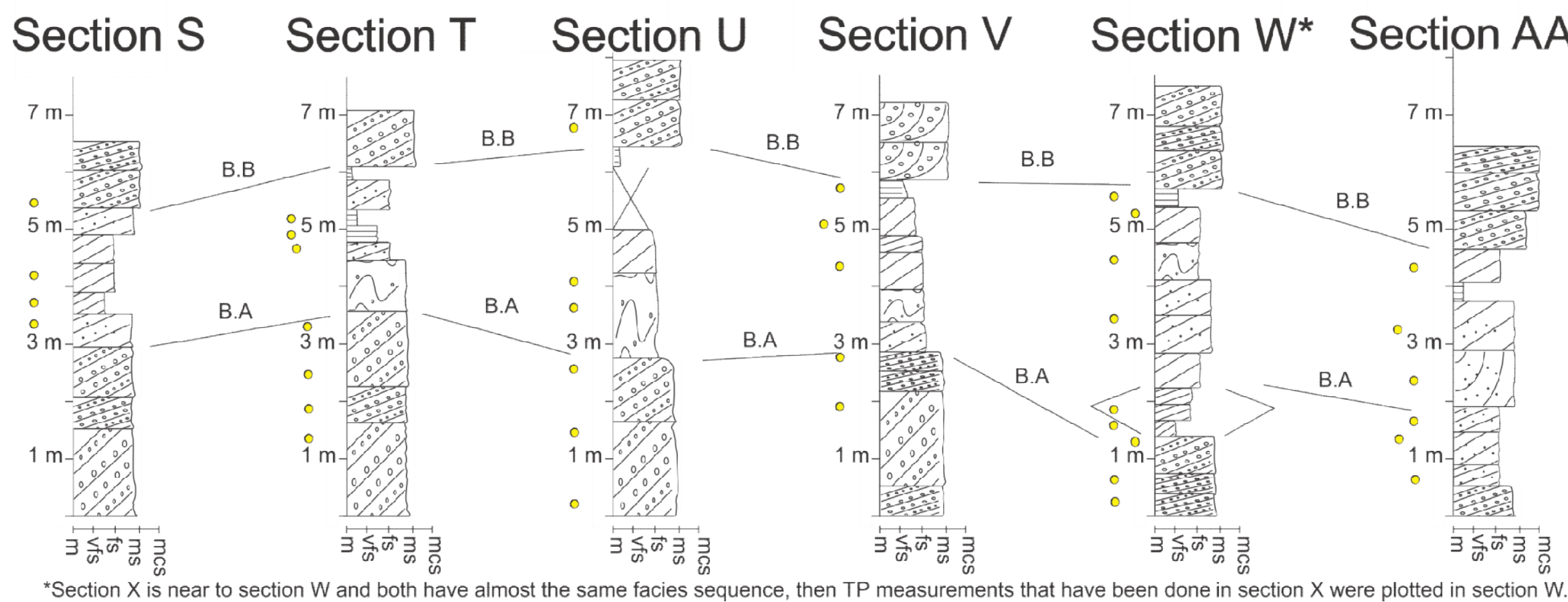




\section{TUC05 Tinny Perm Sections IV}

\section{Section AB Section AC Section AD Section AE Section AF Section AG}

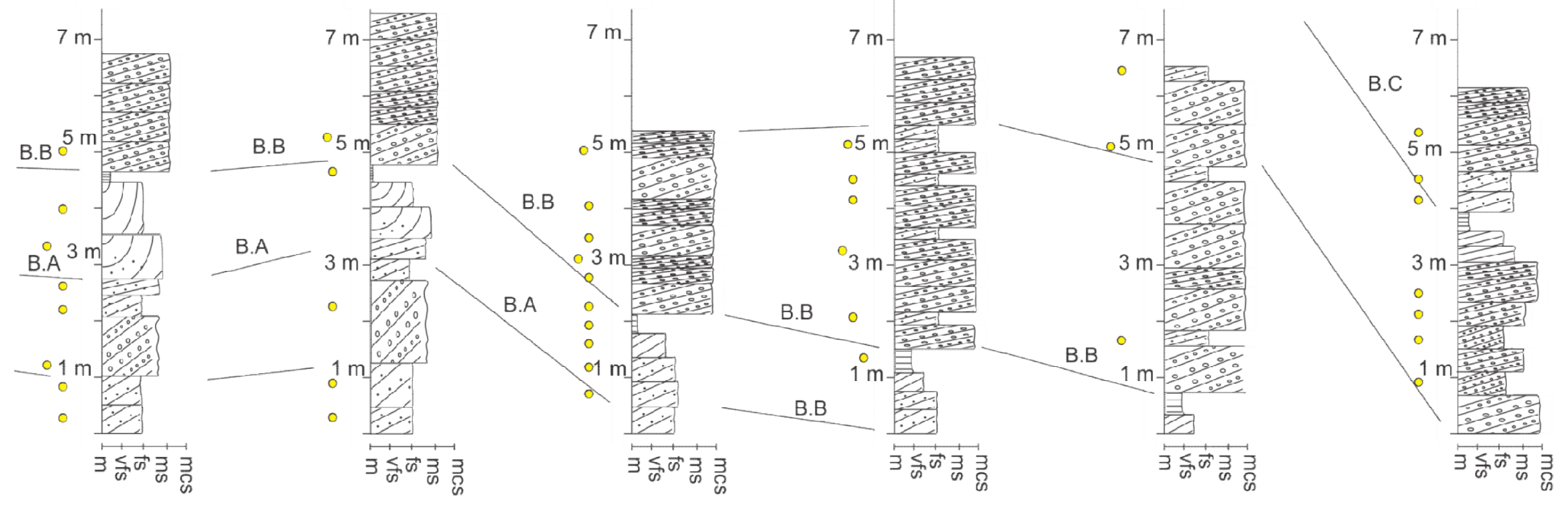




\section{TUC05 Tinny Perm Sections V}

Section Al Section AJ Section AK Section AL Section AM Section AN

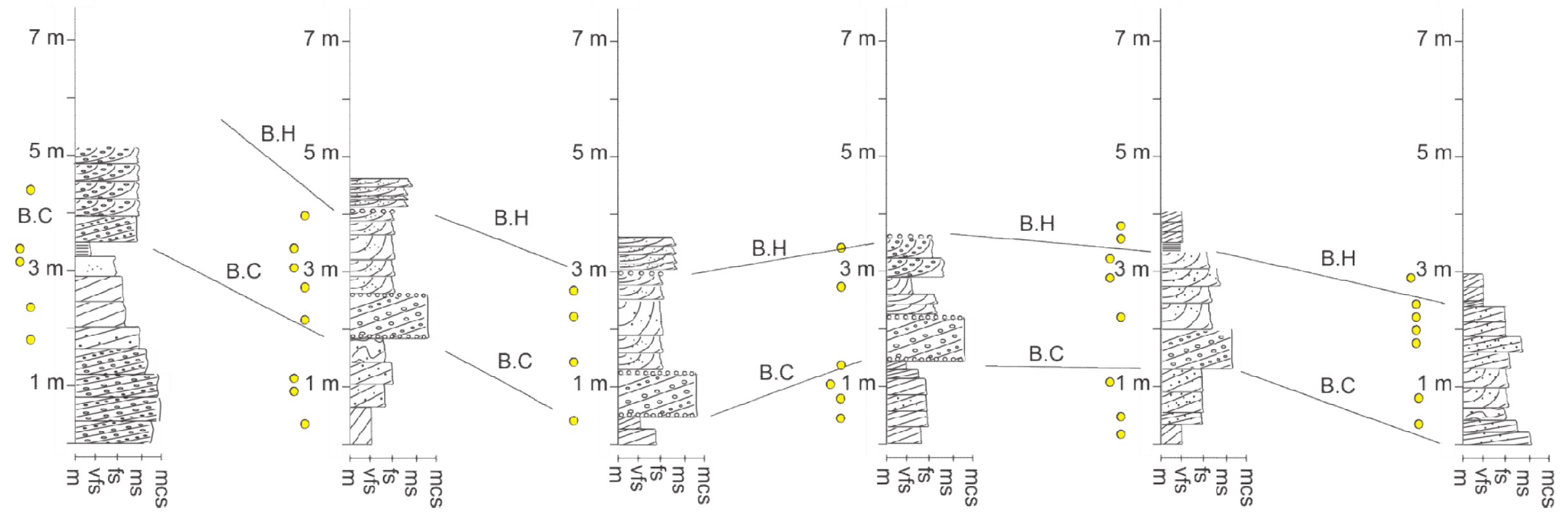




\section{TUC05 Tinny Perm Sections VI}

Section AP Section AQ Section AR Section AS Section AT Section AU

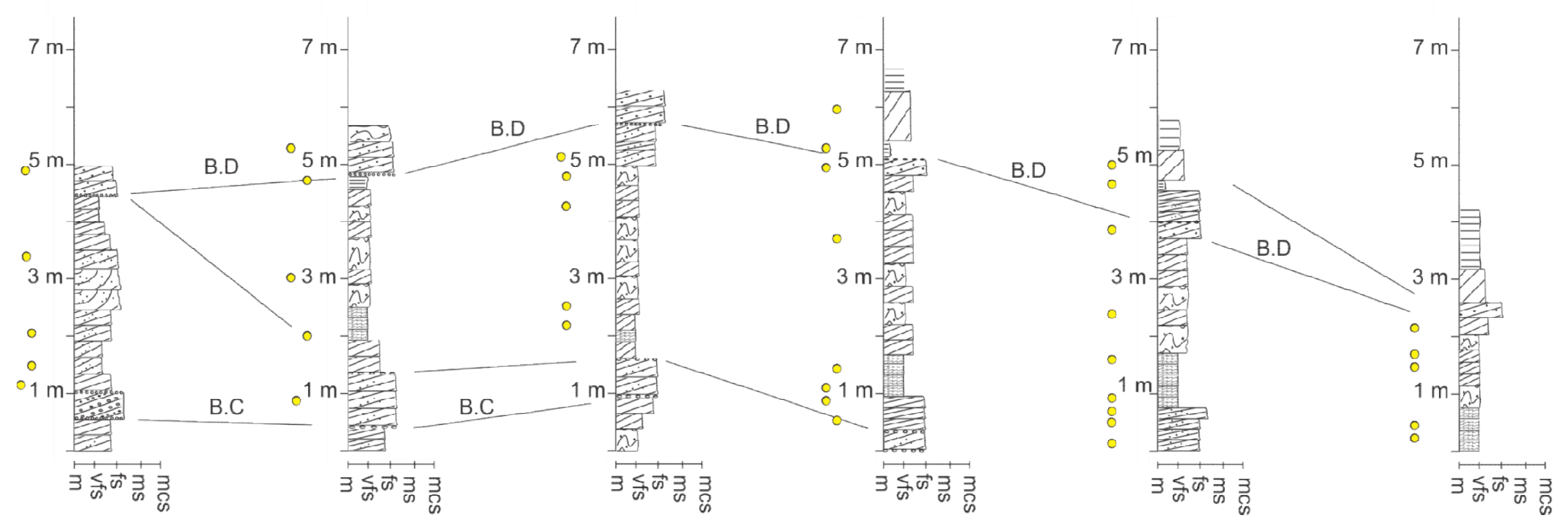


Apêndice B - Seções estratigráficas do afloramento TUC41 (obs: a mesma legenda utilizada para o afloramento TUC05 também foi utilizada nessas seções) TUC41 Tinny Perm Sections I

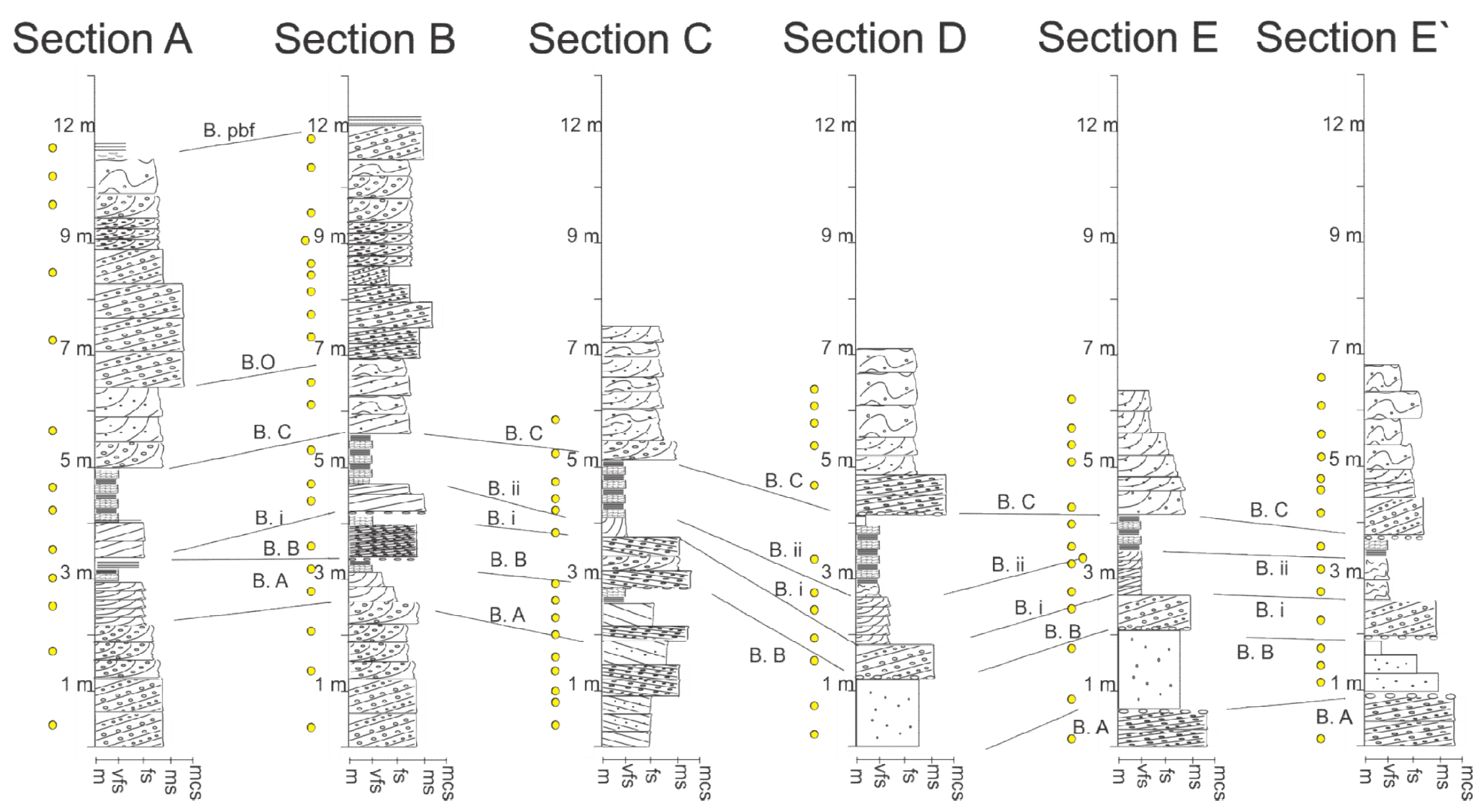




\section{TUC41 Tinny Perm Sections II}

"Section $\mathrm{K}$ is nearby section J, so the first wasn't drawn and its tinny perm measurements wey plact in section

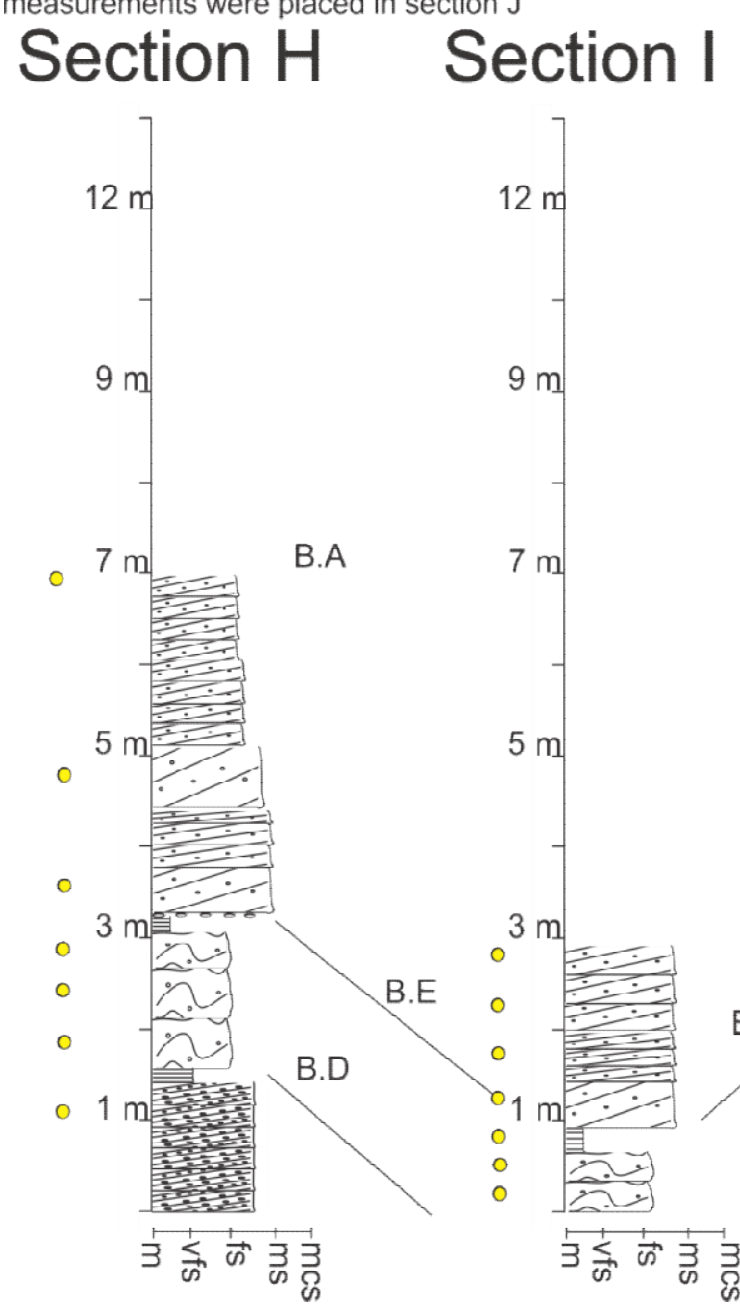

\section{Section $J^{*}$}

\section{Section L}

Section M Section N

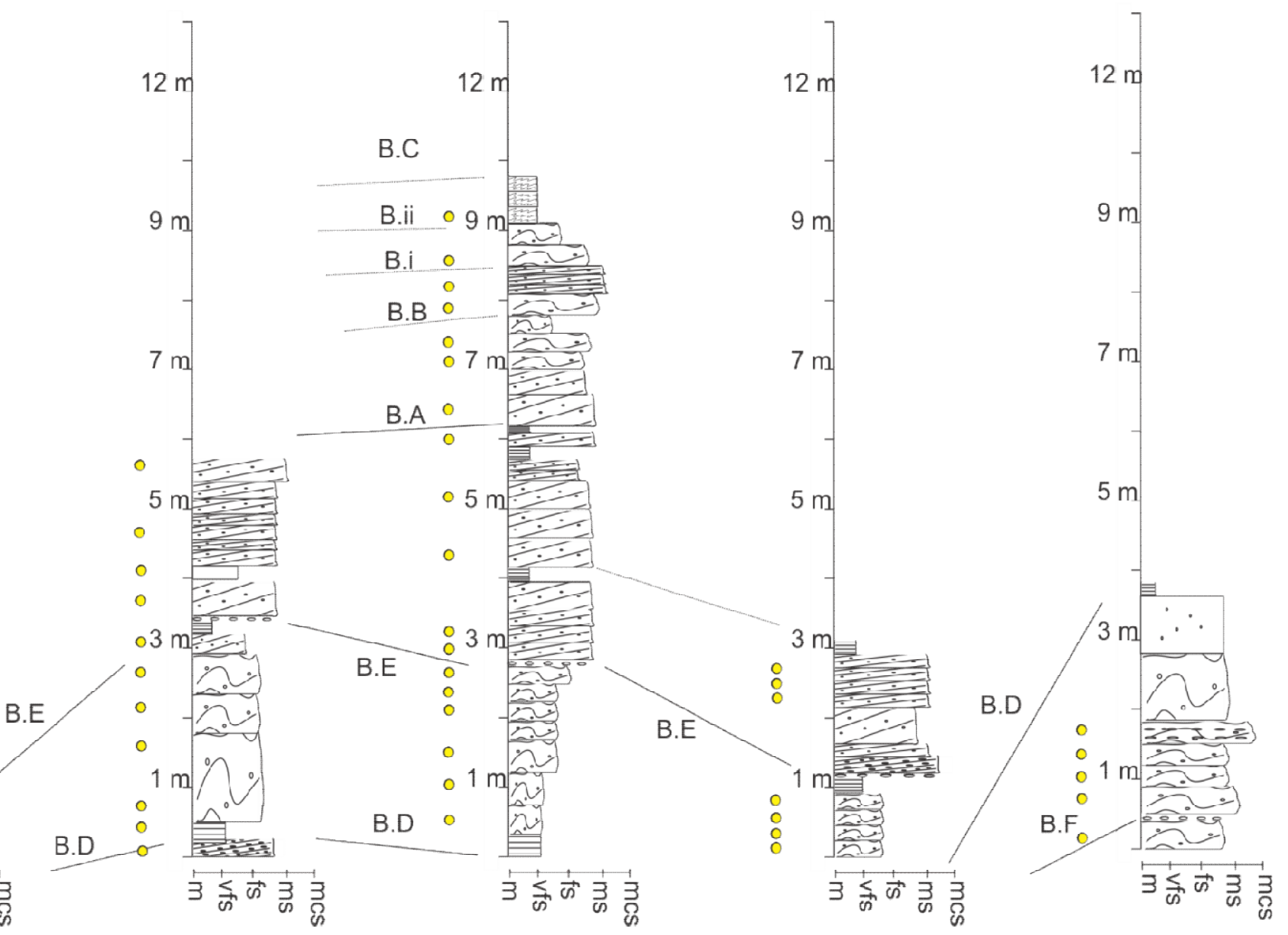




\section{TUC41 Tinny Perm Sections III}

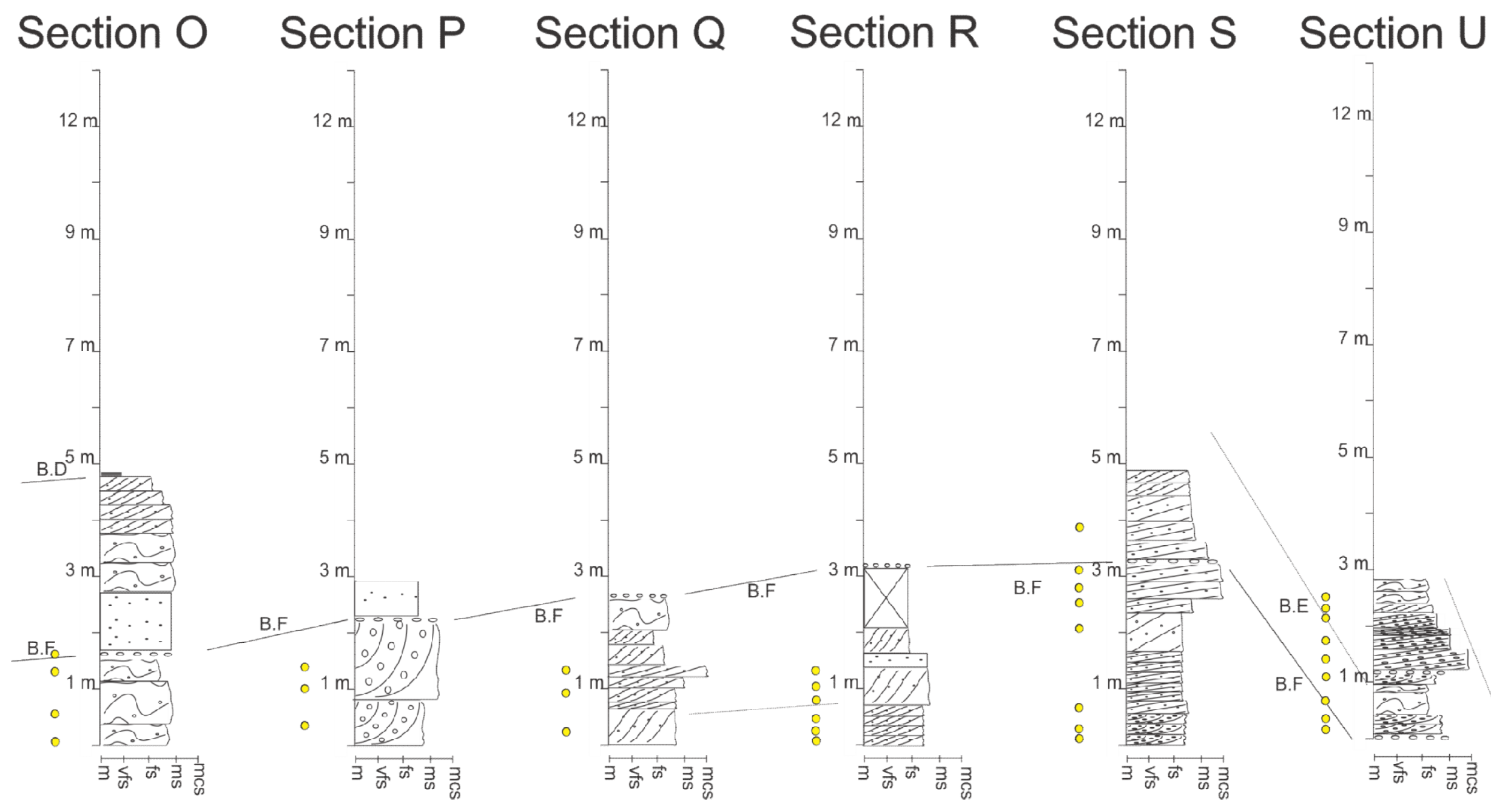




\section{TUC41 Tinny Perm Sections IV}

Section $\mathrm{V}$ Section $\mathrm{X}$ Section $\mathrm{W}$ Section $\mathrm{Y} \quad$ Section $\mathrm{Z}$ Section $\mathrm{AA}$

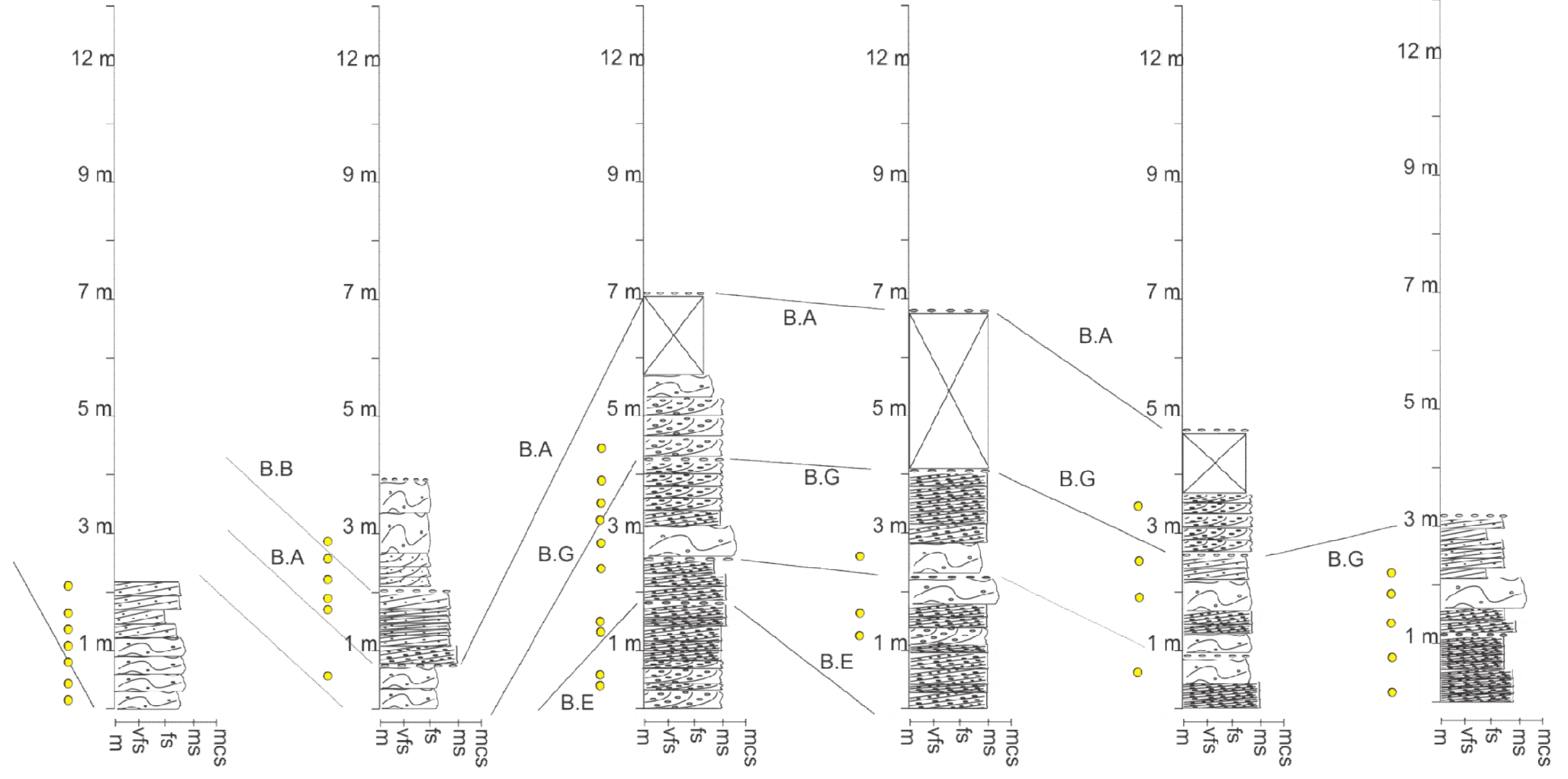




\section{TUC41 Tinny Perm Sections V}

Section $A B$ Section $A C$ Section $A D$ Section $A E$ Section AF Section AG

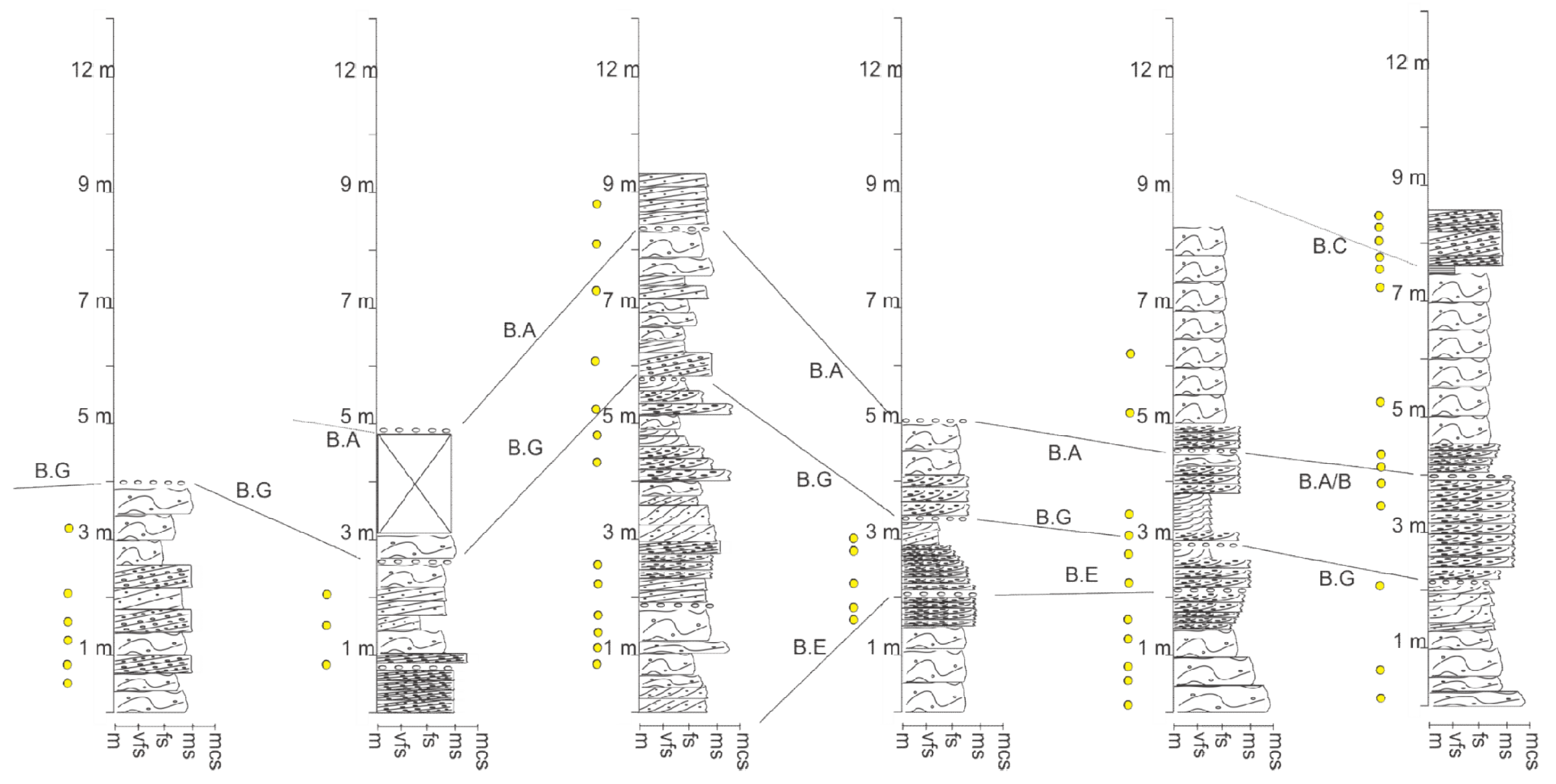


TUC41 Tinny Perm Sections VI

Section AH Section Al Section AJ Section AK Section AL Section AM
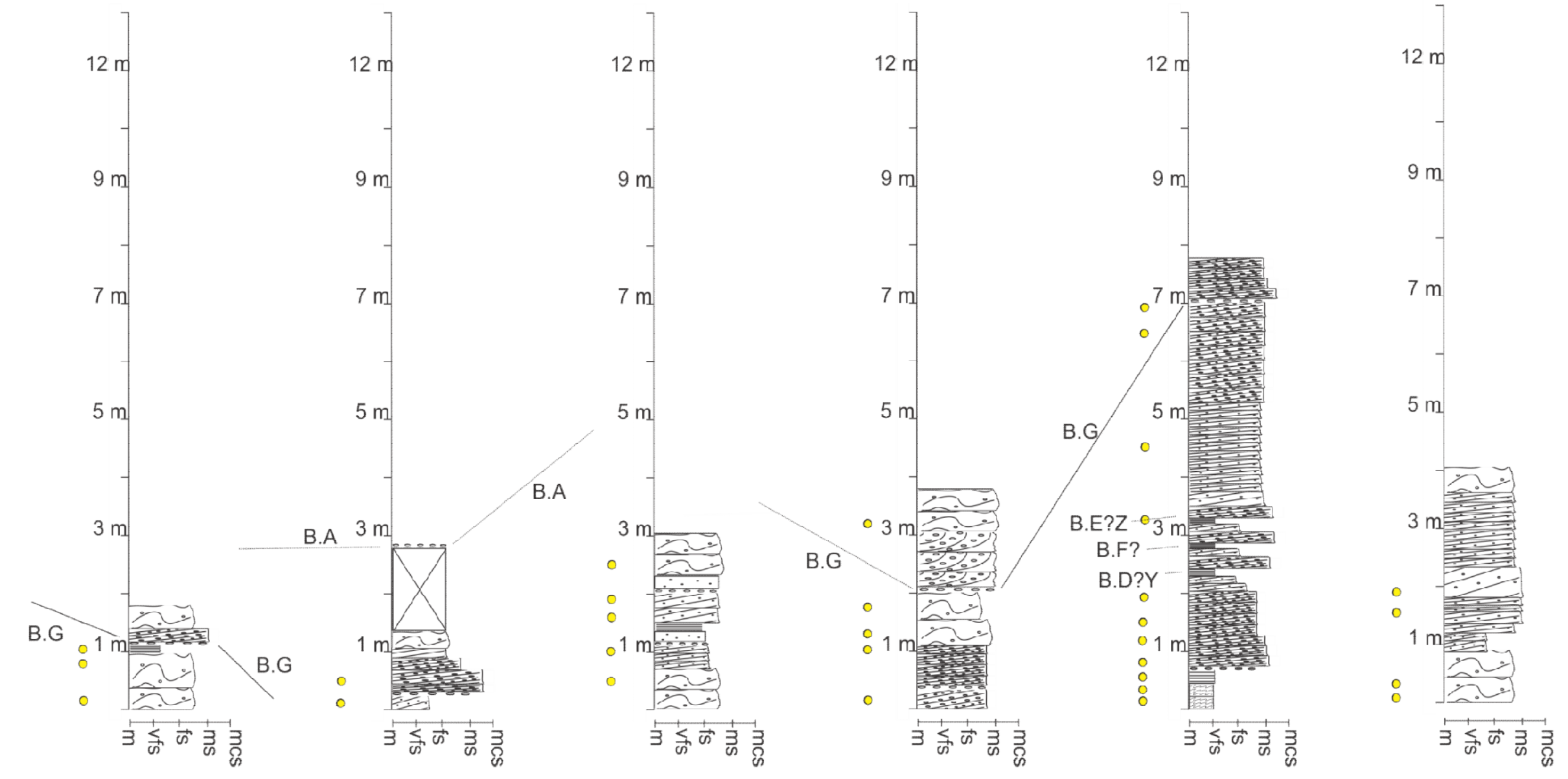


\section{TUC41 Tinny Perm Sections VII}

Section $A 01$ keeps up in section $A O 2$, and section $A Z 1$ in section $A Z 2$

Section $A N$ Section $A O_{1}$ Section $A O_{2}$ Section $A Z_{1}$ Section $A Z_{2}$ Section $A C$
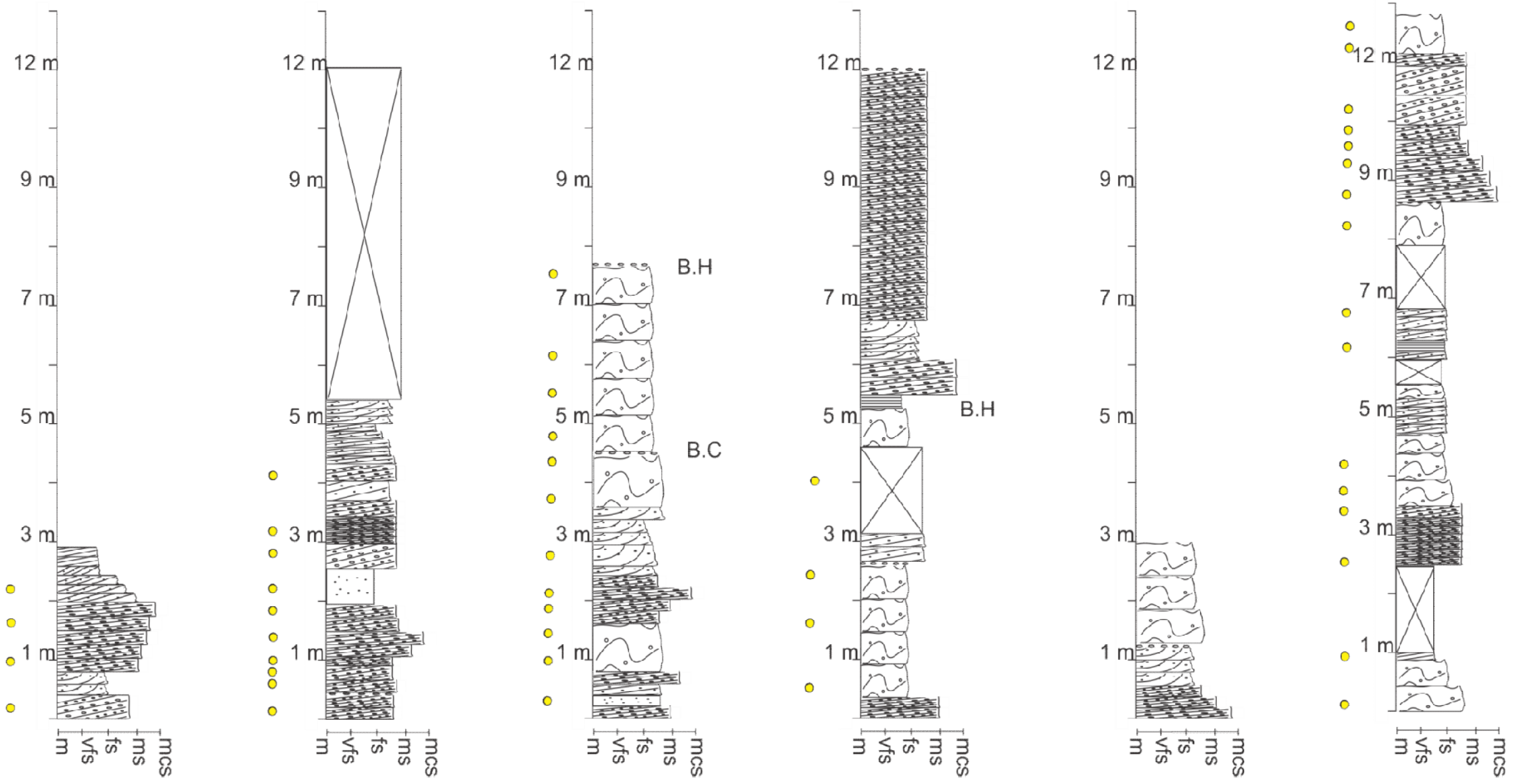
Apêndice C - A) Nuvem de pontos 3D do afloramento TUC05 inteiro (corte norte-sul, com norte representado pelo eixo y) (quadrado representa visão de detalhe do apêndice B. B) Visão de detalhe no afloramento TUC05 (mesmo corte) com destaque para superfície B (seta amarela)
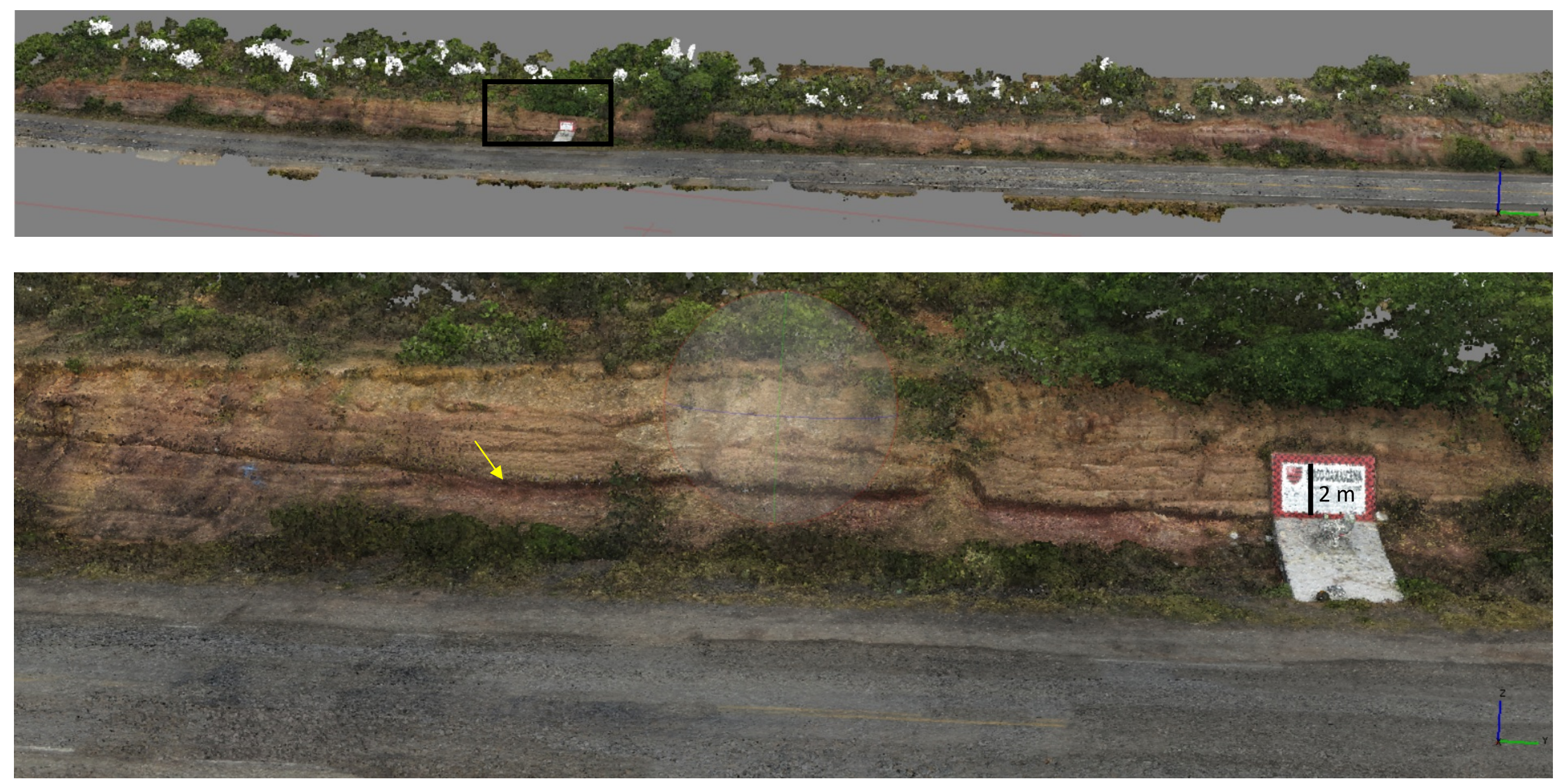
Apêndice D - A) Principais superfícies sedimentares do afloramento TUC05 delimitadas na imagem de drone (superfícies descritas no item 6.1) (CH remete aos elementos arquiteturais de canais abandonados. B) Principais superfícies sedimentares do afloramento TUC05 importadas e interpoladas como horizontes no RMS. Superfície 1 (ou A) erosiva de terceira ordem, colocando barra composta sobre barra unitária. Essa superfície também é resultado da reativação do sistema trativo, após período inativo, representado por canais abandonados de pequeno porte (sobre barras as unitárias). Superfície 2 (ou B) erosiva sobre topos de barras (de barras compostas) delimitando base de nova barra composta. Supefície 3 (ou C) erosiva, delimitando a base de nova barra composta, preservando apenas localmente topos de barra. Superfície 4 (ou H) de reativação de barra composta. Superfície 5 delimitadora de canal abandonado. Superfície 6 de escavação, delimitadora de canal abandonado de maior porte que o delimitado pela superfície 5
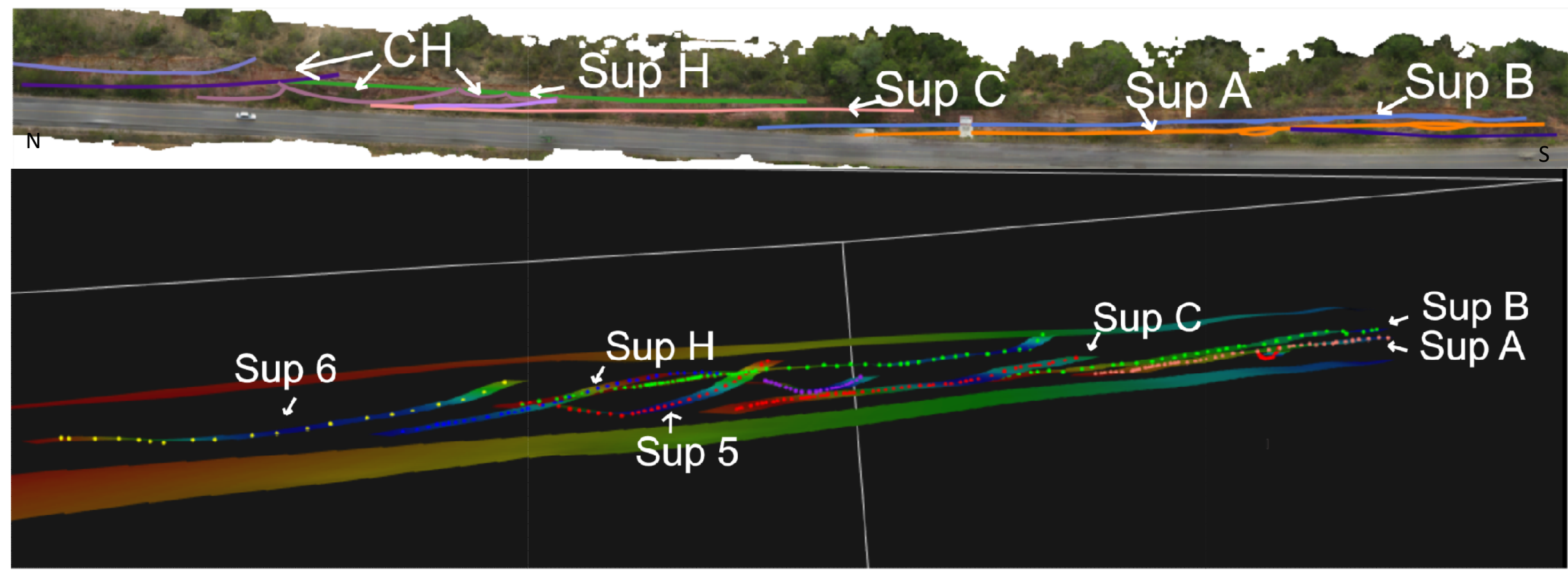
Apêndice E - Modelo estratigráfico do afloramento TUC05. A coloração vermelha representa os topos de barra, enquanto a roxa representa os canais abandonados. As cores verde-azulado, branca, salmom e bege representam barras (quadrado azul representa local do modelo do apêndice $F(A)$ quadrado verde do modelo apresentado na figura $F(B)$ ) (superfícies descritas no apêndice $D$ e item 6.1)

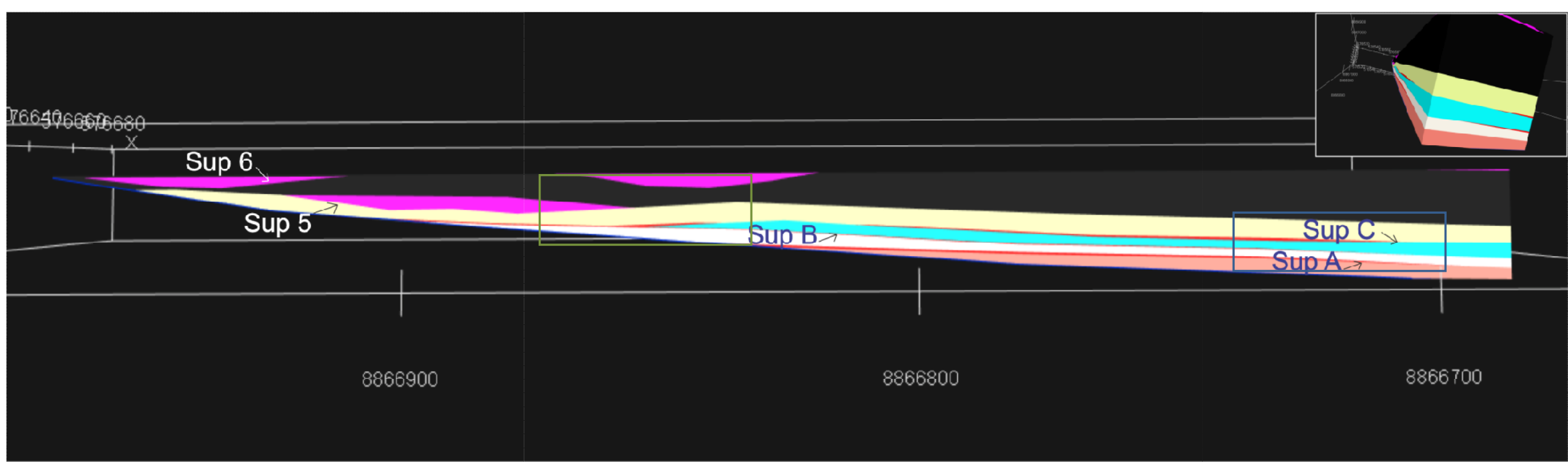


Apêndice F - Modelo de elementos arquiteturais, utilizando a SIS, do afloramento TUC 05. A coloração vermelha representa os topos de barra e a verde os canais abandonados. A coloração azul representa os depósitos de barra (células em z=0.1m; células em x e y= $1.0 \mathrm{~m}$ ) (superfícies descritas no apêndice $\mathrm{D}$ e item 6.1)

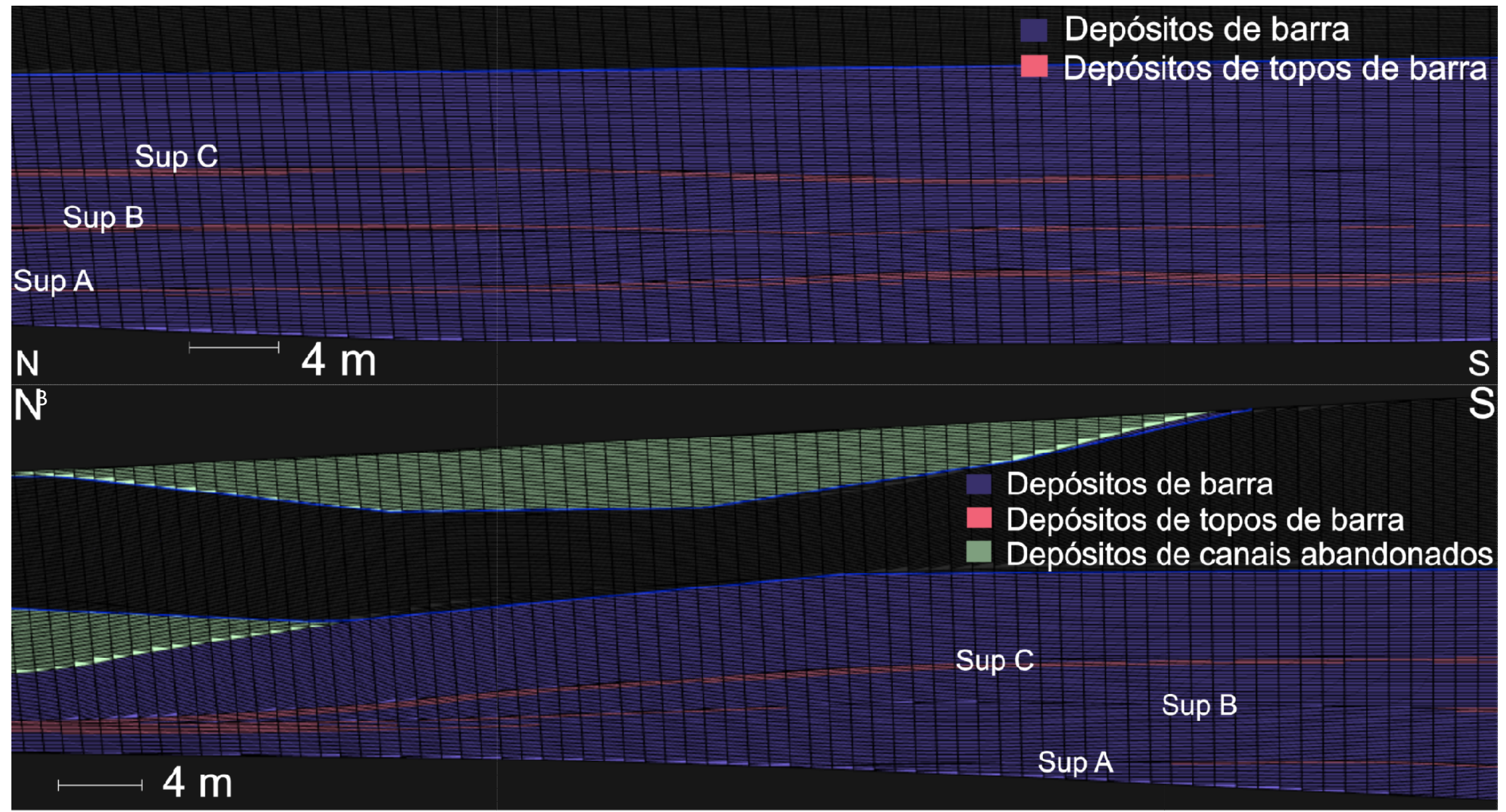


Apêndice G - Tabela de porcentagens de elementos arquiteturais entre superfícies do afloramento TUC05

\begin{tabular}{|c|c|c|}
\hline TUC05 & & \\
\hline Zone & Architetural element & Percent (\%) \\
\hline \multirow[t]{3}{*}{ Selection } & $\operatorname{bar}(1)$ & 69.95 \\
\hline & bartop (2) & 1.58 \\
\hline & Channel (3) & 28.47 \\
\hline \multirow[t]{3}{*}{ Below_topo } & bar (1) & 0.00 \\
\hline & bartop (2) & 0.00 \\
\hline & Channel (3) & 100.00 \\
\hline \multirow[t]{3}{*}{ Below_sup_g } & bar (1) & 53.55 \\
\hline & bartop (2) & 0.00 \\
\hline & Channel (3) & 46.45 \\
\hline \multirow[t]{3}{*}{ Below_sup_h } & bar (b1) & 4.68 \\
\hline & artop (2) & 0.00 \\
\hline & Channel (3) & 95.32 \\
\hline \multirow[t]{3}{*}{ Below_canal_d } & $\operatorname{bar}(1)$ & 99.46 \\
\hline & bartop (2) & 0.54 \\
\hline & Channel (3) & 0.00 \\
\hline \multirow[t]{3}{*}{ Below_sup_c } & $\operatorname{bar}(1)$ & 95.92 \\
\hline & bartop (2) & 4.08 \\
\hline & Channel (3) & 0.00 \\
\hline \multirow[t]{3}{*}{ Below_sup_b } & bar (1) & 94.35 \\
\hline & bartop (2) & 5.65 \\
\hline & Channel (3) & 0.00 \\
\hline \multirow[t]{3}{*}{ Below_sup_a } & $\operatorname{bar}(1)$ & 91.83 \\
\hline & bartop (2) & 8.17 \\
\hline & Channel (3) & 0.00 \\
\hline
\end{tabular}

\begin{tabular}{|c|c|c|c|}
\hline Limits & X & Y & Z \\
\hline Min & 576528.6 & 8866671 & -315.54 \\
\hline Max & 576590.1 & 8867012 & -292.54 \\
\hline
\end{tabular}


Apêndice H - Modelo de fácies, utilizando a simulação indicadora sequencial, do aflorameto TUC 05 (mesma localização do apêndice $F$ (A)) (células em $z=0.1 \mathrm{~m}$; células em $x$ e $y=1.0 \mathrm{~m}$ )

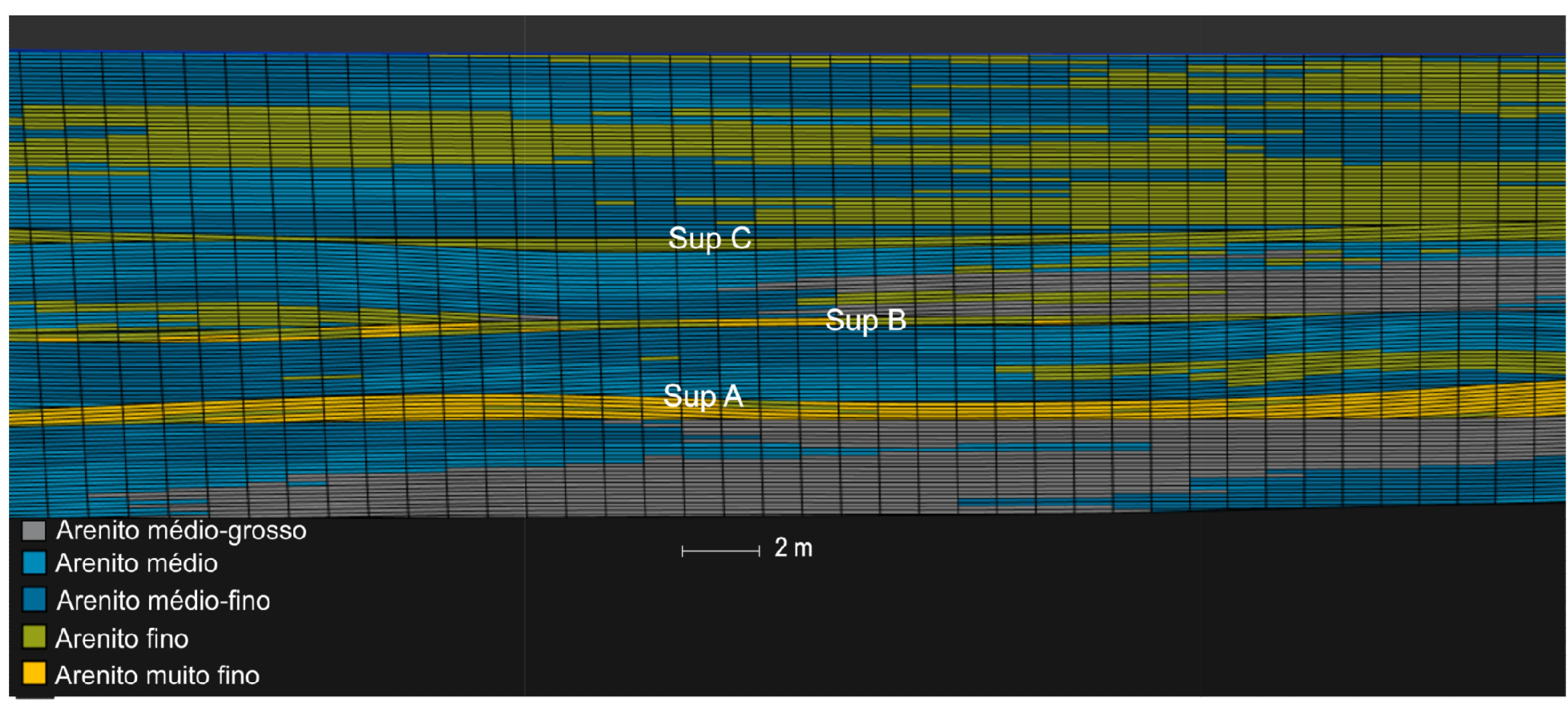


Apêndice I - Tabela de porcentagens de fácies entre superficies do afloramento TUC05 (aff = arenito muito fino; af = arenito fino; $a m f=$ arenito médio fino; $a m=$ arenito médio; amg = arenito médio grosso) (obs: zonas acima da superfície below_teste representam topos de barra criados no modelo estratigráfico)

\begin{tabular}{|c|c|c|}
\hline \multicolumn{2}{|l|}{ TUC05 } & \multirow[b]{2}{*}{ Percent (\%) } \\
\hline Zone & Facies & \\
\hline \multirow[t]{5}{*}{ Selection } & aff (1) & 28.16 \\
\hline & af $(2)$ & 36.28 \\
\hline & $\operatorname{amf}(3)$ & 21.23 \\
\hline & am (4) & 10.21 \\
\hline & amg (5) & 4.12 \\
\hline \multirow[t]{5}{*}{ Below_topo } & aff (1) & 50.19 \\
\hline & af $(2)$ & 49.81 \\
\hline & $\operatorname{amf}(3)$ & 0.00 \\
\hline & am (4) & 0.00 \\
\hline & amg (5) & 0.00 \\
\hline \multirow[t]{5}{*}{ Below_sup_g } & aff (1) & 50.87 \\
\hline & af $(2)$ & 49.13 \\
\hline & $\operatorname{amf}(3)$ & 0.00 \\
\hline & am (4) & 0.00 \\
\hline & amg (5) & 0.00 \\
\hline \multirow[t]{5}{*}{ Below_sup_h } & aff (1) & 66.01 \\
\hline & af $(2)$ & 33.99 \\
\hline & $\operatorname{amf}(3)$ & 0.00 \\
\hline & am (4) & 0.00 \\
\hline & amg (5) & 0.00 \\
\hline \multirow[t]{5}{*}{$\begin{array}{c}\text { Below_canal } \\
\text { _d }\end{array}$} & aff (1) & 0.00 \\
\hline & af $(2)$ & 26.87 \\
\hline & $\operatorname{amf}(3)$ & 60.00 \\
\hline & am (4) & 13.13 \\
\hline & amg (5) & 0.00 \\
\hline \multirow[t]{5}{*}{ Below_sup_c } & aff (1) & 11.50 \\
\hline & af $(2)$ & 88.50 \\
\hline & $\operatorname{amf}(3)$ & 0.00 \\
\hline & am (4) & 0.00 \\
\hline & amg (5) & 0.00 \\
\hline \multirow[t]{3}{*}{ Below_teste4 } & aff (1) & 0.00 \\
\hline & af $(2)$ & 16.50 \\
\hline & $\operatorname{amf}(3)$ & 25.92 \\
\hline
\end{tabular}

\begin{tabular}{|c|c|c|}
\hline & am (4) & 34.33 \\
\hline & amg (5) & 23.25 \\
\hline \multirow[t]{5}{*}{ Below_sup_b } & aff (1) & 14.23 \\
\hline & af $(2)$ & 85.77 \\
\hline & $\operatorname{amf}(3)$ & 0.00 \\
\hline & am (4) & 0.00 \\
\hline & amg (5) & 0.00 \\
\hline \multirow[t]{5}{*}{ Below $_{2}$ teste } & aff (1) & 0.00 \\
\hline & af $(2)$ & 15.14 \\
\hline & amf (3) & 56.00 \\
\hline & am (4) & 28.85 \\
\hline & amg (5) & 0.00 \\
\hline \multirow{5}{*}{$\begin{array}{c}\text { Below_sup_a } \\
\ldots\end{array}$} & aff (1) & 59.47 \\
\hline & af $(2)$ & 40.53 \\
\hline & amf (3) & 0.00 \\
\hline & am (4) & 0.00 \\
\hline & amg (5) & 0.00 \\
\hline \multirow[t]{5}{*}{ Below $\frac{1}{1}$ teste } & aff (1) & 0.00 \\
\hline & af $(2)$ & 0.00 \\
\hline & amf (3) & 21.77 \\
\hline & am (4) & 39.37 \\
\hline & amg (5) & 38.86 \\
\hline
\end{tabular}

\begin{tabular}{|c|c|c|c|}
\hline Limits & $X$ & $Y$ & $Z$ \\
\hline Min & 576528.6 & 8866671 & -315.54 \\
\hline Max & 576590.1 & 8867012 & -292.54 \\
\hline
\end{tabular}


Apêndice J - Nuvem de pontos 3D da frente do afloramento TUC41 (referente ao mosaico tuc41.4)

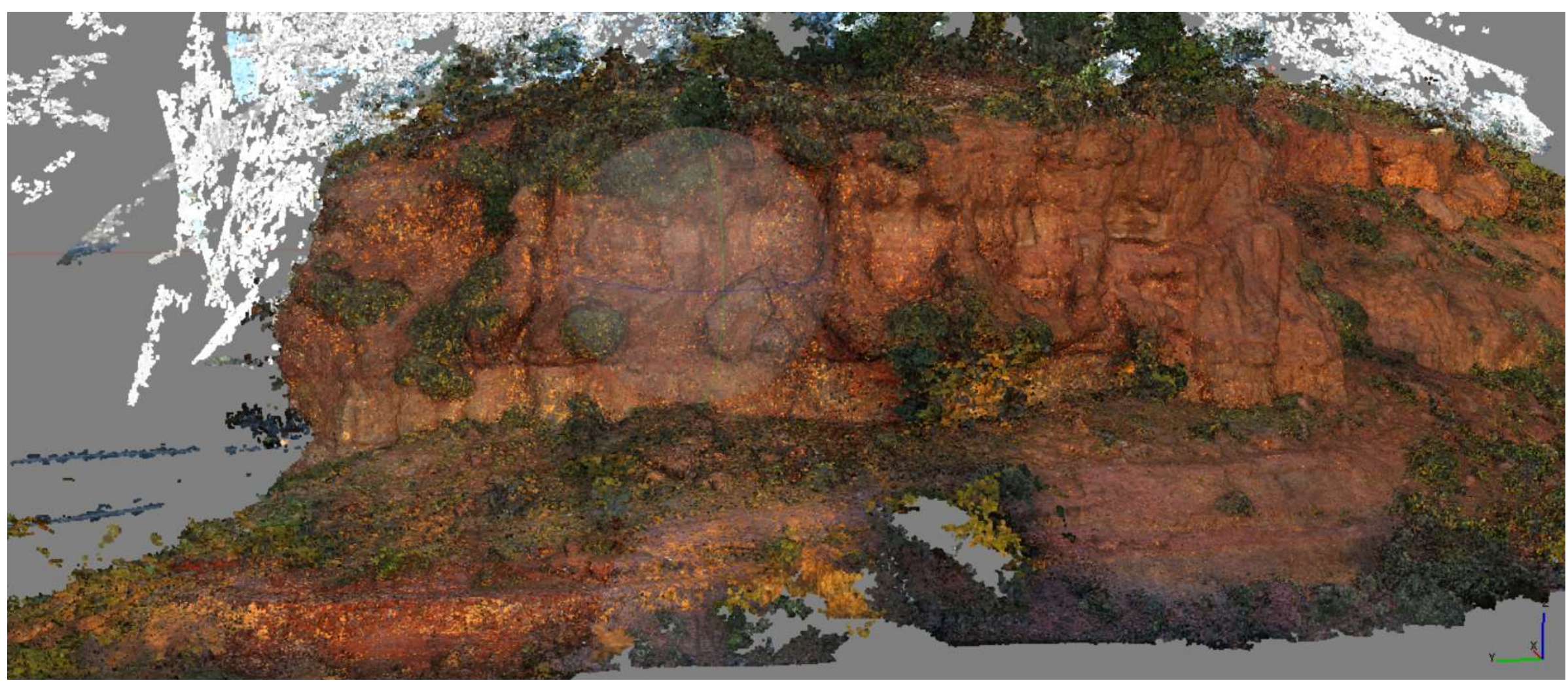


Apêndice K - Principais superfícies sedimentares referentes ao mosaico TUC41.4, delimitadas na imagem de drone. Superfícies de retomada/aumento do fluxo trativo, de barra unitária (superfície $\mathrm{H}$ ) e barra composta (superfície $\mathrm{C}$ ), ambas sobre topos de barra. Superfície i erosiva, de segunda ordem (menor hierarquia que as demais), entre cosets de arenito médio-grosso (fácies Amcc) (base) e convolutas de arenito médio a fino (fácies Acon) (topo).Superfície B erosiva entre barras compostas. Superfície A erosiva entre barras unitárias (base) e barras compostas (topo).

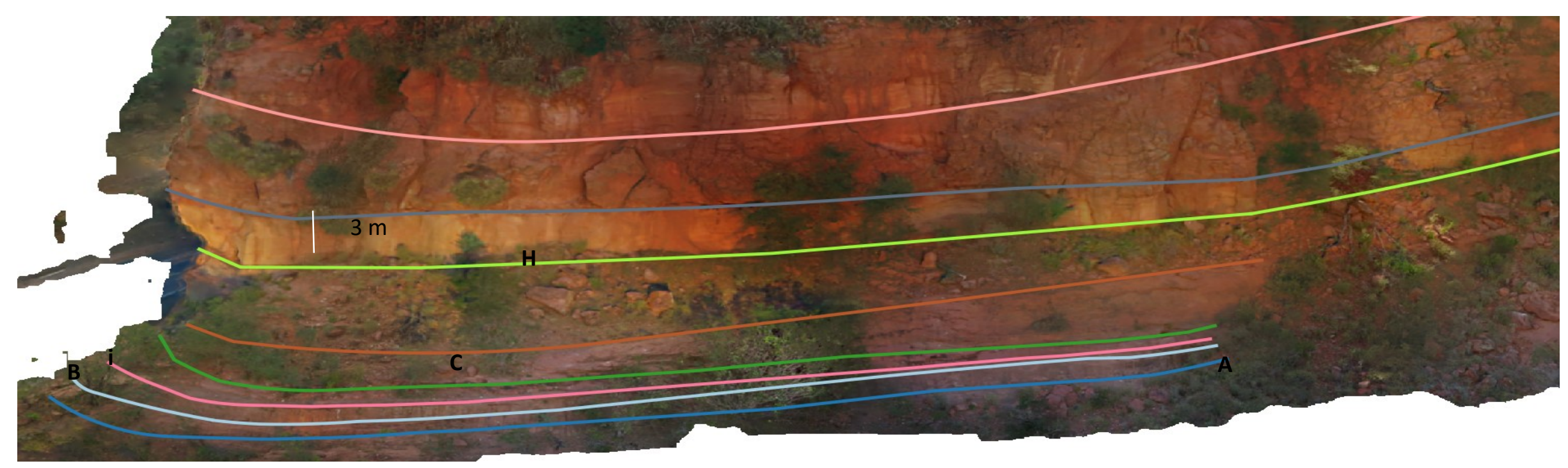


Apêndice L - Nuvem de pontos 3D referentes aos mosaicos TUC41.1, TUC41.2, TUC41.3 (quadro preto em detalhe no apêndice M)

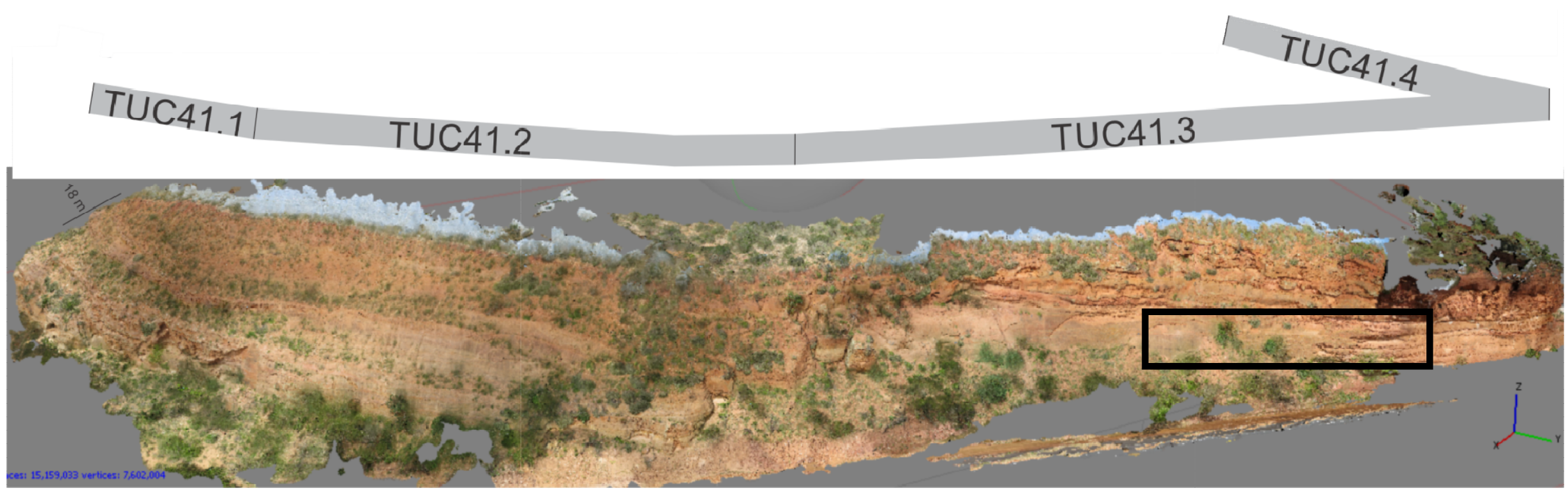


Apêndice M - Aproximação da nuvem de pontos 3D na lateral do afloramento TUC41. Destaque para superfície C (seta em amarelo) e superfície H (seta em preto)

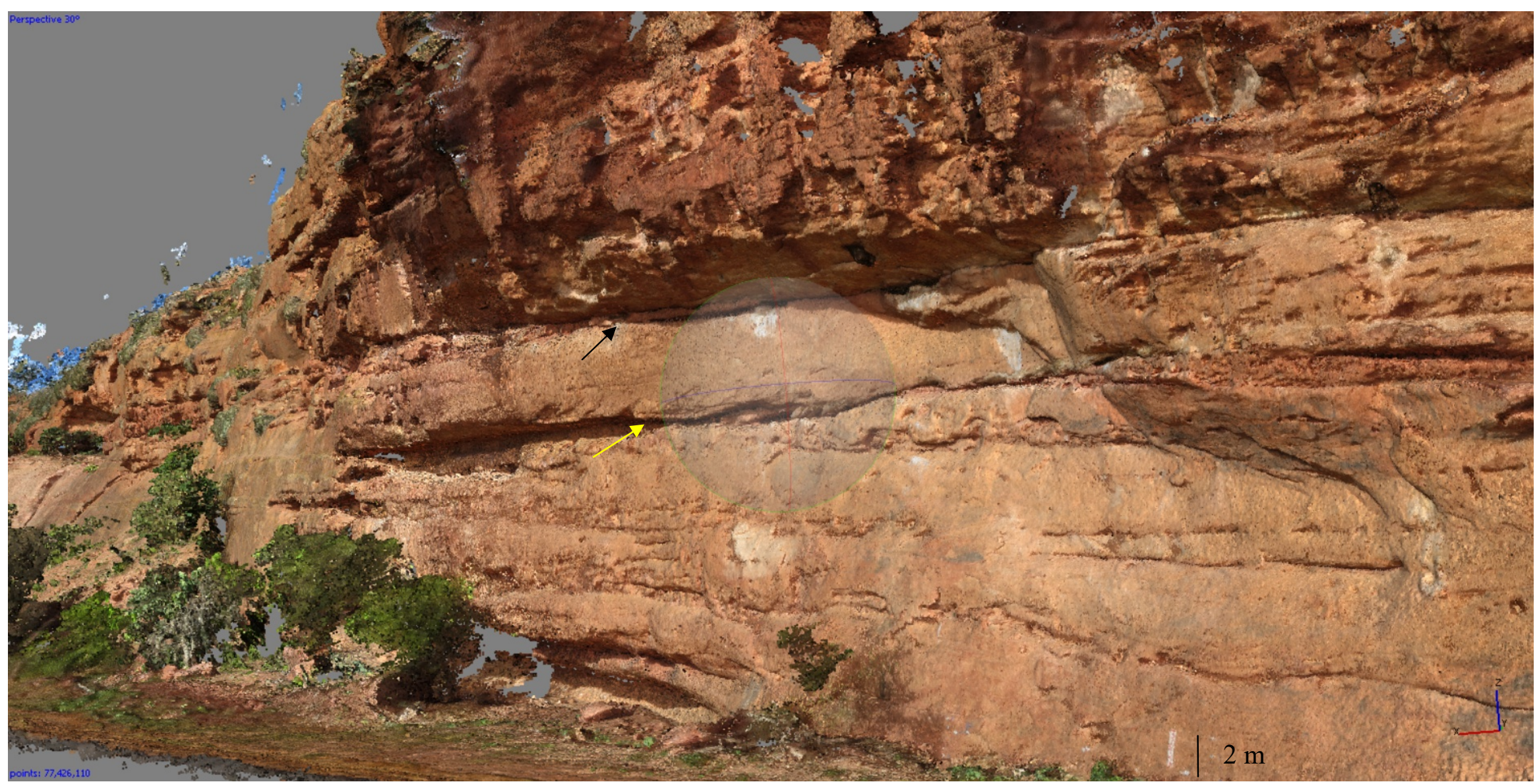




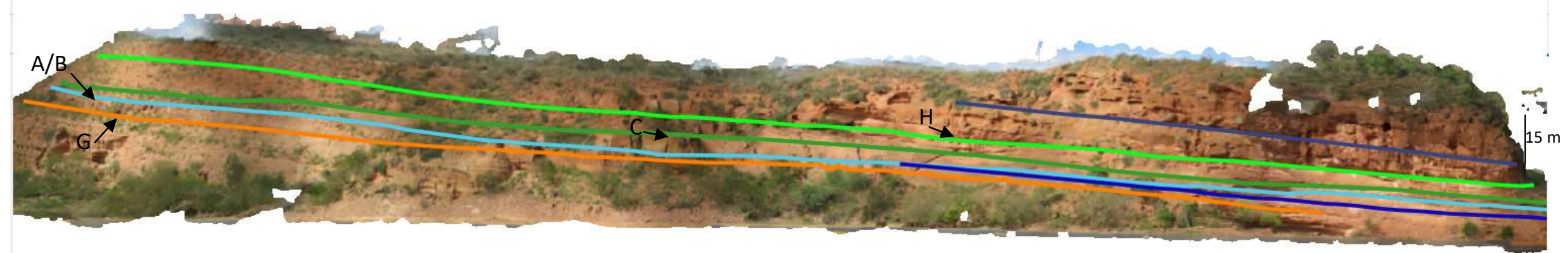

Apêndice $O$ - Principais superfícies sedimentares digitalizadas do afloramento TUC41 (descritas no apêndice P e no item 6.1)

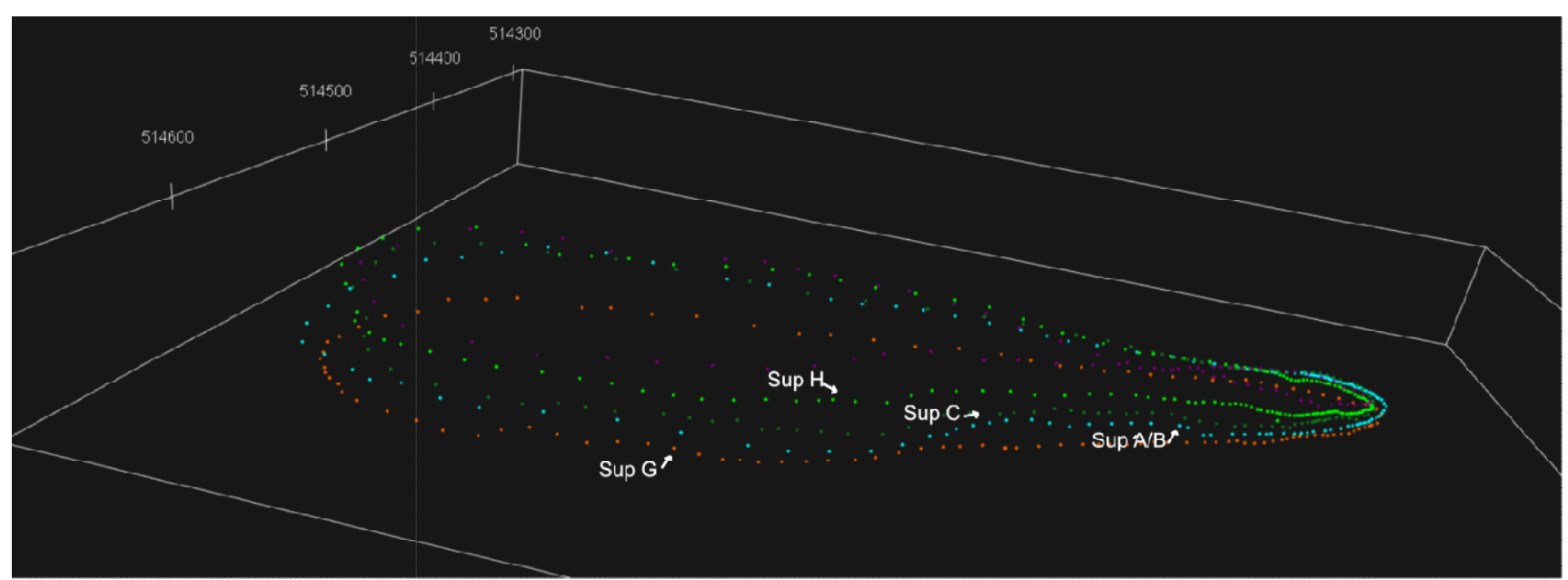


Apêndice P - Modelo estratigráfico do afloramento TUC41, com principais superfícies sedimentares indicadas. . Superfície P (possívelmente superfície H do mosaico TUC41.3 e TUC41.4) erosiva à barra unitária. Superfície $C$ erosiva de barra unitária sobre topo de barra (de barra composta) preservado localmente. Superfície A/B de superimposição de barras compostas. Superfície G, pouco contínua. A continuidade dessa superfície é resultado das sobreposições de formas de leito, gerando cosets da fácies Amcc. Superfície Z representa a reativação do fluxo trativo de barras compostas sobre topo de barra, localmente erosiva.

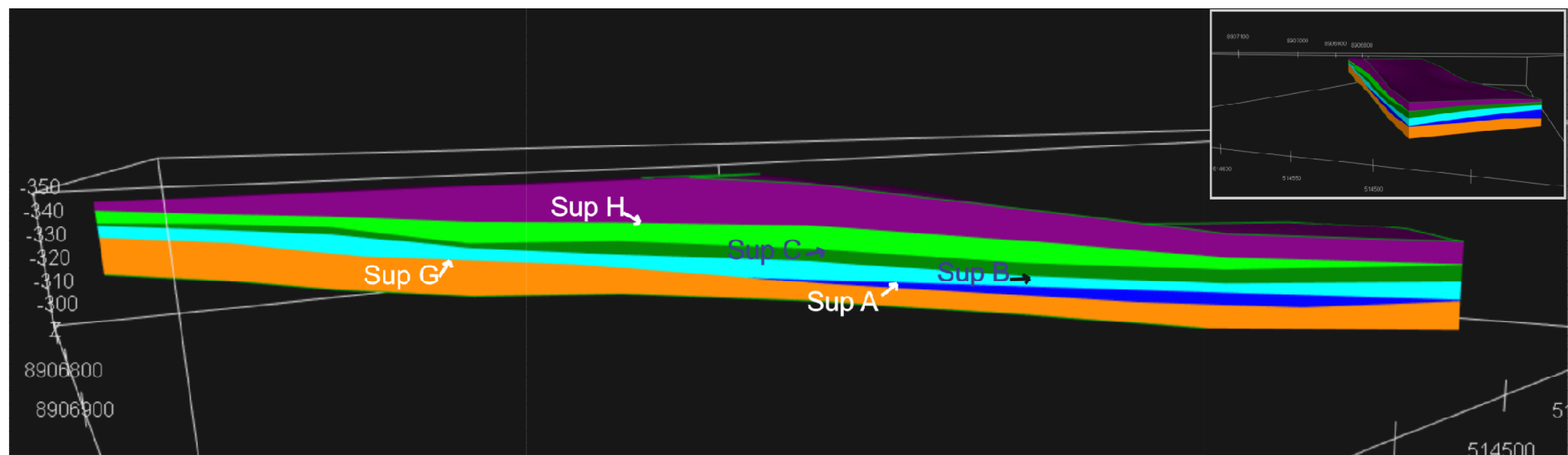


Apêndice Q - Modelo de elementos arquiteturais, utilizando a simulação indicadora sequencial, do afloramento TUC41 (setas brancas indicam topos de barras sotopostos à superfície $\mathrm{C}$, amarelas à $\mathrm{H}$, roxa à $\mathrm{Z}$ e verde à $\mathrm{Y}$ ) (superfícies descritas no apêndice $\mathrm{P}$ e no item 6.1 )

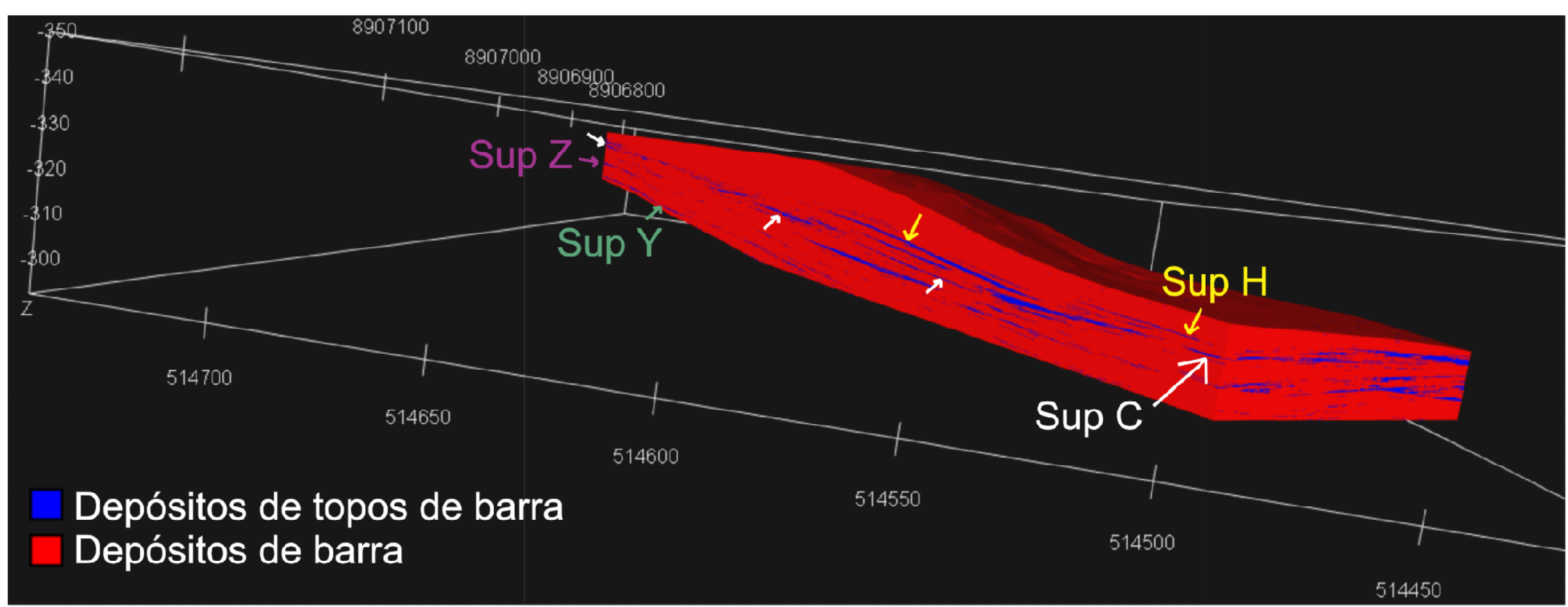


Apêndice R - Tabela de porcentagens dos elementos arquiteturais entre superfícies do afloramento TUC41

\begin{tabular}{|c|c|c|}
\hline TUC41 & \multicolumn{2}{|c|}{} \\
\hline Selection & Architetural element & 90.86 \\
\hline & bar (1) & 9.14 \\
\hline Below_sup_uph & bartop (2) & 99.48 \\
\hline & bar (1) & 0.52 \\
\hline Below_sup_h & bartop (2) & 91.48 \\
\hline & bar (1) & 8.52 \\
\hline Below_sup_c2 & bartop (2) & 67.92 \\
\hline & bar (1) & 32.08 \\
\hline Below_sup_b & bartop (2) & 92.13 \\
\hline & bar (1) & 7.87 \\
\hline Below_sup_a & bartop (2) & 71.70 \\
\hline & bar (1) & 28.30 \\
\hline Below_sup_g & bartop (2) & 92.98 \\
\hline & bar (1) & 7.02 \\
\hline
\end{tabular}

\begin{tabular}{|c|c|c|c|}
\hline Limits & $X$ & $Y$ & $Z$ \\
\hline Min & 514412.3 & 8906830 & -346.43 \\
\hline Max & 514727.1 & 8907226 & -304.43 \\
\hline
\end{tabular}


Apêndice S - Modelo de fácies, utilizando a simulação indicadora sequencial, do afloramento TUC 41. Setas brancas indicam a superfície C, setas amarelas indicam a superfície $H$, setas roxas indicam superfície $Z$, setas verdes indicam a superfície $Y$ (superfícies descritas no apêndice $P$ e no item 6.1 )

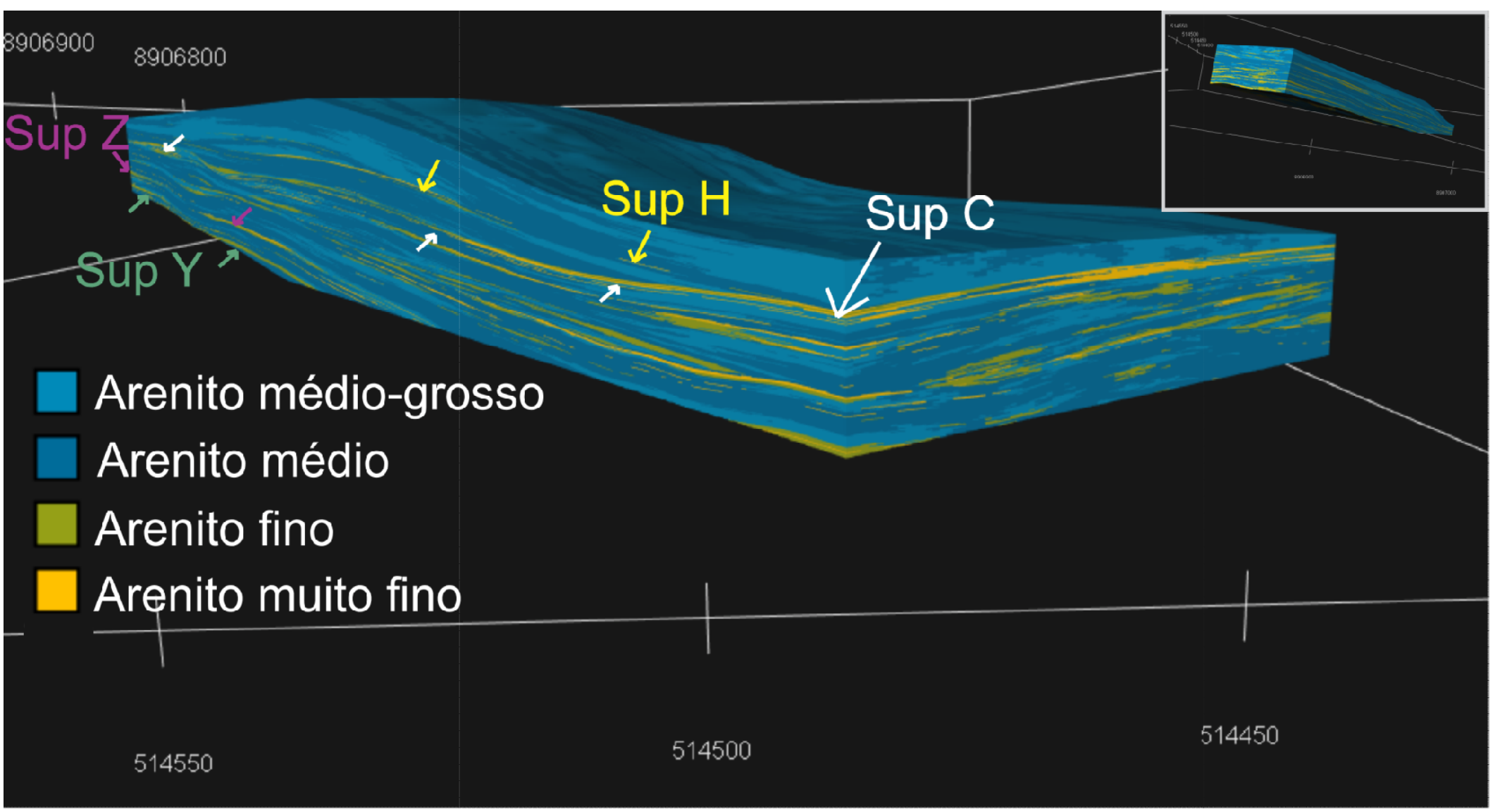


Apêndice $T$ - Tabela de porcentagem de fácies do modelo entre superfícies do afloramento TUC41 (aff = arenito muito fino; af = arenito fino; am = arenito médio; amg = arenito médio grosso)

\begin{tabular}{|c|c|c|}
\hline \multicolumn{3}{|l|}{ Name } \\
\hline Zone & Facies & Percent(\%) \\
\hline \multirow[t]{4}{*}{ Selection } & aff (1) & 5.96 \\
\hline & af (2) & 7.04 \\
\hline & am (3) & 61.13 \\
\hline & amg (4) & 25.86 \\
\hline \multirow[t]{4}{*}{ Below_sup_acimah2 } & aff (1) & 0.00 \\
\hline & af (2) & 1.20 \\
\hline & am (3) & 43.26 \\
\hline & amg (4) & 55.54 \\
\hline \multirow[t]{4}{*}{ Below_sup_h2 } & aff (1) & 1.98 \\
\hline & af (2) & 7.71 \\
\hline & am (3) & 75.40 \\
\hline & amg (4) & 14.91 \\
\hline \multirow[t]{4}{*}{ Below_sup_c2 } & aff (1) & 21.19 \\
\hline & af (2) & 5.40 \\
\hline & am (3) & 48.28 \\
\hline & amg (4) & 25.14 \\
\hline \multirow[t]{4}{*}{ Below_sup_b_frente } & aff (1) & 2.18 \\
\hline & af (2) & 7.37 \\
\hline & am (3) & 67.46 \\
\hline & amg (4) & 23.00 \\
\hline \multirow[t]{4}{*}{ Below_sup_a_frente } & aff (1) & 2.32 \\
\hline & af (2) & 27.32 \\
\hline & $\operatorname{am}(3)$ & 47.95 \\
\hline & amg (4) & 22.41 \\
\hline \multirow[t]{4}{*}{ Below_sup_g2 } & aff (1) & 8.61 \\
\hline & af (2) & 8.44 \\
\hline & am (3) & 67.57 \\
\hline & amg (4) & 15.39 \\
\hline
\end{tabular}

\begin{tabular}{|l|r|r|r|}
\hline Limits & $X$ & $Y$ & $Z$ \\
\hline Min & 514412.3 & 8906830 & -346.43 \\
\hline Max & 514727.1 & 8907226 & -304.43 \\
\hline
\end{tabular}


Apêndice U - A) Amostragem de dados hard utilizados na confecção do modelo do afloramento TUC05. B) Amostragem de dados hard utilizados na confecção do modelo do afloramento TUC41
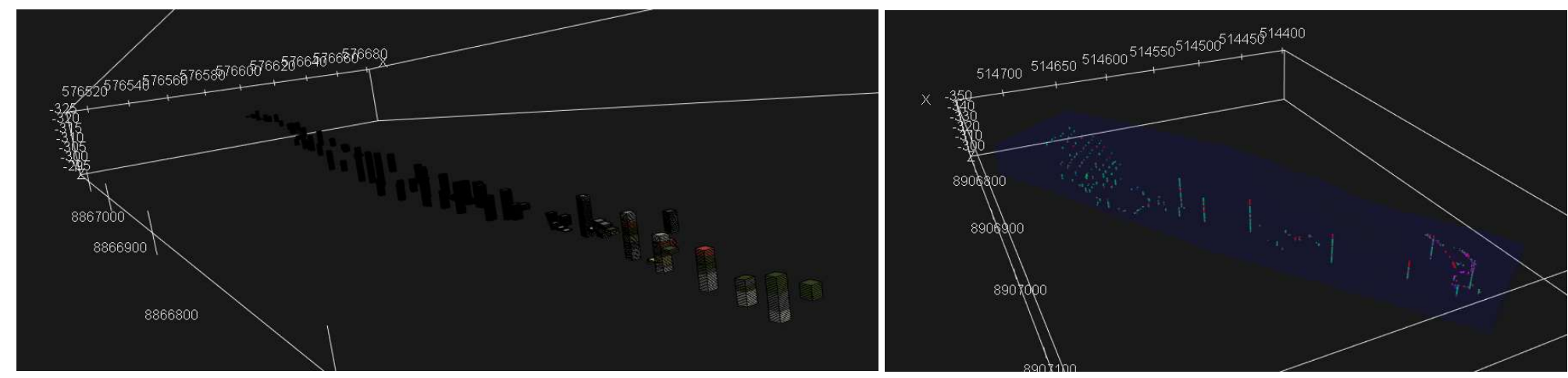

Apêndice $V$ - Variogramas verticais de fácies de fácies (notação representa: fácies_afloramento_superfície acima da fácies)
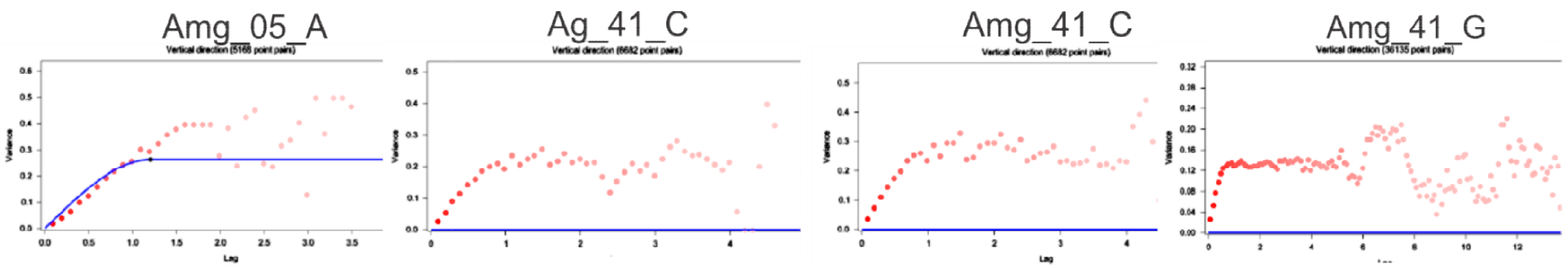
Apêndice W - Modelo de pemeabilidade horizontal (mesma localização do modelo de fácies do apêndice H), utilizando a simulação gaussiana sequencial, do afloramento TUC05 (as zonas com permeabilidades menores que $1000 \mathrm{mD}$ tratam-se, em maioia, de arenitos médios-finos e finos). Zonas de permeabilidade baixa concentram-se nos topos de barra (geometria lenticular), como previsto no item da análise de permeabilidade (item 6.3.2) (células em $z=0.1 \mathrm{~m}$; células em $x$ e y= $1.0 \mathrm{~m}$ ) (principais superfícies sedimentares $A, B$ e $C$ indicadas, descritas no apêndice $D$ ).

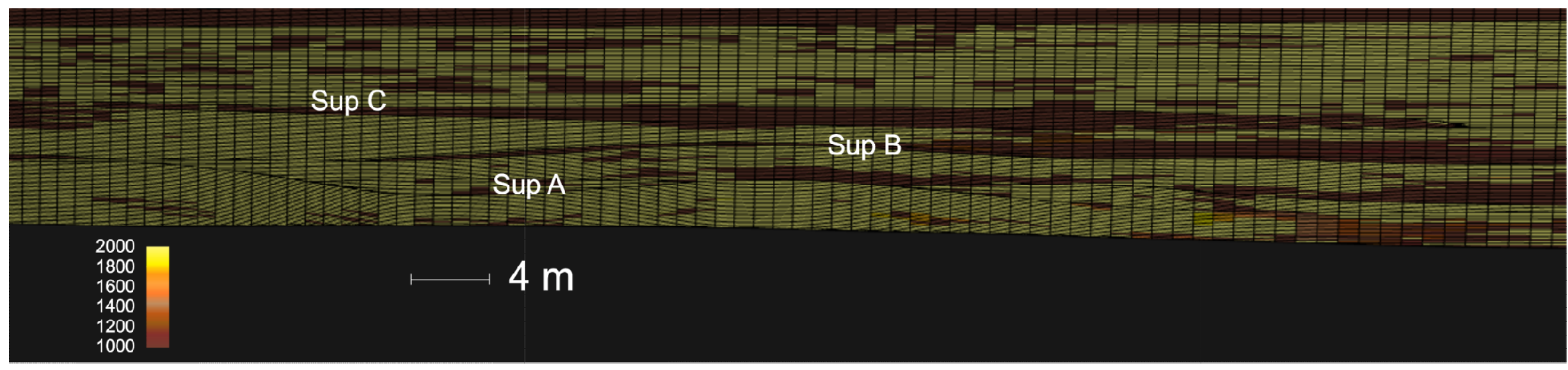


Apêndice X - Continuação para norte do modelo de permeabilidade horizontal do apêndice W (afloramento TUC 05) utilizando a simulação gaussiana sequencial (as zonas com permeabilidades menores que $1000 \mathrm{mD}$ tratam-se, em maioia, de arenitos médios-finos e finos). Zonas de permeabilidade baixa concentram-se nos topos de barra (geometria lenticular), como previsto no item da análise de permeabilidade (item 6.3.2) (células em $z=0.1 \mathrm{~m}$; células em $x$ e $y=1.0 \mathrm{~m}$ ) ) (principais superfícies sedimentares A, B e C indicadas, descritas no apêndice D).

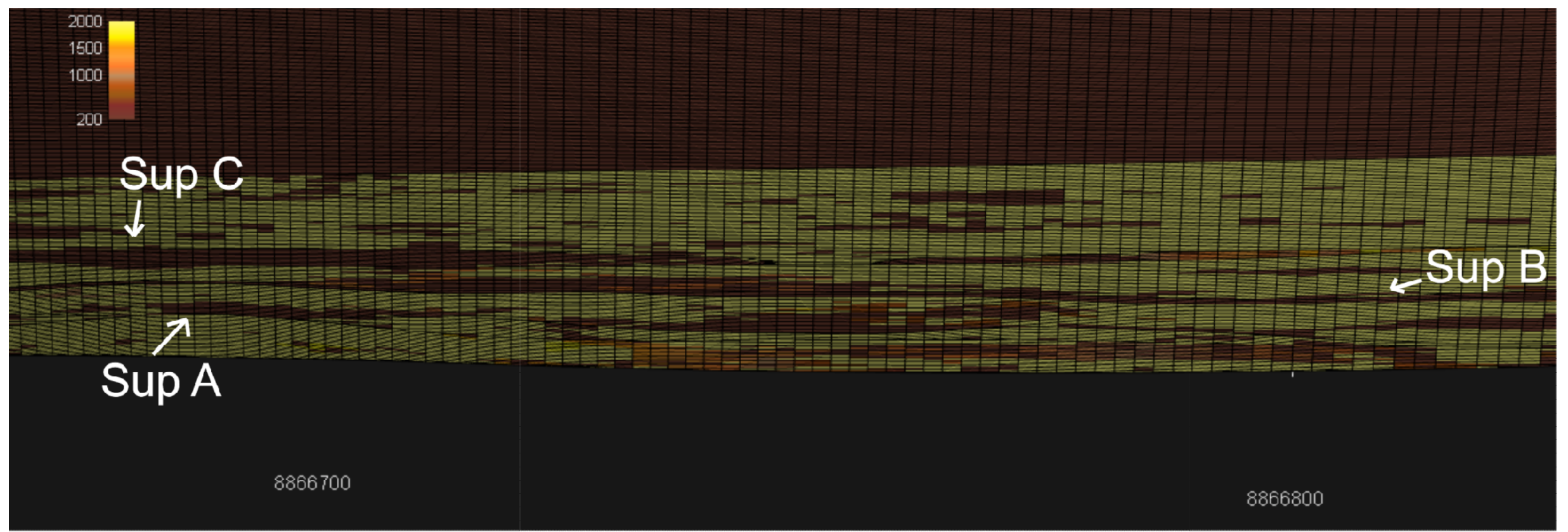


Apêndice $Y$ - Modelo de pemeabilidade horizontal do afloramento TUC 41, utilizando a simulação gaussiana sequencial, (as zonas com permeabilidades menores que $1000 \mathrm{mD}$ tratam-se, em maioia, de finos e muito finos). Zonas de permeabilidade baixa concentram-se nos topos de barra (geometria lenticular), como previsto no item da análise de permeabilidade (item 6.3.2) (células em $z=0.1 \mathrm{~m}$; células em $x$ e y= $1.0 \mathrm{~m}$ ) (superfícies sedimentares que possuem fácies finas relacionadas $\mathrm{C}, \mathrm{H}, \mathrm{Z}$ e Y indicadas, descritas no apêndice $\mathrm{K}$ e P) (quadrado preto indica localização do apêndice Z)

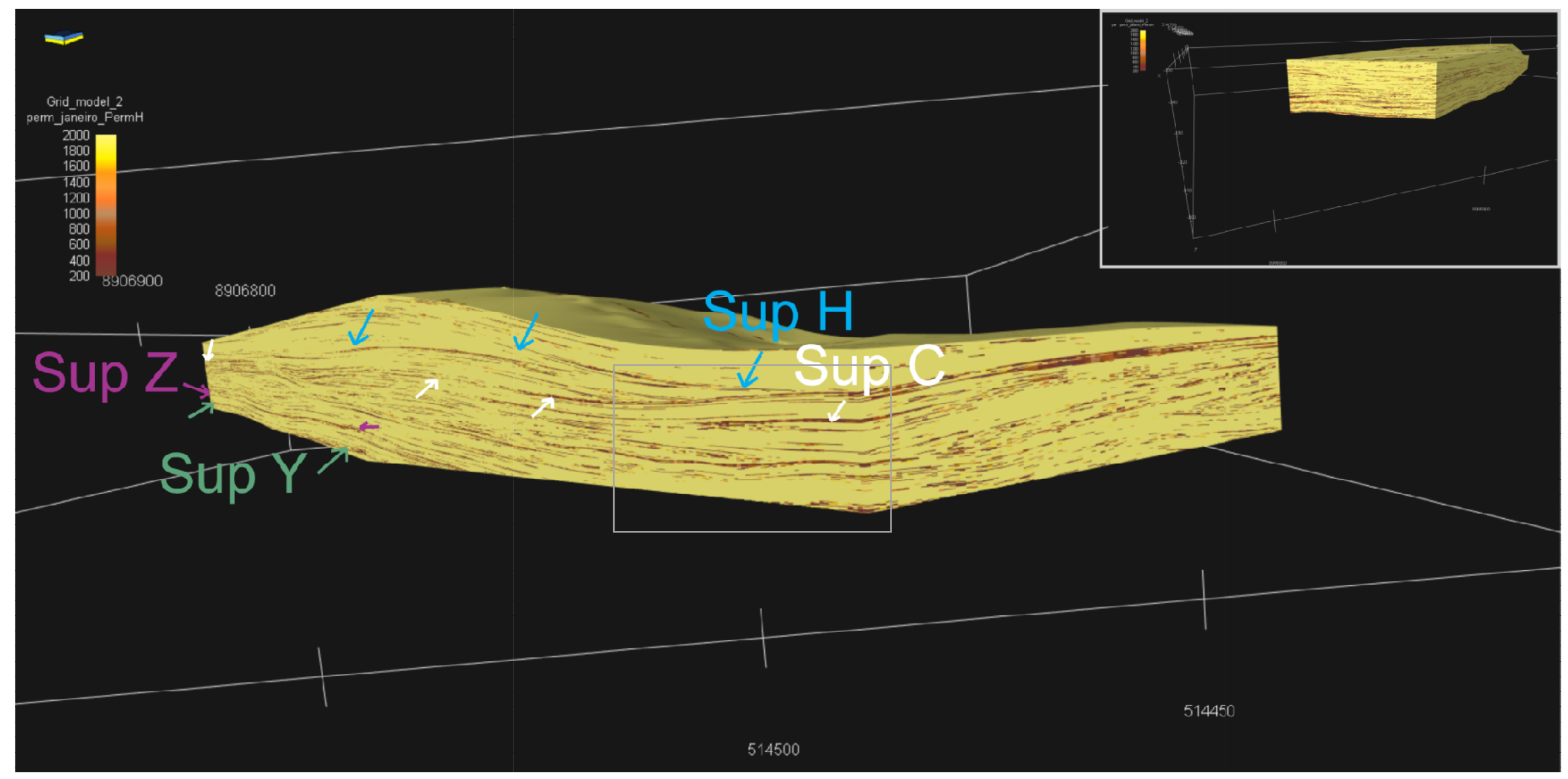


Apêndice Z - Modelo de pemeabilidade horizontal em detalhe do afloramento TUC 41, utilizando a simulação gaussiana sequencial, (as zonas com permeabilidades menores que $1000 \mathrm{mD}$ tratam-se, em maioia, de finos e muito finos). Zonas de permeabilidade baixa concentram-se nos topos de barra (geometria lenticular), como previsto no item da análise de permeabilidade (item 6.3.2) (células em $z=0.1 \mathrm{~m}$; células em $x$ e y= $1.0 \mathrm{~m}$ ) (superfícies sedimentares que possuem fácies finas relacionadas $\mathrm{C}, \mathrm{H}$, e A indicadas, descritas no apêndice $\mathrm{K}$ e $\mathrm{P}$ )

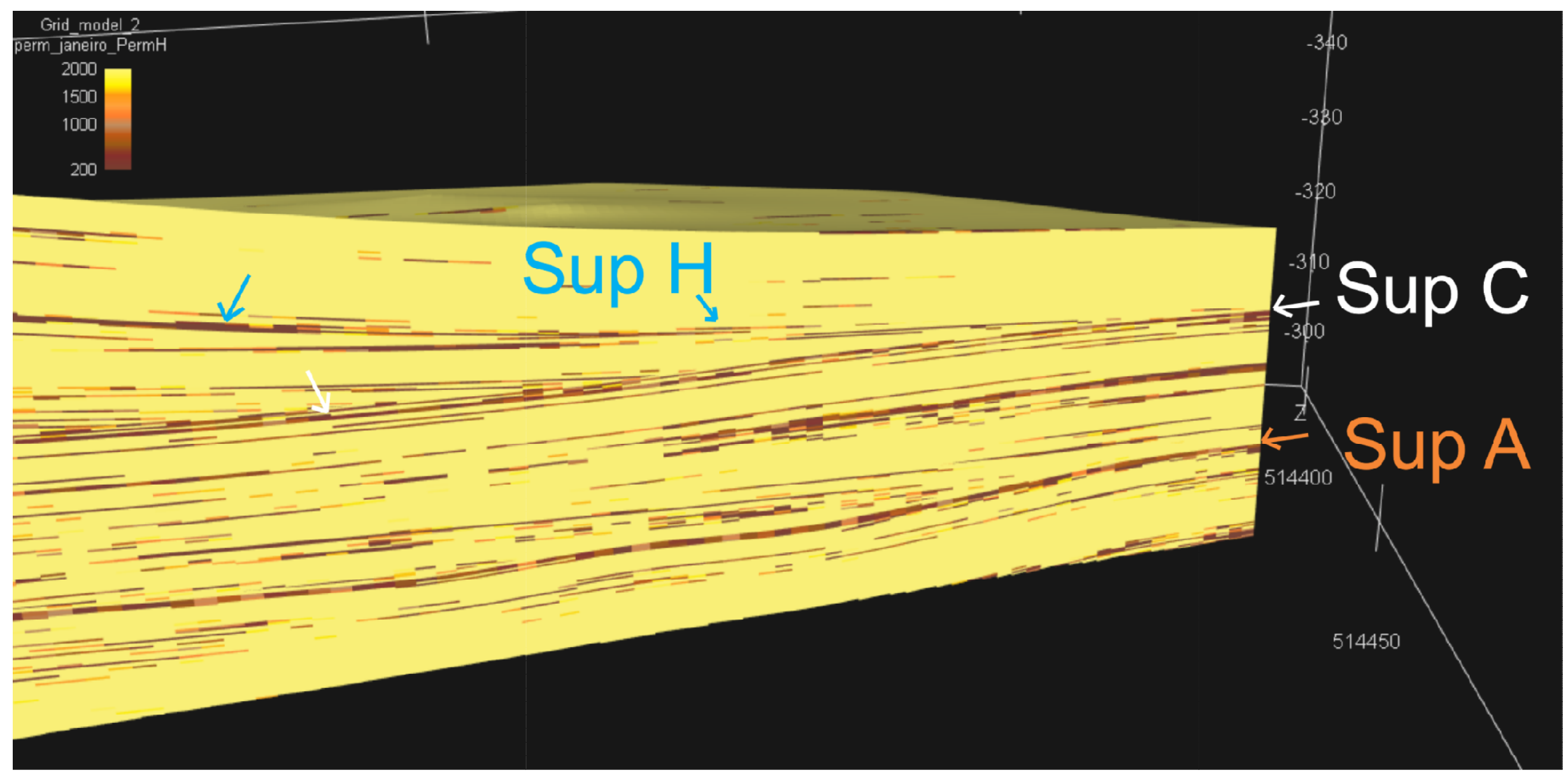


Apêndice AA - Tabela com a mediana dos valores de permeabilidade entre cada superfície adquiridos no modelo de permeabilidade horizontal do afloramento TUC 05, utilizando a simulação gaussiana sequencial (obs: zonas acima da superfície below_teste representam topos de barra criados no modelo estratigráfico)

\begin{tabular}{|l|r|}
\hline Perm H 05 & \\
\cline { 1 - 2 } Zone & Mean (mD) \\
\hline Below_sup_g & 109.87 \\
\hline Below_sup_h & 1472.97 \\
\hline Below_canal_d & 4320.58 \\
\hline Below_sup_c & 2245.21 \\
\hline Below_teste4 & 5547.60 \\
\hline Below_sup_b & 1148.04 \\
\hline Below_teste_2 & 2274.88 \\
\hline Below_sup_a_ & 13245.88 \\
\hline Below_teste_1 & 10128.30 \\
\hline
\end{tabular}

Apêndice BB - Tabela com a mediana dos valores de permeabilidade entre cada superfície adquiridos no modelo de permeabilidade horizontal do afloramento TUC 05, utilizando a simulação gaussiana sequencial. Superfície acima da $\mathrm{H}$, sem topo de barra ou com poucas fácies finas associadas apresenta maior mediana de permeabilidade

\begin{tabular}{|l|r|}
\hline Perm H 41 & \multicolumn{1}{|l}{ Mean (mD) } \\
\cline { 1 - 2 } Zone & 76343.13 \\
\hline Below_sup_acimah & 1251.26 \\
\hline Below_sup_h & 7463.70 \\
\hline Below_sup_c & 8718.34 \\
\hline Below_sup_b & 7612.09 \\
\hline Below_sup_a & 7514.03 \\
\hline Below_sup_g &
\end{tabular}

